ADENILSON CRISTIANO BELIZÁRIO

AVALIAÇÃO ENERGÉTICA E FINANCEIRA PARA UTILIZAÇÃO DE SISTEMAS DE AR CONDICIONADO ACIONADOS POR ENERGIA SOLAR EM AMBIENTES DE MISSÃO CRÍTICA PARA DIFERENTES REGIÕES CLIMÁTICAS

São Paulo 
ADENILSON CRISTIANO BELIZÁRIO

\section{AVALIAÇÃO ENERGÉTICA E FINANCEIRA PARA UTILIZAÇÃO DE SISTEMAS DE AR CONDICIONADO ACIONADOS POR ENERGIA SOLAR EM AMBIENTES DE MISSÃO CRÍTICA PARA DIFERENTES REGIÕES CLIMÁTICAS}

Tese apresentada à Escola Politécnica da Universidade de São Paulo para Obtenção do Título de Doutor em Ciências.

Área de Concentração:

Engenharia Mecânica de Energia e Fluídos

Orientador: Prof. Dr José Roberto Simões Moreira

São Paulo 


\section{FICHA CATALOGRÁFICA}

Autorizo a reprodução e divulgação total ou parcial deste trabalho, por qualquer meio convencional ou eletrônico, para fins de estudo e pesquisa, desde que citada a fonte.

Este exemplar foi revisado e corrigido em relação à versão original, sob responsabilidade única do autor e com a
anuência de seu orientador.
São Paulo, __ de
Assinatura do autor:
Assinatura do orientador:

\section{Catalogação-na-publicação}

Belizário, Adenilson Cristiano

AVALIAÇÃO ENERGÉTICA E FINANCEIRA PARA UTILIZAÇÃO DE

SISTEMAS DE AR CONDICIONADO ACIONADOS POR ENERGIA SOLAR

EM AMBIENTES DE MISSÃO CRÍTICA PARA DIFERENTES REGIÕES

CLIMÁTICAS / A. C. Belizário -- versão corr. -- São Paulo, 2018.

$237 \mathrm{p}$.

Tese (Doutorado) - Escola Politécnica da Universidade de São Paulo. Departamento de Engenharia Mecânica.

1.Ar Condicionado 2.Termodinâmica 3.Energia Solar 4.Resfriamento Solar 5.Resfriamento Natural I.Universidade de São Paulo. Escola Politécnica.

Departamento de Engenharia Mecânica II.t. 


\section{DEDICATÓRIA}

A Deus e todas as forças da natureza.

Àquela que me permitiu embarcar em sua bela travessia, como seu companheiro, abrilhantando minha vida, Viviane Carvalho.

Aos meus amados filhos, Fernando e Felipe, que com sua inocência, motivam-me diariamente na busca de um mundo melhor.

Aos meus pais, Nilson e Ana, que abdicaram de muitas coisas para que este momento fosse possível. 


\section{AGRADECIMENTOS}

Ao homem de sólidos valores, professor José Roberto Simões Moreira, pelas orientações neste trabalho e como amigo de modo geral, ajudando a obter o resultado desta tese e a superar momentos difíceis.

Aos professores e funcionários do Departamento de Engenharia Mecânica e do Programa de Pós-Graduação em Engenharia Mecânica, em especial aos professores Racine Tadeu Prado e Alberto Hernandes Neto pelas valorosas contribuições na qualificação e disponibilização de bibliografia.

À Escola Politécnica da Universidade de São Paulo, meu local de formação primária em engenharia mecânica e pós-graduações subsequentes.

Aos funcionários do programa de pós-graduação de engenharia mecânica, em especial às secretarias Marisa Lara, Regianne Amaral e Adrienne Perilo.

Aos colegas do SISEA pela interação e contribuições durante todo o desenvolvimento deste trabalho.

Ao Programa de Apoio a Pós-Graduação (PROAP), que possibilitou a apresentação de parte dos resultados na conferência ECOS 2017 em San Diego, CA.

Aos engenheiros Jan Carlos Sens, Celso Okuyama, Edson Antonietti e Panagiotis Lazaridis da LZA pelos valorosos conhecimentos e desafios propostos em engenharia de Data Center, além de cessão de bibliografia. Ao Engenheiros José Carlos Felamingo da Union RAC e Walter Lenzi pelos auxílios com orçamentos em equipamentos de absorção e coletores solares.

À Trane do Brasil pela cessão de material e orçamentos sobre unidades de resfriamento e caixas de ventilação, em especial aos engenheiros Giarcarlo Tomazini e Rafael Dutra. A Carrier do Brasil pela cessão de materiais e orçamentos de unidades de resfriamento, em especial ao engenheiro Cristiano Brasil. À Vertiv pela cessão de materiais referente a unidades de ventilação de precisão, em especial aos engenheiros Sérgio Ribeiro e Francisco De Gelo. À Alfa Laval pela cessão de material referente a torres de resfriamento e trocadores de calor. 
Aos valorosos colegas de trabalho Ricardo Eugênio da Schneider Electric, Thiago Maciel, Roberto Henrich, Flávio Borges, William Mota, Carlos Lima e Maurício Becker da HPE, Stefanie Von Heinemann e Gutenberg Pereira da GIZ pelos auxílios e coberturas nas ausências. 


\section{EPÍGRAFE}

"É muito melhor lançar-se em busca de conquistas grandiosas, mesmo expondo-se ao fracasso, do que alinhar-se com os pobres de espírito, que nem gozam muito nem sofrem muito, porque vivem numa penumbra cinzenta, onde não conhecem nem vitória, nem derrota. " (Theodore Roosevelt) 


\section{RESUMO}

Atualmente, o processamento de dados é uma operação vital para os negócios de qualquer companhia, indústria ou prestador de serviços. Entretanto, os servidores em operação, dissipam energia térmica, aquecendo o ambiente, podendo ocasionar problemas operacionais, como funcionamento inadequado, paradas operacionais e até incêndios. Por isso, é necessário um sistema de condicionamento de ar para controlar de temperatura e umidade ambiental, entretanto o consumo de energia elétrica deste sistema aumenta o custo operacional da instalação, sendo necessário minimizá-lo. Baseado neste fato, esta tese avalia a aplicação de 2 tipos de sistemas de resfriamento solar, absorção térmica solar e fotovoltaico, para reduzir o consumo do tradicional sistema elétrico com unidades de resfriamento elétricas operadas por compressão de vapor, apresentando economias, disponibilidade diária e vantagens em uma sala de missão crítica localiza genericamente, em São Paulo, Abu Dhabi, Los Angeles e Nova York. Além disto, analisa a contribuição de sistemas de resfriamento natural e seus efeitos sobre carga e consumo. As densidades de carga propostas foram de $0,5 \mathrm{~kW} \cdot \mathrm{m}^{-2}, 1,0 \mathrm{~kW} \cdot \mathrm{m}^{-2}, 2,0 \mathrm{~kW} \cdot \mathrm{m}^{-2}, 4,0 \mathrm{~kW} \cdot \mathrm{m}^{-2} \mathrm{e} 8,0 \mathrm{~kW} / \mathrm{m}$. Os índices locais de irradiação e temperaturas anuais baseiam-se nos dados apresentados no banco de dados da ASHRAE para as localidades. Os resultados, válidos para um ano típico e são comparados com (1) Sala de missão crítica acionada por um sistema convencional, (2) combinação de métodos de resfriamento solar, (3) combinação de técnicas solares e resfriamento natural. Por meio de estimativas anuais, calculando as contribuições dos métodos de resfriamento solar e natural, concluiu-se que na maioria dos casos o método de absorção solar apresenta maiores vantagens de economia de energia e retorno de investimento que o método fotovoltaico, especialmente quando associado ao resfriamento natural indireto. Ao final, conclui-se que a utilização de resfriamento solar, pode atingir a 50\% de economia na conta de energia e um TIR de 25\%. Quando associado a sistemas de resfriamento natural, a economia pode atingir valores de $68 \%$ de economia e um TIR de $134 \%$. Para tal deverá ser observado a carga aplicada, o valor de investimento e a curva característica da unidade de resfriamento que irá complementar a carga.

Palavras-chave: Ar Condicionado, Data Center, Sustentabilidade, Missão Crítica, Resfriamento solar, Resfriamento natural, Resfriamento Fotovoltaico, Absorção Solar 


\begin{abstract}
Nowadays, data processing is a fundamental operation for modern business such as banks, technology companies, and factories, among others. However, computers dissipate non-negligible amounts of heat and as the operating temperature increases, these machines cannot operate properly or, under extreme conditions, can come to a stop by overheating. Consequently, it is necessary air conditioning systems to keep the proper operating temperature as well as the room temperature itself. On the other hand, a data center air conditioning system drains a large amount of electrical energy in the installation. Based on this, this thesis evaluates two types of solar cooling system, an absorption thermal system, and a photovoltaic system, to support the traditional electric chiller system showing the energy saving, advantage over conventional cooling and day availability for this system. In addition, it analyzed free cooling system contribution and his effects on consumption. A case study is analyzed in a generic data center located in the city of São Paulo, Abu Dhabi, Los Angeles, and New York. At first, the electrical power density simulated by the computers is 0.5 $\mathrm{kW} / \mathrm{m}^{2}, 1.0 \mathrm{~kW} / \mathrm{m}^{2} 2.0 \mathrm{~kW} / \mathrm{m}^{2}, 4.0 \mathrm{~kW} / \mathrm{m}^{2}$ and $8 \mathrm{~kW} / \mathrm{m}^{2}$, that would occur in half loads or in high loads computer installations. Local solar irradiation and temperature indexes are based on the ASHRAE database. The results are valid for a typical year and are compared to (1) a conventional data center; (2) the event combination of solar cooling; (3) the event combination of solar cooling and free cooling. In conclusion, the energy savings, payback and internal rate of return for 10 years are presented. In the main cases, the solar absorption takes advantage than photovoltaic cooling, However, It must be observed the load replicated and the influence on the work curve of the chiller and the beginning investment. In conclusion, the solar cooling, especially solar absorption can achieve great advantage to installation, resulting in $50 \%$ on savings in the electric bill a return internal rate for 10 years of $25 \%$. When it is associated with free cooling this savings can achieve $68 \%$ and return rate of $134 \%$.
\end{abstract}

Keywords: Air conditioning, data center, sustainability, solar cooling, free cooling, photovoltaic cooling, solar absorption, solar comparison. 


\section{LISTA DE ILUSTRAÇÕES}

\section{llustração}

Pg.

Figura 2.1 - Esquema de Infraestrutura elétrica de um Data Center.(ATS SOLUTION, 2015)

Figura 2.2 - Faixas de aplicação para Temperaturas conforme TC 9.9(ASHRAE, 2016b).

Figura 2.3 - Esquema de resfriamento de água por expansão indireta com condensação à água de um Data Center (ATS SOLUTION, 2015)............

Figura 2.4 - Ambientes relacionado à operação de um Data Center(ASHRAE, 2016b).

Figura 2.5. - Configuração comum em ambientes de Data Center. (SANTAMARIA, 2016).

Figura 2.6 - Corredores frios à esquerda e corredores quentes à direita. (Santos, 2014)

Figura 2.7 - Esquema de Resfriamento Natural Direto (Chen et al. 2009).

Figura 2.8 - Sistema proposto resfriamento natural (CARLSON, 2012)...

52

Figura 2.9: Tarifas internacionais em $\mathrm{R} \$ / \mathrm{MWh}$ - Preços de 2015(BRITO, 2017).

Figura 3.1 - Ciclo Básico de Refrigeração. (VAN WYLEN; SONNTAG; BORGNAKKE, 2013).

Figura 3.2 - Sistema de compressão de vapor (BELIZÁRIO, 2014)........... 65

Figura 3.3- Ciclo ideal de resfriamento por compressão a vapor................ 66

Figura 3.4 - Ciclo básico de resfriamento por absorção e seus componentes principais (FONSECA JR., 2009).

Figura 3.5 - Concentrador solar de Edmond Carre (H.-M. HENNING \& JAKOB 2015)

Figura 3.6 - Classificação de sistemas de resfriamento solar (LAZARIN, 2014; BELIZÁRIO; SIMÕES-MOREIRA, 2017).

Figura 3.7: ângulos solares (ACCA SOFTWARE, 2017)

Figura 3.8 - Unidade de resfriamento de líquido por compressão com painéis fotovoltaicos. 
Figura 3.9 - Esquema de resfriamento solar (BALGHOUTHI; CHAHBANI; GUIZANI, 2008; SCHIAVON ARA, 2010)

Figura 4.1 - Iteração entre bancos de dados.

Figura 4.2 - Iteração de variáveis de dados de entrada............................. 87

Figura 4.3 - Planta Típica de Modelo Adotado ……….............................. 89

Figura 4.4 - Evolução Psicrométrica no processo de condicionamento do ambiente proposto

Figura 4.5 - Metodologia de cálculo de radiação em área de coletores....... 96

Figura 4.6 - Funcionamento de UR de absorção solar............................... 98

Figura 4.7 - Metodologia de cálculo de resfriamento por absorção solar.... 101

Figura 4.8 - Funcionamento de sistema de acionamento fotovoltaico proposto

Figura 4.9 - Metodologia de cálculo de resfriamento fotovoltaico

Figura 4.10 - Funcionamento de sistema de resfriamento natural proposto. Próprio desenvolvimento.

Figura 4.11 - Metodologia de cálculo de resfriamento natural direto.

Figura 4.12 - Esquema de funcionamento de resfriamento natural indireto por torres de condensação.

Figura 4.13 - Metodologia de cálculo de resfriamento natural indireto.

Figura 4.14 - Metodologia utilizada para cálculo de consumo elétrico dos sistemas.

Figura 5.1. Variação horária de carga térmica em dia típico de verão (04 de fevereiro).

Figura 5.2. Irradiação típica e temperatura em dia típico de verão (04 de fevereiro)

Figura 5.3. Irradiação típica e temperatura em dia típico de inverno (11 de setembro)

Figura 5.4. Irradiação de Liu e Jordan para a solução proposta

Figura 5.5. Eficiência de coletores verão (04/02)

Figura 5.6. Eficiência de coletores inverno (11/09) 
Figura 5.7. Capacidade de resfriamento disponível em $\mathrm{W} / \mathrm{m}^{2}$ em dia típico de verão (04/02)

Figura 5.8. Capacidade de resfriamento disponível em $\mathrm{W} / \mathrm{m}^{2}$ em dia típico de inverno (11/09)

Figura 5.9. Contribuição de resfriamento natural direto e dia típico de verão

Figura 5.10. Contribuição de resfriamento natural direto em dia típico de inverno

Figura 5.11. Contribuição de resfriamento natural indireto e dia típico de verão

Figura 5.12. Contribuição de resfriamento natural indireto e dia típico de inverno

Figura 5.13. .Percentual de utilização de economizadores e métodos de resfriamento solar sobre carga total para densidades de carga estudadas ..

Figura 5.14. Evolução COP e Utilização dia típico de verão para carga de $0,5 \mathrm{~kW} / \mathrm{m}^{2}$

Figura 5.15. Evolução COP e Utilização dia típico de inverno para carga de $0,5 \mathrm{~kW} / \mathrm{m}^{2}$

Figura 5.16. Evolução COP e Utilização dia típico de verão para carga de $2,0 \mathrm{~kW} / \mathrm{m}^{2}$

Figura 5.17. Evolução COP e Utilização dia típico de inverno para carga de $2,0 \mathrm{~kW} / \mathrm{m}^{2}$

Figura 5.18. Curva de COP de unidade de resfriamento acionada por compressor do tipo parafuso

Figura 5.19. Indicação de utilização de tecnologia solar fotovoltaica ou de absorção solar pontual para rendimento médio de coletores em São Paulo, considerando $0,5 \mathrm{~kW} / \mathrm{m}^{2}$

Figura 5.20. Indicação de utilização de tecnologia solar fotovoltaica ou de absorção solar pontual para rendimento médio de coletores em São Paulo, considerando $2,0 \mathrm{~kW} / \mathrm{m}^{2}$.

Figura 5.21. Indicação de utilização de tecnologia solar fotovoltaica ou de absorção solar pontual para rendimento médio de coletores em São Paulo, considerando $8,0 \mathrm{~kW} / \mathrm{m}^{2}$ 
Figura 5.22. Indicação de utilização e COP para todas as densidades estudas e tecnologias solares com e sem economizadores.

Figura 5.23. Melhor equipamento segundo critério de economia de energia

Figura 5.24. Melhor equipamento segundo critério de Taxa Interna de Retorno

Figura 5.25. Taxa Interna de Retorno para Tarifa de $\mathrm{R} \$ 1,10 \mathrm{kWh}$ para Absorção Solar

Figura 5.26. Taxa Interna de Retorno para Tarifa de $R \$ 1,10 \mathrm{kWh}$ para Resfriamento Fotovoltaico.

Figura 5.27. Melhor tecnologia solar associada a economizadores segundo economia de energia.

Figura 5.28. Melhor tecnologia solar associada a economizadores segundo taxa interna de retorno para 10 anos...

Figura 5.29. Taxa Interna de Retorno para Tarifa de $\mathrm{R} \$ 1,10 \mathrm{kWh}$ para Absorção Solar com resfriamento natural indireto.

Figura 5.30. Taxa Interna de Retorno para Tarifa de $R \$ 1,10 \mathrm{kWh}$ para Resfriamento Fotovoltaico com resfriamento natural indireto.

Figura 6.1 Irradiação típica e temperatura em dia típico de verão (11 de setembro).

Figura 6.2. Irradiação típica e temperatura em dia típico de inverno (04 de fevereiro)

Figura 6.3. Utilização de Economizadores e métodos de resfriamento solar sobre carga total para densidades de carga estudadas para Abu Dhabi......

Figura 6.4. Indicação de utilização e COP para todas as densidades estudas e tecnologias solares com e sem economizadores para Abu Dhabi. . . . .

Figura 6.5. Melhor equipamento segundo critério de economia de energia para Abu Dhabi.

Figura 6.6 Melhor equipamento segundo critério de taxa interna de retorno para Abu Dhabi.

Figura 6.7. Melhor tecnologia solar associada a economizadores segundo economia de energia em Abu Dhabi. 
Figura 6.8. Melhor tecnologia solar associada a economizadores segundo taxa interna de retorno em Abu Dhabi

Figura 6.9. Irradiação típica e temperatura em dia típico de verão (11 de setembro) em Los Angeles.

Figura 6.10. Irradiação típica e temperatura em dia típico de inverno (11 de setembro) em Los Angeles.

Figura 6.11. Utilização de Economizadores e métodos de resfriamento solar sobre carga total para densidades de carga estudadas para Los Angeles.

Figura 6.12. Indicação de utilização e COP para todas as densidades estudas e tecnologias solares com e sem economizadores para Los Angeles

Figura 6.13. Melhor equipamento segundo critério de economia de energia para Los Angeles.

Figura 6.14. Melhor equipamento segundo critério de taxa interna de retorno para Los Angeles.

Figura 6.15. Melhor tecnologia solar associada a economizadores segundo economia de energia em Los Angeles.

Figura 6.16. Melhor tecnologia solar associada a economizadores segundo taxa interna de retorno em Los Angeles.

Figura 6.17. Irradiação típica e temperatura em dia típico de verão (11 de setembro) em Nova York.

Figura 6.18. Irradiação típica e temperatura em dia típico de verão (4 de fevereiro) em Nova York.

Figura 6.19. Utilização de Economizadores e métodos de resfriamento solar sobre carga total para densidades de carga estudadas para Nova York.

Figura 6.20. Indicação de utilização e COP para todas as densidades estudas e tecnologias solares com e sem economizadores para Nova York.

Figura 6.21. Melhor equipamento segundo critério de economia de energia para Nova York.

Figura 6.22. Melhor equipamento segundo critério de taxa interna de retorno Nova York. 
Figura 6.23. Melhor tecnologia solar associada a economizadores segundo economia de energia em Nova York.

Figura 6.24. Melhor tecnologia solar associada a economizadores segundo taxa interna de retorno em Nova York.

Figura 6.25. Curva de eficiência de Unidade de Resfriamento centrífuga.....

Figura 6.26. Indicação de utilização e COP para todas as densidades estudas e tecnologias solares com e sem economizadores para compressores centrífugos em São Paulo

Figura 6.27 - Melhor tecnologia solar para instalação com centrífugas em São Paulo, segundo critério de Economia de energia.

Figura 6.28 - Melhor tecnologia solar para instalação com centrífugas em São Paulo, segundo critério de taxa interna de retorno para 10 anos.

Figura 6.29 - Melhor tecnologia solar com economizadores para instalação com centrífugas em São Paulo, segundo critério de Economia de energia ..

Figura 6.30. Melhor tecnologia solar associada a economizadores segundo taxa interna de retorno em São Paulo para compressores centrífugos .........

Figura 6.31 - Ponderações de critérios para utilização de métodos solares e economizadores segundo economia de energia

Figura 6.32 - Ponderações de critérios para utilização de métodos solares e economizadores segundo retorno de investimento

Figura 6.33 - Percentual de casos onde há maior vantagem de um método face os outros, segundo economia de energia

Figura 6.34 - Percentual de casos onde há maior vantagem de um método 


\section{LISTA DE TABELAS}

Tabelas

Tabela 3.1 - Equivalência entre unidade de refrigeração de líquido de 68 compressão / absorção (MAGGl et al., 2014)

Tabela 3.2: Comparativo entre os principais tipos de unidade de 82 refrigeração solar (SCHIAVON ARA, 2010; FERREIRA \& KIM, 2014) Adaptado.

Tabela 4.1 - Áreas consideradas da edificação 89

Tabela 4.2 - Coeficiente de cargas não aplicadas em função de mês e 92 hora.

Tabela 4.3 Constantes para diferentes tipos de coletores solares (GERBRESLASSIE et al., 2010; FERREIRA \& KIM, 2014)

Tabela 4.4 Constantes para diferentes tipos de painéis fotovoltaicos. 103 (HULD et al., 2010)

Tabela 4.5 - Correlação entre carga térmica e vazão volumétrica de 108 unidades de ventilação (VERTIV, 2016)

Tabela 4.6 - Correlação entre quantidade de FC e caixas de ventilação 109 (TRANE, 2013)

Tabela 4.7. Área de troca para seleção de trocador de calor. 113

Tabela 4.8 - coeficientes polinomiais de acordo com a capacidade de cada 117 unidade de resfriamento de líquido.

Tabela 4.9. Nomenclatura de índices de consumo

Tabela 4.10. Nomenclatura de índices de economia 123

Tabela 4.11. Preço base de unidades de resfriamento de líquido do tipo 123 parafuso.....

Tabela 4.12. Preço base de caixas de ventilação e módulos de filtros.

Tabela 4.13. Preço base de trocadores de calor.

Tabela 4.14. Preço base de equipamentos e serviços para absorção solar.

Tabela 4.15. Nomenclatura para capital investido em cada sistema 125

Tabela 5.1 - Carga Térmica máxima em Toneladas de Refrigeração para 129 cada densidade 
Tabela 5.2 - Seleção de quantidade de caixas de ventilação

Tabela 5.3 - Seleção de trocadores de calor para resfriamento natural 138 indireto

Tabela 5.4 - Seleção de unidades de resfriamento de líquido.

Tabela 5.5 - Consumo de cada tecnologia

Tabela 5.6 - Economia de energia percentual

Tabela 5.7 - Seleção de método solar para economia de energia e taxa interna de retorno de investimento para a instalação desejada

Tabela 5.8 - Seleção de método solar com economizadores para economia de energia e taxa interna de retorno de investimento para a instalação desejada em São Paulo

Tabela 6.1 - Seleção de método solar para economia de energia e taxa interna de retorno de investimento para a instalação desejada em Abu Dhabi

Tabela 6.2 - Seleção de método solar com economizadores para economia de energia e taxa interna de retorno de investimento para a instalação desejada em Abu Dhabi

Tabela 6.3 - Seleção de método solar para economia de energia e taxa interna de retorno de investimento para a instalação desejada em Los Angeles

Tabela 6.4 - Seleção de método solar com economizadores para economia de energia e taxa interna de retorno de investimento para a instalação desejada em Los Angeles..

Tabela 6.5 - Seleção de método solar para economia de energia e taxa interna de retorno de investimento para a instalação desejada em Nova York

Tabela 6.6 - Seleção de método solar com economizadores para economia de energia e taxa interna de retorno de investimento para a instalação desejada em Nova York...

Tabela 6.7 - Seleção de método solar para economia de energia e taxa interna de retorno de investimento para a instalação desejada em São Paulo com Centrífugas

Tabela 6.8 - Melhor tecnologia solar para instalação com centrífugas em 194 São Paulo, segundo critério de Economia de energia 


\section{LISTA DE SIGLAS}

ABNT Associação Brasileira de Normas Técnicas

ANSI American National Standards Institute

ASHRAE American Society of Heating, Refrigeration, Air Conditioning and Engineering.

ANEEL Agência Nacional de Energia Elétrica

ATS

Automatic Transfer Swicht

COP Coeficiente de performance [-]

CFURH Compensação Financeira pela Utilização de Recursos Hídricos

CDE Conta de Desenvolvimento Energético

COFINS Contribuição para Financiamento da Seguridade Social

CGC Custo de Geração de equipamento de Absorção

EER Encargo de Energia de Reserva

ESS Encargo de Serviços do Sistema

GIZ Agência de Cooperação Internacional Alemã

GTD Geração, Transmissão e Distribuição

ICMS Imposto sobre circulação de mercadorias e serviços

SISEA Laboratório de Sistemas Energéticos Alternativos

LEED Leadership in Energy and Environmental Design

MMA Ministério do Meio Ambiente

ONS Operador Nacional do Sistema

P\&D/EE Pesquisa e Desenvolvimento e Eficiência Energética 
PROINFA Programa de Incentivo às Fontes Alternativas de Energia Elétrica

PROCEL Programa Nacional de Conservação de Energia Elétrica

PIS Programa de Integração Social

PNUD Programa das Nações Unidas para o Desenvolvimento

SEBRAE Serviço Brasileiro de Apoio às Micro e Pequenas Empresa

STS Static Transfer Swicht

TFSEE Taxa de Fiscalização de Serviços de Energia Elétrica

TC Techinical Committee

TIA Telecommunications Infrastructure Standard for Data Center

UR Unidade de Resfriamento de líquido - Chiller

CRAH Unidade de Ventilação - Fan Coil

UPS Uninterruptable power supply 


\section{LISTA DE SÍMBOLOS LATINOS}

\begin{tabular}{|c|c|}
\hline Alt & Altitude Local, [m] \\
\hline$A_{S C}$ & Área da sala de computadores, [m²] \\
\hline$A_{\text {troc }}$ & Área de troca do trocador de calor, $\left[\mathrm{m}^{2}\right]$ \\
\hline$c_{\mathrm{H}_{2} \mathrm{O}}$ & Calor específico da água a pressão constante, $\left[\mathrm{kJ} \cdot \mathrm{kg}^{-1 .{ }^{\circ}} \mathrm{C}^{-1}\right]$ \\
\hline$C_{T R D}$ & Calor Residual, [kW] \\
\hline$Q_{f c d}$ & Calor retirado resfriamento natural direto, $[\mathrm{kW}]$ \\
\hline $\mathrm{Cl}$ & Capital Investido, [R\$] \\
\hline$q_{a c}^{\prime}$ & Carga acumulada em tanque de água fria, [kW] \\
\hline$\dot{q}_{E}$ & Carga gerada pela UR de absorção, [kW] \\
\hline$\dot{q}_{U}$ & Carga requerida pela instalação, $[\mathrm{kW}]$ \\
\hline$C_{C A S}^{\cdot}$ & Carga térmica após a ação do resfriamento solar, [kW] \\
\hline$\dot{C}_{T}$ & Carga térmica calculada, $[\mathrm{kW}]$ \\
\hline$\dot{C}$ & $\begin{array}{l}\text { Carga térmica do sistema após ação de economizadores e } \\
\text { refrigeração solar por absorção, [kW] }\end{array}$ \\
\hline$C \dot{T}_{U R}$ & $\begin{array}{l}\text { Carga térmica residual a ser refrigerada pela UR pós } \\
\text { resfriamento natural indireto, }[\mathrm{kW}]\end{array}$ \\
\hline$\dot{C}_{T R D}$ & Carga térmica residual após resfriamento natural direto, [kW] \\
\hline$x_{C T}$ & $\begin{array}{l}\text { Coeficiente de carga térmica, independente de densidade de } \\
\text { potência em edificação de missão crítica, }\left[\mathrm{kW} \cdot \mathrm{m}^{-2}\right]\end{array}$ \\
\hline$n v_{a r}$ & Coeficiente de transferência de calor do ar, $\left[\mathrm{kW} \cdot \mathrm{m}^{-2 .{ }^{\circ} \mathrm{C}}{ }^{-1}\right]$ \\
\hline$U_{\text {Troc }}$ & $\begin{array}{l}\text { Coeficiente global de transferência de calor do trocador, } \\
{\left[\mathrm{kW} \cdot \mathrm{m}^{\left.-2 .{ }^{\circ} \mathrm{C}^{-1}\right]}\right.}\end{array}$ \\
\hline
\end{tabular}




\begin{tabular}{|c|c|}
\hline$I_{p S T C}$ & $\begin{array}{l}\text { Constante apresentada em testes em células fotovoltaicas de } \\
\text { silicio policristalinico, }\left[\mathrm{kW} \cdot \mathrm{m}^{-2}\right]\end{array}$ \\
\hline$W_{S T C}$ & $\begin{array}{l}\text { Constante apresentada em testes em células fotovoltaicas de } \\
\text { silicio policristalinico, }\left[\mathrm{kW} \cdot \mathrm{m}^{-2}\right]\end{array}$ \\
\hline$G_{S C}$ & Constante de irradiação solar, [kW] \\
\hline$k_{1}, k_{2}$ & Constantes de painéis fotovoltaicos, [-] \\
\hline$k_{3}, k_{4}, k_{5}, k_{6}$ & Constantes de painéis fotovoltaicos, $\left[{ }^{\circ} \mathrm{C}^{-1}\right]$ \\
\hline $\mathrm{C}_{0}, \mathrm{C}_{1}, \mathrm{C}_{2}$ & Constantes do coletor solar, [-] \\
\hline$E_{P V}$ & $\begin{array}{l}\text { Consumo complementar por descarga de baterias do sistema } \\
\text { fotovoltaico, }[\mathrm{kWh}]\end{array}$ \\
\hline$E_{\text {Sist }}$ & Consumo complementar total do sistema, [kWh] \\
\hline$E_{\text {Base }}$ & Consumo de energia do caso base, $[\mathrm{kWh}]$ \\
\hline$E_{A S}$ & $\begin{array}{l}\text { Consumo do sistema com refrigeração solar por absorção, } \\
\text { [kWh] }\end{array}$ \\
\hline$E_{R D}$ & Consumo do sistema com resfriamento natural direto, [kWh] \\
\hline$E_{R I}$ & Consumo do sistema com resfriamento natural indireto, [kWh] \\
\hline CON & Custos tarifários em 1 ano, $[\mathrm{R} \$]$ \\
\hline DP & Depreciação, $[R \$]$ \\
\hline$T_{a p p}$ & $\begin{array}{l}\text { Diferencial de temperatura entre a TBU e a temperatura de } \\
\text { água que a torre envia ao sistema, }\left[{ }^{\circ} \mathrm{C}\right]\end{array}$ \\
\hline EAE & Economia de Energia em $R \$$, $[R \$]$ \\
\hline$S_{\text {Sist }}$ & Economia gerada pelo sistema, $\left[{ }^{\circ} \mathrm{C}\right]$ \\
\hline$S_{P V}$ & Economia gerada pelo sistema fotovoltaico, $[R \$]$ \\
\hline$S_{R D}$ & Economia gerada por resfriamento natural direto, $[R \$]$ \\
\hline
\end{tabular}




\begin{tabular}{|c|c|}
\hline$S_{R I}$ & Economia gerada por resfriamento natural indireto, $[R \$]$ \\
\hline$S_{R I}$ & Economia gerada por resfriamento natural indireto, $[\mathrm{R} \$]$ \\
\hline$S_{A S}$ & $\begin{array}{l}\text { Economia gerada sistema com refrigeração solar por } \\
\text { absorção, }[\mathrm{R} \$]\end{array}$ \\
\hline$\dot{W}_{a c}$ & Energia disponível no instante anterior em baterias, [kWh] \\
\hline$\dot{W}_{\text {Disp }}$ & $\begin{array}{l}\text { Energia em baterias disponível para utilização do sistema, } \\
\text { [kWh] }\end{array}$ \\
\hline$\dot{W}_{U}$ & Energia requerida pela instalação, [kWh] \\
\hline$\dot{W}_{P V}$ & Energia solar fotovoltáica disponível, [kWh] \\
\hline$h_{\text {ins }}$ & Entalpia específica do ar de insuflação, $\left[\mathrm{kJ} \mathrm{kg}^{-2}\right]$ \\
\hline$h_{r}$ & Entalpia específica do ar de retorno, $\left[{\left.\mathrm{kJ} \cdot \mathrm{kg}^{-2}\right]}\right.$ \\
\hline$h_{e x}$ & Entalpia específica do ar exterior, $\left[\mathrm{kW} \cdot \mathrm{kg}^{-2}\right]$ \\
\hline$\dot{q}_{G}$ & $\begin{array}{l}\text { Fluxo de calor de geração em unidade de refrigeração por } \\
\text { absorção, [kW] }\end{array}$ \\
\hline$\dot{Q}_{\text {conv }}$ & Fluxo de calor por Convecção, [kW] \\
\hline$\dot{Q}_{\text {rad }}$ & Fluxo de calor por radiação, [kW] \\
\hline $\mathrm{H}$ & Hora local, [h] \\
\hline $\mathrm{kT}$ & Índice de claridade, [-] \\
\hline$\dot{m}_{U R}$ & Massa de água refrigerada, $[\mathrm{kg}]$ \\
\hline $\mathrm{N}$ & Número de dias transcorridos a partir de $1^{\circ}$ de janeiro, [dias] \\
\hline PB & Payback - Tempo de retorno de investimentos, [R\$] \\
\hline$P_{h}$ & Perdas hidráulicas e de transporte de fluidos, $[\mathrm{kW}]$ \\
\hline$V_{\text {vent } f c d}$ & Potência dos ventiladores de resfriamento natural direto, [kW] \\
\hline
\end{tabular}




\begin{tabular}{|c|c|}
\hline$P_{a t m}$ & Pressão Atmosférica, [kPa] \\
\hline$P_{v}$ & Pressão de vapor parcial do ar, [Pa] \\
\hline$I_{0}$ & Radiação extraterrestre, [kWh] \\
\hline$I_{T}$ & Radiação total captada pelo coletor/ placa fotovoltaica, [kWh] \\
\hline $\mathrm{R}_{\mathrm{b}}$ & Razão entre radiação direta e total, [-] \\
\hline I & $\begin{array}{l}\text { Razão integrada em certo intervalo de tempo sobre o plano } \\
\text { horizontal, [-] }\end{array}$ \\
\hline$\dot{Q}_{\text {torre }}$ & $\begin{array}{l}\text { Taxa de calor rejeitada pela torre de resfriamento do sistema, } \\
{[\mathrm{kW}]}\end{array}$ \\
\hline$\dot{Q}_{R I}$ & Taxa de calor retirado pelo resfriamento natural indireto, [kW] \\
\hline$\dot{Q}_{t r o c}$ & Taxa de transferência de calor do trocador de calor, [kW] \\
\hline TIR & Taxa Interna de Retorno, [-] \\
\hline$T_{S_{U R}}$ & $\begin{array}{l}\text { Temperatura de água que a UR deverá prover às unidades } \\
\text { de ventilação, }\left[{ }^{\circ} \mathrm{C}\right]\end{array}$ \\
\hline TBS & Temperatura de bulbo seco, $\left[{ }^{\circ} \mathrm{C}\right]$ \\
\hline TBU & Temperatura de bulbo úmido do ar exterior, $\left[{ }^{\circ} \mathrm{C}\right]$ \\
\hline$T_{E_{U R}}$ & $\begin{array}{l}\text { Temperatura de entrada de água na UR, proveniente das } \\
\text { unidades de ventilação, }\left[{ }^{\circ} \mathrm{C}\right]\end{array}$ \\
\hline$T_{f S T R O C}$ & $\begin{array}{l}\text { Temperatura de fluído que retorna a torre ou na entrada do } \\
\text { condensador da UR, }\left[{ }^{\circ} \mathrm{C}\right]\end{array}$ \\
\hline$T_{f E T R O C}$ & $\begin{array}{l}\text { Temperatura do fluído que chega das torres de resfriamento, } \\
{\left[{ }^{\circ} \mathrm{C}\right]}\end{array}$ \\
\hline$T_{Q S T R O C}$ & $\begin{array}{l}\text { Temperatura do fluído que irá as unidades de ventilação ou } \\
\text { será resfriada pela UR, }\left[{ }^{\circ} \mathrm{C}\right]\end{array}$ \\
\hline$T_{Q E T R O C}$ & $\begin{array}{l}\text { Temperatura do fluído quente que entra no trocador, vêm da } \\
\text { aplicação, }\left[{ }^{\circ} \mathrm{C}\right]\end{array}$ \\
\hline$T_{\text {painel }}$ & Temperatura do painel fotovoltaico, $\left[{ }^{\circ} \mathrm{C}\right]$ \\
\hline
\end{tabular}




$\begin{array}{cl}T_{c l c} & \text { Temperatura no coletor solar, }\left[{ }^{\circ} \mathrm{C}\right] \\ \text { UR } & \text { Unidade de refrigeração de líquido (chiller) } \\ \text { FC } & \text { Unidade de ventilação (fancoil) } \\ I_{b} & \text { Valor da radiação difusa no plano horizontal, [kWh] } \\ I_{d} & \text { Valor da radiação direta no plano horizontal, }[\mathrm{kWh}] \\ \dot{m}_{t o r r e} & \text { Vazão mássica de água proveniente das torres de } \\ & \text { condensação, }\left[\mathrm{kg} \cdot \mathrm{s}^{-1}\right] \\ m_{a e} & \text { Vazão Mássica de ar exterior (e consequentemente } \\ & \text { descartado) em resfriamento natural direto, }\left[\mathrm{kg} \cdot \mathrm{s}^{-1}\right] \\ V_{\text {arfc }}^{\cdot} & \text { Vazão volumétrica de ar proveniente das unidades de } \\ & \left.\text { ventilação, [kg· } \mathrm{s}^{-1}\right]\end{array}$




\section{Lista de Símbolos Gregos}

\begin{tabular}{|c|c|}
\hline$\alpha_{s}$ & Altitude solar, [m] \\
\hline$\gamma_{s}$ & Ângulo de Azimute, $\left[^{\circ}\right]$ \\
\hline$\gamma$ & Ângulo de Azimute de Superfície, $\left[^{\circ}\right]$ \\
\hline$\theta$ & Ângulo de incidência, $\left[^{\circ}\right]$ \\
\hline$\theta_{z}$ & Ângulo de zênite, $\left[^{\circ}\right]$ \\
\hline$\omega$ & Ângulo horário local, $\left[^{\circ}\right]$ \\
\hline$\delta$ & Declinação solar, $\left[{ }^{\circ}\right]$ \\
\hline$\rho_{P O T}$ & Densidade de potência da sala de computadores, $\left[\mathrm{kW} \cdot \mathrm{m}^{-2}\right]$ \\
\hline$\varepsilon_{A}$ & $\begin{array}{l}\text { Eficiência ótima máxima média de uma unidade de } \\
\text { refrigeração de absorção, [-] }\end{array}$ \\
\hline$\beta$ & Inclinação de coletor solar ou placa fotovoltaica, $\left[^{\circ}\right]$ \\
\hline$\phi$ & Latitude local, $\left[^{\circ}\right]$ \\
\hline$\rho_{\text {ins }}$ & Massa específica de ar de insuflação, $\left[\mathrm{kg} \cdot \mathrm{m}^{-3}\right]$ \\
\hline$\rho_{a r}$ & Massa específica do ar exterior, $\left[\mathrm{kg} \cdot \mathrm{m}^{-3}\right]$ \\
\hline$\rho$ & Refletividade do solo, $[-]$ \\
\hline$\eta_{\text {sol_pow }}$ & Rendimento das células fotovoltaicas, $[-]$ \\
\hline$\eta_{\text {sol_heat }}$ & $\begin{array}{l}\text { Rendimento de coletor solar, excluindo perdas hidráulicas. } \\
\text { Tubo a vácuo, [-] }\end{array}$ \\
\hline$\eta_{\text {sist }}$ & $\begin{array}{l}\text { Rendimento geral do sistema elétrico (cabos, baterias e } \\
\text { inversores), [-] }\end{array}$ \\
\hline$\eta_{c l c}$ & $\begin{array}{l}\text { Rendimento total do coletor solar, incluindo perdas } \\
\text { hidráulicas. Tubo a vácuo, }[-]\end{array}$ \\
\hline
\end{tabular}




\section{SUMÁRIO}

CAPÍTULO 1 - INTRODUÇÃO

1.1. APRESENTAÇÃO

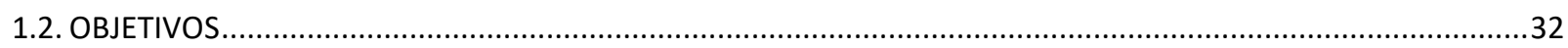

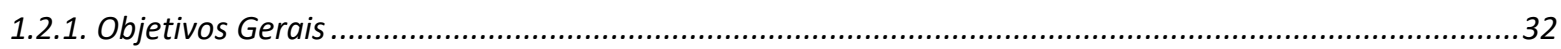

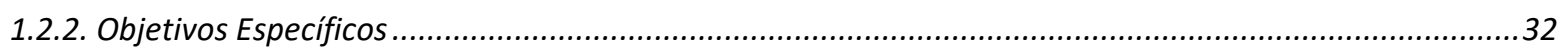

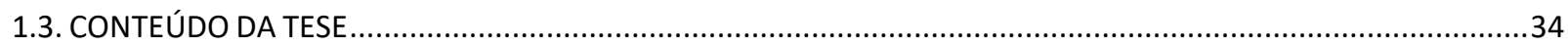

CAPÍTULO 2 - REVISÃO DA LITERATURA - CLIMATIZAÇÃO DE EDIFICAÇõES PADRÃO.........................................36

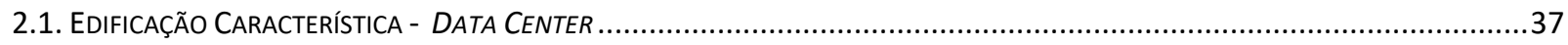

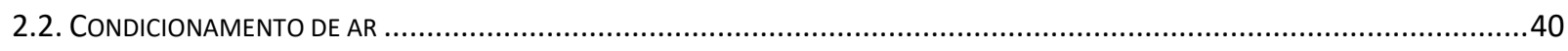

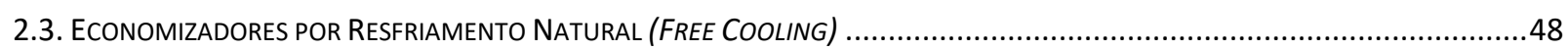

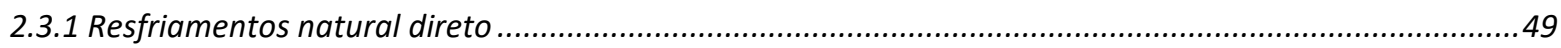

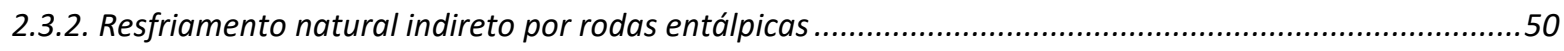

2.3.3. Resfriamento natural indireto por fonte de água não resfriada ........................................................51

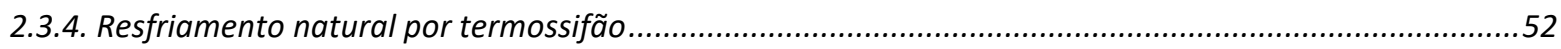

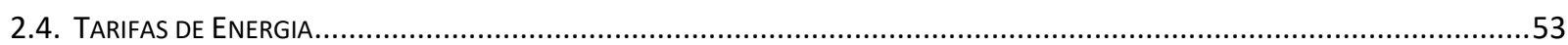

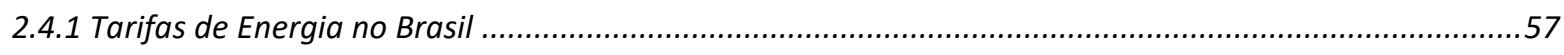

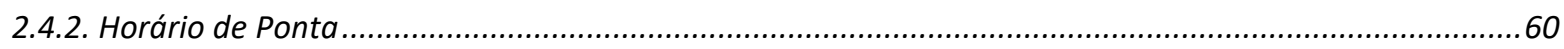

CAPÍTULO 3 - TEORIA - CONDICIONAMENTO DE AR SOLAR E RESFRIAMENTO NATURAL....................................61

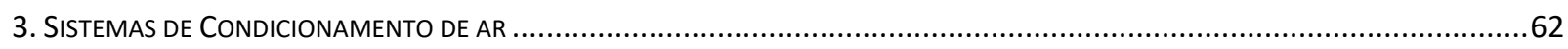

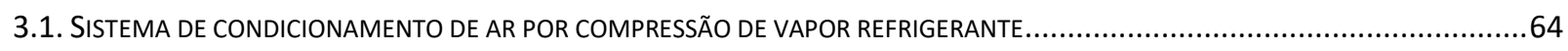

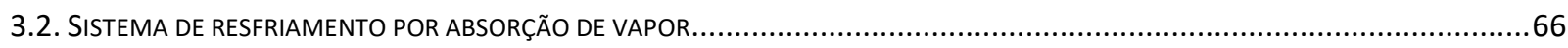

3.2.1. Breve histórico

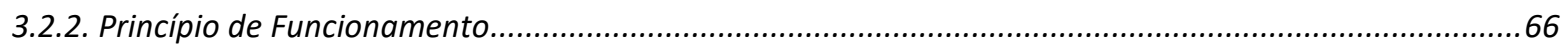

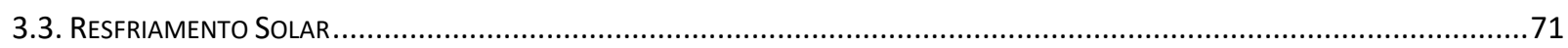

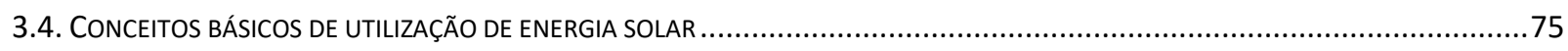

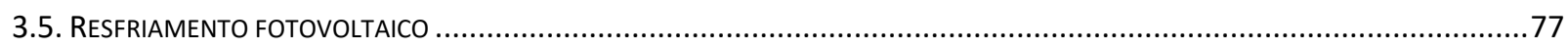

3.6. RESFRIAMENTO SOLAR TÉRMICO POR TRANSFORMAÇÃO DE CALOR UTILIZANDO O PRINCÍPIO DA ABSORÇÃO ..............................78

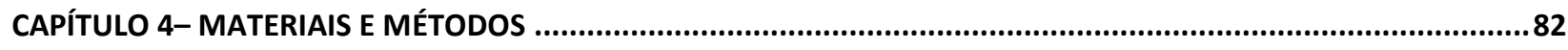

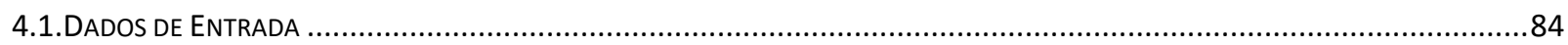

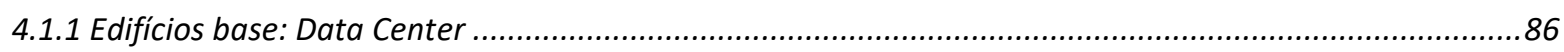

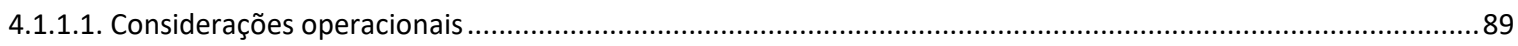

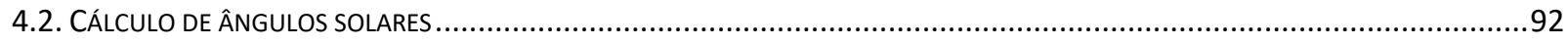

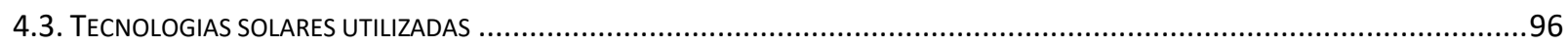

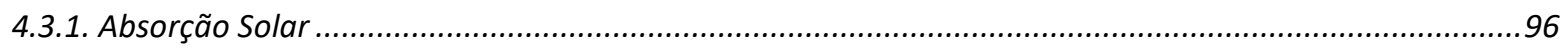

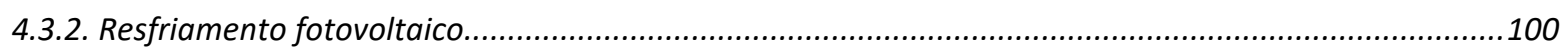

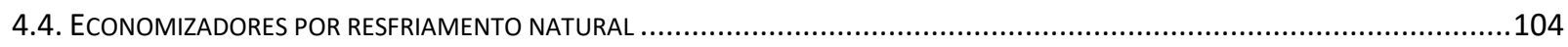

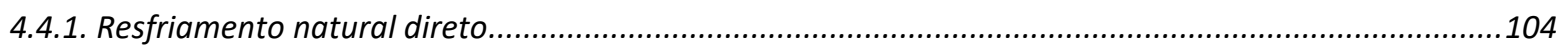

4.4.2. Resfriamento Natural Indireto por torres de resfriamento..................................................................109

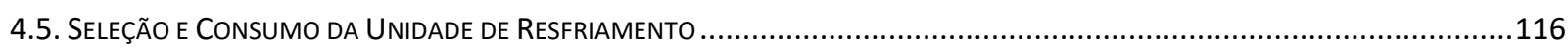

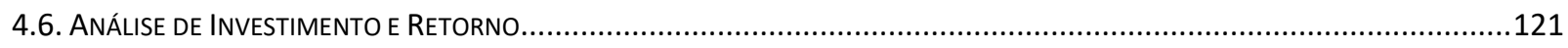




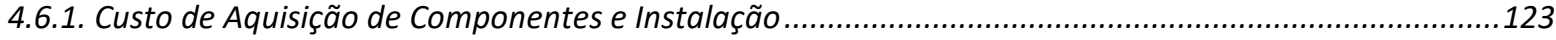

4.6.2. Análise de Retorno de Investimento Simples (Payback Simples) ........................................................126

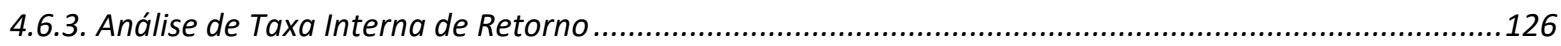

CAPÍTULO 5 - DISCUSSÃO DE RESULTADOS - CIDADE E TECNOLOGIA BASE ......................................................128

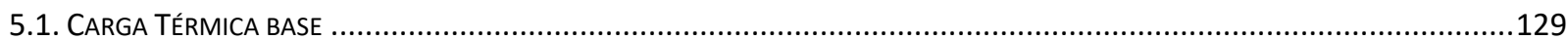

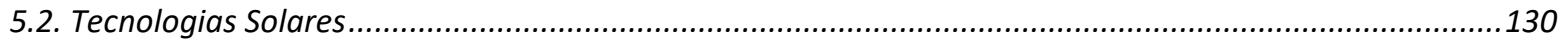

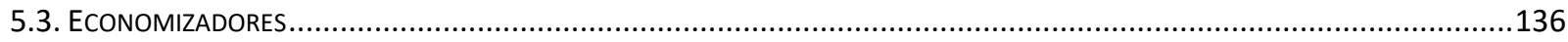

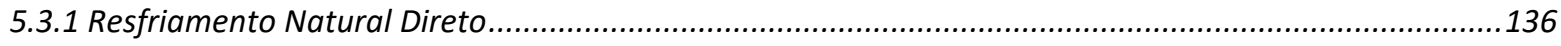

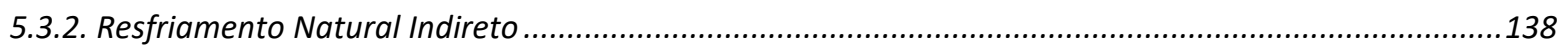

5.4. SELEÇÃO DE UNIDADES DE RESFRIAMENTO DE LíQUIDO PARA CASO BASE E CONSUMO DE ENERGIA....................................141

5.4.1. Influência da Curva do Equipamento sobre a economia de energia...................................................146

5.5. TEMPO DE RETORNO DE INVESTIMENTO E TAXA INTERNA DE RETORNO PARA 10 ANOS.............................................151

\section{CAPÍTULO 6 - DISCUSSÃO DE RESULTADOS - VARIAÇÃO DE ZONA CLIMÁTICA, TECNOLOGIA DE UR E UTILIZAÇÃO}

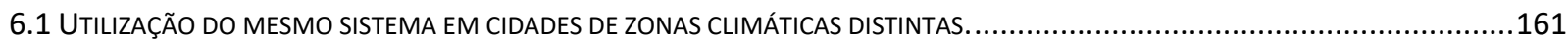

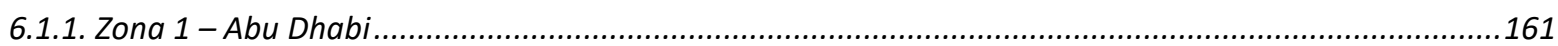

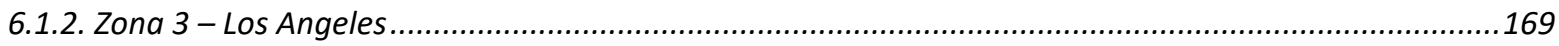

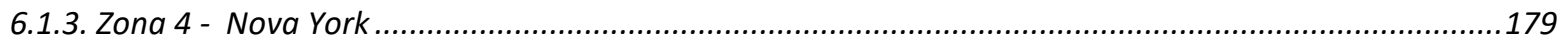

6.2. UTILIZAÇÃO DO MESMO SISTEMA TENDO COMO EQUIPAMENTO COMPLEMENTAR UNIDADES DE RESFRIAMENTO DE LÍQUIDO DO TIPO

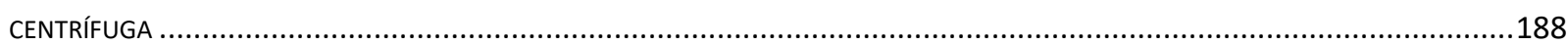

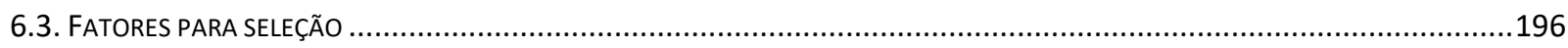

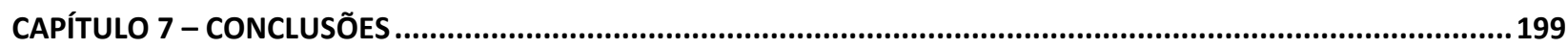

7.1. DESENVOLVIMENTO REALIZADO

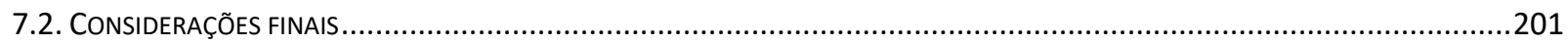

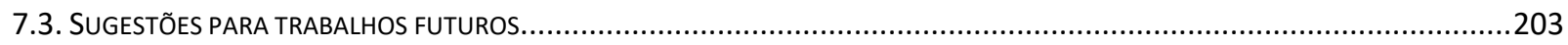

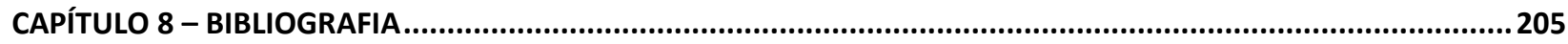

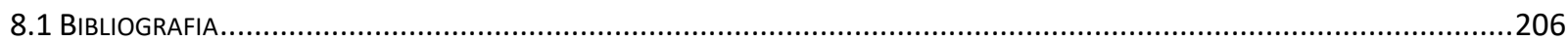

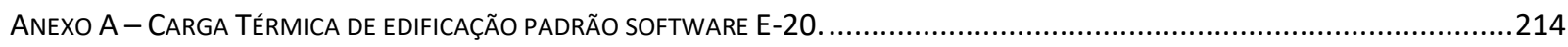

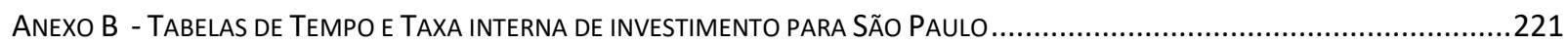




\section{CAPÍTULO 1 - INTRODUÇÃO}

O capítulo de introdução apresenta, de forma resumida, as necessidades operacionais de consumo energético que motivaram o desenvolvimento do presente trabalho de tese de doutorado. Aqui são apresentados os objetivos, a metodologia utilizada e um breve resumo dos capítulos que constituem o presente texto. 


\subsection{APRESENTAÇÃO}

Nos últimos anos, a climatização de ambientes por meio de condicionamento de ar tornou-se algo imprescindível, seja pela necessidade de conforto térmico em residências e edifícios comerciais, onde resulta em aumento de produtividade nos ambientes corporativos, ou por sistemas com necessidades ambientais restritivas devido a rigoroso controle de parâmetros psicrométricos como temperatura e umidade.

No caso de hospitais e laboratórios, o sistema de climatização dificulta a contaminação de pessoas, produtos e processos pelo ar, além de controle de agentes biológicos e químicos. Nos Data Centers, antigamente denominados centros de processamento de dados, as condições ambientais estão associadas diretamente a desempenho de computadores e segurança operacional.

Entretanto, a preocupação com o consumo de energia se contrapõe a esta necessidade. Em edifícios comerciais, a climatização é responsável em média por $40 \%$ do consumo energético (PAPADOPOULOS et al. 2003). Se extrapolarmos isto para edificios de climatização contínua este valor pode aumentar.

No caso de Data Centers, este valor pode chegar a $50 \%$ do consumo total (STRUTT et al., 2012). Considerando este último caso, onde quase sempre há demanda contratada da concessionária e o excedente gera multas e desabastecimentos, além do concorrido espaço solicitado por computadores cada vez mais compactos, porém com maior potência instalada requerendo alta eficiência do sistema elétrico e de clima, cada quilowatt poupado pode resultar em um valor reinvestido aumentando a eficiência do empreendimento gerando maiores resultados financeiros ao proprietário.

Isto se agrava no período chamado horário de pico (ou de ponta), que ocorre entre 17:00 e 22:00 horas, período onde a iluminação pública é ligada, as pessoas chegam em suas residência utilizando chuveiros elétricos, televisores, iluminação e eletro domésticos e concomitantemente as indústrias e escritórios mantém muitos processos ativos. Estes horários costumam ter uma taxa de fornecimento de energia elétrica mais elevada, haja visto que não justificaria um investimento extra da concessionária fornecedora para suprir toda a demanda. 
Outro ponto a ser levado em consideração são as oscilações de tarifa causadas por aumento de custos operacionais relacionados a indisponibilidades, dificuldade em distribuição e necessidade de reinvestimento e manutenção (ANEEL, 2015). Isto leva a grandes variações de custos operacionais e pode aumentar a necessidade de formas alternativas de resfriamento.

Em resumo, o crescimento das demandas por serviços de condicionamento de ar, impactam severamente em diversos países, causando oscilações e altas tarifas em horários de pico, além do risco de desabastecimento (BALARAS et al. 2007; MONTAGNINO, 2017).

Analisando estes fatores supõe-se que desenvolver métodos para poupar energia elétrica com climatização alimentada eletricamente pela rede, especialmente em horários de ponta, é uma prática de fundamental importância para a melhoria de processos. Os sistemas de refrigeração e resfriamento alternativos, como os sistemas que utilizam a energia solar para acionamento de compressores e geradores de vapor, vêm de encontro à esta necessidade.

Os sistemas de condicionamento de ar solar podem economizar parte da energia elétrica consumida em uma instalação, poupando energia proveniente de hidrelétricas ou da queima de combustível fóssil, todavia sistemas solares necessitam de áreas nem sempre pequenas para instalação de coletores ou painéis fotovoltaicos. Uma dificuldade é que nem sempre a capacidade de geração de energia solar ocorre quando se mais necessita, sendo necessário utilizar formas de estoque de energia, como tanques de termo acumulação e bancos de baterias. Algumas alternativas de climatização solar se apresentam, tendo os sistemas mais utilizados: a unidade de resfriamento de líquido ${ }^{1}$ por absorção solar e o resfriador acionado por células fotovoltaicas.

Outro fator a ser considerado em sistemas de climatização é a utilização dos métodos de resfriamento natural, que aproveitam condições exteriores para o

\footnotetext{
${ }^{1}$ Corriqueiramente utiliza-se o termo em inglês chiller para denominar unidade de resfriamento de líquido.
} 
condicionamento ambiental interno de ambientes, seja de forma direta, de forma indireta ou de outras fontes de resfriamento disponíveis. Isto gera reduções no consumo de energia elétrica.

Em contrapartida, é necessário um grande investimento financeiro inicial, agravado por exigência de estratégias de manutenção concorrente ${ }^{2}$. Outro ponto, que em se tratando de certificações de operação em Data Centers, equipamentos alternativos de condicionamento de ar não podem ser considerados como parte da redundância, pois não apresentam disponibilidade total no domínio do tempo.

A proposta desta pesquisa é verificar a análise de desempenho energético de um sistema de ar condicionado solar de um Data Center, provendo a energia necessária para climatização em horários de ponta e horários de alta disponibilidade por meio de sistemas alternativos com acionamento solar e termo acumuladores, avaliando possíveis contribuições de sistemas economizadores de resfriamento natural para estes ambientes, além de seu retorno financeiro através de análise de tempo de retorno de investimento (payback simples) e taxa interna de retorno de investimento (TIR) em 10 anos para a cidade de São Paulo.

Também será avaliado a projeção destes sistemas em outras cidades, tomando como base a classificação climática da $\operatorname{ASHRAE}^{\circledR}($ ASHRAE, 2006), e paralelamente com a norma ABNT 16.401 (ABNT, 2008), para regiões condições externas anuais, a utilização deste sistema com equipamentos de alta eficiência e a aplicação destes sistemas à loja de departamento modelo em comparação à condição Data Center.

Como contribuição final, esta tese tem função de auxiliar ao proprietário, engenheiro responsável e projetista a discutir sobre o método de climatização desejado, a demanda de energia elétrica contratada junto a concessionária e os fatores necessário para esta decisão, além de fomentar a discussão sobre custos operacionais (OPEX) na fase conceitual de implementação de projetos ou previsão de modernização ou remodelagem de uma instalação.

2 O sistema de condicionamento de deverá estar operante em janelas de manutenção, através de equipamentos redundantes e também deverá ser tolerante a falhas simples. 


\subsection{OBJETIVOS}

\subsubsection{Objetivos Gerais}

O presente trabalho tem como objetivo avaliar a utilização de sistemas de condicionamento de ar acionados por energia solar fotovoltaica e térmica por absorção em uma edificação típica de missão $\mathrm{crítica}^{3}$, utilizando a área de cobertura (laje/ telhado) para a instalação de coletores com diferentes densidades de dissipação de carga térmica proveniente dos computadores, tomando como base a cidade de São Paulo, Abu Dhabi, Los Angeles e Nova York, bem como apresentando as economias de energia em comparação à um sistema convencional e índices de retorno de investimento.

\subsubsection{Objetivos Específicos}

As configurações propostas foram produtos de uma avaliação de índices energéticos e econômicos, os quais avaliaram o potencial de utilização de sistemas de condicionamento de ar solares em áreas de computadores de um Data Center (missão crítica). A metodologia é baseada nas análises energéticas de plantas de conversão de energia. Assim, os seguintes objetivos específicos são propostos:

- $\quad$ Avaliar plantas de Data Centers, identificando pontos de climatização para atendimento;

- Analisar a aplicação de processos de condicionamento de ar solar e resfriamento natural;

- Aplicar a metodologia para uma planta padrão com características típicas dos Data Centers, com diferentes dissipações de carga: $0,5 \mathrm{~kW} / \mathrm{m}^{2}, 1,0 \mathrm{~kW} / \mathrm{m}^{2}, 2,0$ $\mathrm{kW} / \mathrm{m}^{2}, 4,0 \mathrm{~kW} / \mathrm{m}^{2}$ e $8,0 \mathrm{~kW} / \mathrm{m}^{2}$;

- Aplicar a metodologia para cidades características de diferentes regiões climáticas do mundo, segundo a ASHRAE ${ }^{\odot}$.

\footnotetext{
${ }^{3}$ No universo de TI, o termo missão crítica é utilizado para se referir à estabilidade de sistemas, aplicações e processos que, se interrompida, pode ocasionar graves consequências (DATACENTER DYNAMICS, 2017).
} 
- Analisar o consumo complementar de energia elétrica, quando há utilização de processos de condicionamento de solar: elétrico fotovoltaico e solar térmico por absorção;

- Por meio de análises de redução de carga térmica, avaliar as vantagens de consumo de energia obtidas através de modos de resfriamento natural, ou seja, em horários em que a temperatura exterior é adequada e pode-se ter diretamente a entrada de ar exterior no ambiente, ou resfriamento direto por água proveniente de torres de condensação;

- Com estimativas orçamentárias, avaliar taxa de retorno de acordo com a variação tarifária aplicando às cidades características;

- Fazer comparativo deste sistema com a utilização de equipamentos de maior eficiência com diferente curva de operação característica; 


\subsection{CONTEÚDO DA TESE}

O trabalho é dividido em sete capítulos conforme a seguinte sequência:

- No Capítulo 1 contextualiza-se a tese e apresenta a motivação do trabalho, definindo objetivos gerais por meio da pergunta de pesquisa e objetivos específicos desenvolvidos no decorrer deste trabalho.

- No Capítulo 2 na revisão bibliográfica, faz-se uma análise crítica sobre as edificações características, apresentando detalhes de funcionamento e aplicação de condicionamento de ar e métodos de resfriamento natural, e também características que influenciam em tarifação do consumo de energia elétrica. Também se discorre brevemente sobre certificações ambientais e pontuações correspondentes.

- No Capítulo 3 é apresentada a análise teórica sobre condicionamento de ar e resfriamento solar. Neste capítulo são definidos quais os métodos serão abordados nesta tese com suas justificativas.

- No Capítulo 4 apresenta-se o método para efetuar os cálculos das cargas térmicas e consumo energético para o caso base. Isto posto, expõe-se a forma de cálculo de inserção dos métodos de condicionamento de ar solar e resfriamento natural, suas atenuações em carga térmica resfriada e consumo energético. Após apresentação de estimativa de orçamentos, por fim, procede-se para cálculo de taxa interna de retorno e análise financeira.

- No Capítulo 5 são revelados os resultados obtidos por meio da metodologia apresentada no capitulo 4 para o caso base na cidade de São Paulo, analisando os valores apresentados. 
- No Capítulo 6 aplica-se o modelo abordado para a cidade de São Paulo para diferentes regiões climáticas, representadas por Abu Dhabi, Los Angeles e Nova York e para diferente tecnologia de unidade de resfriamento base. Ao final discute-se sobre os valores apresentados.

- O Capítulo 7 é reservado para conclusões e recomendações desta tese, além de indicar futuras obras para o desenvolvimento deste assunto.

- No Capítulo 8 segue bibliografia referenciada para a execução desta dissertação.

- Esta obra possui Anexos que facilitam a compreensão dos dados apresentados no trabalho. 


\section{CAPÍTULO 2 - REVISÃO DA LITERATURA - CLIMATIZAÇÃO DE EDIFICAÇÕES PADRÃO}

No presente capítulo são apresentados os conceitos de clima para as edificações selecionadas. Dessa forma, o leitor se familiarizará com os conceitos de cada edificação. 


\subsection{Edificação Característica - Data Center}

O processamento e armazenamento de dados se tornou uma necessidade primordial nos tempos atuais. Hoje, é impossível imaginar qualquer sistema industrial sem um banco de dados. Devido a isto, a cada dia é maior a necessidade do projeto e construção de novos Data Centers. Por exemplo, Sem um data center ágil e funcionando eficientemente, as empresas, bancos e governos não conseguem reagir rapidamente à competição, ou alterar corretamente as condições de negócio, ou ainda serem capaz de implementar novas regulações (JESUS, 2006).

Entretanto, estas instalações devem ser construídas de acordo com regras de segurança e redundância, visando sua utilização ininterrupta, pois sua paralização pode gerar custos imensuráveis e perdas de dados sigilosos e de alta importância, segundo (RAPOZA, 2017), o custo médio de parada de um Data Center é de US $\$ 262.000,00$ por hora, no caso de empresas de hospedagem este valor pode chegar a US\$492.000,00

No início da década de 60, mais especificamente em 1964, a IBM® lançou o IBM System 360 (GANTZ, 2004), o qual poderia ser caracterizado como um mainframe que prometia centralizar e processar todos os dados de uma mesma organização. A superioridade e domínio da IBM ${ }^{\circledR}$ se estenderam até a metade da década se 70 , quando outras empresas lançaram seus centros de processamento de dados corporativos, ou seja, seus próprios Data Centers.

Inicialmente a denominação dada ao Data Center era CPD (Centro de Processamento de Dados). A edificação, doravante assim foi denominada, pois nesse local residiam os mainframes das empresas, outrossim neste local ocorria 0 processamento, automatização da distribuição de informações. O nome migrou para "Data Center", visto que este, contemporaneamente, adquire a função mais importante dentro de uma corporação: reter a informação. Por ter uma função única, abrigar um bem tão precioso às empresas, o Data Center tornou-se um centro no qual falhas são minimamente aceitas, em alguns casos essas falhas não podem ocorrer sob nenhuma hipótese, caso contrário o faturamento e lucro das corporações podem ser seriamente comprometidos (SANTOS, 2014).

Por isso, as salas de computadores, popularmente conhecidas com áreas de piso 
branco, recebem o nome de área de missão crítica. Estes ambientes devem sempre estar sob condições rigorosas de temperatura e umidade, possuir energia estabilizada livre de interferências eletrostáticas e eletromagnéticas.

A perspectiva para o futuro é a diminuição de áreas ocupadas, porém com o aumento da densidade dos racks. Em 2003 o valor considerado variava entre 250 e 1500 $\mathrm{W} / \mathrm{m}^{2}$, para o futuro a ideia é se atinja os $52 \mathrm{~kW} / \mathrm{m}^{2}$ (VERGE \& SMITH, 2014).

A estrutura atual de um Data Center diferencia-se muita daquela surgida em 1964 quando o mainframe central apenas processava os dados. Agora as corporações buscam um local que além de processar os dados, mantenha suas informações seguras e em sigilo e ainda sejam eficientes em seu funcionamento. Podemos citar o exemplo de empresas como a GOOGLE® que investiu 951 milhões de dólares no último trimestre de 2011, com um total de 3,44 bilhões de dólares no mesmo ano em recursos e sistemas que conferissem melhor eficiência energética aos seus Data Centers (SANTOS, 2014).

Pela norma ANSI/TIA 942, existem regras aplicáveis para a classificação do Data Center em redundâncias, telecomunicações, Arquitetura e estrutural, Elétrica e Mecânica (VERAS, 2009; TIA, 2015)

O sistema básico de um Data Center de alta confiabilidade deve possuir:

- Entrada de Rede Elétrica e Cabine Primária, por onde ocorre a alimentação da rede elétrica no Data Center proveniente da concessionária de energia;

- Geradores de Energia: Os geradores de energia são motores de combustão interna movidos a óleo diesel ou gás natural e devem possuir capacidade para atender a demanda total do Data Center e sua infraestrutura. Neste caso, devido a intermitência em alguns lugares da rede elétrica, este não pode ser considerado como elemento de redundância dos geradores, em caso de manutenção, portanto deve-se prever ao menos um equipamento para redundância parcial ou total do Data Center, podendo ocorrer manutenção de um gerador concorrentemente à falta de energia proveniente da rede;

- $\quad$ Dispositivos de energia ininterrupta: Os principais dispositivos de energia ininterrupta são as UPS, associadas a bancos de bateria (UPS estática) ou discos de inércia (UPS rotativa). A finalidade deste dispositivo é que não haja interrupção de queda de energia no momento de transição entre geradores e rede elétrica em computadores do Data Center e também mantém a estabilidade de fornecimento de energia. 
- $\quad$ Dispositivos de transição rápida em caso de falha de fonte de energia e retorno de fonte prioritária, os principais são as chaves ATS e STS;

- Sistemas de condicionamento de ar, que poderão por sistemas de expansão direta no caso de pequenos Data Centers e expansão indireta no caso de grandes Data Centers, onde se utilizam unidades de resfriamento de líquido, Torres e Unidades de Ventilação 4 .

O Uptime Institute ${ }^{\odot}$, que classifica os data centers segundo sua infraestrutura em camadas chamadas Tiers, onde:

- Tier I: Data Center com o mínimo de componentes necessários para funcionamento e manutenção com parada programada e disponibilidade de $95 \%$;

- Tier II: Edificação com redundância de principais componentes, com caminhos de alimentação elétrica e de condicionamento de ar singelos, sendo necessário manutenção programada com disponibilidade de $99,7 \%$.

- Tier III: Edificação com redundância de componentes e caminhos, sendo disponível manutenção concomitante com a operação e disponibilidade de 99,992\%.

- Tier IV: Edificação com redundância de componentes e caminhos, tolerante a falha e ato de vandalismo, com condicionamento de ar ininterrupto (mesmo em caso de transferência de alimentador principal) e disponibilidade de 99,99997\% (UPTIME-INSTITUTE, 2013).

A camada escolhida varia de acordo com a necessidade de utilização do usuário. Organizações com impossibilidade de parada programada para manutenção e resiliência a falhas devem optar pelas camadas mais altas. Isto impacta consideravelmente 0 investimento inicial do usuário e devido a isto algumas organizações decidem por alugar espaços em grandes datacenters, conhecidos como colocation (ASHRAE, 2015).

\footnotetext{
${ }^{4}$ Para unidades de ventilação é comum utilizar o termo em inglês "Fan coil", no caso de ambientes de missão crítica utiliza-se o termo "Fan Coil de precisão", que são equipamentos com automação embarca e maior capacidade de retirada de calor sensível.
} 
A Figura 2.1 ilustra o sistema elétrico básico de um Data Center Tier $\|^{\circledR}$, o recomendado para aplicações do mercado financeiro, ambientes de colocation e telecomunicações. Os Geradores $\mathrm{X}$ e $\mathrm{Y}$ alimentam os quadros elétricos, que também podem ser alimentados pela energia da rede após passarem pelos trafos $\mathrm{X}$ e $\mathrm{Y}$. Após passar pelas chaves de transferência automática, que são responsáveis pela seleção de fontes que alimentarão o Data Center, a energia elétrica irá alimentar as UPS associadas a bancos de bateria, que garantem alimentação continua de energia, mesmo no caso de troca de fontes e pequenas faltas de energia, e os equipamentos de climatização, que farão o condicionamento do ambiente para impedir o aquecimento dos equipamento, gerando falhas. As UPS alimentarão os computadores e servidores presentes em um Data Center.

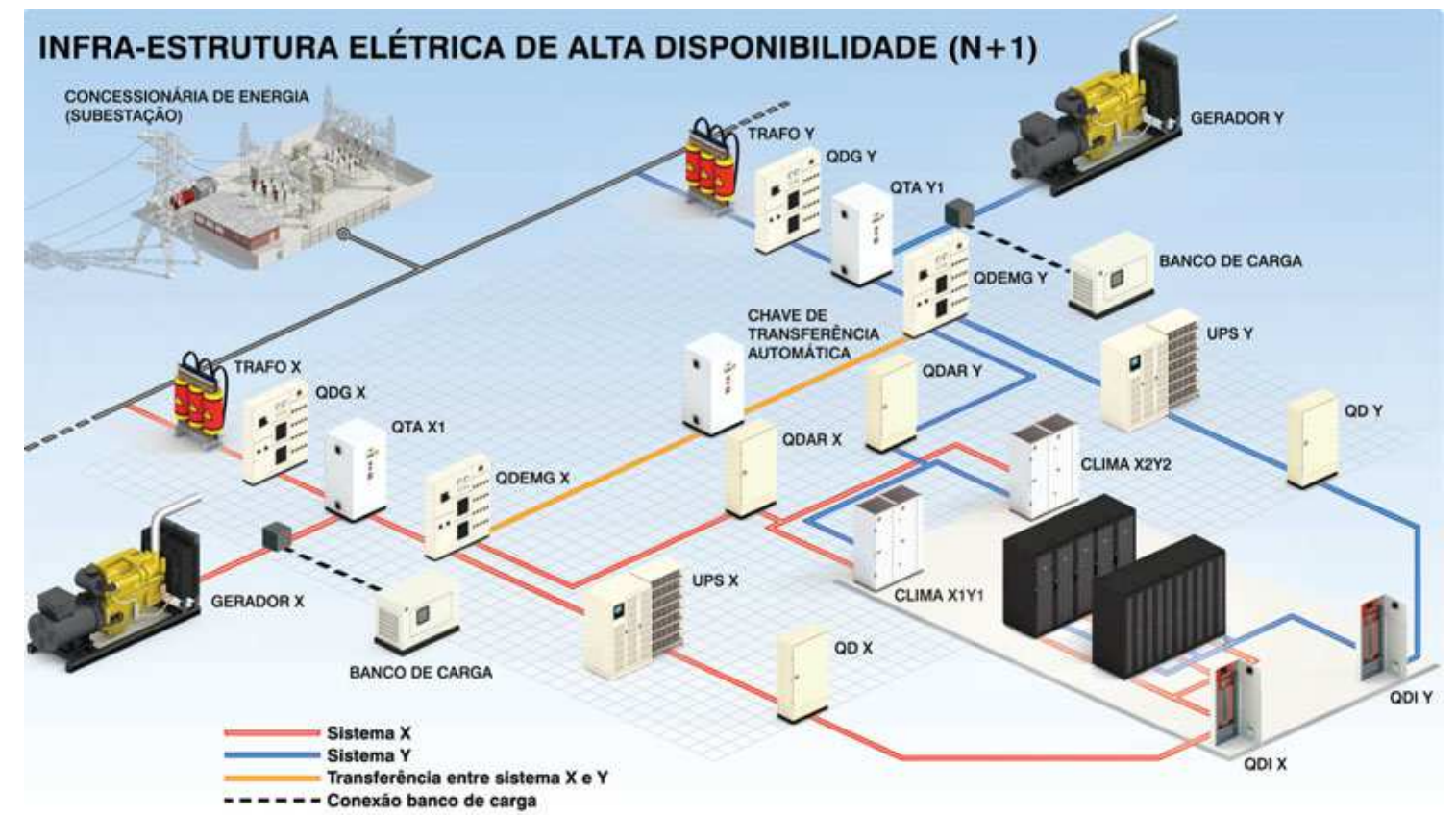

Figura 2.1 - Esquema de Infraestrutura elétrica de um Data Center.(ATS SOLUTION, 2015)

\subsection{Condicionamento de ar}

Data centers e estações de comunicações são diferentes de outras instalações típicas, pois neste caso a ocupação não é realizada por pessoas e sim por computadores. Geralmente para o mesmo tipo de edificação é necessário um sistema de climatização 
de capacidade 10 vezes ou maior que para instalações de escritórios do mesmo tamanho (ASHRAE, 2015).

Os computadores dissipam alta energia térmica, aquecendo o ambiente e acelerando seus mecanismos de falha e colocando em risco todo o processamento e armazenamento de informações, além do aumento de risco de incêndios, tornando-se primordial a climatização do ambiente por sistemas de condicionamento de ar e ventilação forçada. A dissipação de um servidor pode ser superior a $90 \mathrm{~kW} / \mathrm{m}^{2}$ no caso de super servidores, porém para a utilização de sistemas de arrefecimento por ar condicionado é recomendado até no máximo $12 \mathrm{~kW} / \mathrm{m}^{2}$ (Fitas, Servidores Stand Alone e Storages). Em densidades superiores é necessário um sistema de refrigeração dedicado a cada rack $^{5}$ (ASHRAE, 2016a).

Desse modo, em um sistema de missão crítica de alta confiabilidade, a sala de computadores deverá ter climatização contínua, redundante e a prova de falhas. Os hardwares de uma sala de servidores devem operar com temperatura exterior estável. A carga térmica dissipada por este hardware em um ambiente fechado poderia elevar a temperatura além dos limites de emergência. Os CRAHs mantêm a temperatura e umidade dentro dos parâmetros estipulados, além de propiciar grande economia de espaço físico e energia.

Entretanto, o processo de condicionamento de ar para um ambiente de missão crítica é responsável pelo aumento de $30 \%$ a $100 \%$ do consumo de energia elétrica, tendo como referência o consumo energético dos computadores. No atual contexto, com consecutivas alterações tarifárias e reduzida oferta, a utilização racional de energia elétrica é de fundamental importância para viabilizar a operação de um Data Center.

A necessidade de climatizar uma sala de missão crítica surge com as primeiras edificações. Na década de 60 , surgem as primeiras técnicas de climatização para centro de processamento de dados, onde seguiam regras da indústria gráfica devido a utilização de cartão perfurado. Na década de 70 , a ANSI publicou as primeiras normas

\footnotetext{
${ }^{5}$ Rack é um armário que pode conter até 44 computadores instalados verticalmente
} 
Internacionais para este tipo de edificação. Baseada nesta norma, surge em 1982 a NBR10080, com o título "Instalações de Ar Condicionado para Sala de Computadores".

Entre o final da década de 60 e início da década de 70, percebendo o novo nicho de mercado, Ralph Liebert (ex funcionário Carrier) desenvolve a primeira unidade de ventilação (CRAH) para a utilização em centro de processamento de dados, com grande capacidade de retirada de carga sensível, diferentemente dos equipamentos de conforto. Em 1995 Nakazato, Hayama, Kishita, e Nakao publicam a primeira patente de Condicionamento de com insuflação sob o piso elevado, transportando o ar a sala de computadores por diferencial de pressão, o que se tornaria comum no século XXI (VERTIV CO, 2016).

Até então, cada fabricante de servidores e computadores sugeria uma temperatura padrão e umidade para funcionamento de seus servidores. Porém isto gerava grande dificuldades para projetistas e engenheiros. Com o grande crescimento deste mercado em 2004, a ASHRAE forma o comitê TC 9.9, com representantes dos principais fabricantes de computadores, fabricantes de condicionadores de ar e engenheiros da área, padronizando assim, as regras de climatização para esta aplicação. $\mathrm{Na}$ recomendação original, a temperatura de ar recomendada é entre 20 e $25^{\circ} \mathrm{C}$ no retorno (ASHRAE, 2016a).

Estas regras foram revisadas em 2008, e 2011, onde foram flexibilizadas as temperaturas de trabalho para este tipo de edificações, e estabelecido a temperatura na entrada de ar do computador como parâmetro de controle, não importando o valor atingido no retorno à unidade de ventilação como anteriormente.

Todavia, desde 2010, alguns especialistas já publicavam suas impressões sobre o controle de umidade em datacenters, apresentando estudos sobre a precisão dos sensores de umidade e o impacto disso na operação de unidades de ventilação, questionando a real necessidade de se controlar umidade em um data center (HYDEMAN E SWENSON, 2010). Em 2007, a Associação de Descargas Eletrostáticas (ESDA) recomendava a eliminação da umidificação forçada como uma forma de controle primário para prevenção de descargas eletrostáticas em ambientes de manufatura (ANSI, 2007). 
Entre 2011 e 2014, a ASHRAE financiou o Laboratório de Compatibilidade Eletromagnética na Missouri University of Science and Technology para investigar os riscos de danos em componentes eletrônicos relativos às descargas eletrostáticas, com ênfase no aumento do risco em baixas umidades (ASHRAE, 2016a). Os resultados obtidos demostraram que um data center com baixo índice de falhas devido à descarga eletrostática operando à $25 \%$ de umidade relativa permanece com o mesmo índice de falhas quando sua umidade é reduzida para $8 \%$. Portanto, as preocupações levantadas quanto ao risco pela baixa umidade passaram a não fazer mais sentido (MORADIAN et al., 2014).

Outra importante definição são as classes, o qual é classificação de ambientes em operação total e os diferentes níveis de controle sobre cada um deles:

- Classe A1: Um ambiente de Data Center com um rígido controle dos parâmetros do ambiente (ponto de orvalho, temperatura, umidade relativa do ar) e em missão crítica de operação. Geralmente desenvolvidos para grandes empresas com um grande número de racks (altos níveis de processamento de dados e armazenamento de informações). A temperatura de bulbo seco ${ }^{6}$ requerida na entrada dos computadores é entre 15 e $32^{\circ} \mathrm{C}$ e ponto de orvalho ${ }^{7}$ mínimo a $12^{\circ} \mathrm{C}, 8 \%$ de umidade relativa a $17^{\circ} \mathrm{C}$ e umidade relativa ${ }^{8}$ máxima de $80 \%$.

- Classe A2: Geralmente um ambiente de produção tecnológica ou um escritório ou um laboratório com algum controle dos parâmetros ambientais. São ambientes que abrigam pequenos racks, podem ser servidores pessoais ou estações de trabalho. A temperatura de bulbo seco requerida na entrada dos computadores é entre 10 e $35^{\circ} \mathrm{C}$ e ponto de orvalho mínimo a $-12^{\circ} \mathrm{C}, 8 \%$ de umidade relativa a $21^{\circ} \mathrm{C}$ e umidade relativa máxima de $80 \%$.

- Classe A3/A4: Geralmente um ambiente de produção tecnológica ou um escritório ou um laboratório com algum controle dos parâmetros ambientais.

\footnotetext{
${ }^{6}$ Temperatura medida com um termômetro comum

7 Temperatura a qual o vapor de água presente no ar ambiente passa ao estado líquido na forma de pequenas gotas por via da condensação

${ }^{8}$ Relação entre a pressão parcial da água contida no ar e a pressão de vapor da água tomada à temperatura do ar (BOILIGER JR.; MARIANI, 2005), (SIMÕES-MOREIRA, 1999).
} 
São ambientes que abrigam pequenos racks, podem ser servidores pessoais ou Estações de trabalho. Diferenciam-se do anterior pelo menor porte de seus equipamentos. A temperatura de bulbo seco requerida na entrada dos computadores é entre 5 e $40^{\circ} \mathrm{C}$ e ponto de orvalho mínimo a $-12^{\circ} \mathrm{C}, 8 \%$ de umidade relativa a $24^{\circ} \mathrm{C}$ e umidade relativa máxima de $85 \%$.

A ASHRAE (ASHRAE, 2016b) apresenta ainda uma faixa recomendada para insuflação de temperatura de bulbo seco requerida na entrada dos computadores entre 18 e $27^{\circ} \mathrm{C}$ e ponto de orvalho mínimo a $-9^{\circ} \mathrm{C}$ a $15^{\circ} \mathrm{C}$ e umidade relativa máxima de $60 \%$. Estes limites atuais estabelecidos pela ASHRAE em 2015 são ilustrados na Figura 2.2.

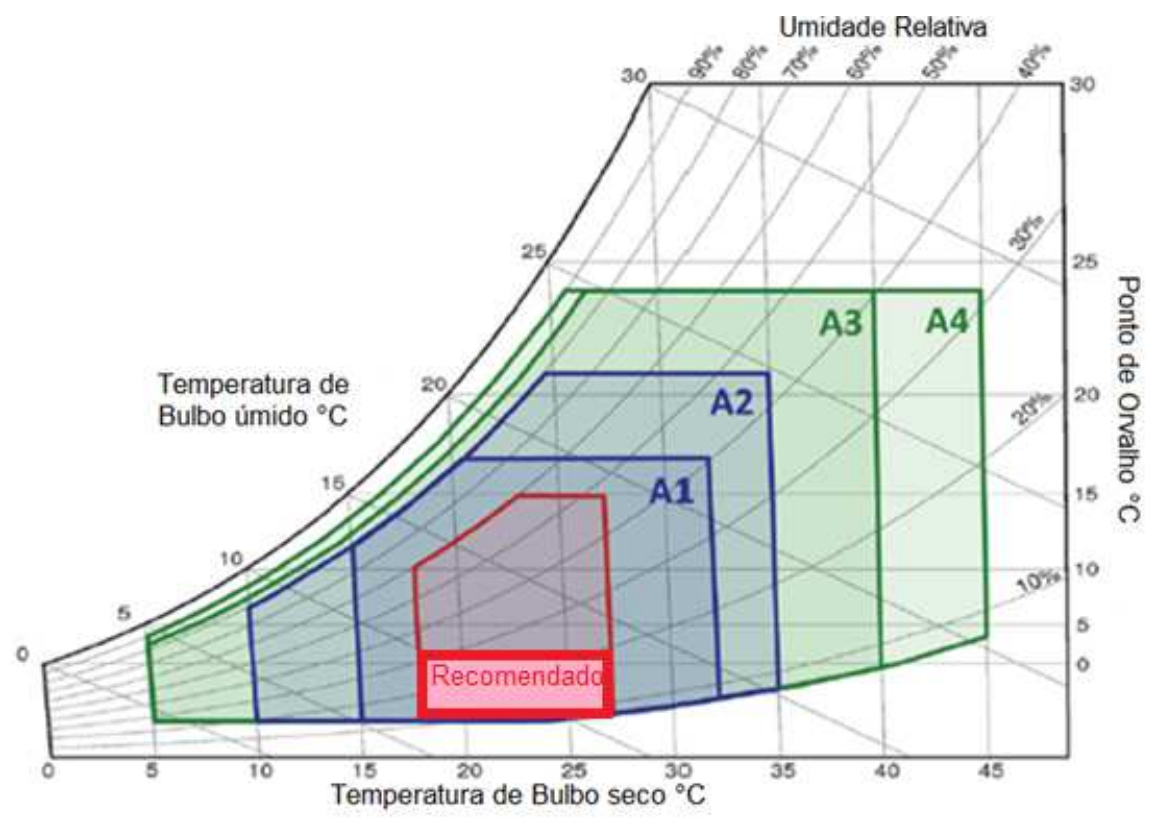

Figura 2.2 - Faixas de aplicação para Temperaturas conforme TC 9.9(ASHRAE, 2016a). Adaptado

Para um Data Center de grande produção (acima de $100 \mathrm{~kW}$ ), a climatização utilizada, na maioria dos casos, é de um sistema de expansão indireta, que engloba resfriadores de líquidos, bombas de recalque e sucção, válvulas de bloqueio e balanceamento hidráulico. O condicionamento do ar é feito por unidades de ventilação. O resfriamento da UR deverá ser feito por um sistema de condensação, que poderá ser 
realizado por torres de condensação ou sistemas de ventiladores sob estas, porém com alto consumo energético.

A Figura 2.3 ilustra esquema de condicionamento ambiental por expansão indireta, onde a água gelada troca calor com o ar quente proveniente da sala de computadores em um ambiente de missão crítica por meio das CRAHs. Esta água retorna às unidades de resfriamento através de bombas de água. Nas URs a água será resfriada através um processo de expansão de vapor frio de um fluido refrigerante interno. Encerrando o ciclo, o fluído refrigerante da unidade de resfriamento rejeita calor para o meio por um sistema de torres evaporativas.

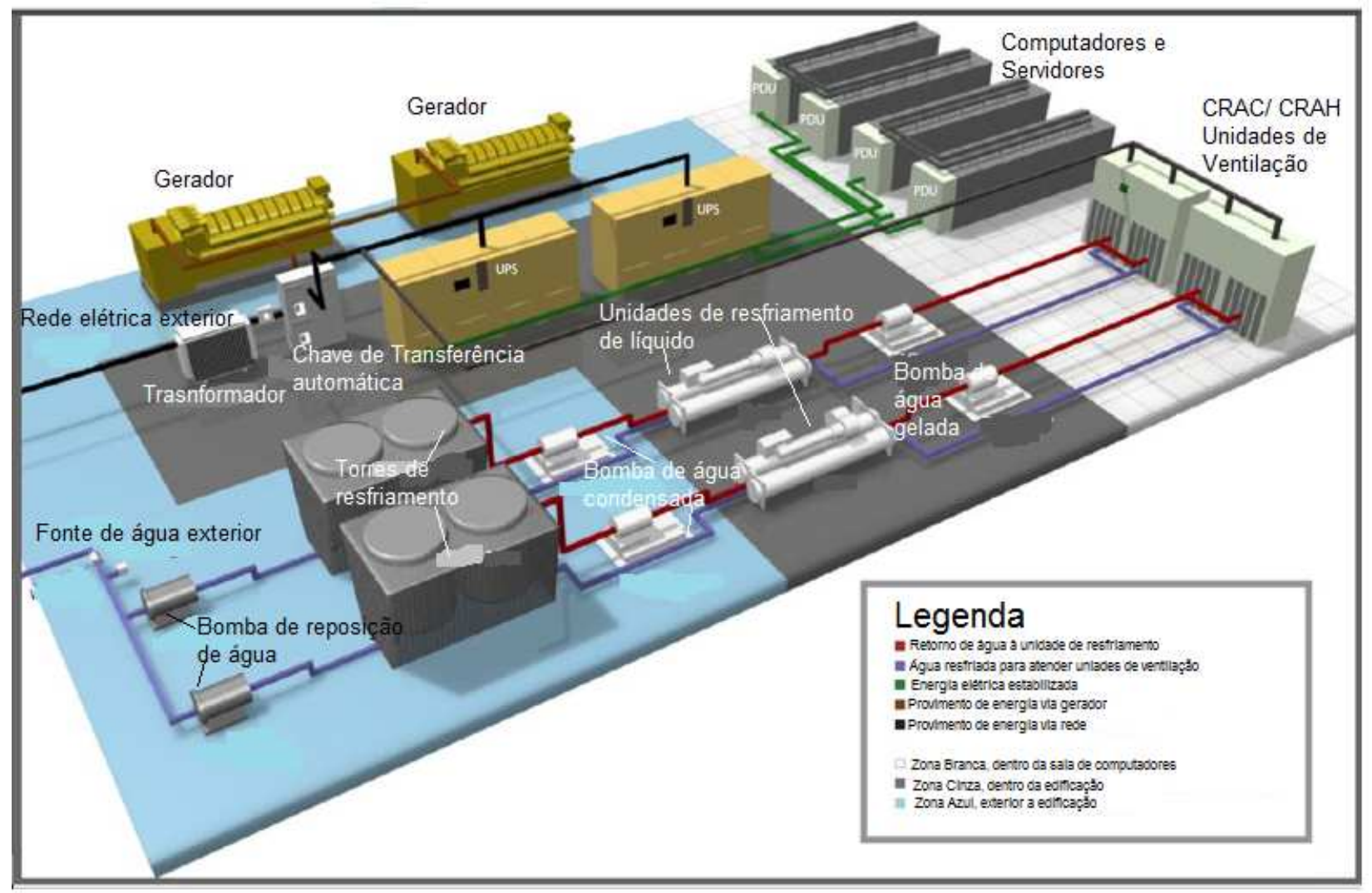

Figura 2.3 - Esquema de resfriamento de água por expansão indireta com condensação à água de um Data Center (ATS SOLUTION, 2015).

$\mathrm{Na}$ concepção de um sistema de missão crítica, existem diversos parâmetros que, necessariamente, devem ser considerados para a boa operação. A relação entre estes ambientes poderá ser observada na Figura 2.4. É possível observar que não há interligação direta entre as variáveis, indicando que cada um desses parâmetros pode 
ser de maior ou menor importância para construção ou operação de um Data Center, isso dá ao usuário maior flexibilidade no gerenciamento.

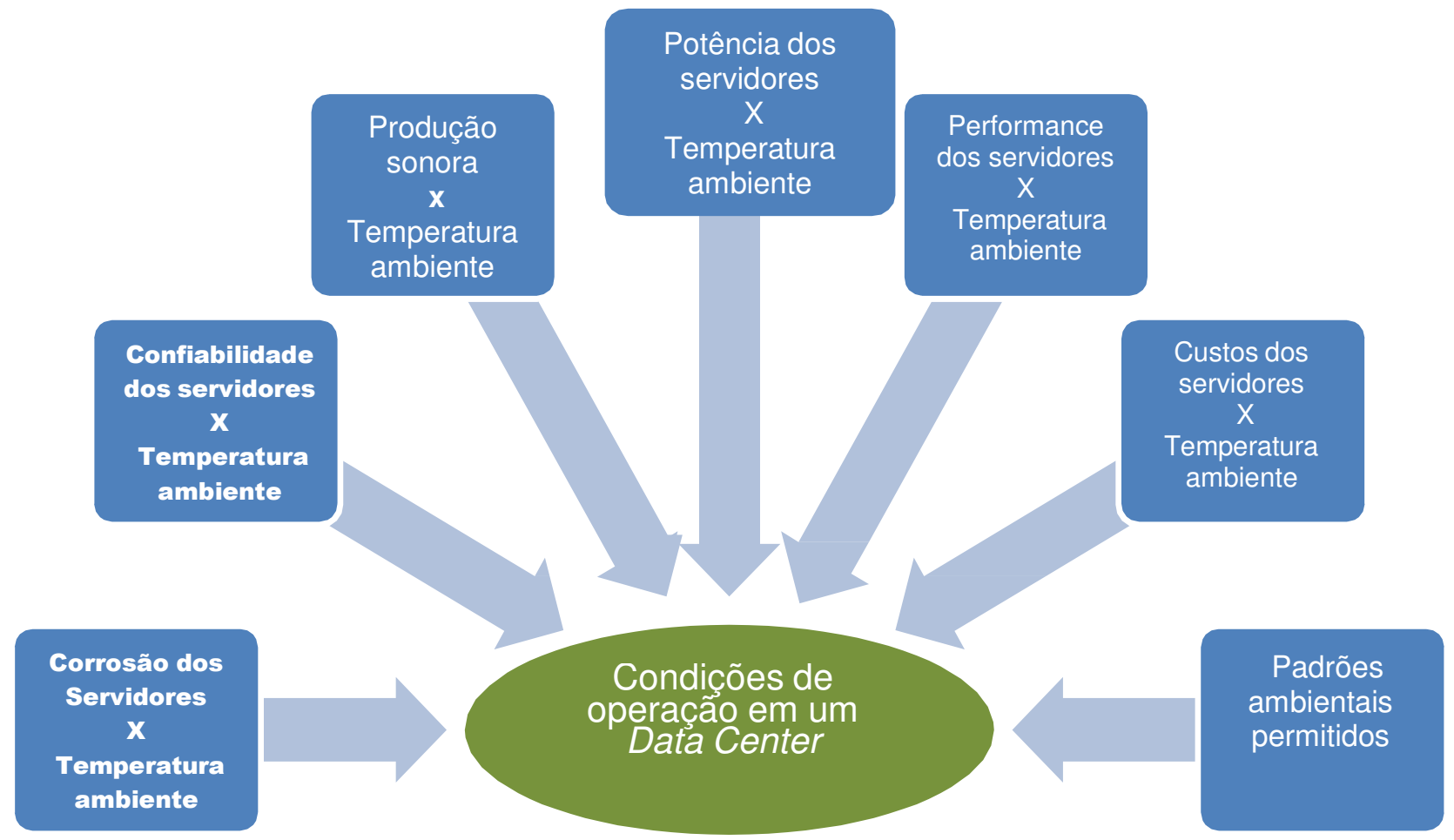

Figura 2.4 - Ambientes relacionado à operação de um Data Center (ASHRAE, 2016a).

Outro fator importante, para o bom funcionamento do sistema de condicionamento de ar deve-se prover ar frio na entrada dos servidores, que devem estar todos voltados para a tomada de ar e o ar quente de retorno deverá estar em seu retorno, separando os sistemas de inflação e retorno de ar. Essa configuração é denominada Corredor Quente/ Corredor Frio (Hot Aisle / Cold Aisle - HACA).

As práticas de condicionamento de ar em um Data Center podem ser variadas de acordo com o projeto. As duas abordagens mais comuns são a de insuflação através de placas perfuradas posicionadas no piso elevado (under floor) e a de insuflação pelos dutos superiores internos ao forro do teto (overhead). Na utilização do sistema superior não deve haver o emprego dos difusores situados nas saídas de cada duto, pois estes direcionam o fluxo de ar para regiões acima dos racks, aumentando a perda energética. No sistema de piso elevado, mais comum nas aplicações, devem ser utilizadas placas nos corredores frios na frente dos racks que estejam ocupados. Esta configuração foi 
criada a fim de prevenir a mistura do ar frio com o ar quente de exaustão. Como o próprio nome sugere também cria áreas de acesso para das equipes técnicas para procedimentos de manutenção, substituição ou instalação de novos equipamentos. Para esta aplicação será considerado um sistema com inflação por piso elevado (STRUTT et al., 2012). A Figura 2.5 exemplifica esta aplicação:

O controle sobre o fluxo de ar implica no desenvolvimento de formas a fim de minimizar ou eliminar a mistura de ar condicionado insuflado no interior das salas de produção e o ar quente expelido pelos servidores e computadores. Quando aplicado de maneira correta o controle do fluxo de ar pode reduzir custos de investimentos e operacionais, aumentar a capacidade de produção da instalação e reduzir o número de paradas para eventuais manutenções (STRUTT et al., 2012).

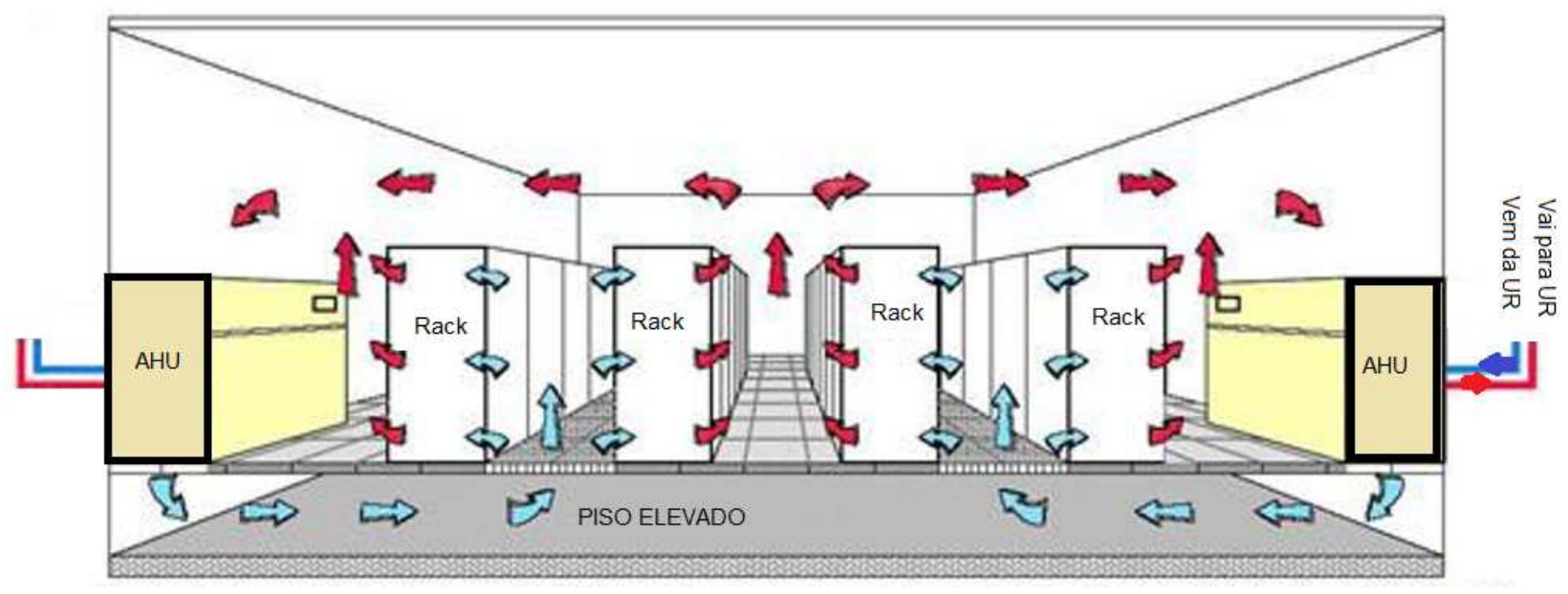

Figura 2.5. - Configuração comum em ambientes de Data Center (SANTAMARIA, 2016).

Todavia, surgem alguns problemas comuns como o ar de insuflação que não chegam às entradas de ar nos equipamentos e retorna as CRAHs, sem condicionar os computadores e a recirculação do ar quente que é a saída de ar dos servidores e retornam a tomada de ar sem passar pelas unidades de ventilação (SANTAMARIA, 2016). Para evitar tal efeito, uma prática usual é o confinamento de corredores, que pode ocorrer, com o confinamento do ar quente, quanto com o confinamento do ar frio.

O confinamento do ar quente consiste na captura deste diretamente das máquinas e retorno às unidades de ventilação. Este procedimento gera um pequeno 
ganho de eficiência energética, porém auxilia no conforto térmico dos operadores do Data Center, conforme simulações CFD.

O confinamento do ar frio consiste no enclausuramento dos corredores onde estão localizadas as placas de piso perfurado, evitando a dispersão do ar condicionado. Este procedimento propicia uma melhor eficiência energética, porém é deficitário em conforto térmico para a circulação na edificação. O confinamento dos corredores frios propicia um aumento de $5^{\circ} \mathrm{C}$ na temperatura de insuflação com a mesma eficiência das configurações sem confinamento de corredores (SANTOS, 2014). Aa figura 2.6 exemplifica estas proposições:
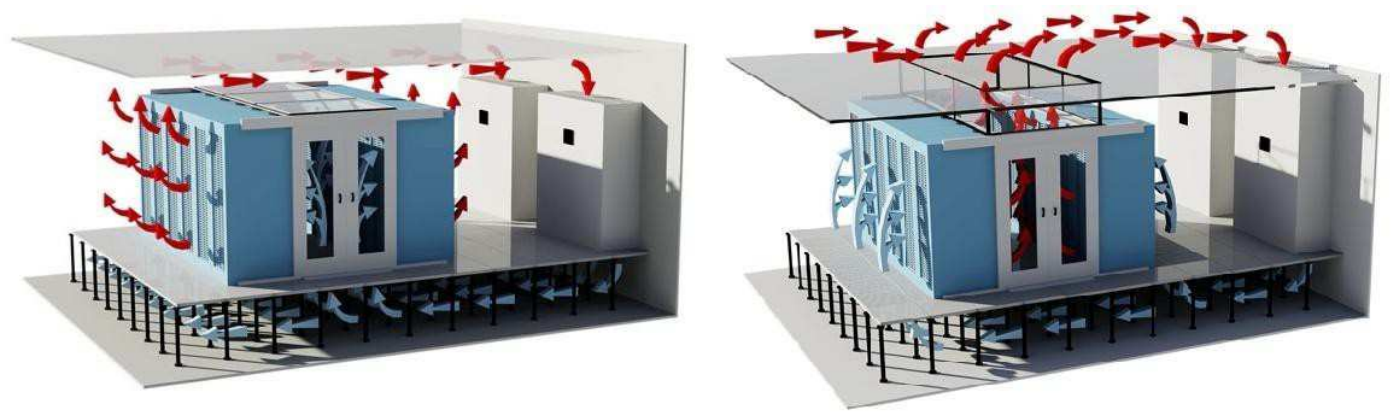

Figura 2.6 - Corredores frios à esquerda e corredores quentes à direita.

(SANTOS, 2014)

\subsection{Economizadores por Resfriamento Natural (Free Cooling)}

No passado os economizadores eram utilizados como dispositivos suplementares à operação de uma edificação climatizada, durante determinadas épocas do ano para ganho de energia.

Hoje, em ambientes de missão crítica, com o rápido crescimento da densidade de computadores, o resfriamento natural, em muitos casos, é utilizado como fonte prioritária a fim de aumentar a eficiência de uma edificação (DARAGHMEH \& WANG, 2016). Em 2008, a companhia Inte/C adotando uma estratégia de resfriamento natural atingiu em suas dependências de data center uma economia de US\$2,88 milhões (ATWOOD \& MINER, 2008).

A técnica de climatizar ambientes através de ciclos economizadores utilizando o clima externo natural, quando o ar exterior é frio o suficiente para ser utilizado diretamente 
ou indiretamente é chamado de Free Cooling (ZHANG et al., 2014), aqui denominado de resfriamento natural. Após as últimas revisões da ASHRAE, onde as temperaturas de trabalho foram flexibilizadas entre 5 e $45^{\circ} \mathrm{C}$ (para insuflação) e a umidade relativa varia de limites entre 10 e 90\% (ASHRAE, 2016b). O resfriamento natural se dá de 4 modos (ORÓ et al., 2015):

- Resfriamento natural direto (Direct Airside Free Cooling), que ocorre através de entrada e exaustão direta de ar exterior no ambiente.

- Resfriamento natural indireto por ar (Indirect Air Side Free Cooling), que ocorre através da troca de ar exterior com rodas entálpicas.

- Resfriamento natural indireto por fonte de água não resfriada (Waterside Free Cooling), que ocorre através da entrada da troca de calor em sistemas de expansão indireta com água proveniente de meio externo não condicionado. Isto ocorre de 3 modos: diretamente de fontes de água gelada disponíveis na natureza, através de resfriamento direta nos trocadores de calor de circuito fechado, onde não há evaporação de água ou através de trocadores de calor de circuito aberto, onde há evaporação.

- Resfriamento natural por termossifão (Heat Pipe-System), obtido em um sistema de resfriamento passiva através de troca de calor com termo sifões ou com sistemas de armazenamento de resfriamento de outros sistemas, como câmaras frias.

\subsubsection{Resfriamentos natural direto}

Conforme dito acima, o sistema de resfriamento natural direto, consiste na entrada direta de ar ambiente na sala de computadores de um Data Center. Para o funcionamento deste tipo condicionamento, a entalpia exterior deverá ser no mínimo ligeiramente inferior a entalpia de retorno, e calculado a quantidade de ar condicionado para complemento da carga térmica, além disto é necessário um sistema efetivo de filtragem para evitar a entrada de ar externo sem partículas.

Todavia, a injeção de ar diretamente em um ambiente poderá causar alguns problemas em um ambiente, como qualidade do ar, alta umidade. Isto pode acelerar o risco de degradação de um ambiente de missão crítica, devido a isto quase sempre é 
necessário um sistema de pré tratamento de ar e filtros, que alteram a pressão de ar na entrada do ambiente (DAl et al. 2012).

Outro ponto a observar, seria que devido aumento da umidade interna graças ao ar exterior, parte da energia economizada seja despendida com processos de desumidificação (UDAGAWA et al., 2010).

A figura 2.7 abaixo mostra um esquema de condicionamento ambiental natural para estação de telecomunicações em Goughanzou na China.

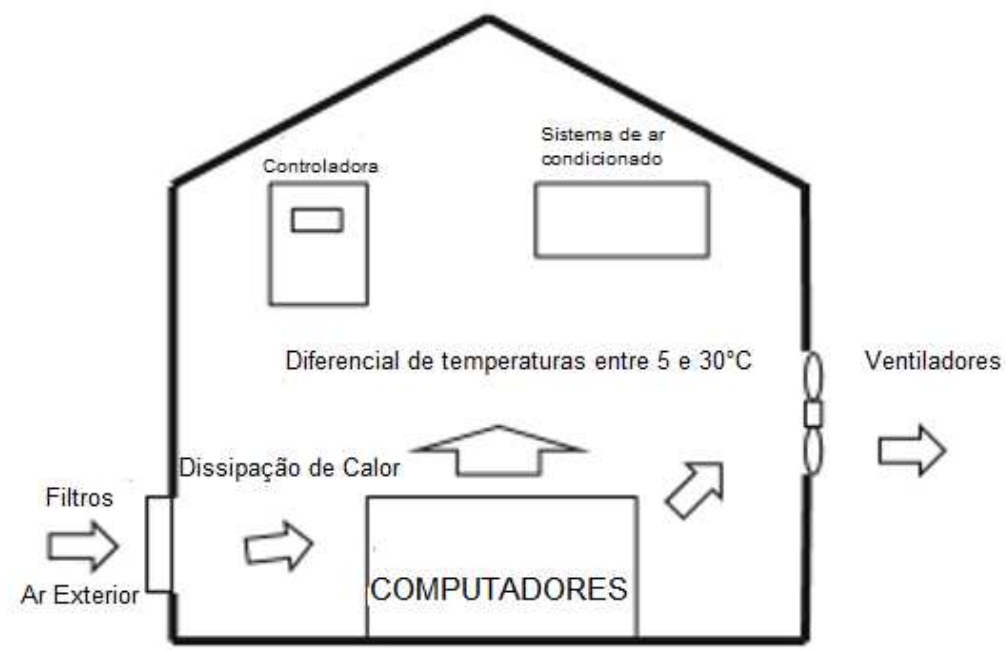

Figura 2.7 - Esquema de Resfriamento Natural Direto (Chen et al. 2009).

\subsubsection{Resfriamento natural indireto por rodas entálpicas}

O sistema de resfriamento natural indireto apresenta grandes vantagens em relação ao sistema de resfriamento direto. O ar externo não é utilizado diretamente na sala de computadores, tendo menor influência nas condições climáticas do ambiente e evita a contaminação do ambiente por partículas de poeira e fumaça exterior (Lin et al. 2015).

Este sistema utiliza-se de rodas entálpicas que farão a troca de calor com o ar que retorna as unidades de ventilação. Uma grande desvantagem em relação ao resfriamento natural direto é geralmente o fluxo menor de ar, a menor eficiência e a maior custo de aquisição de equipamentos. 


\subsubsection{Resfriamento natural indireto por fonte de água não resfriada}

O resfriamento natural indireto por água não resfriada (Waterside Free Cooling) ocorre através de fonte de água fria externa que realiza a troca de calor nas unidades de ventilação em substituição a unidade de resfriamento de líquido.

Este sistema subdivide-se de acordo com a fonte exterior que irá prover água para o sistema. Basicamente, a fonte exterior de água pode ser obtida de três formas:

A primeira, com água fria proveniente diretamente da natureza de reservatórios com baixa temperatura, como por exemplo o sistema é resfriado em regiões com grandes fontes de água com baixa temperatura (ZHANG et al., 2014). Este tipo de resfriamento é recomendado para áreas litorâneas de baixa temperatura, ou de grandes lagos frios.

O segundo método dá-se por troca de calor por "resfriamento seco" (Dry Cooler), que é realizado de forma isolada no sistema ou de forma integrada com as unidades de resfriamento de líquido. Neste sistema, a água passa em circuito fechado por trocadores de calor, onde é arrefecida por um sistema de ventilação cruzada através de ventiladores que se localizam acima dos trocadores. Uma vantagem deste sistema é o pouco consumo de água, porém sua capacidade de troca de calor é limitada em relação às torres abertas. Neste caso as temperaturas de bulbo seco, serão as referências para a troca.

No terceiro sistema, tem-se o aproveitamento proveniente de torres de resfriamento de circuito aberto, ou seja, em casos onde há contato do ar com a água de condensação, em contra fluxo. Neste caso, a temperatura de bulbo úmido é a referência para o cálculo da troca de calor, todavia há grande evaporação de água, sendo necessária a reposição desta. Segue figura 2.8 abaixo sistema proposto (CARLSON, 2012): 


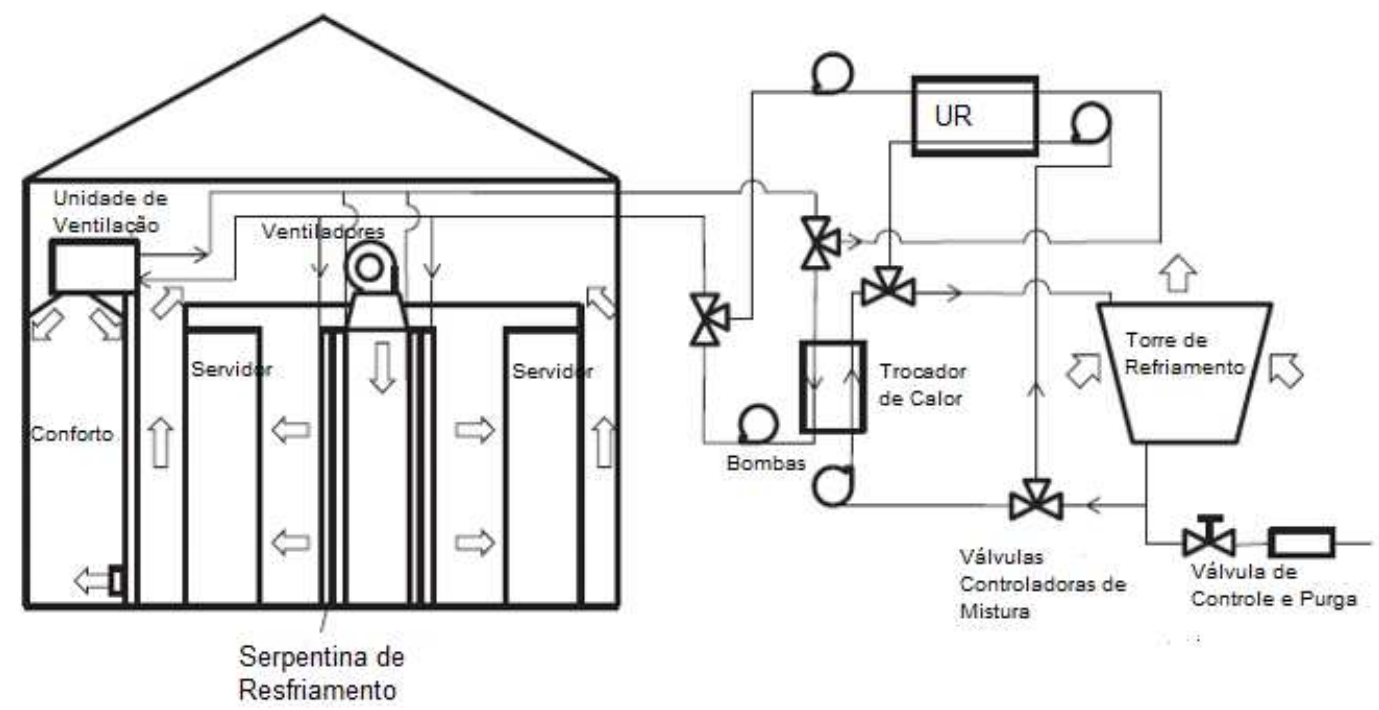

Figura 2.8 - Sistema proposto resfriamento natural (CARLSON, 2012).

Neste sistema as unidades de ventilação recebem água resfriada em suas serpentinas de um trocador de calor. Este trocador de calor recebe água gelada de um resfriador ou recebe água resfriada de uma torre de resfriamento se a temperatura externa de bulbo úmido é suficientemente fria para realizar a climatização do ambiente. Uma boa estimativa, é que o ar de resfriamento é $3{ }^{\circ} \mathrm{C}$ maior que a temperatura da água de resfriamento. Em torres de resfriamento a diferença entre a temperatura de bulbo seco e da temperatura da água que retorna ao sistema é por volta de $3^{\circ} \mathrm{C}$, chamado assim approach, ou seja, aproximação ao bulbo úmido, sendo definido como a diferença entre a temperatura de água resfriada e a temperatura de bulbo úmido.

Em todos os casos de resfriamento natural por água é necessário a utilização de resfriadores intermediários. A água proveniente, se utilizada diretamente, do meio exterior pode causar prejuízos as unidades de ventilação, ou a contaminação do ambiente com bactérias, com é o caso da Legionella9 .

\subsubsection{Resfriamento natural por termossifão}

\footnotetext{
9 Legionella pneumophila é uma bactéria que causa um tipo atípico de pneumonia, presente em gotículas de água, geralmente proveniente de torres de resfriamento.
} 
Este sistema de termossifões tende a minimizar a carga térmica da água, antes que esta retorne às unidades de resfriamento. Outra forma deste tipo de resfriamento ocorre quando há solicitação de frio para outros sistemas, como por exemplo câmaras fria e através de trocadores de calor realiza-se um pré resfriamento da água antes de enviá-las as unidades de resfriamento. Este sistema não será abordado nesta tese.

\subsection{Tarifas de Energia}

Um fator decisivo para a construção desta tese é a tarifação de energia elétrica, pois a economia atingida através desta podem aumentar, reduzir ou inviabilizar a utilização de formas alternativas de climatização.

As tarifas de energia elétrica apresentam elevado grau de dispersão entre os diversos países e não existe nenhuma razão e condições para que no longo prazo elas devam convergir. Os custos da cadeia de produção da eletricidade não são os mesmos nos diversos países e não há mecanismos econômicos que façam com que vantagens de custos de um país sejam transferidas para os demais. A eletricidade é um produto que só pode ser comercializado localmente, em uma dada rede elétrica. Por não poder ser estocada, a eletricidade precisa ser produzida e transportada simultaneamente ao consumo em tempo real. Devido a essas características físicas da eletricidade, o preço no atacado também tem necessariamente um caráter local: o mercado para a eletricidade está delimitado pela rede de transmissão e distribuição, que conecta produtores e consumidores (DE CASTRO et al., 2015).

De uma forma geral, os países possuem um ou mais sistemas interconectados e em alguns casos há interconexões que ligam alguns países, viabilizando mercados de energia regionais. Mas o comércio da eletricidade não é tecnicamente possível a nível global e, por isso, não há porque os preços no atacado convergirem internacionalmente o custo das redes, isto é, dos sistemas de transmissão e distribuição, também têm caráter local. E também neste segmento produtivo, não há porque os custos de redes serem semelhantes a nível internacional, uma vez que eles refletem e dependem de características técnicas e econômicas de cada sistema (RAMOS BALLESTÉ, 2016). 
Pode-se identificar em análise comparativa pode-se identificar dois conjuntos de fatores que determinam as diferenças entre tarifas de energia elétrica em diversos países:

- Características técnico-econômicas de cada sistema elétrico;

- Políticas públicas relacionadas ao setor elétrico

Neste primeiro conjunto identificados como características técnico-econômicas destacam-se as seguintes variáveis (DE CASTRO et al., 2015):

Fatores de Produção: Os principais fatores de produção envolvidos na geração, transmissão e distribuição de energia elétrica são elencados abaixo.

Recursos naturais (recursos energéticos): Constituem um dos principais insumos para a produção de eletricidade, sendo seus preços determinados pela escassez relativa. O Brasil é abundante em recursos energéticos (hídricos, eólicos, biomassa, solar e petróleo) embora importe carvão mineral e (ainda) gás natural, justamente os principais combustíveis fósseis para geração termoelétrica.

Capital: O setor elétrico tem como uma de suas principais características econômicas a de ser capital intensivo. Mesmo com a possibilidade de movimentação dos fluxos de capital entre os países, fatores institucionais e condicionantes de oferta e demanda, resultam em custos de capital diferentes (inflação, risco país, risco cambial et cet.) determinando um diferencial estrutural dos investimentos no setor em relação aos países desenvolvidos.

Trabalho: Representa uma proporção pequena dos custos da indústria de energia elétrica. Mesmo tendo posição secundária, seu valor pode ser considerado nos custos da indústria de energia elétrica, observando-se que a mão-de-obra especializada detém elevado conteúdo de capital humano.

Eficiência das Empresas: Empresas mais eficientes conseguem praticar custos relativamente menores quando comparadas a empresas similares pouco eficientes. Assim, Marcos Regulatórios que preconizam o incentivo à eficiência e que capturam parte 
dos ganhos de produtividade e eficiência para o consumidor são indutores de tarifas com preços módicos.

Características do Mercado: Algumas das principais características do mercado consumidor que devem ser ponderadas ao se estabelecer tarifas de energia elétrica, especialmente quando se tem em vista explicar eventuais discrepâncias em um processo analítico comparativo, são:

- Composição de carga;

- Padrões de consumo;

- Renda per capita;

- Densidade de carga;

- Qualidade e confiabilidade no sistema;

- Inadimplência;

- Perdas técnicas e comerciais;

- Requisitos mínimos de qualidade na prestação do serviço.

Marco Institucional e Regulatório: O Marco Institucional e Regulatório de um País é, dentre todos os fatores determinantes da tarifa de energia elétrica, um dos que condiciona mais fortemente o nível tarifário a ser praticado, posto que é aí que estão estabelecidas as próprias regras para definição das tarifas (por exemplo, Tarifa pelo Custo do Serviço; "Price Cap"; "Revenue Cap"; entre outras), sendo ainda contempladas as exigências para exploração do potencial de produção, que rebatem diretamente nos custos de produção.

As tarifas do consumidor final dependem fortemente das políticas públicas adotadas para o setor elétrico ou, de forma mais geral, das escolhas feitas por cada país, seja em utilizar o setor elétrico para arrecadar recursos ou arcar com o custo de políticas públicas, seja, inversamente, em utilizar recursos públicos ou o peso das empresas estatais para reduzir os custos da eletricidade ao consumidor (DE CASTRO et al., 2015).

Políticas sociais: As políticas sociais que impactam diretamente a definição do nível tarifário em cada país pode ser resumida pela seguinte agenda: 
- Universalização do atendimento;

- Subsídio aos consumidores de baixa renda e a outros programas de governo;

- Compensações por danos socioambientais;

- Execução de melhorias nos municípios e regiões de influência das grandes obras de geração.

Política ambiental: A política ambiental também condiciona de forma importante a tarifa de energia elétrica. As restrições ambientais podem elevar os custos dos projetos, particularmente no que se refere a:

- Redução do potencial de geração de projetos hidrelétricos (redução da dimensão das represas das usinas hidrelétricas);

- Permissões de emissões de gases pelas termelétricas;

- Subsídios para custear fontes alternativas;

- Aumento do custo de capital em decorrência dos riscos ambientais e potenciais atrasos nos empreendimentos.

Política tributária: É necessário explicitar que o Setor Elétrico é um alvo "sedutor" e "tentador" para as Finanças Públicas dado que o aumento da receita por parte do Estado, é muito simples de ser aplicada, fácil de ser fiscalizar e apresenta elevado grau de cobertura econômica. Porém, enquanto alguns países se aproveitam deste fato para tributar fortemente o setor e incrementar a arrecadação fiscal, outros 11 aplicam alíquotas baixas à atividade, tornando as tarifas relativamente mais baratas.

Política de remuneração de capital das empresas estatais: A política de remuneração do capital de estatais também aparece em alguns países como um fator chave para o nível de tarifas. Em países onde o setor elétrico foi liberalizado, prevalece a lógica de remunerar o capital investido no setor elétrico a taxas compatíveis com o retorno de mercado. Mas em outros países não é adotada uma lógica de retorno de mercado para o capital estatal. As estatais são utilizadas para manter baixos os custos da energia elétrica para o consumidor final, praticando tarifas fixadas não sob uma ótica de rentabilizar o capital investido, mas de sustentabilidade global das finanças públicas, 
em que as empresas estatais disputam com outras atividades típicas do estado (saúde, educação, etc.) recursos fiscais para manterem suas atividades ou seu ritmo de investimentos. Política de preços de combustíveis fósseis.

Diversos países praticam preços administrados ou subsídios para os combustíveis fósseis comercializados internamente. Isto é frequente em países exportadores, que muitas vezes praticam internamente preços para combustíveis inferiores aos de exportação.

A figura 2.9 ilustra um comparativo em dólares por quilowatt hora entre tarifas médias praticadas em diversos países do mundo no ano de 2015, sendo que o Brasil possuí os mais altos custos para a indústria.

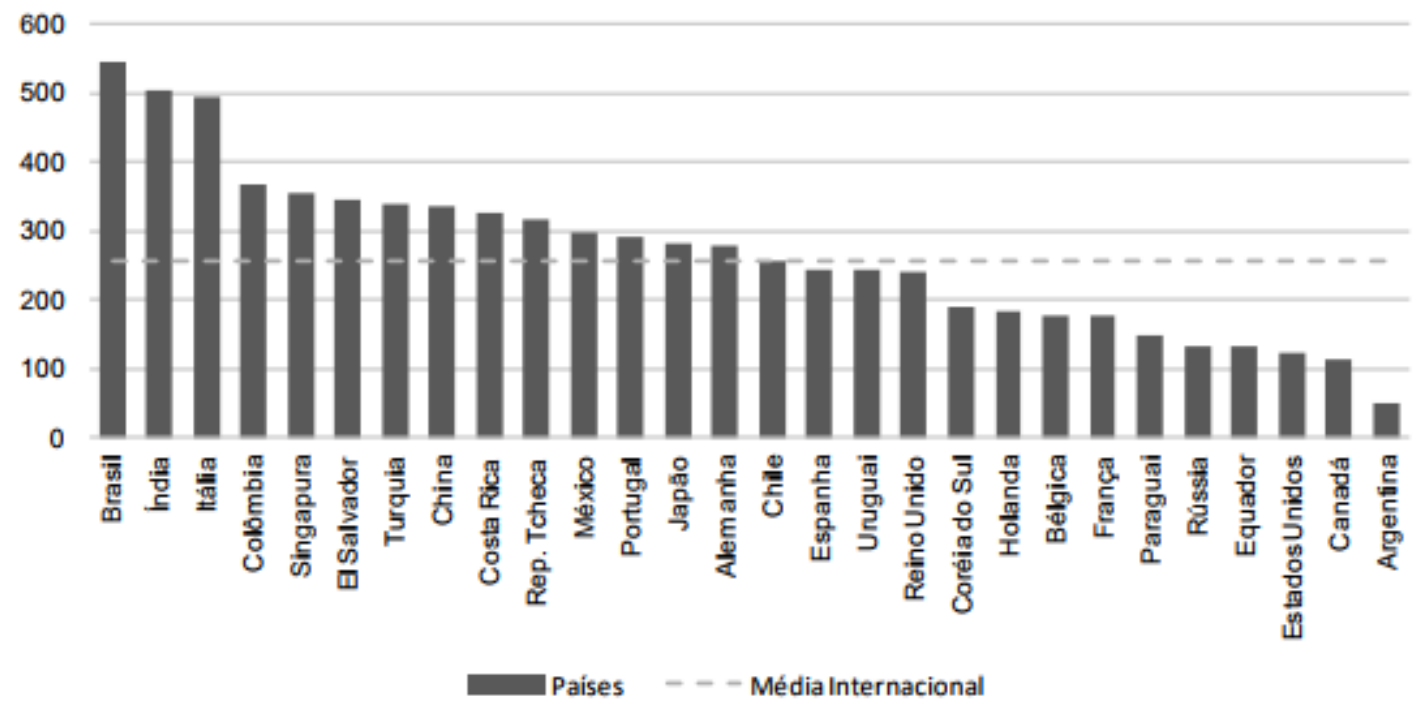

Figura 2.9: Tarifas internacionais em $\mathbf{R} \$ / M W h$ - Preços de 2015(BRITO, 2017)

\subsubsection{Tarifas de Energia no Brasil}

A energia elétrica é insumo fundamental e estratégico, sendo o principal energético utilizado por $79 \%$ das empresas e podendo representar mais de $40 \%$ de seus custos de produção. Em vista disso, seu fornecimento com segurança, qualidade adequada e a custos competitivos é imprescindível para a garantia da competitividade da indústria nacional (ANEEL, 2015). 
O custo médio da energia elétrica no país pode ser dividido em cinco componentes:

- Geração, transmissão e distribuição (GTD);

- Perdas técnicas e não técnicas;

- Encargos setoriais;

- Bandeiras tarifárias;

- Tributos estaduais e federais.

A parcela GTD representa a maior parte do custo médio (56,4\%), estando ligada efetivamente à cadeia produtiva da eletricidade. A geração diz respeito ao custo de produção da energia e é repassada integralmente aos consumidores pelas distribuidoras, que compram o insumo majoritariamente em leilões regulados com contratos de longo prazo.

Transmissão e distribuição, por sua vez, estão relacionadas ao transporte da energia até as unidades consumidoras, e seus custos referem-se ao pagamento das despesas com operação e manutenção dessas atividades, além de remunerar o capital investido. $O$ item "perdas" refere-se tanto às perdas técnicas quanto às não técnicas. As técnicas são aquelas inerentes ao sistema elétrico e estão relacionadas à perda física de eletricidade nas redes de transmissão e de distribuição. As perdas não técnicas, são comerciais derivadas de furtos e fraudes na medição. Juntas, representam 7,0\% do custo médio e, portanto, devem ser combatidas com vistas à redução do preço da energia elétrica (ANEEL, 2015).

Representando 4,5\% do total, os encargos setoriais são custos instituídos por lei com finalidade de remunerar serviços prestados como suporte ao funcionamento do sistema elétrico, financiar o desenvolvimento e tornar viável a implantação de políticas públicas para o setor. Atualmente estão incluídos na tarifa de energia elétrica: Conta de Desenvolvimento Energético (CDE); Taxa de Fiscalização de Serviços de Energia Elétrica (TFSEE); Programa de Incentivo às Fontes Alternativas de Energia Elétrica (PROINFA); Compensação Financeira pela Utilização de Recursos Hídricos (CFURH); Encargo de Serviços do Sistema (ESS); Encargo de Energia de Reserva (EER); Pesquisa 
e Desenvolvimento e Eficiência Energética (P\&D/EE) e Operador Nacional do Sistema (ONS) (PROCEL, 2011).

O Sistema de Bandeiras Tarifárias, por sua vez, entrou em vigor em janeiro de 2015 e sinaliza aos consumidores os custos da geração de energia elétrica no país. Na média dos primeiros 12 meses de aplicação, representou 5,1\% do custo para a indústria (FIRJAN, 2016).

Idealizado antes da crise hídrica, o sistema de Bandeiras Tarifárias que entrou em vigor em 2015, tem como objetivo sinalizar mensalmente ao consumidor o custo de produção da energia. O mecanismo de bandeiras tarifárias permite que o custo, antes repassado ao consumidor apenas no reajuste anual, seja cobrado a cada mês indexando a utilização da matriz energética.

Foram definidos três níveis de bandeiras: Verde, Amarela e Vermelha. A primeira sinaliza que as condições de geração de energia estão favoráveis não acarretando acréscimo à tarifa. Já a bandeira amarela, reflete condições menos favoráveis à geração de energia, desta forma a tarifa é acrescida $R \$ 0,015$ para cada quilowatt-hora ( $k W h$ ) consumido. Por fim a bandeira vermelha, subdividida em dois níveis, reflete condições mais custosas de geração de energia. O primeiro nível provoca um aumento de $R \$ 0,030$ para cada quilowatt-hora $(\mathrm{kWh})$ consumido e o segundo $\mathrm{R} \$ 0,045$ por kWh. A cor da bandeira é estabelecida mensalmente e informada na conta de energia (ANEEL, 2015).

O último item refere-se aos tributos estaduais e federais. No âmbito federal incide sobre a tarifa de energia elétrica o PIS/COFINS, enquanto a nível estadual é cobrado o ICMS. Na média, esses tributos representam $27 \%$ do custo da energia elétrica industrial (FIRJAN, 2016).

Nos últimos anos o setor tem sofrido constantes elevações no custo da energia elétrica. Por um lado, a análise da matriz elétrica brasileira mostra uma elevada participação de fontes renováveis e tradicionalmente de menor custo, como as hidrelétricas (cerca de 65\% da capacidade instalada). Entretanto, quase metade dessas usinas são as chamadas "a fio d'agua", ou seja, não possuem grandes reservatórios de acumulação, o que deixa o sistema cada vez mais vulnerável a hidrologia. As chuvas 
abaixo da média histórica no biênio 2014/2015 agravaram ainda mais esse quadro, provocando a necessidade de intensificação do acionamento termelétrico. Com isso, sua participação passou de um patamar de $9 \%$ em 2011 para mais de 25\% em 2015. Tal situação elevou o preço da energia elétrica, uma vez que a geração termelétrica é mais cara, além de outros custos operacionais de distribuidoras, onde foram necessários empréstimos públicos e privados, hoje repassados a tarifa. Somada a conjuntura econômica desfavorável, a elevação real do preço da energia elétrica nos últimos anos contribuí ainda mais para a queda da produção industrial e a redução da competitividade nacional. (FIRJAN, 2016).

As tarifas praticadas no Brasil, segundo a classificação de tarifas da ANEEL a tarifa mais barata é de $R \$ 0,309$ (Coopera - SC) e de $R \$ 0,712$ (Cemhe - SP), excluindo impostos. Isto significa que a tarifa no Brasil pode variar de $R \$ 0,36$ a $R \$ 1,07 / \mathrm{kWh}$ para a concessionária mais cara em bandeira vermelha (ANEEL, 2017).

\subsubsection{Horário de Ponta}

Horário de Ponta, também conhecido como horário de Pico e Horo-Sazonal são horários de maior consumo de energia. Neste horário, a iluminação pública é ligada, as pessoas chegam em suas residência utilizando eletro domésticos e concomitantemente as indústrias e escritórios mantém muitos processos ativos. Como trata-se de uma demanada sazonal periódica, não justifica-se investimento da concessionária. Segundo registros históricos, isto ocorre entre 17:00 e 22:00 horas

A Resolução da ANEEL n 414/2010, regulamentou este horário no Brasil em 3 horas diárias a critério da concessionária, excetuando sábados, domingos e 8 dadas consideradas feriados nacionais (ANEEL, 2010).

Segundo a Resolução da ANEEL n 733/2016, que regulamenta a Tarifa Branca ${ }^{10}$ a partir de 2018, a energia ficará mais cara na ponta 88\% (ANEEL, 2016).

10 Tarifa diferenciada para horários de ponta e fora de ponta 


\section{CAPÍTULO 3 - TEORIA - CONDICIONAMENTO DE AR SOLAR E RESFRIAMENTO NATURAL}

No presente capítulo são apresentados os conceitos e opções de utilização de condicionamento de ar solar. Dessa forma, o leitor dispõe dos fundamentos teóricos, sobre os temas e também dos termos utilizados para os temas propostos. 


\section{Sistemas de Condicionamento de ar}

O condicionamento de ar é o processo de tratamento do ar interior em espaços fechados. Esse tratamento consiste em regular a qualidade do ar interior, no que diz respeito às suas condições de temperatura, umidade, limpeza e movimento. Para tal, um sistema de condicionamento de ar inclui as funções de aquecimento, arrefecimento, umidificação, renovação, filtragem e ventilação do ar (CRÉDER, 2004).

Embora a máquina moderna de ar condicionado foi inventada em 1902 por Willis Carrier, existem relatos desde a China do século II D.C. de dispositivos utilizados para climatização de ar.

Um equipamento de ar condicionado tradicional resfria o ar tendo como base 0 ciclo de refrigeração termodinâmico, no qual um fluído refrigerante circula por uma serpentina entre um evaporador a baixa pressão recebendo energia de um ambiente condicionado e um condensador a alta pressão rejeitando energia para o meio exterior (VAN WYLEN et al. 2013; MORAN et al. 2018).

Este ciclo é passível de realização por meio de um elemento, que realiza trabalho devido à ação de uma fonte externa, transportando o fluído do evaporador para o condensador. Esta fonte, em seu modo mais tradicional, dá-se basicamente por um compressor que recebe alimentação elétrica e aumenta a pressão do fluído refrigerante, ou de um sistema térmico que absorve o fluído refrigerante a uma mistura pouco saturada e após a saturação desta, o rejeita este com o auxílio de uma fonte de calor externa.

Há também um dispositivo de expansão, entre o condensador e o evaporador, que resulta em queda de pressão do fluído refrigerante e consequente queda de temperatura. A Figura 3.1 ilustra este ciclo. 


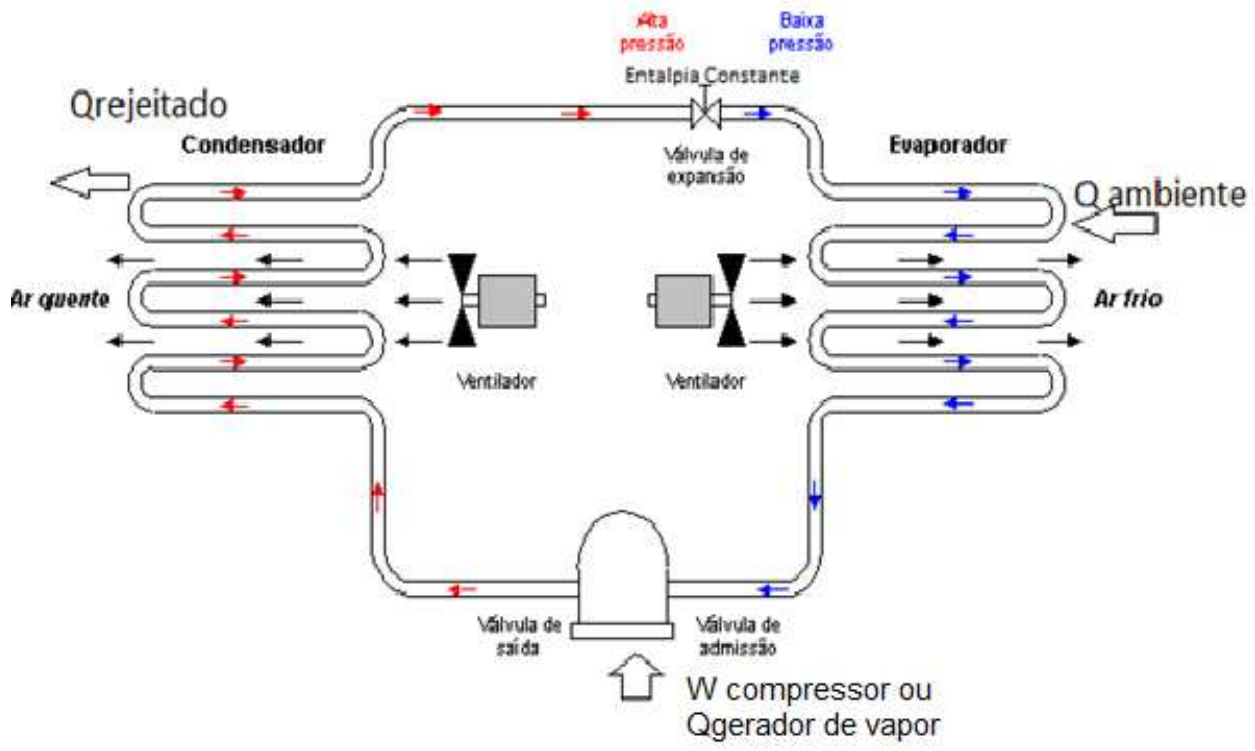

Figura 3.1 - Ciclo Básico de Refrigeração. (VAN WYLEN; SONNTAG; BORGNAKKE, 2013)

De acordo com a utilização, o condicionamento de ar pode ser do tipo expansão direta, quando há contato do ar com a serpentina do fluído refrigerante ou de expansão indireta, quando há um fluído intermediário (geralmente água ou etileno glicol) entre o fluído refrigerante e o meio condicionado. O primeiro destina-se a pequenas dimensões ou ambientes isolados. O segundo destina-se a grandes ambientes, evitando uma grande circulação de gás refrigerante em um ambiente.

Nesta pequisa trata-se basicamente do segundo caso, por entender que os ambientes propostos são de grandes proporções e podem ser integrados a outros ambientes.

Existem alguns outros sistemas que operam de modo diferente como sistema Peltier e sistema de ejeção de vapor, porém como não se aplicam nas aplicações propostas neste trabalho, não serão explicitados. 


\subsection{Sistema de condicionamento de ar por compressão de vapor refrigerante}

Os principais componentes de uma unidade de resfriamento de compressão de vapor são o compressor, condensador, dispositivo de expansão e evaporador. O fluído refrigerante é comprimido no compressor, onde é levado ao condensador. Nesta etapa o a taxa de transmissão de calor é transportada do sistema ao meio exterior. A forma de rejeição de taxa de calor, no caso da unidade de resfriamento de líquido é realizada por de forma convectiva, através de ventiladores ou de troca de calor com água arrefecida por torres de resfriamento. Após esta etapa o fluído chega a estado líquido ao dispositivo de expansão, onde com o amento de volume e consequente perda de pressão e temperatura, se gasifica, chegando à baixa temperatura ao evaporador para absorver energia térmica do fluído intermediário. Segue esquema de ciclo de refrigeração/ resfriamento por compressão de vapor conforme Figura 3.2.

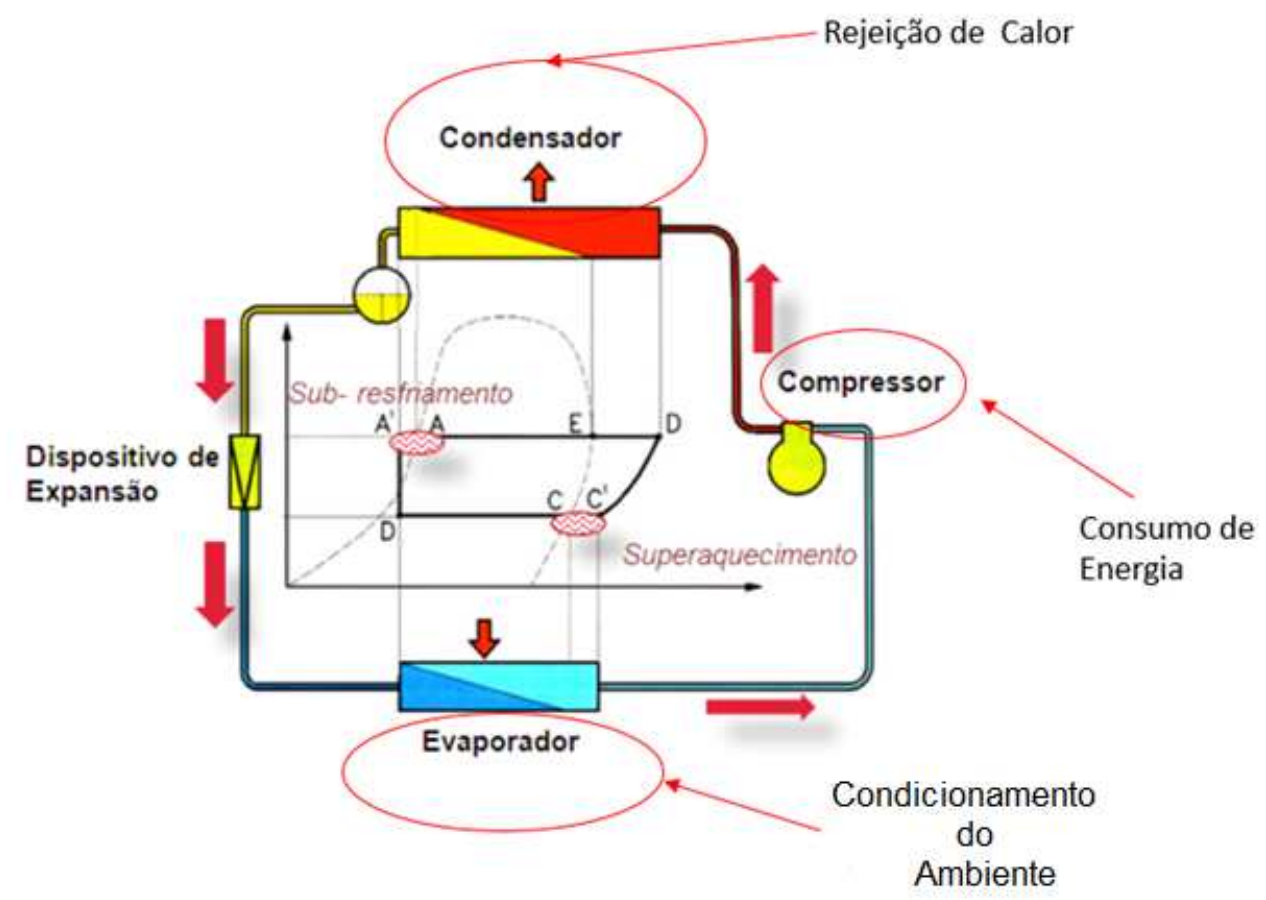

Figura 3.2 - Sistema de compressão de vapor (BELIZÁRIO, 2014). 
O fluído de trabalho destes equipamentos foi, durante muito tempo oriundo da família dos CFCs. Todavia, a utilização de fluídos como R12 e R22 está desaconselhada e segundo o protocolo de Montreal seu uso deverá ser descontinuado até 2040 (MMA; PNUD; GIZ, 2011). A indústria trabalha com alternativas menos agressivas ao meio ambiente, como fluídos naturais.

O ciclo de compressão de vapor é constituído dos seguintes processos:

1. Compressão de vapor, isto é, um compressor, que realiza trabalhos sobre o vapor, transferindo energia, por meio de fonte de exterior;

2. Condensação do vapor, que ocorre no condensador (o trocador de calor à direita, na figura acima);

3. Expansão do líquido após o condensador, que ocorre via dispositivo de expansão (válvula termostática, tubo capilar, etc.);

4. Evaporação do fluido refrigerante através da troca de calor entre água quente no caso de expansão indireta ou ar no caso de expansão direta.

A Figura 3.3 apresenta este ciclo em um gráfico de pressão por entalpia.

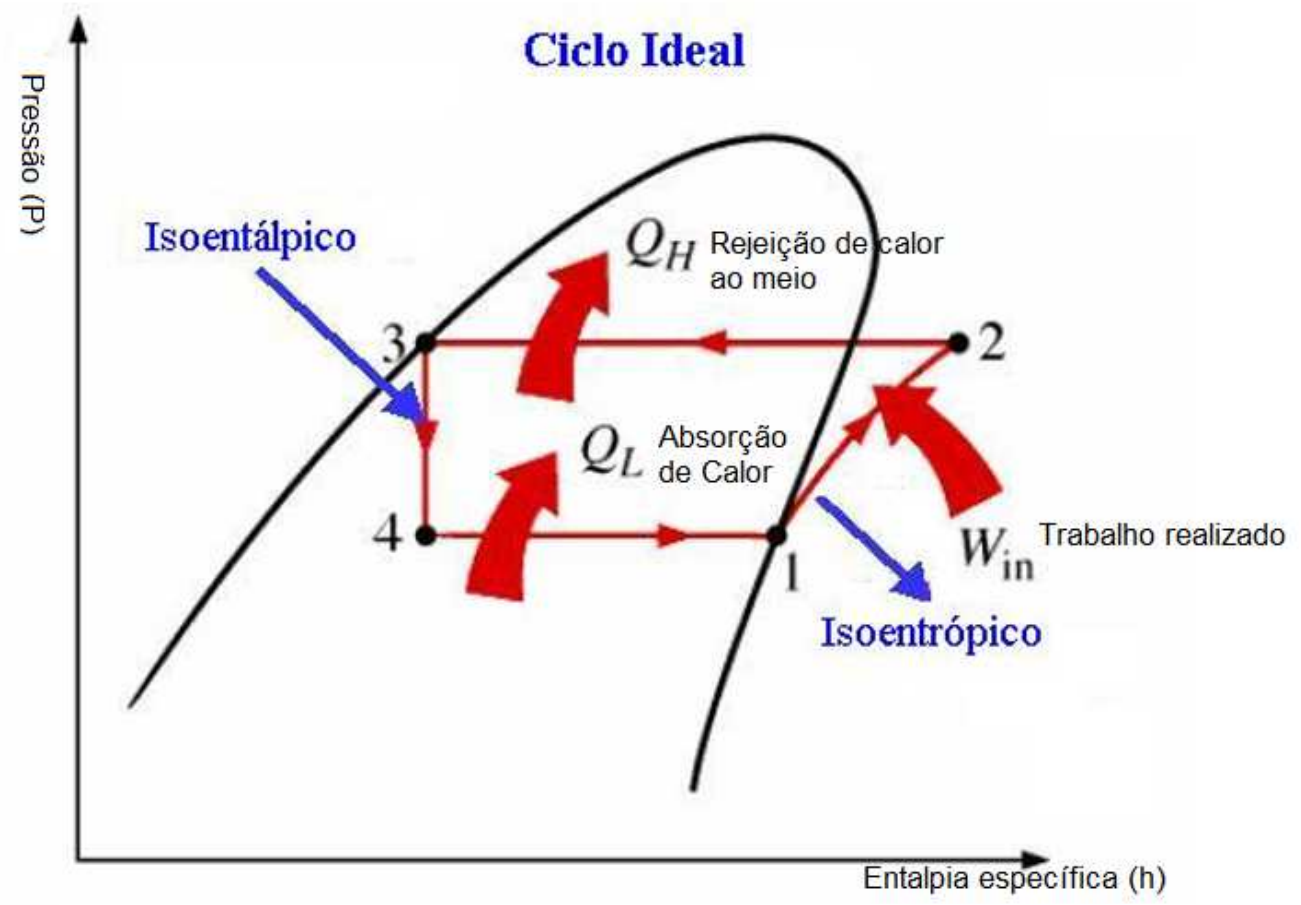

Figura 3.3-Ciclo ideal de resfriamento por compressão a vapor (VAN WYLEN; SONNTAG; BORGNAKKE, 2013; MORAN et al., 2018) 


\subsection{Sistema de resfriamento por absorção de vapor}

\subsubsection{Breve histórico}

O sistema de refrigeração ou resfriamento por absorção tem como seu autor o francês Ferdinand Carré (1824-1900), onde no ano de 1859 obteve a primeira patente, utilizando um sistema de amônia e agua. Entretanto, foi somente nas primeiras décadas do século $X X$, que este sistema se desenvolveu para aplicações comerciais. Mais precisamente na segunda década deste século o alemão Edmund Altenkirch, deu início a investigação de melhorias do sistema. Posteriormente o italiano Maluri (1938) desenvolveu estudos visando melhorar as perdas térmicas na região do absorvedor, seguido pelos suecos Von Platen e Munters, que aperfeiçoaram o sistema proposto por Carré, criando uma máquina mais simples que poderia ser utilizada em uma residência como fonte de frio para conservação de alimentos (MATOS, 2010).

O sistema clássico de absorção de amônia foi aperfeiçoado em 1930 e 1940 para a produção de gelo. A evolução permitiu que estes sistemas fossem aplicados em instalações petroquímicas e de gás, sendo instalados a posterior em sistemas de geração de turbina a gás para, satisfazendo critérios de eficiência energética para reaproveitar energia exaurida na forma de calor (ASHRAE, 2004).

\subsubsection{Princípio de Funcionamento}

Em um sistema de absorção, o compressor elétrico das unidades de resfriamento por compressão de vapor, é substituído por um compressor termoquímico, chamado de gerador de vapor. Outra grande diferença são os fluidos refrigerantes, que para compressão são substâncias puras ou homogêneas e em absorção são misturas heterogêneas, em que a transformação de energia, só é possível na separação dos componentes desta solução (MAGGl et al., 2014).

A tabela abaixo apresenta um comparativo entre os componentes de um sistema de compressão a vapor e um sistema de absorção. 
Tabela 3.1 - Equivalência entre unidade de resfriamento de líquido de compressão/ absorção (MAGGI et al., 2014)

\begin{tabular}{ll}
\hline Sistema de absorção & Sistema de compressão de vapor \\
\hline Condensador & Mesma função do condensador \\
Evaporador & Mesma função do evaporador \\
Válvula de expansão & Mesma função da válvula de expansão \\
Absorvedor & Mesma função da sucção do compressor \\
Gerador & Mesma função do compressor \\
Receptor & Mesma função do depósito de refrigerante \\
Retificador & Condensa parte do vapor de amônia ou água \\
Trocador de calor & Reduz a entrada de calor no gerador e a vazão de \\
& água de resfriamento no absorvedor. \\
\hline
\end{tabular}

No caso de uma máquina que utiliza solução água e brometo de lítio, a água é o fluído evaporado e o brometo de lítio, o fluido encarregado do processo de absorção, chamado de absorvedor. No evaporador, a água em estado líquido, usada como refrigerante, é pulverizada sobre os tubos que estão em vácuo, provocando a evaporação e consequentemente a retirada de calor sensível da água gelada que passa dentro dos tubos do evaporador, reduzindo sua temperatura em média $5^{\circ} \mathrm{C}$.

O vapor de água saí do evaporador, e vai para o absorvedor onde a solução de brometo de lítio o absorve por diferença de pressão termo quimicamente, mantendo as condições de baixa pressão na câmara do evaporador e absorvedor. O resfriamento provocado pela passagem da água de torre condensa a solução que se acumula no fundo do trocador.

A solução diluída de brometo de lítio acumulada é bombeada para o gerador de vapor. O gerador de vapor aquece a solução diluída, através de uma fonte de calor externa (vapor superaquecido, líquido e gases quentes), promovendo a separação entre a água e o brometo de lítio através da evaporação do refrigerante. A solução concentrada de brometo de lítio retorna para o absorvedor, a fim de reiniciar o ciclo de compressão de vapor pós passagem no evaporador. 
O refrigerante vaporizado fluí para o condensador onde retorna ao estado líquido através da retirada de calor latente, pelo resfriamento provocado pela circulação da água de torre ou por circulação de ar exterior. A água em estado líquido é pulverizada novamente sobre os tubos do evaporador, onde absorve o calor do ambiente a ser climatizado (água no caso de expansão indireta ou ar no caso de expansão direta) reiniciando o ciclo básico de resfriamento de uma unidade de refrigeração por absorção. No caso das soluções Amônia/ Água, a amônia é o fluído refrigerante evaporado e a água é o absorvedor. A Figura 3.4 ilustra um esquema de uma unidade de resfriamento de líquido de absorção.

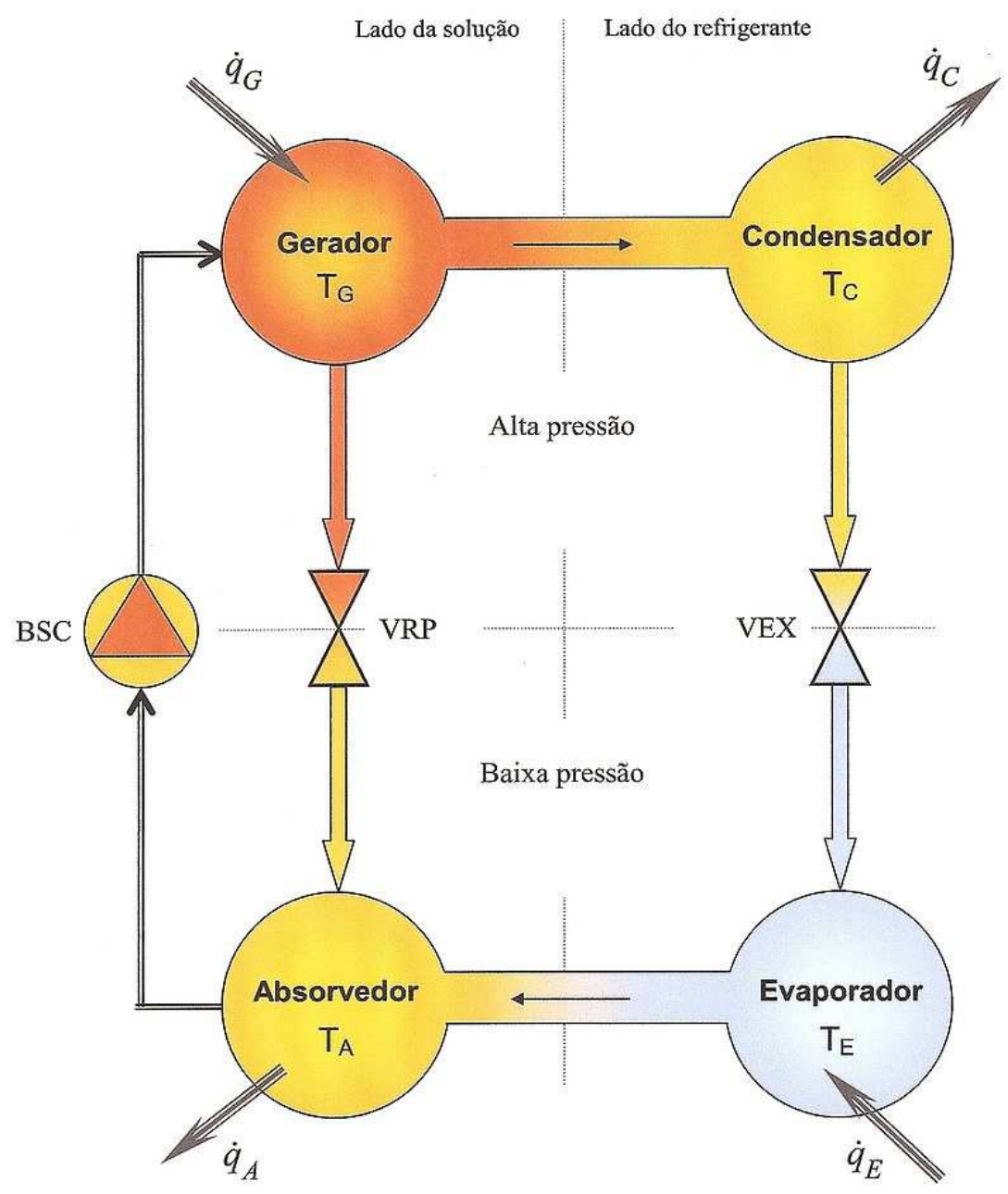

Figura 3.4 - Ciclo básico de resfriamento por absorção e seus componentes principais (FONSECA JR., 2009). 
Conforme (WANG, 2010), um sistema que opere os principais componentes de um ciclo de absorção são:

- Gerador (dessorvedor): O gerador é um trocador de calor e massa do tipo casco e tubo, sendo que o fluido de aquecimento (vapor ou um fluido a temperatura moderada) escoa pelo interior dos tubos e a solução absorvente é mantida do lado do casco ou lançada na forma de "spray" por sobre os tubos. O vapor de refrigerante liberado da solução passa por um separador líquido-vapor, sendo posteriormente enviado para o condensador. Materiais ferrosos são usados para o compartimento do absorvente. Os materiais empregados para o banco de tubos podem ser cobre, ligas cobre-níquel, aço inoxidável ou titânio.

- Condensador: Os condensadores são compostos por bancos de tubos localizados na região ocupada pelo vapor do refrigerante. Estes tubos são resfriados por água que escoa pelo interior dos tubos, provocando a condensação do vapor na superfície externa dos tubos. O compartimento do condensador é construído em aço carbono e o material do banco de tubos é cobre ou cobre-níquel.

- Evaporador: Este trocador de calor é geralmente do tipo casco e tubo, sendo que o refrigerante é borrifado sobre a superfície externa dos tubos. O líquido a ser resfriado passa pela parte interna dos tubos. Os bancos de tubos do evaporador são construídos em cobre ou numa liga cobre-níquel. $\mathrm{O}$ compartimento do evaporador é construído em aço carbono e os eliminadores de gotas em aço inoxidável.

- Absorvedor: O absorvedor é composto por um banco de tubos sobre os quais a solução forte é borrifada na presença do vapor de refrigerante. Durante o processo de absorção há transferência de calor (entalpia de diluição e condensação) para a água de resfriamento que escoa através dos tubos. A solução diluída é removida pela parte inferior do banco de tubos do absorvedor. Os materiais empregados são aço carbono para o compartimento do absorvedor e cobre ou ligas de cobre-níquel para o banco de tubos. 
- Bombas: As bombas movimentam a solução absorvente e o refrigerante na fase líquida nos sistemas a absorção. As bombas podem ser do tipo individua ou combinado. Os motores e bombas são herméticos ou semi herméticos. Os impulsores são normalmente fabricados em latão, aço fundido ou aço inoxidável; as volutas são fabricadas em aço ou aço fundido impregnado.

E geralmente também compões um equipamento de absorção:

- Recuperador de calor da solução: Este trocador de calor é do tipo casco e tubo ou de placas e tem como objetivo transferir calor entre os dois fluxos de solução: o que deixa o gerador e o que deixa o absorvedor. $O$ material de construção é o aço carbono ou aço inoxidável.

- Sistema de purga: Estes dispositivos são necessários nos sistemas de absorção que operam com o par água-brometo de lítio e amônia - água para remover incondensáveis (ar) que se infiltram no sistema ou hidrogênio (que é produto de processos de corrosão). Os gases incondensáveis, mesmo em pequenas quantidades, podem acarretar redução na capacidade de resfriamento e até mesmo conduzir à cristalização da solução.

Os sistemas de absorção podem ser de simples, duplo ou triplo efeito. Esta classificação é dada de acordo com a quantidade de geradores de vapor. Por exemplo, um sistema de absorção de duplo efeito possuí dois geradores que separam o refrigerante do líquido absorvedor e enviam para o condensador. Porém, o vapor do refrigerante que sai do gerador primário é enviado primeiramente aos tubos do gerador secundário, o que faz com que ocorra a separação da água que está absorvida com o brometo de lítio. Com a inclusão desse processo no sistema, o vapor do refrigerante que chega no condensador, já apresenta temperaturas menores, o que facilita a condensação e com isso melhora o desempenho de todo o sistema(MILLER, 2014). 


\subsection{Resfriamento Solar}

O sol é a única fonte de energia capaz se sustentar a vida na terra com grande potencial de conversão em diversas formas de energia (KREITH \& KREIDER, 1978). Um dos maiores desafios atuais é a utilização de energia solar para refrigeração e ar condicionado.

O Condicionamento de ar é uma das mais importantes aplicações devido à crescente necessidade de climatização associado a locais onde a utilização solar é disponível (PORUMB et al. 2016), entretanto a ideia de aproveitar a energia solar com finalidade para condicionamento ambiental não é nova. Os primeiros relatos datam do século 19. A figura 3.5 mostra um concentrador solar utilizado para fins de refrigeração apresentado por Edmond Carre na feira de ciências de Paris de 1878.

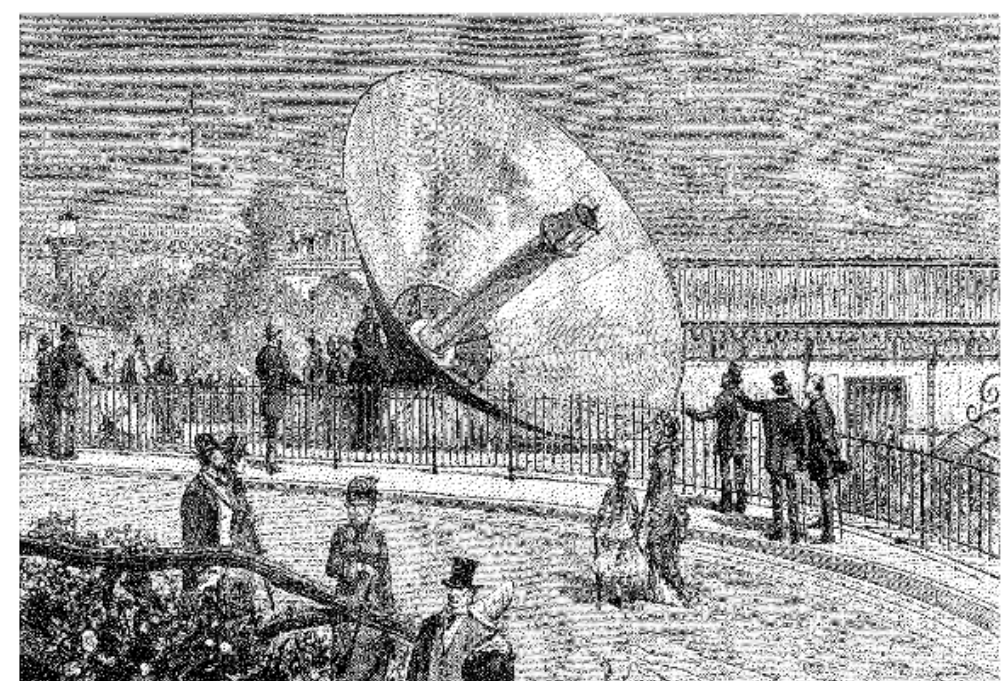

Figura 3.5 - Concentrador solar de Edmond Carre (H.-M. Henning \& Jakob, 2015).

Todavia, no final dos anos 90, com a evidência de mudanças climáticas causadas pela queima de combustíveis fósseis, o investimento em tecnologia e desenvolvimentos de sistemas de resfriamento solar passa a ser considerado estratégico (MONTAGNINO, 2017).

Ultimamente, ações como apresentadas pela União Europeia em processo de descarbonização de edifícios, em suas novas normas diretivas, incentivam este tipo de desenvolvimento, com objetivo de concepção e remodelagem de prédios para auto 
geração total (Net Zero building) ou quase total de edificações até 2020 (EUROPE UNION COMISSION, 2009).

Ações como estas incentivaram grandes avanços acadêmicos nesse sentido. Em 2008 por Kim e Ferreira, foi apresentado notório trabalho sobre o então estado da arte no que tange resfriamento solar.

Posteriormente, fora apresentado por Mokhtar et al. (2010), algoritmo para comparação de coletores solares para a cidade de Abu Dhabi, levando em conta a área de captação e o armazenamento de energia necessário, criando alguns índices como o CGC, que é o custo de geração, que representa o preço do ciclo de vida do sistema de resfriamento solar, e a eficiência geral.

Na sequência, foi escrito um artigo Otanicar et al. (2012), ilustrando a perspectiva sobre condicionamento de ar com acionamento solar para os anos subsequentes com os diferentes métodos de utilização.

Em um trabalho de grande relevância Kim \& Ferreira (2013), relatou-se formas de condicionamento de ar com acionamento solar e seus custos, em que principais técnicas são classificadas conforme sua captação em células fotovoltaicas, tubos evacuados, discos parabólicos e placas planas. A ideia do artigo é comparar eficiência, área utilizada e investimento das diferentes tecnologias para aplicações residenciais na Espanha e Holanda. Este artigo foi revisado no ano seguinte Ferreira \& Kim (2014), apresentado na Tabela 3.2. Nesta revisão foi apresentada a evolução de investimento por quilowatt de resfriamento, conforme várias publicações. Para esta tese atualiza-se estes valores de investimentos. 
Tabela 3.2 - Preço: Investimento (Euro x 1033)/ kW de resfriamento(FERREIRA \& KIM 2014).

Adaptado

\begin{tabular}{|c|c|c|c|c|c|c|}
\hline Autor & $\begin{array}{l}\text { Compressão } \\
\text { de Vapor }\end{array}$ & $\begin{array}{l}\text { Absorção } \\
\text { efeito } \\
\text { parcial }\end{array}$ & $\begin{array}{c}\text { Absorção } \\
\text { Simples } \\
\text { efeito }\end{array}$ & $\begin{array}{c}\text { Absorção } \\
\text { Duplo } \\
\text { Efeito }\end{array}$ & Adsorção & Dissecante \\
\hline Henning (2004) & 300,00 & & 400,00 & & 850,00 & \\
\hline $\begin{array}{l}\text { Kim e Infante } \\
\text { Ferreira (2008) }\end{array}$ & 200,00 & & 400,00 & 300,00 & 500,00 & \\
\hline $\begin{array}{l}\text { Mokhtar et al. } \\
(2010)\end{array}$ & 210,00 & & 250,00 & 550,00 & & \\
\hline Peters (2010) & - & & & & & 370,00 \\
\hline $\begin{array}{l}\text { Otanicar et al. } \\
(2012)\end{array}$ & . & & 210,00 & 855,00 & 855,00 & 1065,00 \\
\hline Lazzarin (2014) & 300,00 & & 400,00 & 700,00 & 600,00 & \\
\hline $\begin{array}{l}\text { Kim e Infante } \\
\text { Ferreira (2014) }\end{array}$ & 250,00 & 700,00 & 400,00 & 700,00 & 700,00 & 700,00 \\
\hline
\end{tabular}

Em 2013, Sarbu \& Serbachievi escrevera sobre técnicas de condicionamento de ar solar relatando desempenhos e COP, fazendo um balanço e projeção da utilização de energia solar para estes fins até 2030.

Em 2014, Lazarin publicou um estudo de caso sobre um comparativo entre a utilização de Resfriadores Solares Elétricos e Térmicos em uma análise econômica e de eficiência similar à de Kim e Infante fora publicado.

Em 2016, foi publicado um estudo baseado em banco de dados anuais sobre a utilização de unidades de resfriamento solares elétricas e térmicas para a cidade de Cluj Napoca na Romênia por Porumb et al.

Em todas estas obras, pode-se notar que atualmente, existe uma grande variedade de técnicas e métodos de condicionamento de aproveitando a irradiação solar. Nesta obra será adotada a subdivisão os sistemas segundo seu acionamento, como Solar Elétrico Fotovoltaico e Solar Térmico, conforme apresentado por Sarbu \& Serbachievi em 2013 e Ferreira \& Kim em 2014. No sistema solar elétrico fotovoltaico, a irradiação solar é convertida em energia elétrica por painéis fotovoltaicos sendo fonte de energia para unidades de unidades de resfriamento acionadas eletricamente. 
No sistema solar térmico, a irradiação solar será responsável por aquecer um fluído que pode ser captado e utilizado para diferentes finalidades. Na primeira, a energia solar é captada por concentradores solares, como calhas ou discos, com finalidade de aquecer um fluído que posteriormente ira movimentar uma caldeira a vapor ou motor Stirling, gerando eletricidade e posterior utilização de unidade de resfriamento elétrico.

No segundo modo temos a transformação direta de energia solar em energia térmica. Através de coletores solares, do tipo plano ou tubo evacuado, ocorre o aquecimento de água que posteriormente aciona o gerador de vapor de uma unidade de resfriamento de absorção, adsorção o dessecante (FERREIRA \& KIM 2014). Pode-se considerar a utilização de concentradores solares para 0 acionamento de máquinas térmicas por absorção.

A Figura 3.6 ilustra esta divisão, onde pode-se observar em que os sistemas em quadros laranja necessitam de conversão de energia solar em energia elétrica e posteriormente em energia térmica. Os sistemas nos quadros cinza há conversão de energia solar para energia térmica diretamente.

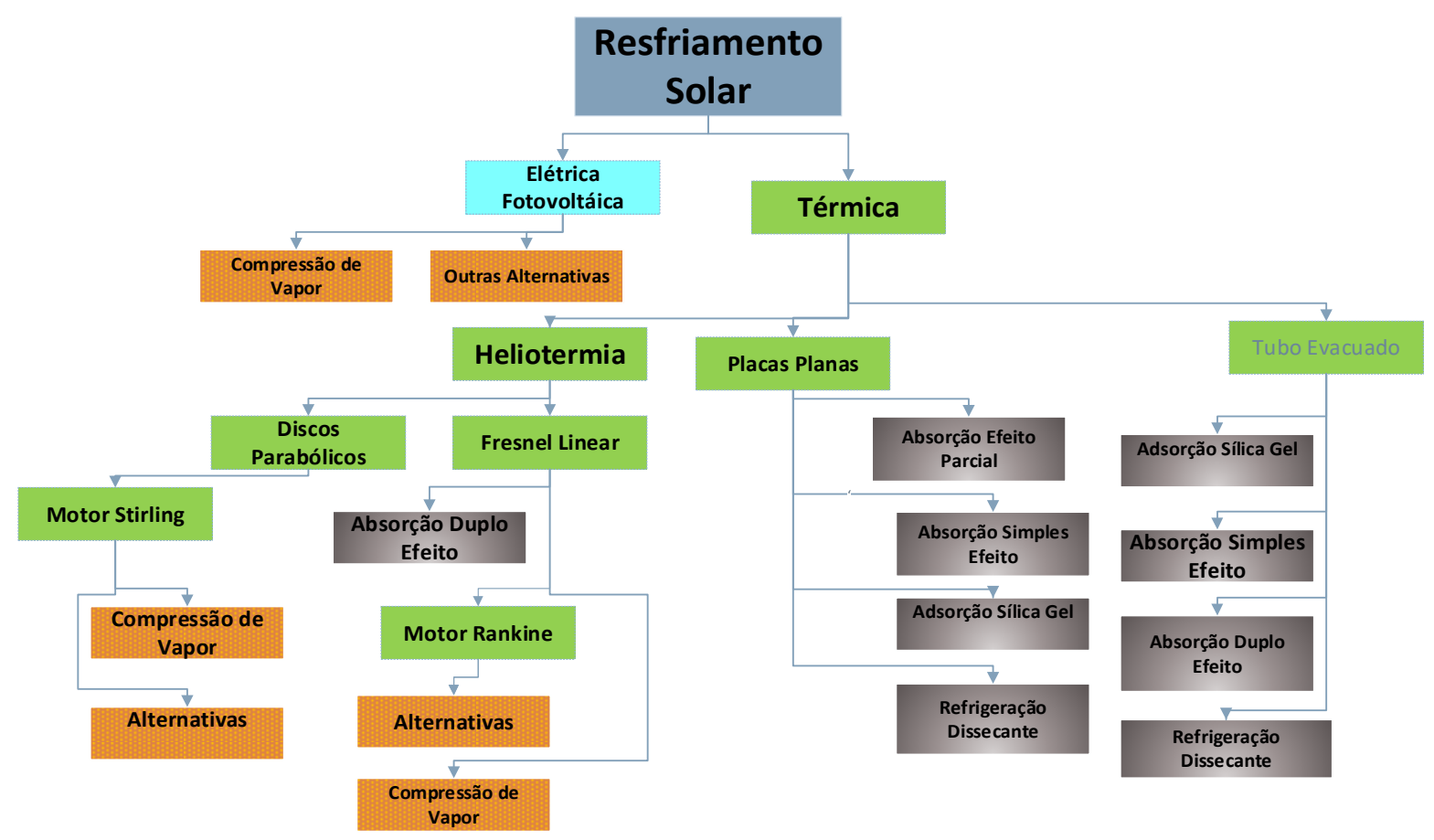

Figura 3.6 - Classificação de sistemas de resfriamento solar (BELIZÁRIO \& SIMÕESMOREIRA 2017; LAZARIN 2014). 


\subsection{Conceitos básicos de utilização de energia solar}

O Sol é a nossa principal fonte de energia, responsável pela manutenção das várias formas de vida existentes na Terra. No centro do Sol, mais propriamente numa região denominada fotosfera solar (camada muito tênue com aproximadamente $300 \mathrm{~km}$ de espessura e temperatura superficial da ordem dos $5.800 \mathrm{~K}$ ), a energia resultante das reações de fusão dos núcleos dos átomos de hidrogênio, originando núcleos de hélio, é irradiada para o espaço sobre a forma de energia eletromagnética, a uma velocidade próxima dos $300.000 \mathrm{~km} / \mathrm{s}$. Esta energia, ao atingir a atmosfera terrestre pode ser absorvida ou refletida pelos seus diferentes componentes (SILVA, 2014).

Nas utilizações de energia solar deve-se aproximar a área da aplicação de energia solar em um plano horizontal (PACHECO, 2017). Para tal são considerados os seguintes ângulos de localização terrestre da superfície:

Latitude $(\Phi)$ : ângulo de vértice do centro da terra, formado pela semirreta com direção do ponto considerado e plano do Equador. Positivo no Hemisfério Norte (DUFFIE \& BECKMAN, 2006; PACHECO, 2017).

Ângulo Horário ( $\omega)$ : ângulo com diedro com aresta no eixo de rotação da Terra, formado pelo semipleno que contém o Sol e o semipleno que contém o meridiano local. Negativo nas manhãs (DUFFIE \& BECKMAN, 2006; PACHECO, 2017).

Declinação Solar (ס): Ângulo de Vértice no centro da Terra, formado pela semirreta determinada pela direção do sol e o plano do equador. Positivo de 21/3 a 21/9 (DUFFIE \& BECKMAN, 2006; PACHECO, 2017).

Ângulo de Zênite $\left(\boldsymbol{\theta}_{\boldsymbol{z}}\right)$ : Ângulo de incidência solar sobre um plano horizontal dado pela direção do sol (DUFFIE \& BECKMAN, 2006; PACHECO, 2017).

Altitude Solar $\left(\alpha_{s}\right)$ : Deslocamento angular da projeção do raio solar no plano horizontal a partir da direção Sul, sendo negativo ao Leste e positivo ao Oeste. É o complemento do ângulo de Zênite (SILVA, 2014).

Azimuth $\left(\gamma_{s}\right)$ : Ângulo formado pela projeção do Sol no plano horizontal e o meridiano Norte-Sul (DUFFIE \& BECKMAN, 2006; PACHECO, 2017). 
Azimute de Superfície (Y): Ângulo entre a projeção da normal à superfície no plano horizontal e a direção Sul, sendo positivo para Oeste e negativo para Leste (SILVA, 2014).

Ângulo de Incidência $(\boldsymbol{\theta})$ : Ângulo entre o raio de sol incidente em uma superfície e a normal a esta superfície (SILVA, 2014). A figura 3.7 ilustra os ângulos aqui citados.

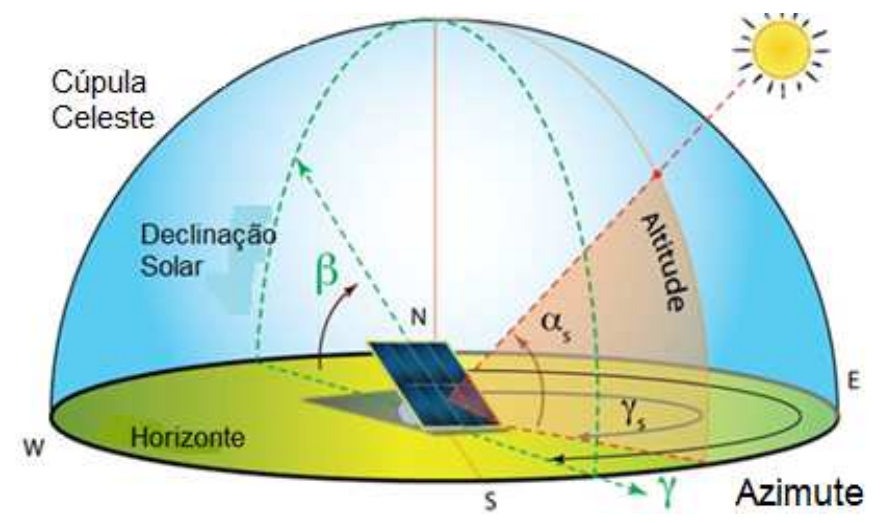

Figura 3.7: ângulos solares (ACCA SOFTWARE, 2017).

A enorme distância da terra e do Sol e seu pequeno diâmetro quando comparado ao Sol, permitem que se faça a aproximação de que a radiação solar seja construída por um feixe de raios paralelos (KALOGIROU, 2004; PACHECO, 2017).

A constante solar $G_{S C}$ é a energia proveniente do Sol, por unidade de tempo, recebida por unidade de área em uma superfície perpendicular à direção de propagação da radiação, na distância média Terra-Sol, fora da atmosfera. $G_{S C}=1367 \mathrm{~W} / \mathrm{m}^{2}$ é um valor recomendado para cálculos de engenharia. O Valor da radiação extraterrestre integrada horária sobre uma superfície horizontal lo, é dada pela equação 4.2.8, descrita na seção referente.

Entretanto, a irradiação extraterrestre é atenuada através da incidência da atmosfera pelo espalhamento das moléculas do ar, vapor d'água e poeira e absorção atmosférica por ozônio, resultando em uma radiação que chega a superfície terrestre de forma direta e outro componente devido a absorção por $\mathrm{CO}_{2}$ e $\mathrm{H}_{2} \mathrm{O}$, de forma difusa.

Para o cálculo destes das parcelas direta e difusa utiliza-se os índices de claridades, $(\mathrm{kT})$, que significa a razão integrada em certo intervalo de tempo sobre o plano 
horizontal (I), obtido através de um banco solarimétrico associado a escolha da cidade nos dados de entrada (4.1) e seu valor equivalente e radiação extraterrestre (10), calculado em 4.2.9 e às correlações de Orgill e Hollands (1977).

Para estimas a disponibilidade de energia solar em um plano horizontal e inclinado, utiliza-se modelos consagrados. Neste trabalho utiliza-se o modelo de Liu e Jordan (1962), que considera a hipótese de que a radiação total sobre uma superfície inclinada se compusesse da radiação direta mais a radiação solar difusa isotrópica ${ }^{11} \mathrm{e}$ radiação refletida difusamente pelo solo (PACHECO, 2017).

Os equacionamentos dos ângulos solares e radiação, encontram-se na seção 4.2 desta tese.

\subsection{Resfriamento fotovoltaico}

Um sistema de resfriamento elétrico fotovoltaico consiste basicamente em uma unidade de resfriamento elétrica convencional à compressão de vapor e painéis fotovoltaicos. Em 2010, células fotovoltaicas de silício cristalino representam em torno de 90\% do total do mercado de fotovoltaicas (FERREIRA \& KIM, 2014).

A energia solar será utilizada neste sistema para o acionamento dos compressores, através de energia fotovoltaica captada por painéis, conforme Figura 3.8.

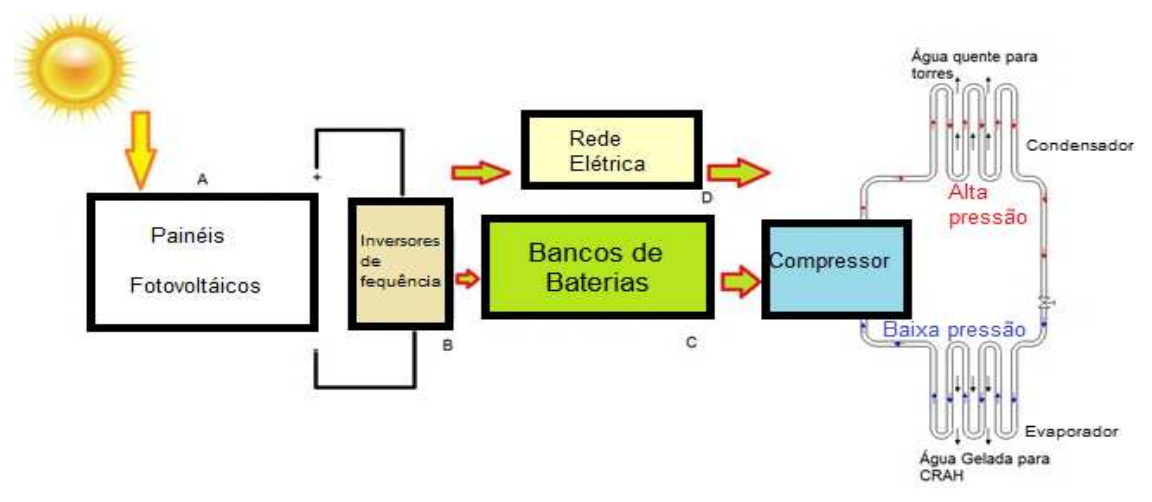

Figura 3.8 - Unidade de resfriamento de líquido por compressão com painéis fotovoltaicos.

${ }^{11}$ Radiação difusa diretamente no coletor 
Neste caso a irradiação total solar (direta + difusa) será captada pelas células fotovoltaicas (A) e transformada em energia elétrica. Para regulação de tensão e frequência elétrica, a energia passa por inversores elétricos (B). Porém é pouco recomendado que se utilize esta energia diretamente do inversor, para tal pode-se recorrer a duas soluções.

A primeira seria a conexão dos inversores a rede elétrica (D), fornecendo energia a esta no excedente e captando energia da rede à falta. Este procedimento depende de regulação e de regras locais. A segunda seria fornecer energia a um banco de baterias (C) e descarrega-lo em horários desejados, que será abordado nesta tese. As perdas estão associadas ao rendimento do painel fotovoltaico, transmissão, rendimentos de inversores e bancos de bateria.

A eficiência desta unidade de resfriamento é medida através da relação entre energia disponível para as células fotovoltaicas e energia aproveitada pela unidade de resfriamento, ou seja, a energia necessária para a movimentação do compressor sobre a potência de resfriamento do evaporador.

\subsection{Resfriamento solar Térmico por transformação de calor utilizando o princípio da absorção}

Um sistema solar que opera segundo o ciclo de absorção vapor tem seus principais componentes semelhantes à unidade de resfriamento por absorção convencionais, descrito na Sessão 3.3, onde a diferença ocorre no gerador de vapor, que é acionado por água quente, que absorveu e energia solar, proveniente de coletores solares. Este esquema básico é mostrado na Figura 3.9

No caso da unidade de resfriamento solar de absorção, a parcela responsável pelo fluxo de calor de geração $\left(\dot{q}_{G}\right)$, será obtida através de troca de calor com água quente proveniente de coletores solares, conforme podemos visualizar na Figura 3.4. 


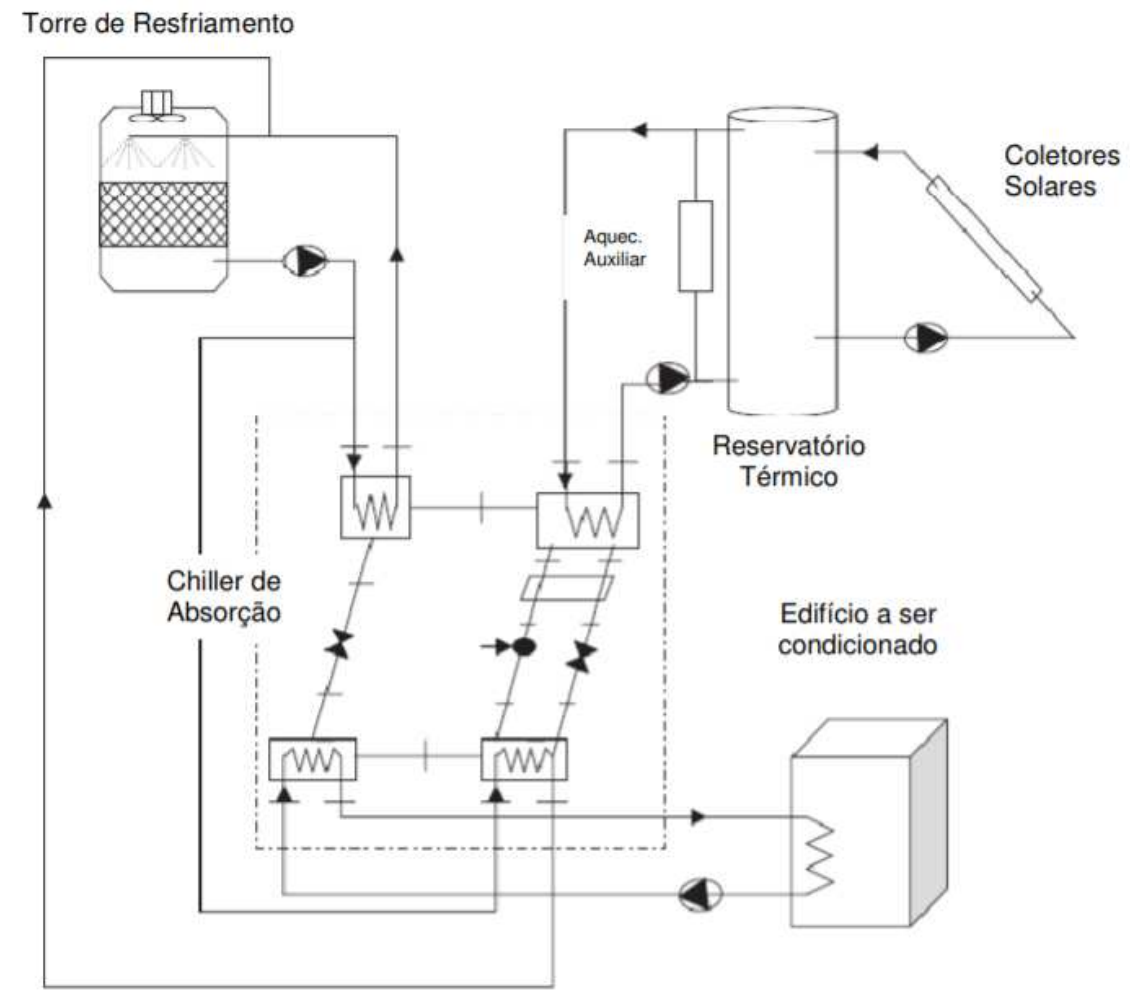

Figura 3.9 - Esquema de resfriamento solar (BALGHOUTHI; CHAHBANI; GUIZANI, 2008; SCHIAVON ARA, 2010).

A eficiência desta unidade de resfriamento é medida através da relação entre energia solar disponibilizada pela área dos coletores e energia aproveitada, ou seja, o calor cedido no gerador de vapor somado a aquecedores auxiliares e potência de bombeamento de solução sobre a quantidade de taxa de calor rejeitada para 0 evaporador.

Este sistema, vêm se mostrado, conjuntamente com os sistemas fotovoltaicos a mais vantajosa relação custo x benefício apresentados (LAZZARIN \& NORO, 2018; SCHIAVON ARA, 2010).

As demais técnicas de condicionamento de ar solar não serão tratadas nesta tese, pois com os recursos atuais, pouco se aplicam ao modelo estudado nesta tese.

Os equipamentos térmicos movidos por heliotermia apresentam maturidade tecnológica pouco viável, especialmente no Brasil (SCHIAVON ARA, 2010). Estes sistemas apresentam uma grande complexidade em sua implementação, haja visto a necessidade de um conversor de energia térmica para elétrica (Rankine Orgânico, 
Stirling), o que encareceria a instalação. Também há de se ressaltar o fato que concentradores solares não absorvem energia solar difusa, sendo esta parcela desperdiçada (KIM; FERREIRA, 2013b; TIAN; ZHAO, 2013).

As URs de adsorção necessitariam de área muito grandes para sua aplicação (CHOULDHURY; CHATTERJEE; SAKTAR, 2010) e sistemas dissecantes seriam específicos para regiões muito úmidas (AHMED; TAHA, 2011).

No caso de utilização de células fotovoltaicas foi utilizado o método de reserva de energia por bancos de baterias, pois muitas concessionárias não definiram suas regras de integração a rede, o que dificultaria a análise. No caso do equipamento térmico considera-se de duplo efeito aproveitando a melhor tecnologia para a mesma área coletada. A Tabela 3.2 obtida através de dados apresentados por Ferreira \& Kim (2014) e Schiavon Ara (2010) e atualizada com tendências atuais apresenta este comparativo. 
Tabela 3.2: Comparativo entre os principais tipos de unidade de resfriamento solar (SCHIAVON ARA 2010; FERREIRA \& KIM 2014) Adaptado.

\begin{tabular}{|c|c|c|c|c|c|c|c|c|}
\hline$\frac{{ }^{2}}{\frac{\pi}{n}}$ & के & 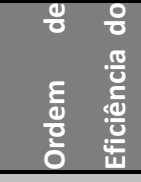 & 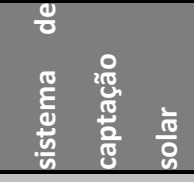 & 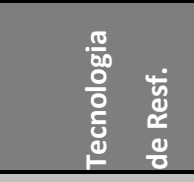 & சি & ᄅू & 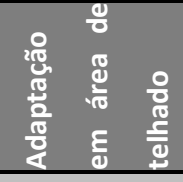 & 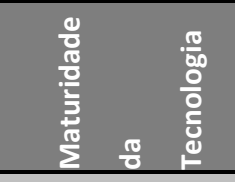 \\
\hline \multirow{3}{*}{ Elétrico } & \multirow{3}{*}{ Fotovoltaico } & \multirow{3}{*}{\multicolumn{2}{|c|}{$12 \%$}} & \multirow{3}{*}{ UR elétrico } & \multirow{3}{*}{5,2} & Bateria & \multirow{3}{*}{ Boa } & \multirow{3}{*}{ Boa } \\
\hline & & & & & & Conexão à rede & & \\
\hline & & & & & & $\begin{array}{l}\text { Tanque de Termo acumulação água } \\
\text { gelada }\end{array}$ & & \\
\hline \multirow{4}{*}{$\begin{array}{l}\text { Térmico } \\
\text { Termomecânico/ } \\
\text { Heliotermia }\end{array}$} & \multirow{4}{*}{$\begin{array}{l}\text { Concentrados } \\
\text { solares } \\
\text { (parabólicos/ } \\
\text { calhas) }\end{array}$} & \multirow{4}{*}{\multicolumn{2}{|c|}{$82 \%$}} & \multirow{4}{*}{ UR elétrico } & \multirow{4}{*}{5,2} & Bateria & \multirow{4}{*}{ Pouco Viável } & \multirow{4}{*}{ Experimental } \\
\hline & & & & & & Conexão à rede & & \\
\hline & & & & & & $\begin{array}{l}\text { Tanque de Termo acumulação água } \\
\text { quente }\end{array}$ & & \\
\hline & & & & & & $\begin{array}{l}\text { Tanque de Termo acumulação água } \\
\text { gelada }\end{array}$ & & \\
\hline \multirow{7}{*}{$\begin{array}{c}\text { Térmico - } \\
\text { Transformação de } \\
\text { calor }\end{array}$} & \multirow{7}{*}{$\begin{array}{c}\text { Coletores de Placa } \\
\text { Plana e Tubo a } \\
\text { vácuo }\end{array}$} & \multirow{7}{*}{\multicolumn{2}{|c|}{$\begin{array}{c}83 \% \text { para tubo a ao } \\
\text { vácuo/ } 70 \% \text { para placas } \\
\text { planas }\end{array}$}} & \multirow{3}{*}{ UR Absorção } & 0,5 - Efeito Parcial & $\begin{array}{l}\text { Tanque de Termo acumulação água } \\
\text { quente/ }\end{array}$ & \multirow{3}{*}{ Boa } & \multirow{3}{*}{ Boa } \\
\hline & & & & & 1,1 - Simples Efeito & \multirow{2}{*}{$\begin{array}{l}\text { Tanque de Termo acumulação água } \\
\text { gelada }\end{array}$} & & \\
\hline & & & & & 1,51 - Duplo Efeito & & & \\
\hline & & & & \multirow{2}{*}{ UR Adsorção } & \multirow{2}{*}{0,4} & $\begin{array}{l}\text { Tanque de Termo acumulação água } \\
\text { quente/ }\end{array}$ & \multirow{2}{*}{ Boa } & \multirow{2}{*}{$\begin{array}{c}\text { Necessária } \\
\text { Evolução para } \\
\text { baixas Capacidades }\end{array}$} \\
\hline & & & & & & $\begin{array}{l}\text { Tanque de Termo acumulação água } \\
\text { gelada }\end{array}$ & & \\
\hline & & & & \multirow{2}{*}{$\begin{array}{l}\text { Sistemas } \\
\text { Dissecantes }\end{array}$} & \multirow{2}{*}{0,78} & $\begin{array}{l}\text { Tanque de Termo acumulação água } \\
\text { quente/ }\end{array}$ & \multirow{2}{*}{ Boa } & \multirow{2}{*}{$\begin{array}{c}\text { Restrições de } \\
\text { utilização para } \\
\text { regiões quentes e } \\
\text { úmidas } \\
\end{array}$} \\
\hline & & & & & & $\begin{array}{l}\text { Tanque de Termo acumulação água } \\
\text { gelada }\end{array}$ & & \\
\hline
\end{tabular}




\section{CAPÍTULO 4- MATERIAIS E MÉTODOS}

No presente capítulo é apresentada a metodologia a qual pretende-se atingir os objetivos, além de materiais utilizados e equacionamento de soluções. 
Conforme apresentado nas seções 1.2.1 e 1.2.2, este trabalho objetiva a avaliação de aproveitamento da energia solar disponível no telhado de uma edificação típica de Data Center com diferentes densidades para a avaliação de economia de energia.

A Figura 4.1 ilustra a iteração entre planilhas e bancos de dados presentes nesta tese. A tese parte da escolha da cidade, com seu respectivo banco solarimétrico e de temperaturas de bulbo seco e bulbo úmido (retângulo amarelo). Com o modelo de aplicação proposto e densidade de dissipação de computadores é possível estimar a carga térmica e consumo de caso base, com UR de compressão de vapor, sem economizadores e sem contribuição solar, bem como selecionar os equipamentos que atenderão a edificação (retângulo vermelho).

Na sequência calculam-se os ângulos solares conforme condições locais (azul) e a aplicação em sistemas de condicionamento de ar solar (verde). Em paralelo calculase a redução de consumo devido a economizadores, proveniente de resfriamento natural (rosa). Após a estimativa de contribuição de resfriamento solar e resfriamento natural, faz-se um balanço de energia, em que as parcelas de resfriamento natural e resfriamento solar atendem prioritariamente a edificação.

A carga térmica residual, será climatizada pela unidade de resfriamento convencional (retângulo laranja). Nesta tese define-se como a carga térmica residual, 0 valor de energia térmica complementar, a qual deverá ser resfriada pela UR convencional, após o sistema de condicionamento de ar do Data Center receber contribuições do sistema de resfriamento natural e do sistema de resfriamento solar.

Com os valores estimativos de aquisição enviados por fornecedores de mercado, calcula-se a taxa interna de retorno para 10 anos e tempo de retorno de investimento simples (retângulo cinza). 


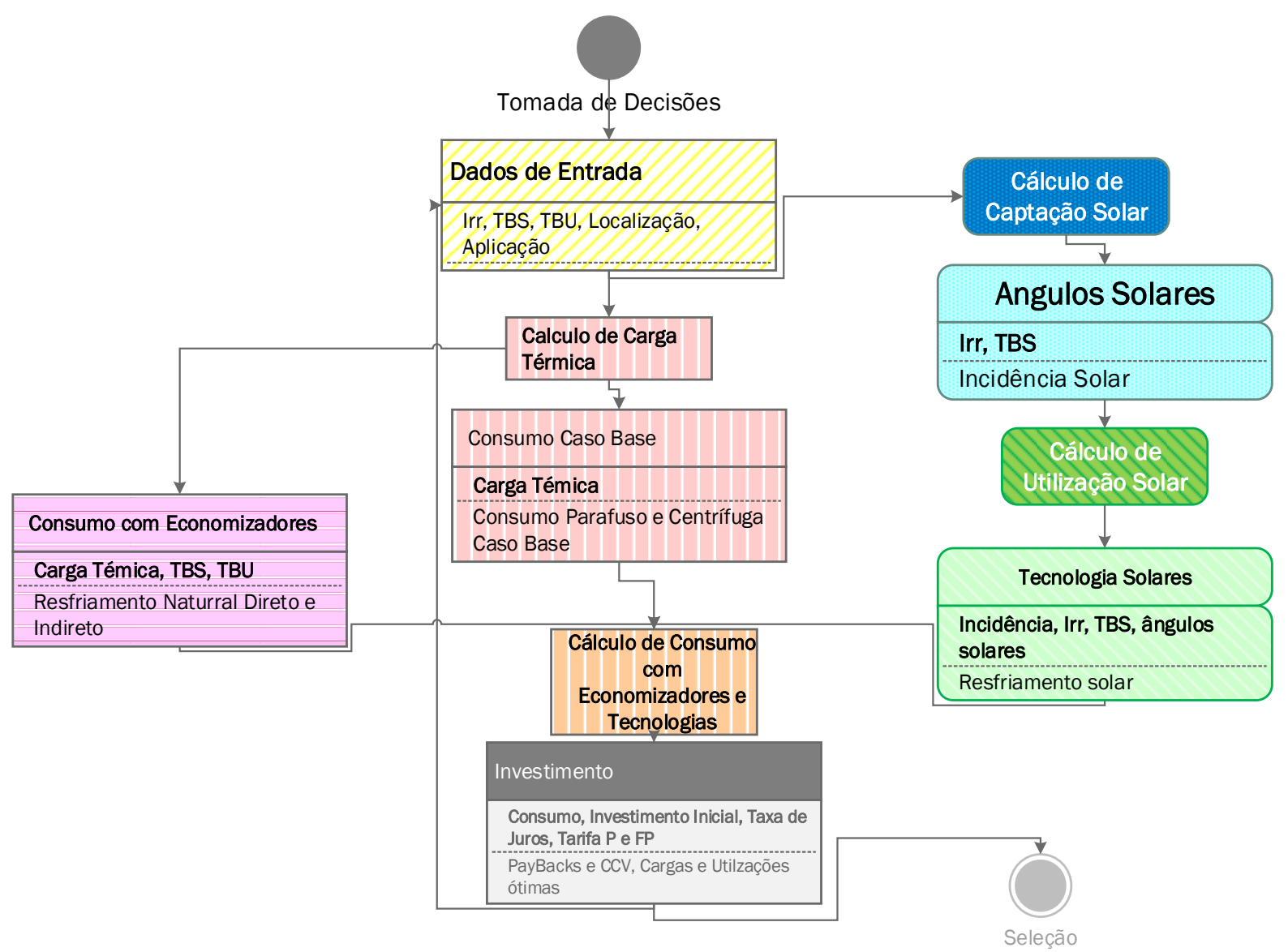

Figura 4.1 - Iteração entre bancos de dados

Neste presente trabalho, propõe-se iterações de bancos de dados e planilhas a fim de calcular as economia e taxas de retorno. Os softwares utilizados foram:

- Microsoft Excel 2013

- Microsoft VBA 2013

- Hour Analysis Program E-20 versão 4.9, Carrier Corporation

\subsection{Dados de Entrada}

Os dados de entrada são relativos a escolha da cidade, edifício padrão e dados de utilização. A partir da escolha da cidade padrão, obtém-se o respectivo banco de dados climáticos horário com dados de temperatura de bulbo seco, temperatura de bulbo húmido, irradiação solar direta e irradiação solar total, além de dados de latitude, 
longitude e altitude. Para esta tese será detalhada a aplicação do modelo na cidade representativa de São Paulo, localizada no Brasil, América do Sul, zona climática II da ASHRAE, definida como quente e úmida (ASHRAE, 2006).

Os dados referentes à edificação padrão referem-se a materiais construtivos, área útil de equipamentos e área de captação solar. Os dados referentes à utilização referem-se a horários de utilização, densidades de cargas elétricas, de iluminação e de ocupação.

Por meio destes dados, utiliza-se software para o cálculo de carga térmica ${ }^{12}$ (HAP Carrier E-20 V 4.90). Pode-se visualizar os fatores que são variáveis apenas devido a área do edifício e os valores que variam, também de acordo com equipamentos e pessoas.

Nesta tese, os valores variáveis de acordo com a área da edificação serão:

- Iluminação

- Condução pelas paredes

- Condução pelo teto

- Ocupação (caso de Data Centers)

- Infiltração de ar exterior

- Equipamentos elétricos

Os valores variáveis de acordo com ocupação serão:

- Equipamentos Elétricos

- Ocupação (caso escola e escritórios)

Isto é mostrado na Figura 4.2.

12 Carga térmica é a quantidade de calor a ser retirada (regime de verão) ou fornecida (regime de inverno) ao ar para manter, em um ambiente, as condições desejadas (SOBRAL, 2008). 


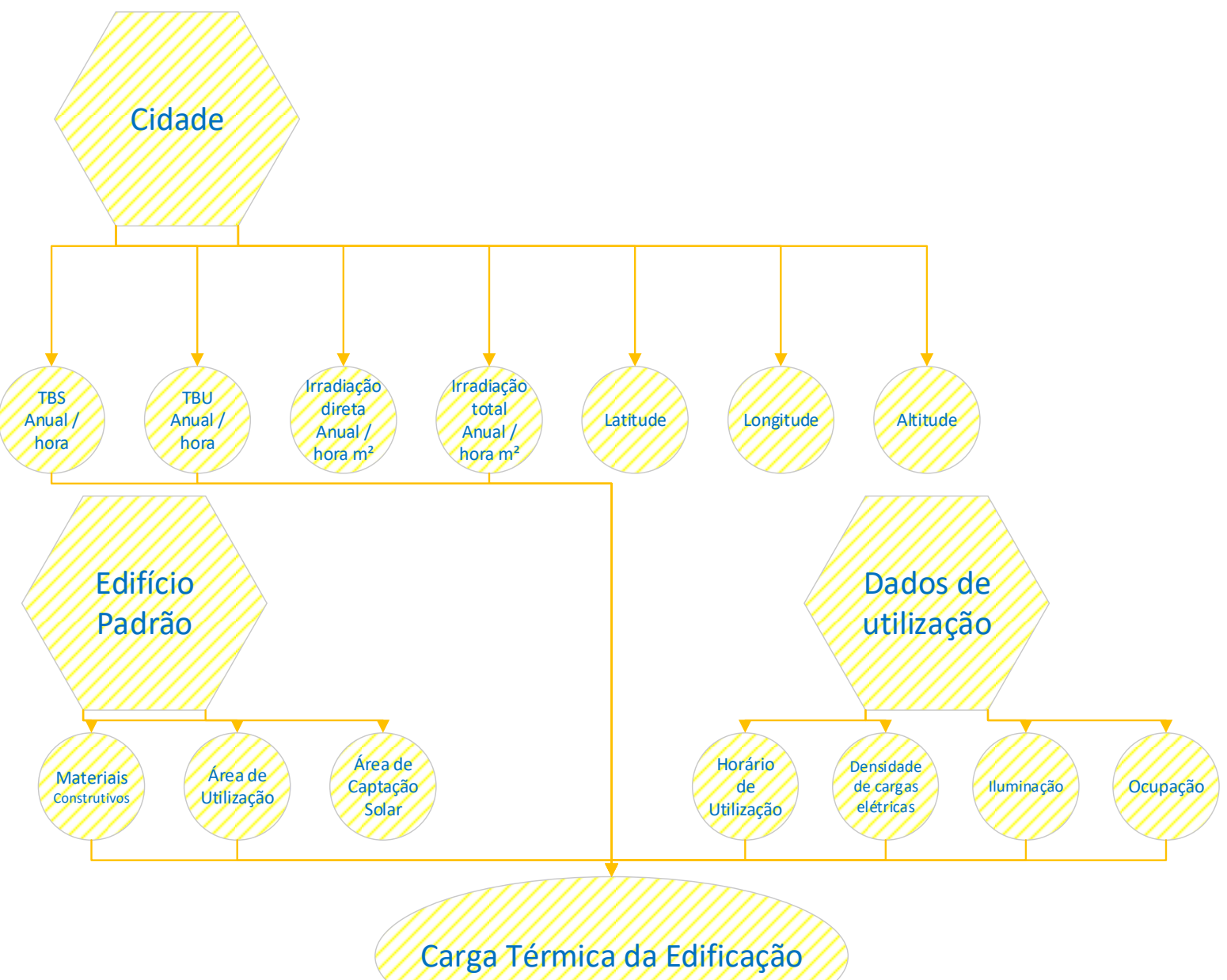

Figura 4.2 - Iteração de variáveis de dados de entrada

As próximas sessões desta tese mostrarão as edificações base (4.1.1 e 4.1.2).

\subsubsection{Edifícios base: Data Center}

Para este fim foi considerado um modelo para os 365 dias do ano para a cidade de São Paulo. Para esta a realização deste trabalho é adotado um Data Center típico e sua infraestrutura associada:

- Área de Computadores: É a área onde os servidores (mainframes) estão instalados. É esta área onde a climatização dever ser priorizada e a qual a carga de ar condicionado aqui citada deve atender. O principal fator considerado é a densidade de potência medida em $\mathrm{kW}$ Instalado/ $\mathrm{m}^{2}$. Devido 
à alta criticidade, este trabalho foca a utilização do ar condicionado neste local.

- Central de água gelada: É o local onde devem estar situadas unidades de resfriamento e bombas para ar condicionado responsável pela climatização dos ambientes, especialmente as salas de computadores.

- Oficina: Local onde ficam os responsáveis pela manutenção do edifício e pequena oficina utilizada para pequenos reparos.

- Extinção de Incêndio: Local utilizado para depósito de cilindros de gás de extinção de incêndio.

- Sala de Baterias: Local utilizado como depósito de baterias, responsáveis por ceder energia por 10 minutos a edificação.

- Sala de Painéis Elétricos e UPS: Sala onde estão localizados os painéis da área de computadores, as chaves de transição (baterias X geradores X Rede) e UPS, que são equipamentos para equalização da energia e transição fechada.

- Sala de Média Tensão: Sala onde está localizada a cabine primária de média tensão

- Recepção: Entrada da Edificação, e sala para procedimentos de segurança.

- BMS: Está sala está localizado o BMS (Bulding Management System), que é o sistema de monitoramento de toda a edificação.

- Corredor Técnico: Salas Adjacentes a Área de Computadores, onde estão localizadas as unidades de ventilação responsáveis pelo ar condicionado da área de computadores.

Segue ilustrado na planta típica na Figura 4.3. As áreas em verde recebem climatização dedicada para missão crítica, segundo as normas da ASHRAE TC 9.9., as áreas em azul são climatizadas por regras de conforto térmico e as demais áreas não necessitam de condicionamento de ar. 


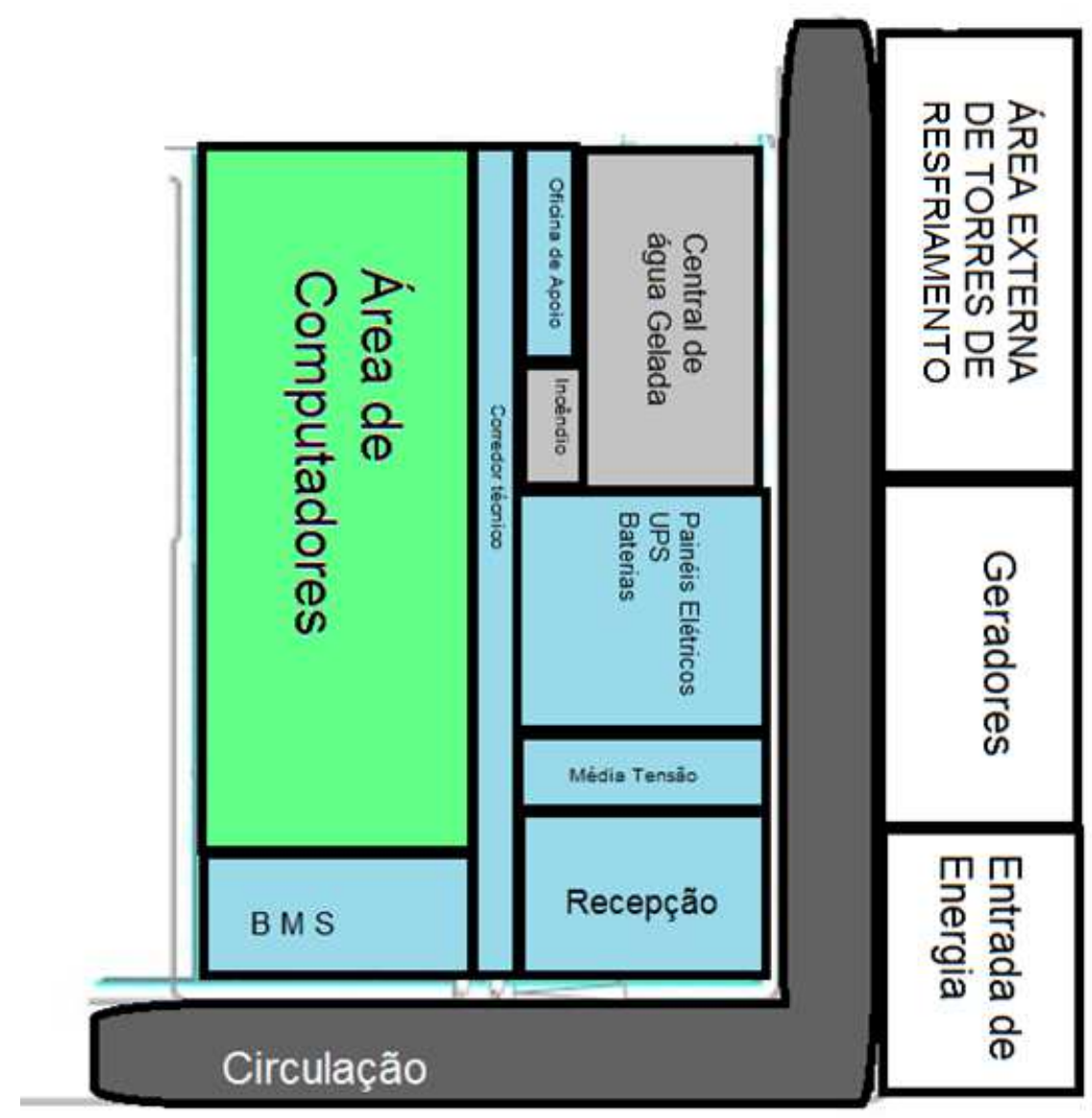

Figura 4.3 - Planta Típica de Modelo Adotado

A Tabela 4.1 apresenta as dimensões de cada sala para um data center com $2.000 \mathrm{~m}^{2}$ de área construída. A área de para equipamentos de TI é de $625 \mathrm{~m}^{2}$ e estimase área útil de coletores solares em $2000 \mathrm{~m}^{2}$.

Tabela 4.1 - Áreas consideradas da edificação

\begin{tabular}{ll}
\hline Localidade & Área $\left(\mathbf{m}^{\mathbf{2}}\right)$ \\
\hline Área de Computadores & 625 \\
Central de água Gelada & 270 \\
Oficina & 30 \\
Extinção de Incêndio/ Oficina & 40 \\
Sala de Trafos & 70 \\
Sala de Baterias & 70 \\
Sala de Painéis e UPS & 135 \\
Sala de Média Tensão & 70 \\
Recepção & 180 \\
BMS & 150 \\
Corredor Técnico & 200 \\
Áreas de Circulação & 160 \\
Total de áreas Cobertas & 2000 \\
\hline
\end{tabular}


As áreas de geradores, torres de arrefecimento e cabine primária de rede elétrica devem ficar fora, porém adjacentes a edificação. A área considerada para células fotovoltaicas ou coletores solares será a área de telhado da área coberta.

Para efeito de cálculo será considerado o ar condicionado somente na área de computadores, pois as outras áreas possuem característica de conforto e sua climatização, pode estar segregada da área de computadores, pois não há rigor para temperatura e umidade.

\subsubsection{Considerações operacionais}

Segue condição considerada para cálculos de carga térmica.

- A temperatura máxima de retorno é de $34^{\circ} \mathrm{C}$.

- Potência de equipamentos instalados: $0,5 \mathrm{~kW} / \mathrm{m}^{2} ; 1,0 \mathrm{~kW} / \mathrm{m}^{2} ; 2,0 \mathrm{~kW} / \mathrm{m}^{2} ; 4,0$ $\mathrm{kW} / \mathrm{m}^{2}$ e $8,0 \mathrm{~kW} / \mathrm{m}^{2}$.

- Potência de iluminação: $20 \mathrm{~W} / \mathrm{m}^{2}$

- Ocupação: 2 pessoas

- Horário de ocupação, equipamentos e iluminação: 24 horas dias/ 7 dias por semana

- Área de computadores: $625 \mathrm{~m}^{2}$

- Perfil de cargas anuais conforme software E-20 HAP Analysis.

- Desconsiderada área de janela.

- Insolação nas 4 faces

- Densidade da construção - 341,8 kg/m²

- Absorvidade das paredes -0,675

- Coeficiente global de transferência de calor de paredes $(\mathrm{U})-1,409 \mathrm{~W} /\left(\mathrm{m}^{2} \mathrm{~K}\right)$

- Absorvidade telhado - 0,675

- Coeficiente global de transferência de calor de paredes $(\mathrm{U})-0,518 \mathrm{~W} /\left(\mathrm{m}^{2} \mathrm{~K}\right)$

Conforme simulação obtida no programa HAP - Hour Analisys Program da

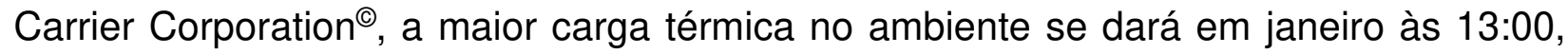
onde o ar externo estrará no ambiente à $40 \%$ de umidade relativa e $31^{\circ} \mathrm{C}$, se mistura ao ar externo onde estará a $34^{\circ} \mathrm{C}$ e $22 \%$ de umidade relativa na entrada das unidades de 
ventilação. Em contato com a água proveniente das unidades de resfriamento (ou Resfriamento natural indireto), o ar será resfriado até $22,3^{\circ} \mathrm{C}$ e $45 \%$ de umidade relativa. $\mathrm{O}$ ar passará pelos ventiladores onde haverá um pequeno acréscimo de temperatura e será disponibilizado nas saídas de ar das placas perfuradas com $24^{\circ} \mathrm{C}$ e $38 \%$ de umidade relativa. Nos servidores ocorrerá a troca de calor, onde estes resfriarão e o ar se aquecerá chegando a temperatura de aproximadamente $34^{\circ} \mathrm{C}$ e $22 \%$ de umidade relativa, retornando às unidades de ventilação. A Figura 4.4 ilustra este processo.

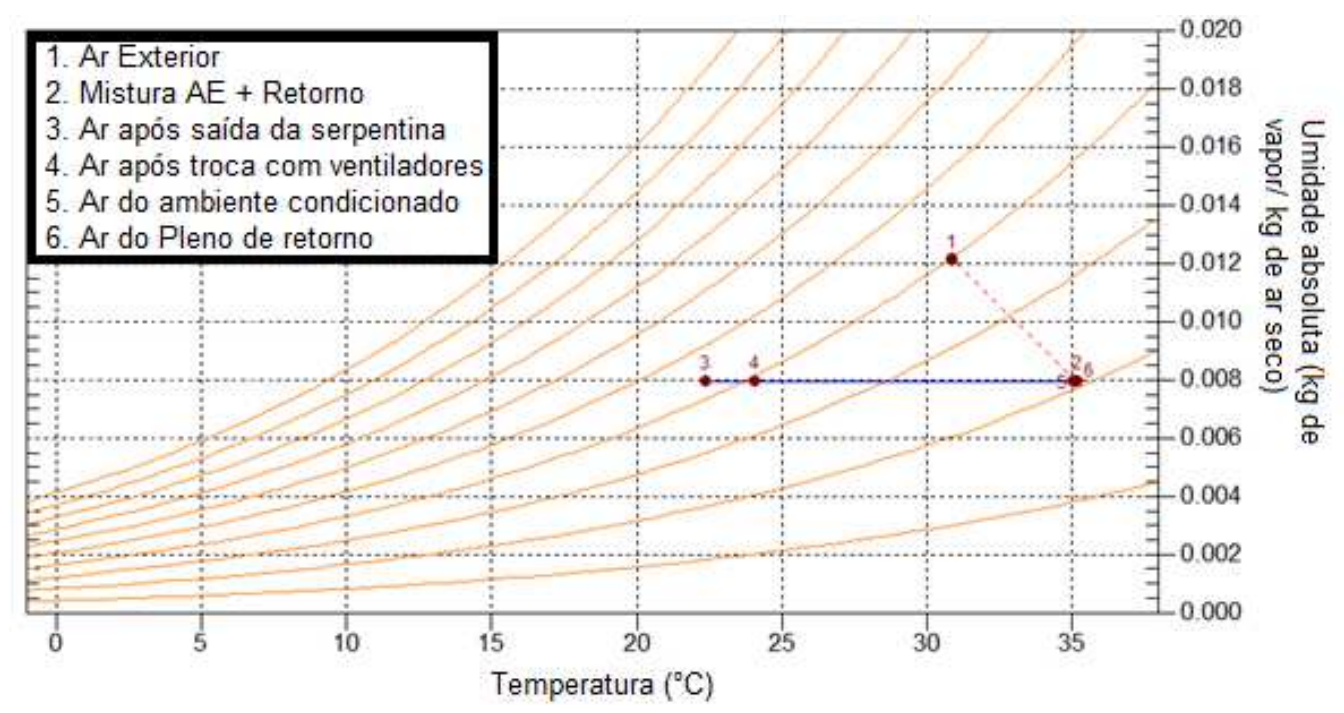

Figura 4.4 - Evolução Psicrométrica no processo de condicionamento do ambiente proposto.

O cálculo de varga térmica básico desta edificação realizado pelo software está no anexo A. O cálculo nos indica fatores que são variáveis de acordo com a área da edificação e com condições climáticas externas, independentes da carga de computadores aplicados, como condução térmica por paredes, telhado, fator de ocupação (trabalhadores para manutenção de espaço), infiltração e dissipação térmica em ventiladores de unidades de ventilação. Estes fatores originarão o coeficiente de fatores externos $\left(x_{C T}\right)$.

Sua utilização varia conforme o mês aferido e hora correspondente. Como se trata de média mensal, considera o mesmo fator para todas as determinadas horas de um respectivo mês. Por isso, é possível construir a Tabela 4.2, utilizando a hora e o mês de aplicação. 
A carga de equipamento elétricos no site é expressa pela densidade de potência $\left(\rho_{\text {РОT }}\right)$ multiplicada pela área. Com este cenário a carga térmica para o modelo Data Center pode ser expressa pela equação 4.1 .

Tabela 4.2 - Coeficiente de cargas não aplicadas em função de mês e hora.

\begin{tabular}{|c|c|c|c|c|c|c|c|c|c|c|c|c|}
\hline \multicolumn{13}{|c|}{ Coeficientes de cargas não aplicadas $x_{C T}\left(\frac{k W}{m^{2}}\right)$} \\
\hline Hora & Jan & Fev & Mar & $\overline{A b r}$ & Mai & Jun & Jul & Ago & Set & Out & Nov & Dez \\
\hline 0:00 & 0,44 & 0,44 & 0,45 & 0,44 & 0,43 & 0,43 & 0,43 & 0,43 & 0,43 & 0,43 & 0,45 & 0,45 \\
\hline 1:00 & 0,44 & 0,45 & 0,45 & 0,43 & 0,44 & 0,44 & 0,43 & 0,43 & 0,44 & 0,43 & 0,44 & 0,45 \\
\hline 2:00 & 0,43 & 0,45 & 0,44 & 0,44 & 0,44 & 0,43 & 0,42 & 0,44 & 0,43 & 0,44 & 0,44 & 0,44 \\
\hline 3:00 & 0,43 & 0,45 & 0,44 & 0,43 & 0,43 & 0,42 & 0,42 & 0,43 & 0,43 & 0,44 & 0,44 & 0,45 \\
\hline 4:00 & 0,43 & 0,44 & 0,44 & 0,44 & 0,43 & 0,42 & 0,42 & 0,43 & 0,44 & 0,44 & 0,44 & 0,44 \\
\hline 5:00 & 0,43 & 0,45 & 0,44 & 0,43 & 0,42 & 0,43 & 0,42 & 0,42 & 0,43 & 0,43 & 0,44 & 0,44 \\
\hline 6:00 & 0,44 & 0,44 & 0,44 & 0,43 & 0,43 & 0,42 & 0,43 & 0,42 & 0,44 & 0,43 & 0,44 & 0,45 \\
\hline 7:00 & 0,44 & 0,45 & 0,43 & 0,44 & 0,44 & 0,42 & 0,42 & 0,43 & 0,43 & 0,43 & 0,45 & 0,45 \\
\hline 8:00 & 0,44 & 0,45 & 0,45 & 0,43 & 0,43 & 0,43 & 0,43 & 0,44 & 0,43 & 0,44 & 0,45 & 0,45 \\
\hline 9:00 & 0,45 & 0,46 & 0,45 & 0,43 & 0,43 & 0,44 & 0,43 & 0,43 & 0,44 & 0,45 & 0,46 & 0,46 \\
\hline $10: 00$ & 0,46 & 0,46 & 0,46 & 0,44 & 0,44 & 0,44 & 0,44 & 0,45 & 0,45 & 0,46 & 0,46 & 0,46 \\
\hline 11:00 & 0,46 & 0,46 & 0,46 & 0,46 & 0,44 & 0,44 & 0,44 & 0,44 & 0,46 & 0,45 & 0,47 & 0,47 \\
\hline $12: 00$ & 0,47 & 0,47 & 0,47 & 0,46 & 0,45 & 0,45 & 0,45 & 0,45 & 0,46 & 0,46 & 0,47 & 0,48 \\
\hline 13:00 & 0,47 & 0,48 & 0,48 & 0,46 & 0,45 & 0,45 & 0,44 & 0,45 & 0,46 & 0,45 & 0,47 & 0,47 \\
\hline 14:00 & 0,48 & 0,47 & 0,46 & 0,47 & 0,45 & 0,45 & 0,45 & 0,45 & 0,47 & 0,46 & 0,47 & 0,47 \\
\hline $15: 00$ & 0,47 & 0,47 & 0,47 & 0,45 & 0,45 & 0,45 & 0,45 & 0,45 & 0,45 & 0,47 & 0,47 & 0,47 \\
\hline $16: 00$ & 0,47 & 0,47 & 0,46 & 0,45 & 0,45 & 0,44 & 0,45 & 0,44 & 0,46 & 0,45 & 0,47 & 0,47 \\
\hline $17: 00$ & 0,46 & 0,46 & 0,46 & 0,45 & 0,44 & 0,44 & 0,44 & 0,44 & 0,45 & 0,45 & 0,46 & 0,46 \\
\hline 18:00 & 0,46 & 0,46 & 0,46 & 0,45 & 0,44 & 0,45 & 0,44 & 0,44 & 0,44 & 0,44 & 0,45 & 0,46 \\
\hline 19:00 & 0,46 & 0,46 & 0,45 & 0,45 & 0,45 & 0,43 & 0,43 & 0,44 & 0,44 & 0,44 & 0,45 & 0,46 \\
\hline 20:00 & 0,45 & 0,45 & 0,45 & 0,44 & 0,45 & 0,43 & 0,44 & 0,44 & 0,44 & 0,44 & 0,45 & 0,45 \\
\hline 21:00 & 0,45 & 0,45 & 0,45 & 0,44 & 0,43 & 0,44 & 0,43 & 0,43 & 0,43 & 0,45 & 0,43 & 0,45 \\
\hline 22:00 & 0,45 & 0,45 & 0,45 & 0,44 & 0,44 & 0,43 & 0,43 & 0,43 & 0,44 & 0,45 & 0,45 & 0,45 \\
\hline 23:00 & 0,45 & 0,45 & 0,45 & 0,43 & 0,43 & 0,44 & 0,44 & 0,43 & 0,44 & 0,45 & 0,45 & 0,45 \\
\hline
\end{tabular}

$C_{T}=A_{S C} \cdot\left(x_{C T}+\rho_{P O T}\right)$ 


\subsection{Cálculo de ângulos solares}

Nesta etapa os dados horários de radiação direta e radiação total (em amarelo na figura 4.5) serão importados dos dados relativos à cidade escolhida e também a reflexividade dos dados de edifício padrão dos arquivos de entrada (ASHRAE, 2006).

Nesta etapa calculam-se os ângulos solares através das equações descritas entre 4.2 e 4.7 (KALOGIROU, 2004; DUFFIE; BECKMAN, 2006).

- Ângulo Horário (ఐ): Positivo à tarde e negativo de manhã e 1 h corresponde a $15^{\circ}$

$\omega=(15 \cdot H)-12$

- Declinação (ס)

$\delta=23,45 \cdot \operatorname{sen}\left(360 \cdot \frac{284+N}{365}\right)$

- Ângulo de Zênite $\left(\theta_{z}\right)$

$\theta_{z}=\operatorname{acos}(\operatorname{sen} \delta \cdot \operatorname{sen} \phi+\cos \delta \cdot \cos \phi \cdot \cos \omega)$

- Altitude Solar $\left(\alpha_{s}\right)$

$\alpha_{s}=\operatorname{asen}(\operatorname{sen} \delta \cdot \operatorname{sen} \phi+\cos \delta \cdot \cos \phi \cdot \cos \omega)$

- Azimute $\left(\gamma_{s}\right)$. Negativo ao Leste e positivo ao Oeste.

$\gamma_{s}=\operatorname{sinal}(\omega)\left|\cos ^{-1} \cdot\left(\frac{\operatorname{sen} \alpha_{s} \cdot \operatorname{sen} \varphi-\operatorname{sen} \delta}{\cos \alpha_{s} \cdot \cos \varphi}\right)\right|$

- Azimute de Superfície (y) - Convenção $0^{\circ}$

- Ângulo de Incidência ( ()

$\theta=\operatorname{acos}\left[\cos \theta_{z} \cdot \cos \beta+\operatorname{sen} \theta_{z} \cdot \cos \left(\gamma_{S}-\gamma\right)\right]$

De posse de todos os ângulos solares é possível estabelecer relação entre radiação direta no plano inclinado e no plano horizontal $\left(R_{b}\right)$. Isto é calculado pela equação 4.8 (PACHECO, 2017). 
$R_{b}=\frac{\cos (\theta)}{\cos \left(\theta_{z}\right)}$

Na sequência calcula-se a radiação extraterrestre pela equação. 4.9.

$I_{0}=\frac{12 \cdot 1000 \cdot G_{S C}}{\pi} \cdot\left(1+0,33 \cos \frac{360 \cdot n}{365}\right) \cdot\left(\cos \varphi \cdot \cos \delta \cdot \operatorname{sen}\left(\operatorname{sen} w_{2}-\operatorname{sen} w_{1}\right)\right)+\frac{\pi\left(w_{2}-w_{1}\right)}{180}$.

$\operatorname{sen} \varphi \cdot \sin \delta$

$I_{0}-$ em kWh.

A posterior, calcula-se o índice de claridade $\left(\mathrm{k}_{\mathrm{T}}\right)$ pela equação 4.10.

$k_{T}=\frac{I}{I_{0}}$

Os resultados de Orgill and Hollands (1977), forneceram uma correlação suficientemente precisa apresentada na equação 4.11. Então, é possível calcular, os valores de radiação direta e difusa pelas equações 4.12, 4.13 e 4.14:

$\frac{I d}{I}=f\left(k_{T}\right)$

Onde pode ser expressa pelas seguintes equações

Para $k_{T}<0,35 ; \frac{I d}{I}=1,0-0,249 \cdot k_{T}$;

Para $0,35<k_{T}<0,75 ; \frac{I d}{I}=1,557-1,84 \cdot k_{T}$;

Para $k_{T}>0,75 ; \frac{I d}{I}=0,177$;

Portanto para o plano horizontal, calcula-se radiação direta, multiplicando os valores de I retirando do banco de dados pela relação obtida em 4.15.

$I d=I \cdot f\left(k_{T}\right)$

O valor de radiação difusa será o complemento em relação a direta no plano horizontal pela equação 4.16.

$I_{b}=I-I_{d}$ 
De posse destes valores calcula-se a radiação total refletida sobre uma superfície inclinada apresentada por Liu e Jordan (1962) na equação 4.17.

$I_{T}=I_{b} \cdot R_{b}+I_{d} \cdot\left(\frac{1+\cos \beta}{2}\right)+\left(I_{b}+I_{d}\right) \cdot \rho \cdot\left(\frac{1-\cos \beta}{2}\right)$

A figura 4.5 ilustra a metodologia de cálculo passo a passo para a radiação solar entre a obtenção de dados a partir da seleção da cidade, escolha de materiais construtivos, até a obtenção de resultados horários de radiação segundo o modelo de Liu e Jordan. 


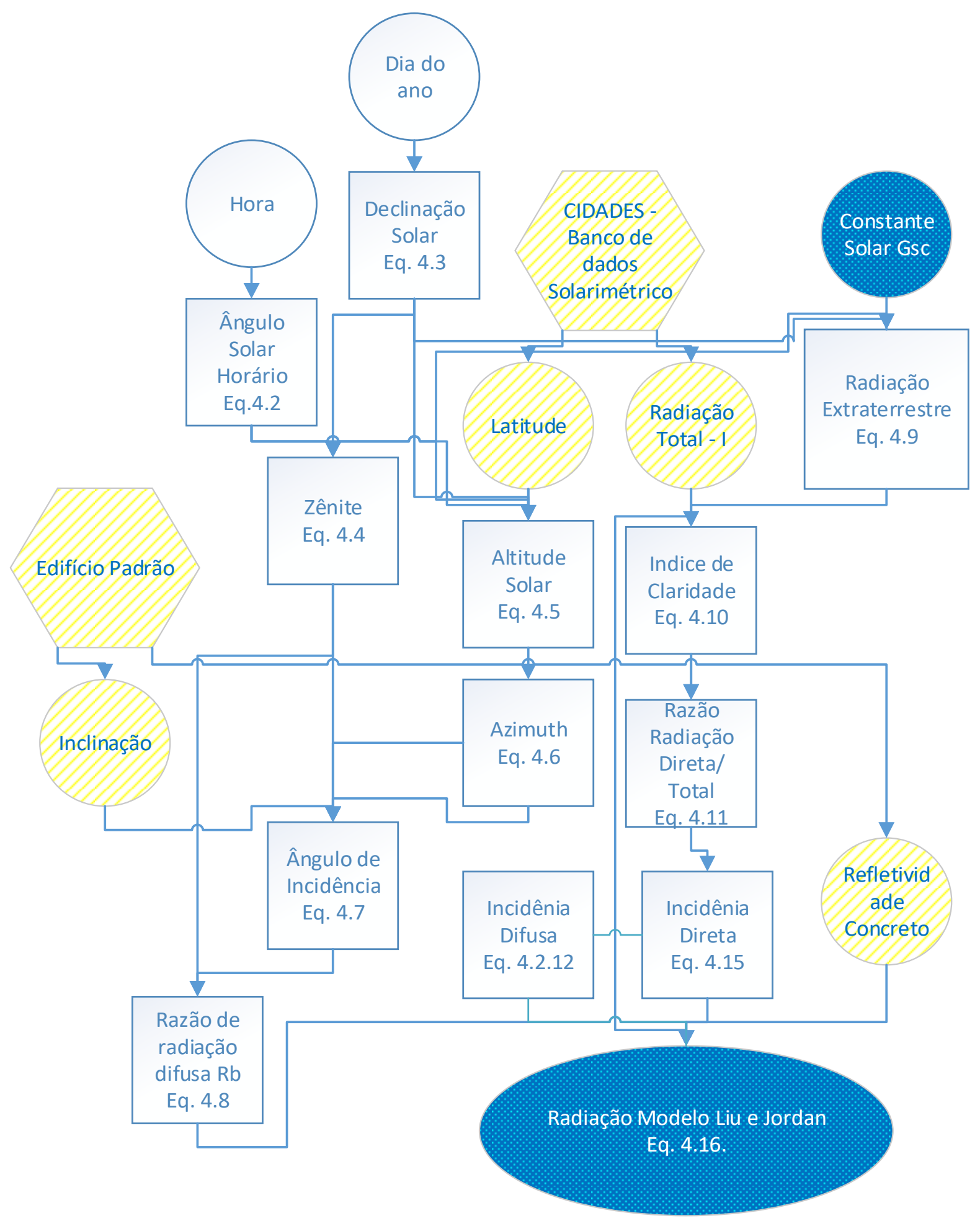

Figura 4.5 - Metodologia de cálculo de radiação em área de coletores. 


\subsection{Tecnologias solares utilizadas}

Nesta etapa será quantificada a energia solar fornecidas às unidades de resfriamento solar, para acionamento de geradores de vapor ou compressores, e a climatização disponível pelas unidades de resfriamento.

Nas próximas seções serão comparados os sistemas elétrico fotovoltaico com unidade de resfriamento por compressão de vapor e térmico com coletores de tubo a vácuo com unidade de resfriamento por absorção.

\subsubsection{Absorção Solar}

Uma possibilidade de utilização da energia solar, seria a utilização de sistemas de absorção solar, neste caso os parâmetros de entrada seriam a radiação horária de Liu Jordan (Eq. 4.17), temperatura de bulbo seco e área de placas provenientes dos dados de entrada (seção 4.1), constantes de materiais (seção 4.1).

Um ciclo de absorção solar deve operar como uma UR de absorção outrora acionado por queima direta ou fluidos quentes, todavia, neste caso, o acionamento ocorre por água quente proveniente de coletores solares. Em sistemas de condicionamento os fluidos de trabalho geralmente utilizados é o par baseado em brometo de lítio e água.

A estratégia abordada é mostrada na figura 4.6. A energia solar é captada através de coletores solares de tubo a vácuo (1) e acumulada em tanques de água quente (2) no processo A. Quando o volume suficientemente necessário para funcionamento de uma UR é atingido para a operação temporal contínua, neste caso uma hora, a água é descarregada para o gerador de vapor da UR em questão (3), no processo B. Após este processo, a água utilizada pelos geradores de vapor retorna aos coletores para reaquecimento, no processo C. Paralelamente, o gerador de vapor da UR é acionado(3), resultando na produção de água gelada para o tanque de termo acumulação (4) no processo D. Este irá disponibilizar a água fria para a instalação em 2 momentos (processo E). O primeiro em horários preferenciais, selecionados pelos usuários (horário de ponta). O segundo ocorrerá quando este (4) atingir sua capacidade máxima de armazenamento de água fria e a UR (3) ainda estiver operando. Após a utilização nas unidades de 
ventilação, a água deste sistema retornará a UR para seu resfriamento. A UR (3) rejeita o calor recebido da instalação e de seu gerador de vapor através de torres de condensação (5), recebendo água resfriada em $\mathrm{G}$ e retornando água a torre em $\mathrm{H}$.

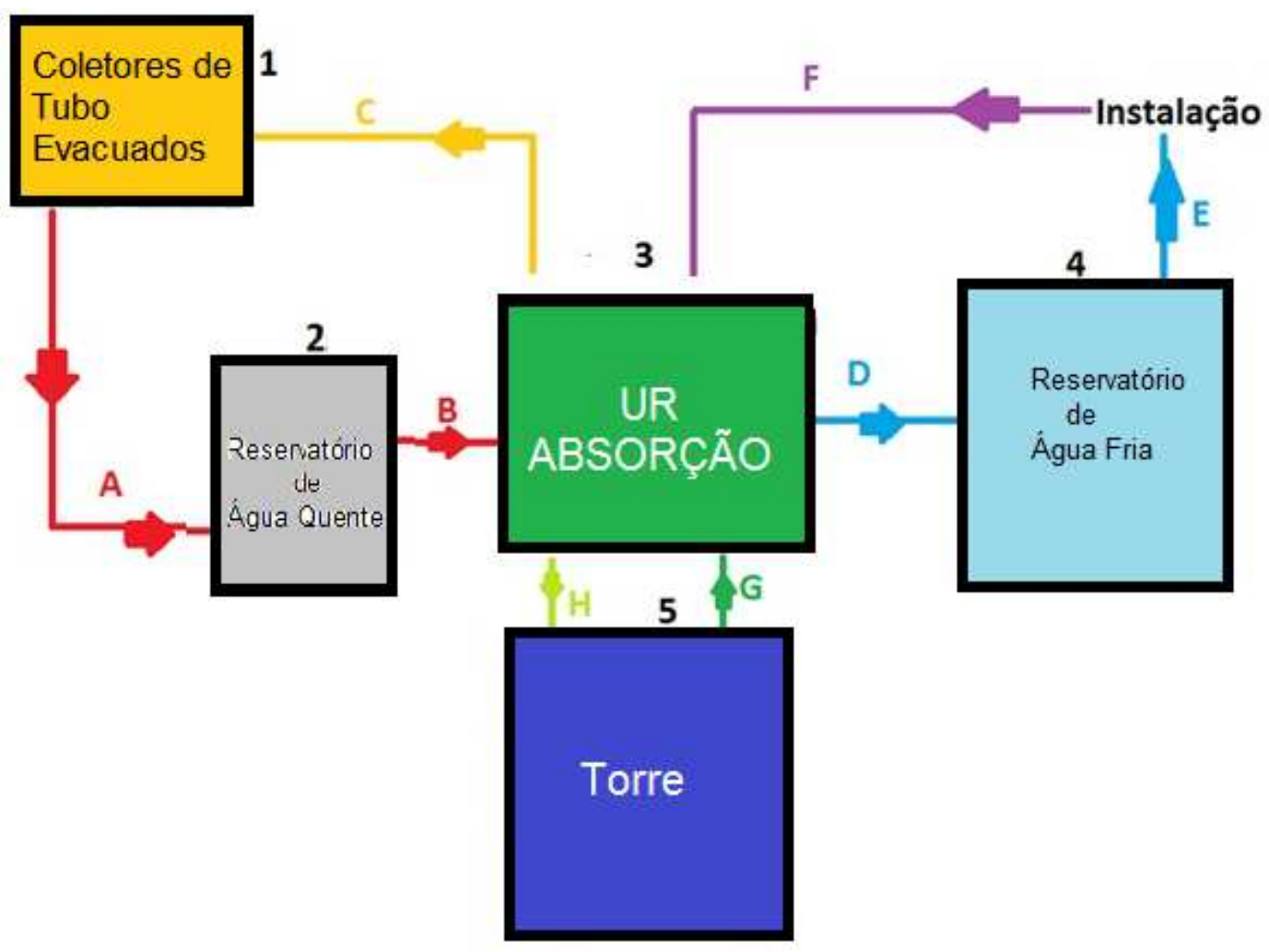

Figura 4.6 - Funcionamento de UR de absorção solar.

A primeira etapa deste processo será o cálculo do rendimento do coletor solar $\left(\eta_{\text {sol_heat }}\right)$. A efificência de um coletor solar é obtida pela equação 4.18 (KOHLENBACH \& JAKOB 2014; LAZARIN 2014; KALOGIROU 2004).

$\eta_{\text {sol_heat }}=C_{0}-C_{1} \cdot x-C_{2} \cdot I_{T} \cdot x^{2}$

$\mathrm{C}_{0}, \mathrm{C}_{1}, \mathrm{C}_{2}=$ constantes do coletor solar

Onde x é calculado em 4.19.

$x=\frac{\left(T_{c l c}-\mathrm{TBS}\right)}{I_{T}}$ 
$T_{c l c}=$ Temperatura no coletor solar

TBS = Temperatura de bulbo seco

Para efeito de cálculo considera a temperatura de trabalho como temperatura de coletor solar. Neste caso, $90^{\circ} \mathrm{C}$.

Os valores de $\mathrm{C}_{0}, \mathrm{C}_{1}$ e $\mathrm{C}_{2}$ são apresentados na Tabela 4.3.

Tabela 4.3 Constantes para diferentes tipos de coletores solares (Gerbreslassie et al. 2010; Ferreira \& Kim 2014)

\begin{tabular}{ccccc} 
Coeficiente & $\begin{array}{c}\text { Concentrador Discos } \\
\text { Parabólicos }\end{array}$ & $\begin{array}{c}\text { Concentrador } \\
\text { Fresnel Linear }\end{array}$ & $\begin{array}{c}\text { Tubo } \\
\text { Evacuado }\end{array}$ & $\begin{array}{c}\text { Placas } \\
\text { Planas }\end{array}$ \\
\hline $\mathbf{C}_{0}$ & 0,82 & 0,76 & 0,84 & 0,8 \\
$\mathbf{C}_{1}$ & 0,22 & 0,22 & 2,02 & 3,02 \\
$\mathbf{C}_{2}$ & & & 0,0046 & 0,0113 \\
\hline
\end{tabular}

Outro fator que deverá ser considerado, são as demais perdas no armazenamento e em transferência de calor no transporte de liquido $\left(P_{h}\right)$, aqui estimadas em $6 \%$, para o cálculo do rendimento total dos coletores $\left(\eta_{c l c}\right)$. A equação 4.20 relata esta necessidade

$\eta_{c l c}=\eta_{\text {sol_heat }} \cdot\left(1-P_{h}\right)$

Devido a intermitência solar, neste caso é necessário armazenar água quente para evitar um funcionamento irregular das unidades de resfriamento, provendo água quente para que estas trabalhem em sua condição de maior eficiência. A energia solar armazenada $\left(\dot{q}_{G}\right)$ será a multiplicação da área útil de placas (dados de entrada, seção 4.1), pela radiação do modelo de Liu e Jordan (Eq. 4.17), pelo rendimento dos coletores (Equação 4.20).

$\dot{q}_{G}=A_{U} \cdot \eta_{c l c} \cdot I_{T}$

Quando a água quente acumulada possibilitar a operação da unidade de resfriamento, esta será descarregada ao equipamento, iniciando a resfriamento de água do ambiente. Em consulta a fabricantes notou-se que este tipo de equipamento tem rendimento ótimo a $70 \%$ de carga, em que apresenta um fator de eficiência médio $\left(\varepsilon_{A}\right)$ de 
1,29 em 2014 (SARBU \& SERBACHIEVI, 2013; FERREIRA \& KIM, 2014). Todavia novos desenvolvimentos e lançamentos para equipamentos de duplo efeito, trabalhando com maior diferencial de temperatura (entrada a $90^{\circ} \mathrm{C}$ e saída a $55^{\circ} \mathrm{C}$, alcançam eficiências da ordem de 1,51 (LAZZARIN \& NORO, 2018; LG, 2017), que serão adotadas nesta tese.

Neste trabalho será utilizado uma UR de 210 TR, que é correspondente a carga máxima disponível em uma hora para a captação solar estimada.

A capacidade de resfriamento $\left(\dot{q_{E}}\right)$ obtida é apresentada na equação 4.22.

$\dot{q_{E}}=\dot{q}_{G} \cdot \varepsilon_{A}$

O conceito sugere que após a resfriamento a água gelada seja acumulada em um segundo tanque para utilização $\left(q_{a c}^{\cdot}\right)$ em horários onde a tarifa seria menos atrativa para utilização da rede. Para cada hora o balanço se dará entre a carga gerada pela unidade de resfriamento $\left(\dot{q_{E}}\right)$ e pela utilização $\left(\dot{q_{U}}\right)$, conforme equação 4.23 .

$q_{\dot{d i s p}}=\dot{q_{E}}-\dot{q_{U}}+\dot{q_{a c}}$

Quando houver insuficiência, a carga térmica complementar $(\dot{C})$, calaculada pela diferença entre a carga térmica calcula na seção $4.1\left(\dot{C}_{T}\right)$ e a carga disponível pelo equipamento de absorção $\left(q_{\text {disp }}\right)$ deverá ser disponibilizada pela unidade de resfriamento elétrica da edificação, como segue na equação 4.24.

$\dot{C}=\dot{C_{T}}-q_{\text {disp }}$

A Figura 4.7 ilustra a metodologia de cálculo para a radiação solar a partir da obtenção dos valores horários de radiação do modelo de Liu e Jordan até o cálculo de carga residual após o descarregamento do tanque de água gelada proveniente da UR de absorção. 


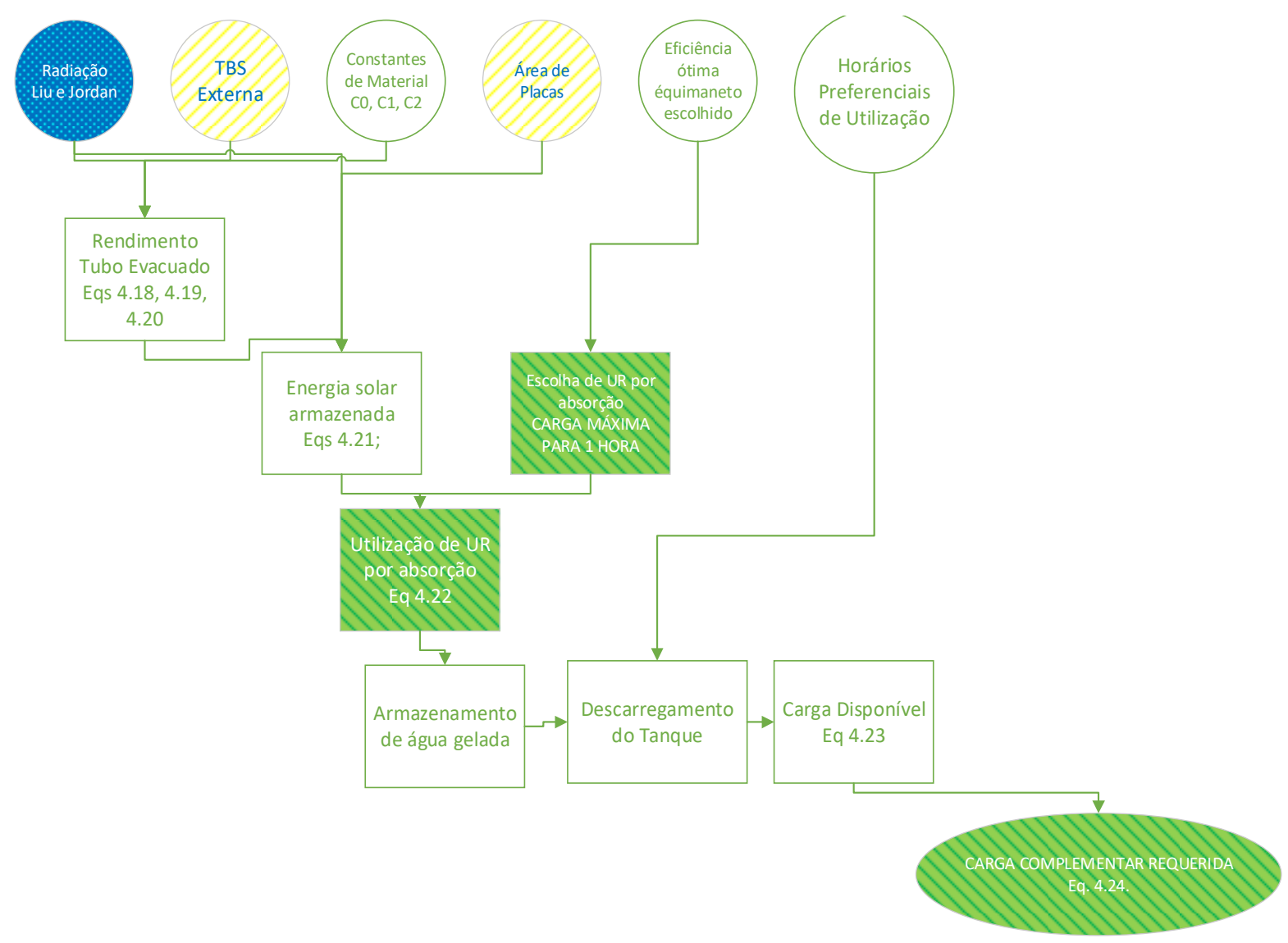

Figura 4.7 - Metodologia de cálculo de resfriamento por absorção solar.

\subsubsection{Resfriamento fotovoltaico}

Outra possibilidade de utilização da energia solar abordada nesta tese, são os sistemas de resfriamento fotovoltaico. Neste caso a energia fotovoltaica será acumulada em um banco de baterias, que será a fonte primária em horários onde a energia é mais cara.

A figura 4.8 ilustra o funcionamento do sistema proposto. A energia solar será transformada em energia elétrica através de painéis fotovoltaicos $(A)$. Esta energia será retificada em inversores de frequência $(B)$ e armazenada em bancos de baterias $(C)$. Ele será descarrega ao equipamento quando estiver no horário preferencial ou o banco de baterias estiver completamente carregado. Em horários normais ou em falta de energia das baterias (C) a energia da rede (E) suprira o consumo elétrico da unidade de resfriamento $(F)$, que é arrefecida pelas torres $(G)$. 


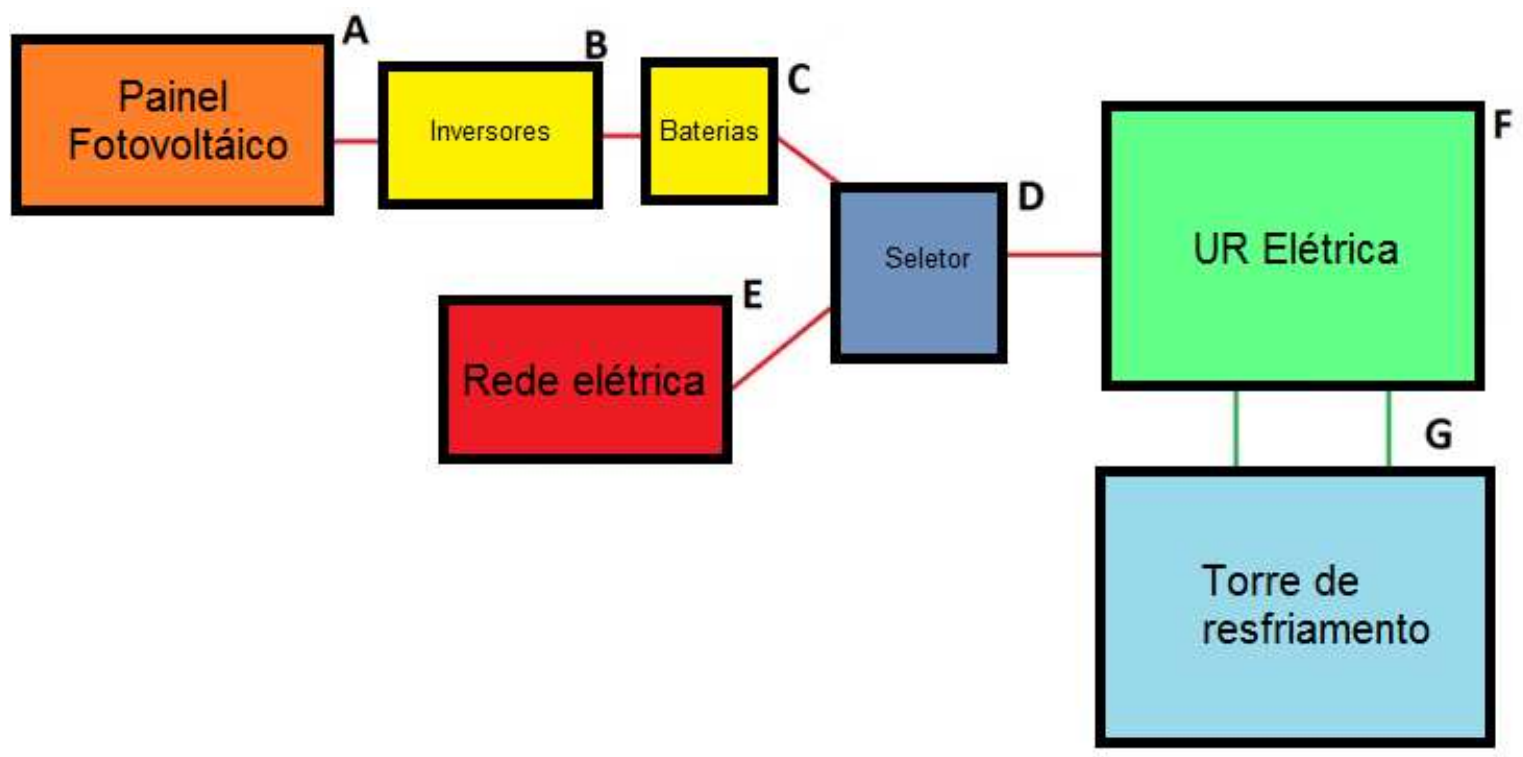

Figura 4.8 - Funcionamento de sistema de acionamento fotovoltaico proposto.

Os parâmetros de entrada seriam a radiação horária do modelo de Liu Jordan (Eq. 4.17), temperatura de bulbo seco e área de placas provenientes dos dados de entrada (seção 4.1) e as propriedades das células fotovoltaicas. Esta estimativa inicia-se pelo o cálculo do rendimento de uma célula fotovoltaica, nas condições apresentadas.

A primeira etapa deste processo será o cálculo do rendimento das células fotovoltáicas $\left(\eta_{\text {sol_pow }}\right)$ apresentado em (HULD et al., 2010) na equação 4.25:

$$
\begin{aligned}
& \eta_{\text {sol_pow }}=\left\{1+k_{1} \cdot \ln I_{T}+k_{2} \cdot\left(\ln I_{T}\right)^{2}+T_{\text {painel }} \cdot\left[k_{3}+k_{4} \cdot \ln I_{T}+k_{5} \cdot\left(\ln I_{T}\right)^{2}\right]+k_{6} \cdot\right. \\
& \left.T_{\text {painel }}^{2}\right\} \cdot \eta_{\text {sist }}
\end{aligned}
$$

Onde os valores da constante $\mathrm{k}$ são apresentados a seguir, na tabela 4.4:

Tabela 4. Constantes para painéis fotovoltaicos. (HULD et al., 2010)

$$
\text { CONSTANTES PV }
$$

\begin{tabular}{llllll}
\hline$k_{1}$ & $\mathbf{k}_{2}$ & $\mathbf{k}_{3}\left({ }^{\circ} \mathbf{C}^{-1}\right)$ & $\mathbf{k}_{4}\left({ }^{\circ} \mathbf{C}{ }^{-1}\right)$ & $\mathbf{k}_{5}\left({ }^{\circ} \mathbf{C}^{-1}\right)$ & $\mathbf{k}_{6}\left({ }^{\circ} \mathbf{C}^{-1}\right)$ \\
\hline $\mathbf{- 0 , 0 1 7 1 6}$ & $-0,04029$ & $-0,00468$ & 0,000148 & 0,000169 & 0,000005 \\
\hline
\end{tabular}


Todavia para a utilização de tal equação é necessário estimar a temperatura superficial da placa. Na superfície apresenta-se os efeitos de convecção e radiação combinados, e por balanço de energia chegamos a temperatura de superfície conforme apresentado nas equações de 4.26 a 4.30 .

$$
\begin{aligned}
& Q_{\text {rad }}+Q_{c o n v}=0 \\
& Q_{\text {rad }}=I_{T} \cdot A \\
& I_{T} \cdot A=h_{\text {conv }} \cdot A \cdot\left(T_{\text {painel }}-T B S\right) \\
& T_{\text {painel }}=T B S+\frac{I_{T}}{h_{\text {convar }}}
\end{aligned}
$$

Para o cálculo do rendimento completo do sistema ( $\left.\eta_{\text {sol_pow }}\right)$, substitui-se a equação 4.30 em 4.25. Outro fator que deverá ser levado em consideração são as perdas por cabos, perdas no inversor e bancos de bateria $\left(\eta_{\text {sistema }}\right)$. A equação 4.31 apresenta o rendimento total da instalação.

$$
\begin{aligned}
& \eta_{\text {sol_pow }}=\left\{1+k_{1} \cdot \ln I_{T}+k_{2} \cdot\left(\ln I_{T}\right)^{2}+\left(T B S+\frac{I_{T}}{h_{\text {convar }}}\right) \cdot\left[k_{3}+k_{4} \cdot \ln I_{T}+k_{5} .\right.\right. \\
& \left.\left.\left(\ln I_{T}\right)^{2}\right]+k_{6} \cdot\left(T B S+\frac{I_{T}}{h_{\text {convar }}}\right)^{2}\right\} \cdot \eta_{\text {sist }}
\end{aligned}
$$

Neste a estimativa de energia fotovotaica gerada $\left(W_{P V}\right)$, utiliza-se a formulação elaborada por (Ferreira \& Kim 2014) na equação 4.32, considerando as constantes apresentadas em testes $W_{S T C}$ e $I_{\text {PSTC }}$, como respectivamente $150 \mathrm{Wm}^{-2}$ e $1.000 \mathrm{Wm}^{-2}$.

$W_{P V}=W_{S T C} \cdot \frac{I_{T}}{I_{p S T C}} \cdot \eta_{S o l_{-} \text {pow }}$

Após a geração de energia, este insumo será armazenado em um banco de baterias $\left(\dot{W}_{a c}\right)$. Em horários preferenciais essas baterias serão descarregadas na alimentação da central de água gelada. A energia disponível $\left(W_{\text {dlsp }}^{\cdot}\right)$, será a energia gerada $\left(\dot{W}_{P V}\right)$ adicionada a acumulada $\left(\dot{W}_{a c}\right)$, menos a energia utilizada $\left(\dot{W}_{U}\right)$. Balanço este apresentado na equação 4.33 . 
$W_{d l s p}=\dot{W}_{P V}-\dot{W}_{U}+\dot{W}_{a c}$

A Figura 4.9 ilustra esta metodologia entre a obtenção da radiação do modelo de Liu e Jordan até o fornecimento de energia elétrica complementar pela rede.

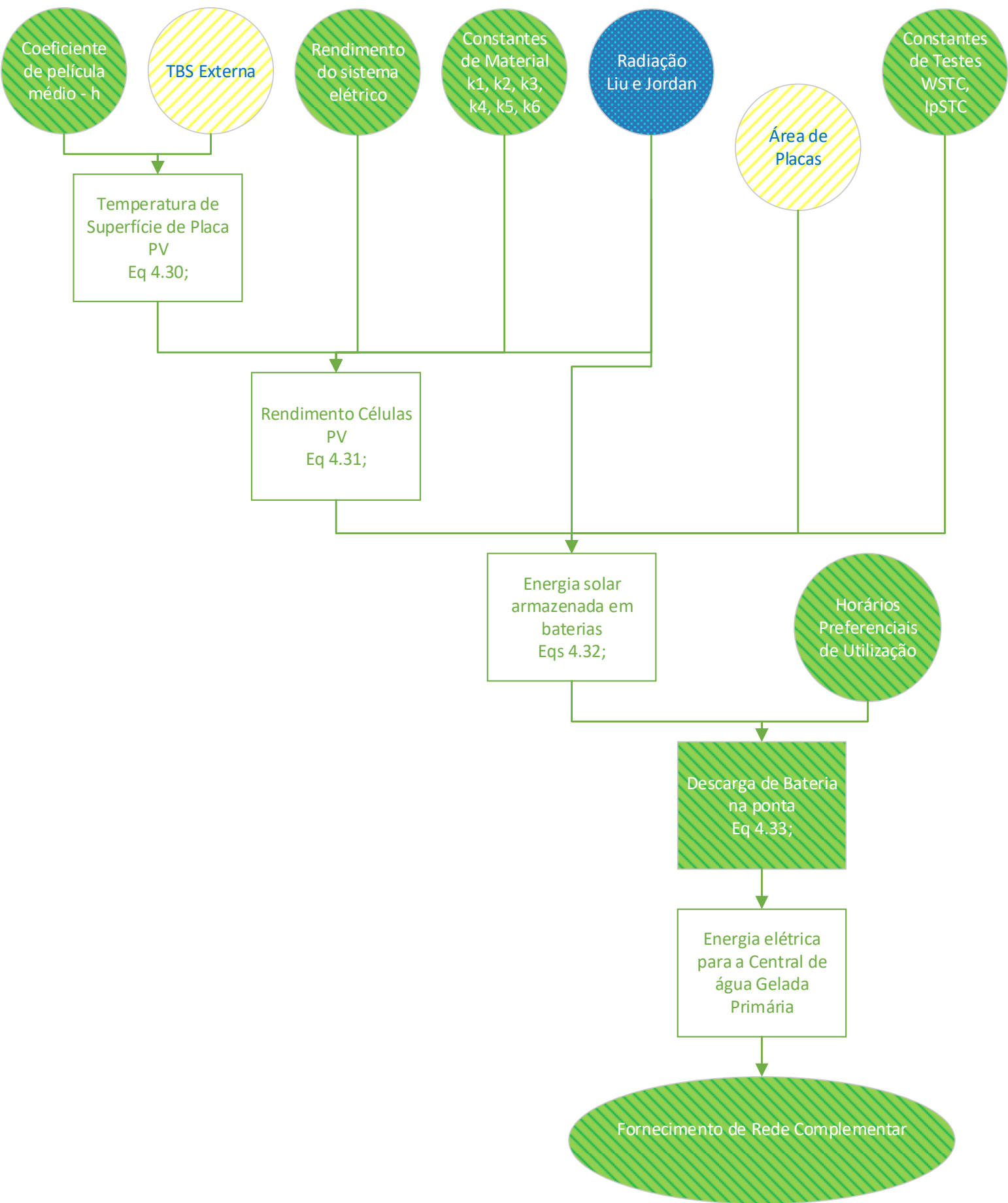

Figura 4.9 - Metodologia de cálculo de resfriamento fotovoltaico. 


\subsection{Economizadores por resfriamento natural}

Devido a flexibilização da faixa de temperaturas e umidades de operação para um Data Center, conforme figura 2.2, apresentada na sessão 2.2, é possível a utilização de resfriamento natural nesta aplicação.

Em um primeiro caso, o resfriamento natural direto será realizado se a entalpia externa for menor que a de retorno, reduzindo a necessidade de resfriamento forçado pela utilização de UR.

No caso do resfriamento natural indireto é considerada uma diferença de $3^{\circ} \mathrm{C}$ de ganho (approach) que consiste na Temperatura da água - TBU. Portanto esta operação é viável quando a Temperatura de Bulbo úmido exterior atingir temperatura inferior a 19 ${ }^{\circ} \mathrm{C}$. A temperatura de insuflação no Data Center deverá ser de $23^{\circ} \mathrm{C}$, consideramos que a água gelada troca calor com as unidades de ventilação (fancoil) entrando a $19^{\circ} \mathrm{C} \mathrm{e}$ saindo a $23^{\circ} \mathrm{C}$. Este trabalho avaliará o modelo proposto por Carlson (2012).

Este trabalho não avaliará o resfriamento natural indireto com a utilização de rodas entálpicas, pois para esta aplicação fica restrito a cargas parciais e devido ao aumento considerável da temperatura de retorno, este passou a ser pouco utilizado. Tão pouco avaliará resfriamento por fonte externa, pois não há garantis de consegui-la e por resfriamento indireto seco, pois é claramente demonstrada a superioridade energética do resfriamento indireto com torres.

\subsubsection{Resfriamento natural direto}

A primeira estratégia seria a utilização do resfriamento natural direto, descrito na seção 2.3.1. Neste caso, é feito balanço de energia entre o ar exterior e o ar de retorno do Data Center. A Figura 4.10 ilustra o funcionamento do resfriamento natural direto. Em operações corriqueiras, o ar condicionado (azul com bolhas) do data center passa pelas unidades de ventilação (1), é insuflado a um pleno (2) e retorna a casa de máquinas por venezianas de comunicação (3). Neste caso teremos uma caixa de ventilação (4) com a filtragem necessária para a utilização de ar exterior (G4 +F5), que proverá as unidades 
de ventilação (1) uma mistura de ar de retorno do Data Center (vermelho com listra transversal) e ar exterior (verde sólido), diminuindo a carga térmica que deve ser retirada pelas unidades de ventilação.

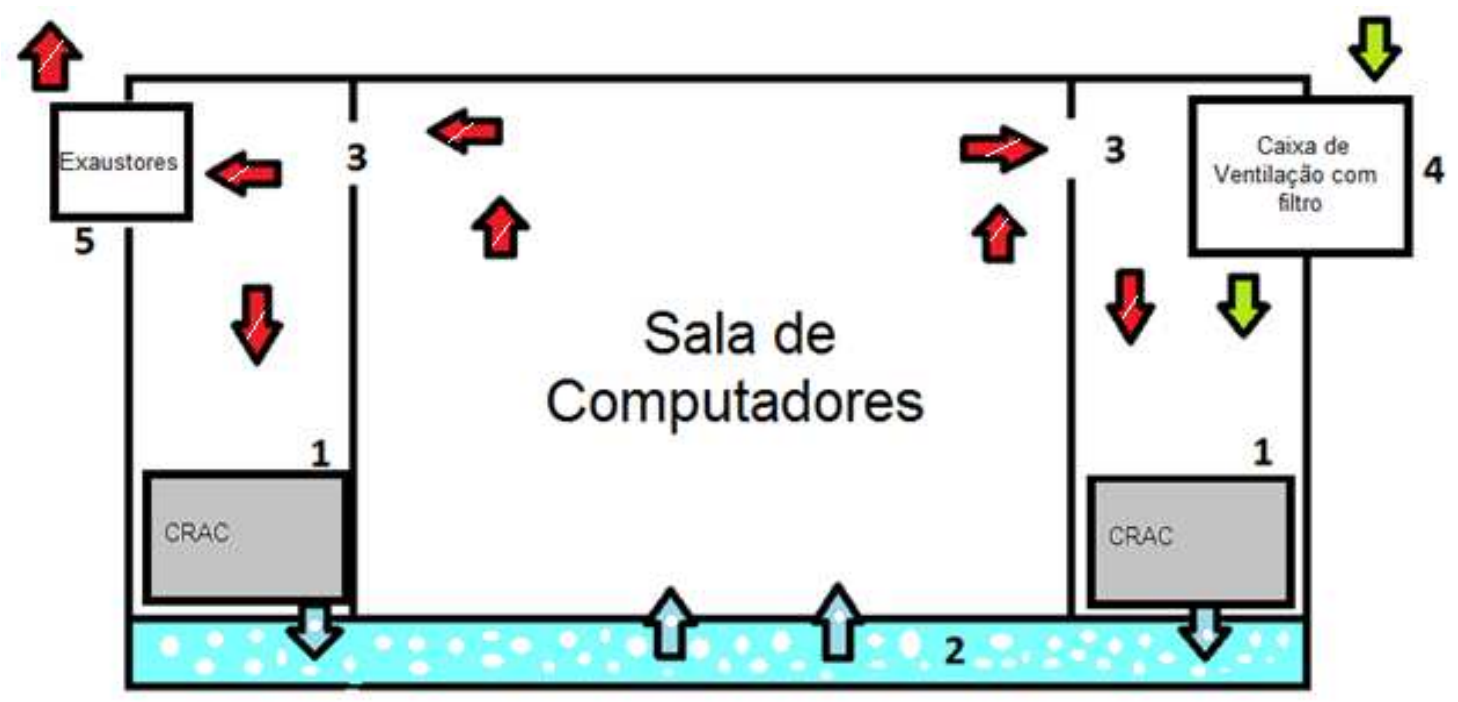

Figura 4.10 - Funcionamento de sistema de resfriamento natural proposto.

Inicialmente deverá proceder ao cálculo das propriedades psicrométricas do ar exterior, começando pela pressão atmosférica $\left(P_{a t m}\right)$ na equação 4.34 , pressão parcial de $\operatorname{vapor}^{13}\left(P_{v}\right)$ na equação 4.35 , umidade específica ${ }^{14}(\omega)$ na equação 4.36 , entalpia específica $^{15}\left(h_{e x}\right)$ na equação 4.37 e massa específica $\left(\rho_{a r}\right)$ na equação 4.38 (ASHRAE 20,17; SIMÕES-MOREIRA, 1999; BOILIGER JR. \& MARIANI, 2005):

$P_{a t m}=101,325 \cdot\left(1-\frac{2,256}{100000} \cdot A l t\right)^{5,256}$

${ }^{13}$ Pressão exercida pelo vapor d'água sobre o ar. Chama-se parcial quando não é suficiente para saturar o $\operatorname{ar}$ (Lopes et al. 2010).

${ }^{14}$ Adimensional que expressa a razão de mistura de vapor d'água e massa de ar seco em uma mistura em $\mathrm{kg}$ de vapor por $\mathrm{kg}$ de ar seco (Lopes et al. 2010).

${ }^{15}$ Energia por unidade de massa passível de ser removida por transferência de calor (Van Wylen et al. 2013). 
$P_{v}=0,61121742 \cdot T B U^{0}+0,0444268 \cdot T B U^{1}+0,0014244 \cdot T B U^{2}+0,0000270506 \cdot$ $T B U^{3}+0,0000002705 \cdot T B U^{4}+0,00000000026287 \cdot T B U^{5}+0,0000000000011 \cdot T B U^{6}$

$\omega=\frac{(2501-2,381 \cdot T B U) \cdot\left(\frac{0,622 \cdot T B U}{P_{a t m}-P_{v}}\right)-(T B S-T B U) \cdot 1,0048}{2501+1,805 \cdot T B S-4,1868 \cdot T B U}$

$h_{e x}=(1,0048+1,805 \cdot \omega) \cdot T B S+2501 \cdot \omega$

$\rho_{a r}=\left(\frac{0,287 \cdot(T B S+273)}{P_{a t m}-P_{v}}\right)^{-1}$

Com estes valores, para estimar a entalpia específica $\left(h_{\text {ins }}\right)$ e massa específica $\left(\rho_{\text {ins }}\right)$ do ar de insuflação da aplicação. Para tal deve se repetir estes cálculos (equações 4.4.2 a 4.4.5) para o ar que é insuflado, considerando TBS em $23^{\circ} \mathrm{C}$ e TBU $17,5{ }^{\circ} \mathrm{C}$ (aproximadamente $60 \%$ de umidade relativa).

A entalpia do ar de retorno é calculada considerando que o condicionamento de ar será responsável pela climatização da carga térmica $\left(\dot{C}_{T}\right)$ do ambiente calculada nas seções 4.1.1 e 4.1.2, ou seja, o volume de ar ventilado $\left(V_{\text {arfancoul }}\right.$ ) multiplicado pela massa específica de insuflação $\left(\rho_{\text {ins }}\right)$ e pela diferença das entalpias específicas de insuflação $\left(h_{\text {ins }}\right)$ e retorno $\left(h_{r}\right)$, deverá ser igual a carga térmica, conforme equação 4.39 .

$\dot{C_{T}}=V_{\text {arfc }}^{\dot{v}} \cdot \rho_{\text {ins }} \cdot\left(h_{r}-h_{\text {ins }}\right)$

Remanejando para encontrar a entalpia de retorno em 4.40:

$h_{r}=\frac{\dot{C_{T}}}{V_{\text {arfc }} \cdot \rho_{\text {ins }}}+h_{\text {ins }}$

Obtém-se a vazão insuflada através da seleção de equipamentos. A tabela 4.5 tem como referência a unidade de ventilação Liebert CRV 181, que resulta em 400 kW fabricada pela Vertiv $\mathrm{Co}^{\oplus}$, onde a cada $400 \mathrm{~kW}$ de carga eu preciso de mais uma unidade de ventilação ativa. A seleção é feita através do valor de $\dot{C}_{T}$. A correlação resulta no valor da vazão volumétrica $\left(V_{a r f c}^{\cdot}\right)$. 
Tabela 4.5 - Correlação entre carga térmica e vazão volumétrica de unidades de ventilação (Vertiv Co, 2016).

\begin{tabular}{rrr|} 
Carga Necessarıa & $\begin{array}{r}\text { Quantıdade de } \\
\text { FC de } \mathbf{4 0 0} \mathbf{~ k W}\end{array}$ & \multicolumn{2}{c|}{ Vazao $(\mathbf{m} / \mathbf{s})$} \\
\hline $\mathbf{4 0 0}$ & 1 & 25,91 \\
$\mathbf{8 0 0}$ & 2 & 51,82 \\
$\mathbf{1 2 0 0}$ & 3 & 77,73 \\
$\mathbf{1 6 0 0}$ & 4 & 103,65 \\
$\mathbf{2 0 0 0}$ & 5 & 129,56 \\
$\mathbf{2 4 0 0}$ & 6 & 155,47 \\
$\mathbf{2 8 0 0}$ & 7 & 181,39 \\
$\mathbf{3 2 0 0}$ & 8 & 207,30 \\
$\mathbf{3 6 0 0}$ & 9 & 233,21 \\
$\mathbf{4 0 0 0}$ & 10 & 259,13 \\
$\mathbf{4 4 0 0}$ & 11 & 285,04 \\
$\mathbf{4 8 0 0}$ & 12 & 310,95 \\
$\mathbf{5 2 0 0}$ & 13 & 336,87 \\
$\mathbf{5 6 0 0}$ & 14 & 362,78 \\
$\mathbf{6 0 0 0}$ & 15 & 388,69 \\
\hline
\end{tabular}

Caso a entalpia do retorno resultante for maior que a entalpia do ar exterior, justifica-se então o resfriamento natural direto. O resfriamento natural funcionará com a provisão de ar externo em parte do Data Center, sendo descartado parte do ar de retorno ao ambiente. Todavia, a vazão de ar exterior está limitada ao espaço necessário para a instalação da vazão de caixas de ventilação providas de filtro. Tomando como base o equipamento WL 40 fabricado pela Trane ${ }^{\odot}$, com vazão máxima de $40.000 \mathrm{~m}^{3} / \mathrm{h}$, que necessita de 5 metros de largura para sua instalação, com limitante de 25 de comprimento disponível na instalação de referência, as caixas de ventilação estão limitadas a 5 unidades, sendo as 5 alocadas em um corredor técnico e no outro lado exaustores. $O$ consumo das caixas de ventilação deverá ser adicionado ao consumo total, ressaltando que os valores apresentados para potência na Tabela 4.6 serão dobrados devido a provisão de ar exterior e exaustão de ar para o meio. 
Tabela 4.5 - Correlação entre quantidade de FC e caixas de ventilação (TRANE, 2013).

Quantidade de

Unidade de

Ventilação

\begin{tabular}{rllll|}
\hline $\mathbf{1}$ & 2 & 2 & 22,22 & 140 \\
$\mathbf{2}$ & 4 & 4 & 44,44 & 280 \\
$\mathbf{3}$ ou mais & 5 & 5 & 55,55 & 350
\end{tabular}

Em conclusão, a taxa de calor rejeitada por resfriamento natural direto $\left(Q_{f c d}\right)$ será a vazão mássica de ar exterior $\left(m_{a e}\right)$ multiplicada pela diferença entálpica $\left(h_{r}-h_{e x}\right)$ entre ar exterior e de retorno, conforme equação 4.41 .

$\dot{Q_{f c d}}=m_{a e} *\left(h_{r}-h_{e x}\right)$

A carga residual $\left(C_{T R D}^{\cdot}\right)$ necessária para o funcionamento da unidade de resfriamento deverá ser realizada pela diferença entre a carga térmica do ambiente $\left(\dot{C}_{T}\right)$ e a taxa de calor rejeitada pelo resfriamento natural direto $\left(Q_{f c d}^{\cdot}\right)$, como em equação 4.42 .

$C_{T R D}^{\cdot}=\dot{C_{T}}-\dot{Q_{f c d}}$

A Figura 4.11 ilustra o método de cálculo para resfriamento natural direto, a partir dos dados climáticos exteriores (retângulos amarelos) até o balanço de energia residual (elipse rosa). 


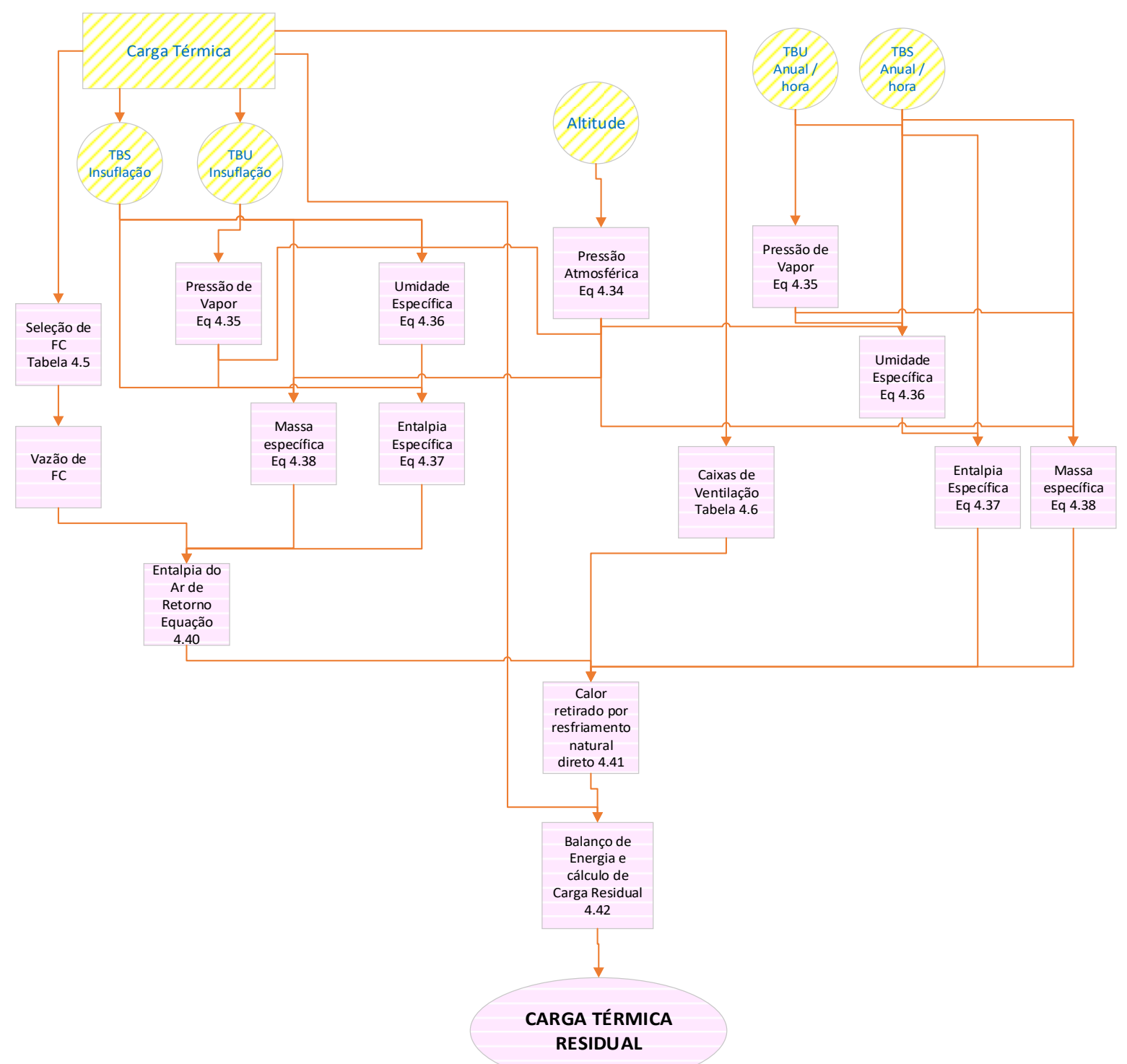

Figura 4.11 - Metodologia de cálculo de resfriamento natural direto.

\subsubsection{Resfriamento Natural Indireto por torres de resfriamento}

Uma outra possibilidade viável de utilização de resfriamento natural indireto é o resfriamento natural indireto por fonte não condicionada (water side free cooling). Como não é possível prever a utilização de um grande reservatório de água fria, e o sistema com torres é indicado para sistemas com condensação a água, a água proveniente das torres de resfriamento quando suficientemente fria será utilizada para troca direta com as unidades de ventilação, retirando parte do calor que seria necessário para a utilização da 
unidade de resfriamento de líquido. Deverão ser utilizados trocadores de calor para arrefecer a água que retorna das unidades de ventilação, após o condicionamento de ar.

Em dias quentes onde a temperatura de saída de água da torre (1), é maior que a temperatura de água que saí das unidades de ventilação (3). Não é possível a utilização deste tipo de condicionamento, e o processo de resfriamento convencional deverá seguir a sequência 1-A-B-2-D-1 para a unidade de resfriamento e 2-E-3-F-G-2 para a unidade de ventilação, conforme figura 4.12. Todavia quando a torre garantir uma temperatura $T_{f E T R O C}$ menor que o retorno das unidades ventilação $T_{Q S T R O C}$, o processo de resfriamento natural torna-se possível. A água saí da torre (1) e entra no trocador contra correntes (4) a temperatura $T_{f E T R O C}$, do lado oposto a água saí da unidade de ventilação (3) em F desvia seu curso para o trocador 4 e entra com temperatura $T_{Q e T R O C}$. Após troca térmica a água que perdeu calor saí do trocador (4) e fluí até G com temperatura $T_{Q S T R O C}$, onde se ainda não atingiu a temperatura de trabalho $T_{S_{U R}}$ é resfriada na UR (2), caso tenha chegado a temperatura de trabalho fluí diretamente ao ponto E e a UR (2) é desligada. Caso a UR (2) seja desligada a água do lado condensado saí com temperatura $T_{f S \text { TROC }}$ e fluí até o ponto $\mathrm{C}$, onde vai diretamente a $\mathrm{D}$ e retorna a torre 1 . Caso não tenha sido desligada, fluirá de 4 para 2 e de 2 para 1 .

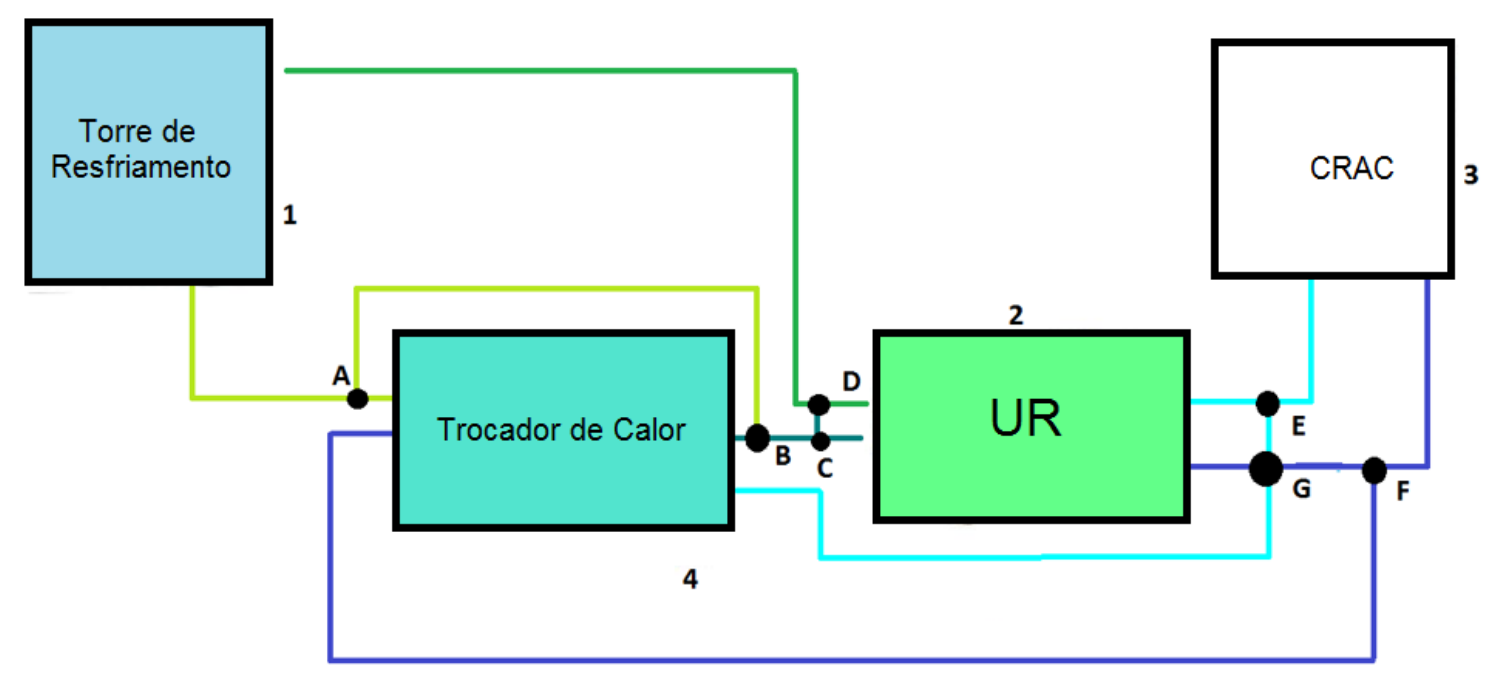

Figura 4.12 - Esquema de funcionamento de resfriamento natural indireto por torres de condensação. 
Para a realização destes cálculos, é inicialmente calculada a quantidade de água necessária para a resfriamento $\left(\dot{m}_{U R}\right)$ com a carga térmica $\left(\dot{C}_{T}\right)$ presente pelo diferencial de temperaturas de entrada $\left(T_{E_{U R}}\right)$ e saída $\left(T_{S_{U R}}\right)$ da UR, como mostrada na equação 4.43 .

$\dot{m}_{U R}=\frac{\dot{C_{T}}}{\left(T_{E_{U R}}-T_{S_{U R}}\right)^{\cdot} c_{H_{2} O} \mathrm{O}}$

As temperaturas de entrada e saída da UR variam de acordo com a aplicação:

- Para lojas de departamento, utilizará o padrão de entrada de água a $12,5^{\circ} \mathrm{e} \mathrm{C}$ e saída à $7^{\circ} \mathrm{C}$.

- Para Data Centers, devido às alterações propostas pela ASHRAE TC 9.9. Se convencionará a entrada a $24,5^{\circ} \mathrm{C}$ e saída à $19^{\circ} \mathrm{C}$.

Sabe-se que a torre de resfriamento é responsável pelo transporte da carga térmica ao meio, que neste processo será a carga térmica (ou o residual, caso tenha ocorrido resfriamento natural direto) mais o trabalho gerado pela UR, mostrado na equação 4.44:

$\dot{Q}_{\text {torre }}=C_{T}+W_{U R}$

No entanto, que o trabalho da UR é função direta da carga térmica, que será abordado nas seções 4.5 e 4.6 .

Para o cálculo da água necessária na utilização do arrefecimento ( $\left.\dot{m}_{\text {torre }}\right)$ é necessário fazer analogia semelhante a 4.43 , utilizando as temperaturas: $T_{f E \text { TROC }}$ para a saída da torre e $T_{f S T R O C}$ para a entrada na torre. Todavia, a temperatura de saída da torre de resfriamento será a temperatura de bulbo úmido (TBU) adicionada da temperatura de approach $\left(T_{a p p}\right)$ do equipamento selecionado (TORRE CARAVELA, 2014), conforme equações 4.45 e 4.46 .

$$
\begin{aligned}
& T_{f E T R O C}=T B U+T_{\text {app }} \\
& \dot{m}_{\text {torre }}=\frac{\dot{Q}_{\text {torre }}}{\left[T_{\text {fSTROC }}-\left(T B U+T_{\text {approaach }}\right)\right] \cdot c_{H_{2} O}}
\end{aligned}
$$


Substituindo 4.44 em 4.46

$\dot{m}_{\text {torre }}=\frac{C_{T}+W_{U R}}{\left[T_{f S T R O C^{-}}\left(T B U+T_{\text {app }}\right)\right]^{\cdot} C_{\mathrm{H}_{2} \mathrm{O}}}$

Entretanto, os trocadores de calor possuem limitação física, sendo a limitação deste processo. O valor de taxa de calor rejeitada por resfriamento natural indireto, não poderá ser superior a capacidade de troca de calor de um equipamento especificado para tal. A carga máxima retirada por este, pode ser estimada através da equação dos trocadores de calor com escoamento contracorrente, segundo (INCROPERA et al., 2014), considerando o fluído quente proveniente das unidades de ventilação e o fluído frio proveniente da torre, apresentado na equação 4.48 .

Um fator que será adotado, é o valor representativo para coeficiente global de transferência de calor para trocadores de água contracorrente $\left(U_{T r o c}\right)$, devido a pouco conhecimento de condições de contorno para cada instalação e localização em cada caso específico (ex: local de instalação sob área ventilada). Este valor conforme será de $1275 \mathrm{~W} / \mathrm{m}^{2} \mathrm{~K}$ (INCROPERA et al., 2014).

Outro fator a ser adotado é a área de troca $\left(A_{\text {troc }}\right)$, onde será tomado por referência valores apresentados pelo fabricante na Tabela 4.7 (ALFA LAVAL, 2017a).

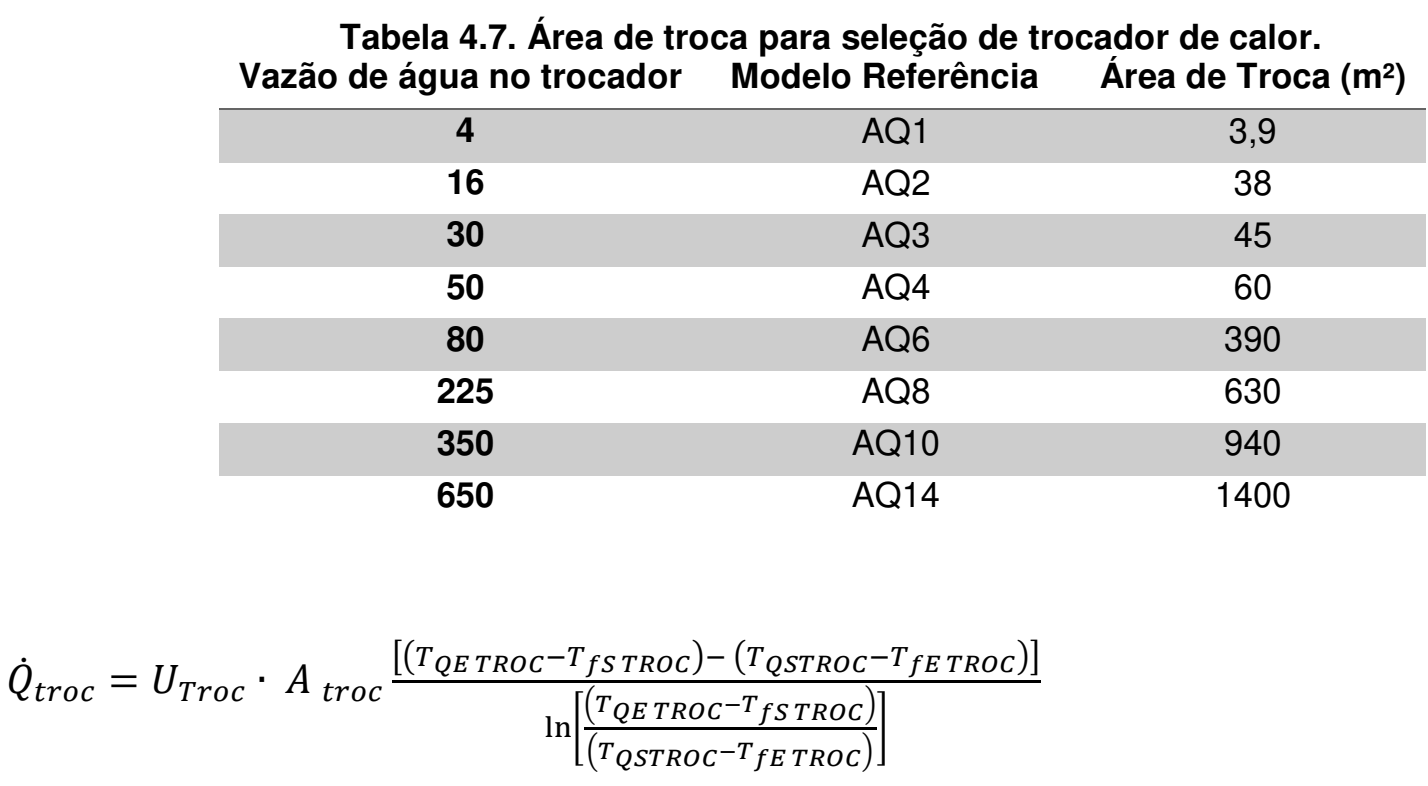


Como neste caso a Temperatura do fluído quente que entra no trocador deverá ser igual a temperatura que sai das unidades de ventilação, ou seja, seria a temperatura que entraria na UR no caso de sistema sem resfriamento natural, apresentado em 4.49.

$T_{Q E T R O C}=T_{E_{U R}}$

Reescrevendo em 4.50:

$\dot{Q}_{\text {troc }}=U_{\text {Troc }} \cdot A_{\text {troc }} \cdot \frac{\left[\left(T_{E U R}-T_{f S T R O C}\right)-\left(T_{Q S T R O C}-\left(T B U+T_{a p p}\right)\right]\right.}{\ln \left[\frac{\left(T_{E U R}-T_{f S T R O C}\right)}{\left(T_{Q S T R O C}-\left(T B U+T_{a p p}\right)\right.}\right]}$

Neste caso, existem 3 incógnitas: A taxa de transmissão de calor $\left(\dot{Q}_{\text {troc }}\right)$, a temperatura do fluído frio que vem da torre e saí do trocador $\left(T_{f S T R O C}\right)$ e a temperatura do fluído que inicialmente quente do trocador para ser posteriormente resfriada nas URs ( $\left.T_{\text {QSTROC }}\right)$.

Sabe-se também que a taxa de transmissão de calor do trocador será a mesma dos fluídos, simplificando em 4.51 e em 4.52:

$\dot{Q}_{\text {troc }}=\dot{m}_{U R} \cdot c_{\text {água }} \cdot\left(T_{E_{U R}}-T_{Q S T R O C}\right)$

$\dot{Q}_{\text {troc }}=\dot{m}_{\text {torre }} \cdot c_{\text {água }} \cdot\left[T_{f S T R O C}-\left(T B U+T_{\text {app }}\right)\right]$

Portanto as equações $4.50,4.51,4.52$, formam um sistema de 3 equações e 3 incógnitas.

Rearranjando as equações 4.51 e 4.52 , chega-se a relação 4.53 :

$T_{Q S T R O C}=T_{E_{U R}}-\frac{\dot{m}_{\text {torre }}}{\dot{m}_{U R}} \cdot\left[T_{f S T R O C}-\left(T B U+T_{a p p}\right)\right]$

Todavia, para resolver a equação 4.50 é necessário recorrer a métodos numéricos iterativos. Para tal será necessário um chute inicial nos valores de temperatura. O critério utilizado nesta tese é apresentado em 4.54 .

$T_{f S T R O C}=T_{Q S T R O C}+0,1$ 
Considera-se para convergência a relação apresentada em 4.55:

$\dot{m}_{U R} \cdot c_{\text {água }} \cdot\left(T_{E_{U R}}-T_{f S T R O C}\right)-\dot{m}_{\text {torre }} \cdot c_{\text {água }} \cdot\left[T_{Q S T R O C}-\left(T B U+T_{\text {app }}\right)\right] \leq 0,1$

A taxa de transmissão de calor do trocador $\left(\dot{Q}_{t r o c}\right)$ será a taxa de taxa de calor rejeitada pelo resfriamento natural indireto $\left(\dot{Q}_{R I}\right)$, apresentado em 4.56.

$\dot{Q}_{\text {troc }}=\dot{Q}_{R I}$

Devido a dias do ano de baixas de temperaturas o valor de troca do trocador poderá ser maior que a carga térmica. Caso ocorra, considera-se a carga térmica totalmente atendida e a carga térmica igual a carga do trocador.

Caso Necessário, a carga térmica residual $\left(C \dot{T}_{U R}\right)$ a ser resfriada pela unidade de resfriamento de líquido será o saldo entre a carga térmica $\left(\dot{C}_{T}\right)$ calculada e a taxa de transmissão de calor por resfriamento natural indireto $\left(\dot{Q}_{R I}\right)$, como apresentado em 4.57.

$C \dot{T}_{U R}=\dot{C}_{T}-\dot{Q}_{R I}$

A Figura 4.13, ilustra o método apresentado, desde a carga térmica (retângulo amarelo) e parâmetros da torre de resfriamento (círculo amarelo) até a carga térmica residual (elipse rosa): 


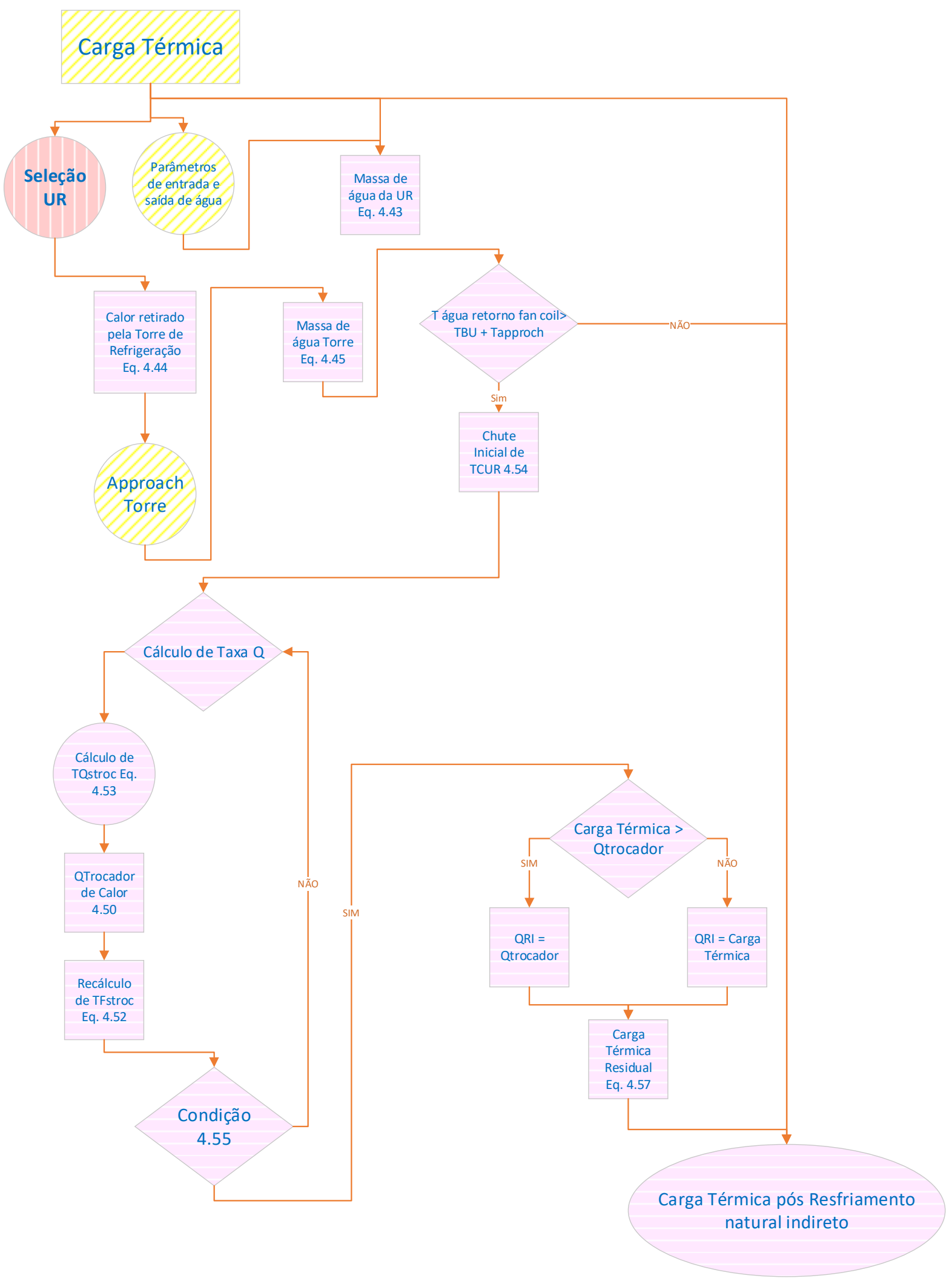

Figura 4.13 - Metodologia de cálculo de resfriamento natural indireto. 


\subsection{Seleção e Consumo da Unidade de Resfriamento}

O primeiro passo desta etapa é a definição da unidade de resfriamento de líquido a ser utilizada. A UR selecionada será a de capacidade nominal imediatamente superior a carga térmica. Com a seleção do condicionado de ar, é possível obter suar curva característica de carga por consumo de acordo com dados fornecidos por fabricantes (TRANE, 2017; CARRIER, 2014). Para esta etapa, os fabricantes forneceram os dados de consumo em cargas parciais e cargas totais de suas unidades de resfriamento de líquido com compressores do tipo parafuso e centrifuga acionadas eletricamente, e através de interpolação polinomial pode-se levantar a curva característica deste tipo de equipamento, onde verificou-se ser um polinômio de terceira ordem.

A equação 4.58 exprime o polinômio característico, e os coeficientes $A, B, C$ e D variam de acordo com a capacidade da UR, onde o valor de y representa o consumo horário e o valor de $C_{T}$, a carga térmica aplicada na unidade de resfriamento. Estes coeficientes são apresentados na Tabela 4.8.

$$
y=A \cdot C_{T}^{3}+B \cdot C_{T}^{2}+C \cdot C_{T}+D
$$

Tabela 4.8 - coeficientes polinomiais de acordo com a capacidade de cada unidade de resfriamento de líquido.

\begin{tabular}{|c|c|c|c|c|c|}
\hline \multicolumn{6}{|c|}{ Equipamentos Parafuso a Água } \\
\hline \multicolumn{2}{|c|}{ Capacidade de Equipamento (TR) } & \multicolumn{4}{|c|}{ Coeficientes } \\
\hline & & A & B & C & D \\
\hline 0 & 80 & $-0,000008$ & 0,0052 & $-0,7875$ & $50,64 c$ \\
\hline 81 & 140 & $-0,000003$ & 0,003 & $-0,7875$ & 88,636 \\
\hline 141 & 180 & $-0,000002$ & 0,0023 & $-0,7875$ & 113,96 \\
\hline 221 & 260 & $-8,00 \mathrm{E}-07$ & 0,0016 & $-0,7875$ & 164,61 \\
\hline 261 & 340 & $-5,00 \mathrm{E}-07$ & 0,0012 & $-0,7875$ & $215,2 \epsilon$ \\
\hline 341 & 420 & $-3,00 E-07$ & 0,001 & $-0,7875$ & 265,91 \\
\hline 421 & 500 & $-2,00 \mathrm{E}-07$ & 0,0008 & $-0,7875$ & 316,56 \\
\hline
\end{tabular}

A partir da seleção da unidade de resfriamento e sua respectiva curva é calculado seu consumo base, que servirá comparativo a todas as formas de utilização de resfriamento natural, através da integração temporal para o período de análise desejado (t), como na equação 4.59 . 
$E_{\text {Base }}=\int_{0}^{t} y\left(\dot{C}_{T}\right) d t$

Para a utilização de cada método de economia de energia/ compensação, algumas regras deverão ser observadas. No caso de utilização de resfriamento natural direto, a subtração de sua contribuição $\left(Q_{f c d}^{*}\right)$ é diretamente na carga térmica, caso nulo, a carga térmica permanece inalterada. Para cálculo de residual procede-se a equação 4.60.

$C_{T R D}^{\cdot}=\dot{C}_{T}-Q_{f c d}$

O consumo $\left(E_{R D}\right)$ será dado pela inserção do resfriamento natural no polinômio 4.59, selecionado com a unidade de resfriamento característica, conforme 4.61.

$E_{R D}=\int_{0}^{t} y\left(C_{T R D}^{\cdot}\right) d t+\int_{0}^{t} \dot{W}_{\text {vent } f c d} d t$

A economia de energia $\left(S_{R D}\right)$ pelo resfriamento natural direto será dada por 4.62:

$S_{R D}=E_{\text {Base }}-E_{R D}$

O próximo método de economia de energia a aplicar-se, é o resfriamento natural indireto, o qual atua após a água sair das unidades de ventilação, onde apresenta-se em 4.63.

$C T_{U R}=C_{T}-\dot{Q}_{R I}$

O consumo é dado pela equação 4.64:

$E_{R I}=\int_{0}^{t} y\left(C \dot{T}_{U R}\right) d t$

A economia de energia pelo resfriamento natural indireto será dada por 4.65:

$S_{R I}=E_{\text {Base }}-E_{R I}$

Após os economizadores, são contabilizadas as contribuições referente aos métodos de resfriamentos solares complementares. O primeiro que deve ser inserido é o resfriador térmico por absorção solar. 
A contribuição do gerador solar por absorção $\left(q_{\text {disp }}\right)$ se dará diretamente na carga térmica a ser resfriada pela UR $\left(\dot{C_{T}}\right)$, portanto neste caso a UR trabalhará para refrigerar a carga complementar do equipamento de absorção $\left(\dot{C}_{C A S}\right)$, conforme segue em 4.66 :

$\dot{C}_{C A S}=\dot{C}_{T}-q_{d i s p}$

O consumo, se só houver contribuição por condicionamento solar, é apresentado por meio da equação 4.67.

$E_{A S}=\int_{0}^{t} y\left(\dot{C}_{C A S}\right) d t$

A economia de energia pelo resfriamento solar por absorção $\left(S_{S A}\right)$ será dada por 4.68.

$S_{A S}=E_{\text {Base }}-E_{A S}$

Pode-se também ocorrer um efeito combinado com contribuições de resfriamento natural direto $\left(Q_{f c d}\right)$ e indireto $\left(\dot{Q}_{R I}\right)$ e absorção solar $\left(q_{d i s p}\right)$ na carga térmica $\left(\dot{C}_{T}\right)$, resultando em uma nova carga $(\dot{C})$, como apresentado em 4.69 .

$\dot{C}=\dot{C}_{T}-Q_{f c d}-\dot{Q}_{R I}-q_{d i s p}$

Neste caso o valor da Carga Térmica não pode ser negativo, sendo no mínimo 0.

O último método a ser inserido é a descarga de baterias do sistema fotovoltaico. Neste caso, não haverá efeito sobre a carga térmica e a energia fotovoltaica será descarregada ao sistema em horários preferenciais. O consumo de energia será dado pela equação 4.70 .

$E_{P V}=\int_{0}^{t} y\left(\dot{C}_{T}\right) d t-\int_{0}^{t} W_{d l s p}^{\cdot} d t$

A economia é o valor descarrega pelas baterias, apresentado em 4.71 .

$S_{P V}=\int_{0}^{t} W_{d l s p}^{\cdot} d t$ 
Pode-se ter também um efeito combinado de economizadores e sistemas solares atuarem conjuntamente, exceto solar fotovoltaico e absorção solar por concorrência em área de cobertura. Neste Caso, o consumo será dado por 4.72 .

$E_{\text {Sistema }}=\int_{0}^{t} y(\dot{C}) d t-\int_{0}^{t} W_{d l s p}^{\cdot} d t+\int_{0}^{t} \dot{W}_{\text {vent } f c d} d t$

E a economia será dada por 4.73:

$S_{\text {Sist }}=E_{\text {Base }}-E_{\text {Sist }}$

A Figura 4.14 ilustra esta metodologia passo a passo. Nota-se que a partir da carga térmica básica da edificação, calculada a partir dos dados de entrada na seção 4.1 parte-se para o selecionamento da unidade de resfriamento para o caso base conforme discutido nesta seção. Com este selecionamento obtêm-se o polinômio característico, e o consumo base, quando há a possibilidade de redução da carga térmica através dos métodos de resfriamento natural direto prioritariamente e posteriormente de resfriamento natural indiretos, estes são compensados através de balanços de energia (losangos em rosa), e a carga térmica é inserida no polinômio característico. No caso de utilização posterior de absorção solar (losango verde), a carga proveniente dos acumuladores de água gelada é compensada após o resfriamento natural e seu consumo obtido com a inserção da carga residual no polinômio característico. No caso de utilização posterior de energia fotovoltaica (losango verde), esta é diretamente debitada do valor residual calculado até então com a inserção das demais contribuições. A elipse vermelha exprime o valor do consumo de energia após as contribuições dos métodos de resfriamento natural e solar. 


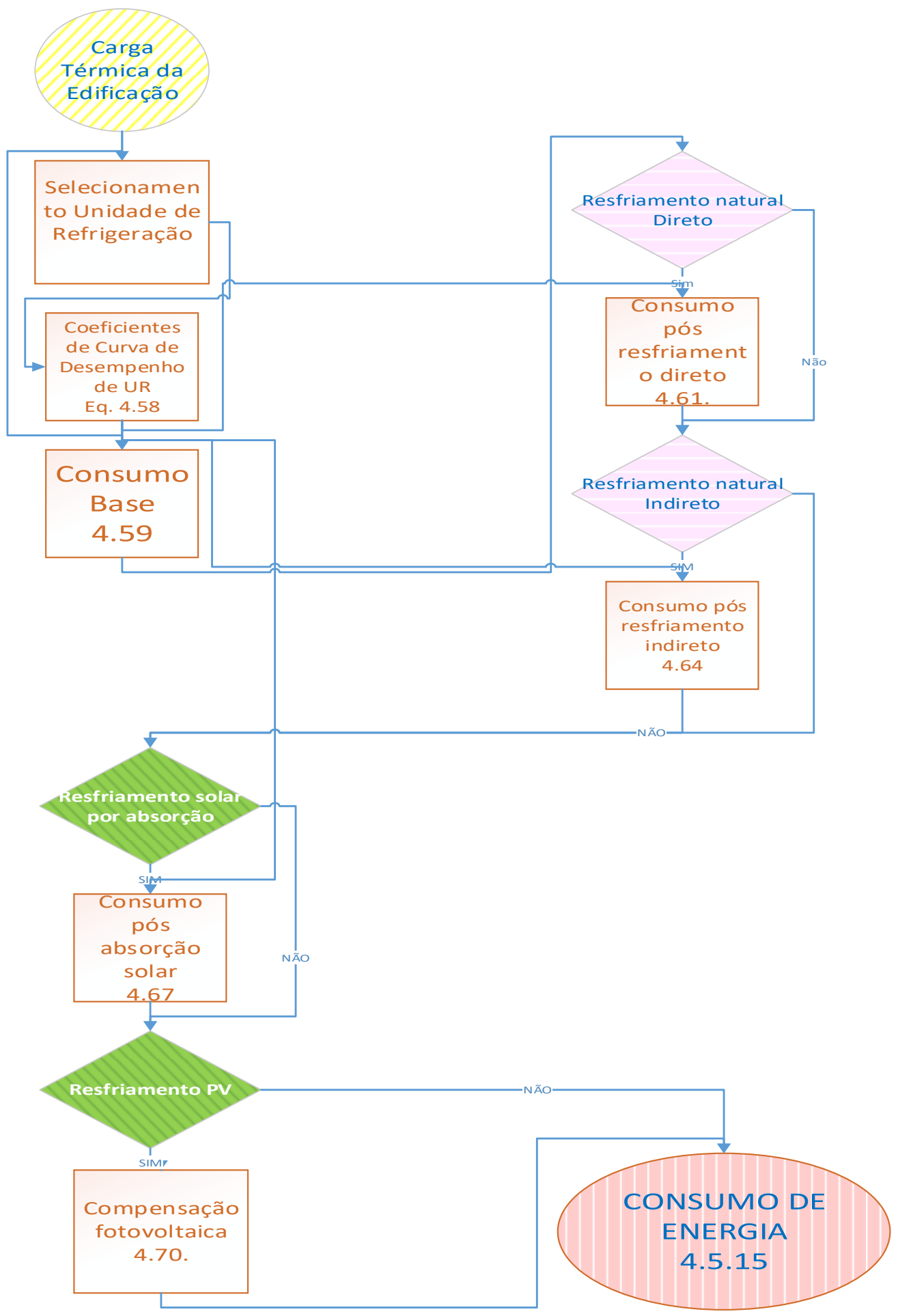

Figura 4.14 - Metodologia utilizada para cálculo de consumo elétrico dos sistemas. 


\subsection{Análise de Investimento e Retorno}

Esta seção apresenta técnicas de análise de investimentos utilizadas nesta tese. Os projetos de energia geralmente envolvem grandes montantes de capital e são de longa maturação tecnológica, ou seja demoram um grande tempo para se auferir retorno financeiro (PARENTE, 2017). Nesta seção serão avaliados os custos tarifários e custos de aquisição de componentes.

Os sistemas analisados serão:

- Resfriamento Natural Direto

- Resfriamento Natural Indireto

- Resfriamento Natural Direto + Indireto

- Resfriamento Solar por Absorção

- Resfriamento Solar por Absorção + Resfriamento Natural Direto

- Resfriamento Solar por Absorção + Resfriamento Natural Indireto

- Resfriamento Solar por Absorção + Resfriamento Natural Direto + Indireto

- Resfriamento Solar Fotovoltaico

- Resfriamento Solar Fotovoltaico + Resfriamento Natural Direto

- Resfriamento Solar Fotovoltaico + Resfriamento Natural Indireto

- Resfriamento Solar Fotovoltaico + Resfriamento Natural Direto + Indireto

$\mathrm{Na}$ primeira etapa é feito uma estimativa de conta de energia anual para o sistema base ( $\left.C O N_{\text {Base }}\right)$ em 4.74 e os diversos sistemas analisados $\left(C O N_{\text {Sist }}\right)$ em 4.75, e os resultados expressos em unidades monetárias:

$\operatorname{CON}_{\text {Base }}=\sum_{\text {ponta }} E_{\text {Base } 1 \text { ano ponta }} \cdot t_{\text {ponta }}+\sum_{\text {fora de ponta }} E_{\text {Base } 1 \text { ano fora de ponta }} \cdot$

$t_{\text {fora de ponta }}$

$\operatorname{CON}_{\text {Sist }}=\sum_{\text {ponta }} E_{\text {Sist } 1 \text { ano ponta }} \cdot t_{\text {ponta }}+\sum_{\text {fora de ponta }} E_{\text {Sist } 1 \text { ano fora de ponta }} \cdot$

$t_{\text {fora de ponta }}$ 
Tabela 4.9. Nomenclatura de índices de consumo.

\begin{tabular}{lc}
\hline Caso & Consumo $(\mathbf{C O N})$ \\
\hline Base & $C O N_{B a s e}$ \\
\hline Resfriamento Natural Direto & $C O N_{R D}$ \\
\hline Resfriamento Natural Indireto & $C O N_{R I}$ \\
\hline Resfriamento Natural Direto + Indireto & $C O N_{R D+R I}$ \\
\hline Resfriamento Solar por Absorção & $C_{A S}$ \\
\hline $\begin{array}{l}\text { Resfriamento Solar por Absorção + Resfriamento Natural } \\
\text { Direto }\end{array}$ & $C O N_{A S+R I}$ \\
\hline $\begin{array}{l}\text { Resfriamento Solar por Absorção + Resfriamento Natural } \\
\text { indireto }\end{array}$ & $C O N_{A S+R D+R I}$ \\
\hline $\begin{array}{l}\text { Resfriamento Solar por Absorção + Resfriamento Natural } \\
\text { Direto + Indireto }\end{array}$ & $C O N_{P V}$ \\
\hline Resfriamento Solar Fotovoltaico & $C O N_{P V+R D}$ \\
\hline $\begin{array}{l}\text { Resfriamento Solar Fotovoltaico + Resfriamento Natural } \\
\text { Direto }\end{array}$ & $C O N_{P V+R I}$ \\
\hline $\begin{array}{l}\text { Resfriamento Solar Fotovoltaico + Resfriamento Natural } \\
\text { indireto }\end{array}$ & $C^{2}$ \\
\hline $\begin{array}{l}\text { Resfriamento Solar Fotovoltaico + Resfriamento Natural } \\
\text { Direto + Indireto }\end{array}$ & \\
\hline
\end{tabular}

A economia de energia anual será a diferença entre o caso base e o sistema desejado na equação 4.76 .

$$
E A E_{\text {Energia }}=C O N_{\text {Base }}-\operatorname{CON}_{\text {Energia }}
$$

Os cenários apresentados foram analisados com variações de tarifa entre $R \$$ 0,30/ kWh, supondo que o consumidor conseguiu algumas vantagens junto a concessionária e $\mathrm{R} \$ 1,10$ / kWh, valor próximo a tarifa mais cara praticada no Brasil. 
Tabela 4.10. Nomenclatura de índices de economia.

Caso

Base

Resfriamento Natural Direto

Resfriamento Natural Indireto

Resfriamento Natural Direto +

Indireto

Resfriamento Solar por Absorção

Resfriamento Solar por Absorção +

Resfriamento Natural Direto

Resfriamento Solar por Absorção +

Resfriamento Natural indireto

Resfriamento Solar por Absorção +

Resfriamento Natural Direto +

Indireto

Resfriamento Solar Fotovoltaico

Resfriamento Solar Fotovoltaico +

Resfriamento Natural Direto

Resfriamento Solar Fotovoltaico +

Resfriamento Natural indireto

Resfriamento Solar Fotovoltaico +

Resfriamento Natural Direto +

Indireto

$\boldsymbol{E A E}$

Equação

\begin{tabular}{|c|c|}
\hline$E A E_{R D}$ & $C O N_{\text {Base }}-C O N_{R D}$ \\
\hline$E A E_{R I}$ & $\mathrm{CON}_{\text {Base }}-\mathrm{CON}_{R I}$ \\
\hline$E A E_{R D+R I}$ & $\operatorname{CON}_{\text {Base }}-\operatorname{CON}_{R D+R I}$ \\
\hline$E A E_{A S}$ & $C O N_{\text {Base }}-C_{A S}$ \\
\hline$E A E_{A S+R D}$ & $C O N_{\text {Base }}-C O N_{A S+R D}$ \\
\hline$E A E_{A S+R I}$ & $\operatorname{CON}_{\text {Base }}-C O N_{A S+R I}$ \\
\hline$E A E_{A S+R D+R I}$ & $\operatorname{CON}_{\text {Base }}-\operatorname{CON}_{A S+R D+R I}$ \\
\hline$E A E_{P V}$ & $\mathrm{CON}_{\text {Base }}-\mathrm{CON}_{P V}$ \\
\hline$E A E_{P V+R D}$ & $C O N_{\text {Base }}-C O N_{P V+R D}$ \\
\hline$E A E_{P V+R I}$ & $\operatorname{CON}_{\text {Base }}-\operatorname{CON}_{P V+R I}$ \\
\hline$E A E_{P V+R D+R I}$ & $\operatorname{CON}_{\text {Base }}-C_{C O N_{P V+R D+R I}}$ \\
\hline
\end{tabular}

\subsubsection{Custo de Aquisição de Componentes e Instalação}

Para os cálculos de investimento, foram levantando os custos de base com fornecedores e fabricantes de cada tecnologia. Os custos de aquisição variaram de acordo com a tecnologia selecionada. A Tabela 4.11 indica os preços da unidade de resfriamento de líquido base com compressores do tipo parafuso (TRANE. 2017).

Tabela 4.11. Preço base de unidades de resfriamento de líquido do tipo parafuso

\begin{tabular}{ll} 
Capacidade & Preço mar/ 2017(R\$) \\
\hline $\mathbf{8 0}$ & $176.000,00$ \\
$\mathbf{1 4 0}$ & $287.000,00$ \\
$\mathbf{1 8 0}$ & $346.140,00$ \\
$\mathbf{2 6 0}$ & $436.800,00$ \\
$\mathbf{3 4 0}$ & $516.800,00$ \\
$\mathbf{4 2 0}$ & $583.939,56$ \\
$\mathbf{5 0 0}$ & $601.440,00$ \\
\hline
\end{tabular}


O valor de mercado para a instalação é de $R \$ 10.000 / T R$ (SERVSET, 2017). Para caixas de ventilação os orçamentos são apresentados na Tabela 4.12 (TRANE, 2017).

$\begin{aligned} & \text { Tabela 4.12. Preço base de caixas de ventilação e } \\
& \text { módulos de filtros }\end{aligned}$
\begin{tabular}{ll} 
Caixa de Ventilação & Preço Mar 2017 (R\$) \\
\hline Modulo de Ventilação & $\mathrm{R} \$ 20.000$ \\
\hline Módulo de Filtros & $\mathrm{R} \$ 10.000,00$
\end{tabular}

Cada sistema é composto por 2 módulos (entrada e saída) mais 1 filtro (entrada).

Para sistemas de resfriamento natural indireto os orçamentos base são apresentados na Tabela 4.13 (ALFA LAVAL, 2017b).

Tabela 4.13. Preço base de trocadores de calor

\begin{tabular}{lrlr}
\hline $\begin{array}{l}\text { Vazão de água } \\
\text { trocador }\left(\mathbf{m}^{3} / \mathbf{h}\right)\end{array}$ & no & $\begin{array}{l}\text { Modelo } \\
\text { Referência }\end{array}$ & Preço Mar 2017 (R\$) \\
\hline & $\mathbf{4}$ & AQ1 & $\mathrm{R} \$ 10.000,00$ \\
\hline & $\mathbf{1 6}$ & $\mathrm{AQ} 2$ & $\mathrm{R} \$ 20.000,00$ \\
\hline $\mathbf{3 0}$ & $\mathrm{AQ} 3$ & $\mathrm{R} \$ 30.000,00$ \\
\hline $\mathbf{5 0}$ & $\mathrm{AQ} 4$ & $\mathrm{R} \$ 40.000,00$ \\
\hline $\mathbf{8 0}$ & $\mathrm{AQ} 6$ & $\mathrm{R} \$ 60.000,00$ \\
\hline $\mathbf{2 2 5}$ & $\mathrm{AQ8}$ & $\mathrm{R} \$ 80.000,00$ \\
\hline $\mathbf{3 5 0}$ & $\mathrm{AQ} 10$ & $\mathrm{R} \$ 100.000,00$ \\
\hline $\mathbf{6 5 0}$ & $\mathrm{AQ14}$ & $\mathrm{R} \$ 140.000,00$ \\
\hline
\end{tabular}

Para sistemas de resfriamento solar por absorção os orçamentos base de equipamentos e serviços são apresentados na Tabela 4.14 (LGE, 2017; UNION RHAC, 2017).

Tabela 4.14. Preço base de equipamentos e serviços para absorção solar março 2017. Capacidade (TR) Modelo UR LG Valor estimado de Valor instalação (R\$) compra (R\$)

\begin{tabular}{rrrr|}
\hline $\mathbf{1 0 0}$ & WC2H-011 & $467.610,00$ & $372.200,00$ \\
\hline $\mathbf{2 1 0}$ & WC2H-021 & $578.820,00$ & $495.800,00$ \\
\hline $\mathbf{5 0 0}$ & WC2H-053 & $1.203 .510,00$ & $1.352 .000,00$ \\
\hline $\mathbf{5 6 0}$ & WC2H-060 & $1.346 .400,00$ & $1.560 .000,00$ \\
\hline
\end{tabular}


Para os coletores, pela área disponível foram instados por volta 180 coletores de tubo a vácuo. O preço de mercado de coletor é de $R \$ 1.792,90$ (PORTAL SOLAR, 2017). O valor gasto com coletores será de $R \$ 325.000,00$. Serão considerados custos de $R \$$ $25.000,00$ para o reservatório de água quente e $R \$ 50.000,00$ para o reservatório de água gelada (UNION RHAC, 2017). O Valor total é de $R \$ 1.474 .620,00$ ou $R \$ 2360,00 / \mathrm{m}^{2}$.

Para a estimativa do resfriamento fotovoltaico foi necessário verificar a máxima capacidade de pico de geração. De acordo com a metodologia aplica, para este caso estima-se $153 \mathrm{~kW} /$ pico. A Instalação de painéis Fotovoltaicos com Inversores e Baterias está prevista para $100 \mathrm{~kW} /$ pico em torno de $R \$ 600.000,00$. A instalação imediatamente superior apresentada na referência é de $R \$$ 2.875.000,00 (PORTAL SOLAR, 2017). Através de interpolação estima-se um investimento inicial em $R \$ 901.437,50$ em placas, baterias e inversores. Estima-se, também $R \$ 400.000,00$ para a Instalação das placas. O valor de $R \$ 1.301,437,50$ ou $R \$ 2082,30 / \mathrm{m}^{2}$.

O capital investido $\left(\mathrm{CI}_{\text {sist }}\right)$ para cada sistema será o somatório do capital investido para cada tecnologia. A tabela 4.15, apresenta a nomenclatura:

Tabela 4.15. Nomenclatura para capital investido em cada sistema.

\begin{tabular}{lc}
\hline Caso & $C I_{\text {sist }}$ \\
\hline Base & $C I_{B a s e}$ \\
\hline Resfriamento Natural Direto & $C I_{R D}$ \\
\hline $\begin{array}{l}\text { Resfriamento Natural Indireto } \\
\text { Resfriamento Natural Direto + Indireto }\end{array}$ & $C I_{R I}$ \\
\hline $\begin{array}{l}R D+R I \\
\text { Resfriamento Solar por Absorção } \\
\text { Direto }\end{array}$ & $C I_{A S}$ \\
$\begin{array}{l}\text { Resfriamento Solar por Absorção + Resfriamento Natural } \\
\text { indireto }\end{array}$ & $C I_{A S+R D}$ \\
$\begin{array}{l}\text { Resfriamento Solar por Absorção + Resfriamento Natural } \\
\text { Direto + Indireto }\end{array}$ & $C I_{A S+R I}$ \\
$\begin{array}{l}\text { Resfriamento Solar Fotovoltaico } \\
\text { Resfriamento Solar Fotovoltaico + Resfriamento Natural } \\
\text { Direto }\end{array}$ & $C I_{A S+R D+R I}$ \\
$\begin{array}{l}\text { Resfriamento Solar Fotovoltaico + Resfriamento Natural } \\
\text { indireto }\end{array}$ & $C I_{P V}$ \\
\hline $\begin{array}{l}\text { Resfriamento Solar Fotovoltaico + Resfriamento Natural } \\
\text { Direto + Indireto }\end{array}$ & $C I_{P V+R D}$ \\
\hline
\end{tabular}




\subsubsection{Análise de Retorno de Investimento Simples (Payback Simples)}

O tempo de Retorno de investimento simples, conhecido como payback simples, é o prazo do retorno dos recursos investidos em um projeto. No caso do retorno de investimento simples (PB), os fluxos de caixa ${ }^{16}$ são tomados por seus valores nominais e os investimentos comparados em quanto se leva para recuperar o investimento inicial. O principal objetivo na utilização deste método é a redução do risco e valorização da liquidez (PARENTE, 2017).

Outro fator que será levado em conta é o tempo de depreciação contábil, que para uma UR de compressão de vapor, de absorção e para torres de resfriamento é de 15 anos (GATTO \& SILVA, 2016) e para coletores solares e painéis fotovoltaicos é de 10 anos (ENERGY SAGE, 2017). A equação 4.77 quantifica monetariamente a depreciação.

$D P_{\text {Sistema }}=\frac{C I_{\text {Sistema }}}{\text { tempo de depreciação }}$

A equação 4.78 apresenta o tempo de retorno de investimento.

$P B=\frac{C I_{\text {Sistema }}}{E A E_{\text {Sistema }}-D P_{\text {Sistema }}}$

\subsubsection{Análise de Taxa Interna de Retorno}

Considerado como um sofisticado método de avaliação, a taxa interna de retorno (TIR) é definida como a taxa pela qual um investimento $\left(C I_{\text {Sistema }}\right)$ é recuperado por meio dos rendimentos auferidos em um projeto. A TIR representa a taxa de desconto periódica que iguala os fluxos de entrada com os de saída de caixa (PARENTE, 2017). Compara todas as entradas e saídas de dinheiro na data inicial do projeto (SAIDEL, 2017). Neste trabalho o período estudado será anual. A equação 4.79 apresenta esta formulação.

\footnotetext{
16 Fluxo de Caixa é um Instrumento de gestão financeira que projeta para períodos futuros todas as entradas e as saídas de recursos financeiros da empresa, indicando como será o saldo de caixa para o período projetado (SEBRAE, 2011).
} 
$\left[\frac{E A E_{\text {Sistema }}}{1+T I R}+\frac{E A E_{\text {Sistema }}}{(1+T I R)^{2}}+\cdots+\frac{E A E_{\text {Sistema }}}{(1+T I R)^{n}}\right]-C I_{\text {Sistema }}=0$

O critério para escolha do período de taxa interna de retorno, será o período mínimo de depreciação, neste caso os coletores, considerando 10 anos. 


\section{CAPÍTULO 5 - DISCUSSÃO DE RESULTADOS - CIDADE E TECNOLOGIA BASE}

Este capítulo apresenta os valores de carga térmica base e aplicação de tecnologias de resfriamento solar isolados e associada a economizadores, segundo dados obtidos, conforme metodologia aplicada para a cidade referência com variação de tarifas aplicadas ao horário usual e de ponta 


\subsection{Carga Térmica base}

Conforme apresentado no Capítulo anterior, os resultados partem de cálculos realizados em bancos de dados fornecidos pela ASHRAE com temperaturas externas e irradiações. A primeira cidade escolhida foi a cidade de São Paulo, região II da ASHRAE.

Utilizando a equação 4.1 para diferentes dias, horários e respectivas propriedades, obtêm-se a carga térmica básica para as diferentes densidades apresentada. A Tabela 5.1, apresenta os valores de carga máxima horária para cada instalação ${ }^{17}$, onde pode-se notar que para as dissipações de energia térmica dos computadores apresentadas não há proporcionalidade direta nos resultados, pois há uma parcela que independe desta.

Tabela 5.1 - Carga Térmica máxima em Toneladas de Refrigeração para cada densidade

\begin{tabular}{|cc|}
\hline Instalação & Carga térmica Máxima (TR) \\
\hline $\mathbf{0 , 5} \mathbf{~ k W / \mathbf { m } ^ { 2 }}$ & 173,8 \\
$\mathbf{1 , 0} \mathbf{~ k W} / \mathbf{m}^{\mathbf{2}}$ & 259,6 \\
$\mathbf{2 , 0} \mathbf{~ k W} / \mathbf{m}^{\mathbf{2}}$ & 440,3 \\
$\mathbf{4 , 0} \mathbf{~ k W} / \mathbf{m}^{\mathbf{2}}$ & 795,8 \\
$\mathbf{8 , 0} \mathbf{~ k W} / \mathbf{m}^{\mathbf{2}}$ & 1506,88 \\
\hline
\end{tabular}

Estes valores são utilizados na seleção das unidades de resfriamento de líquido, pois o sistema deverá ser projetado para atendimento da instalação em sua plenitude, mesmo em dias atípicos com aumento ou redução de carga térmica em virtude de severa condição climática exterior, tanto em dias quentes, quanto em dias frios.

Outro comportamento da carga térmica demostrando, é seu comportamento ao longo de um dia típico. Neste caso é demonstrado um dia típico de verão (figura 5.1), verificando a influência do meio exterior. Observa-se que para esta aplicação, a carga

\footnotetext{
${ }^{17}$ Carga Térmica atendia pelas Unidades de Resfriamentos sob as condições mais severas.
} 
térmica exterior, horário e ocupação é pouco influente, pois independente destes fatores a dissipação de energia ao meio condicionado pouco varia, pois é originada em quase sua totalidade pela dissipação de servidores. Este comportamento se amplifica em maiores densidades de carga, haja visto, neste caso, as cargas de iluminação e insolação representam uma parcela reduzida face a dissipação dos equipamentos.

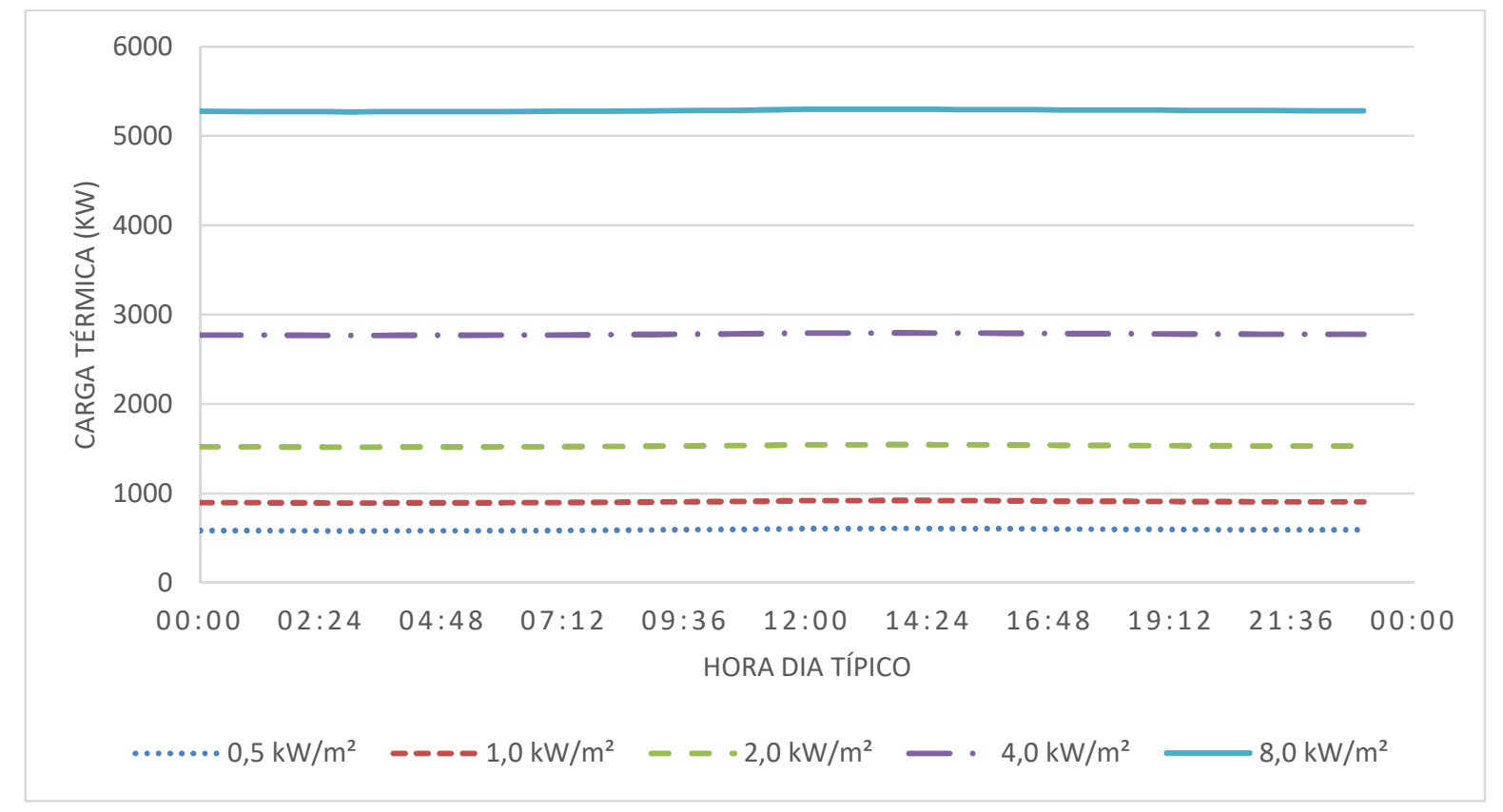

Figura 5.1. Variação horária de carga térmica em dia típico de verão (04 de fevereiro).

\subsection{Tecnologias Solares}

O segundo passo deste trabalho é avaliação da viabilidade de utilização de tecnologias solares. A Figura 5.2 ilustra, amostralmente, a radiação total e direta obtidas junto ao banco de dados (ASHRAE, 2017) para um dia típico de verão. A Figura 5.3 ilustra um dia típico de inverno na cidade de São Paulo.

A temperatura de bulbo seco máxima para São Paulo nos últimos 20 anos é de $36,2^{\circ} \mathrm{C}$ com temperatura de bulbo úmido respectiva de $27,2^{\circ} \mathrm{C}$, a mínima é de $3,2^{\circ} \mathrm{C}$ e 
TBU $2,2{ }^{\circ} \mathrm{C} .{ }^{18}$ Para demais projetos utiliza-se TBS de $31,1{ }^{\circ} \mathrm{C}$ e TBU de $20,2{ }^{\circ} \mathrm{C}$ (ASHRAE, 2017).

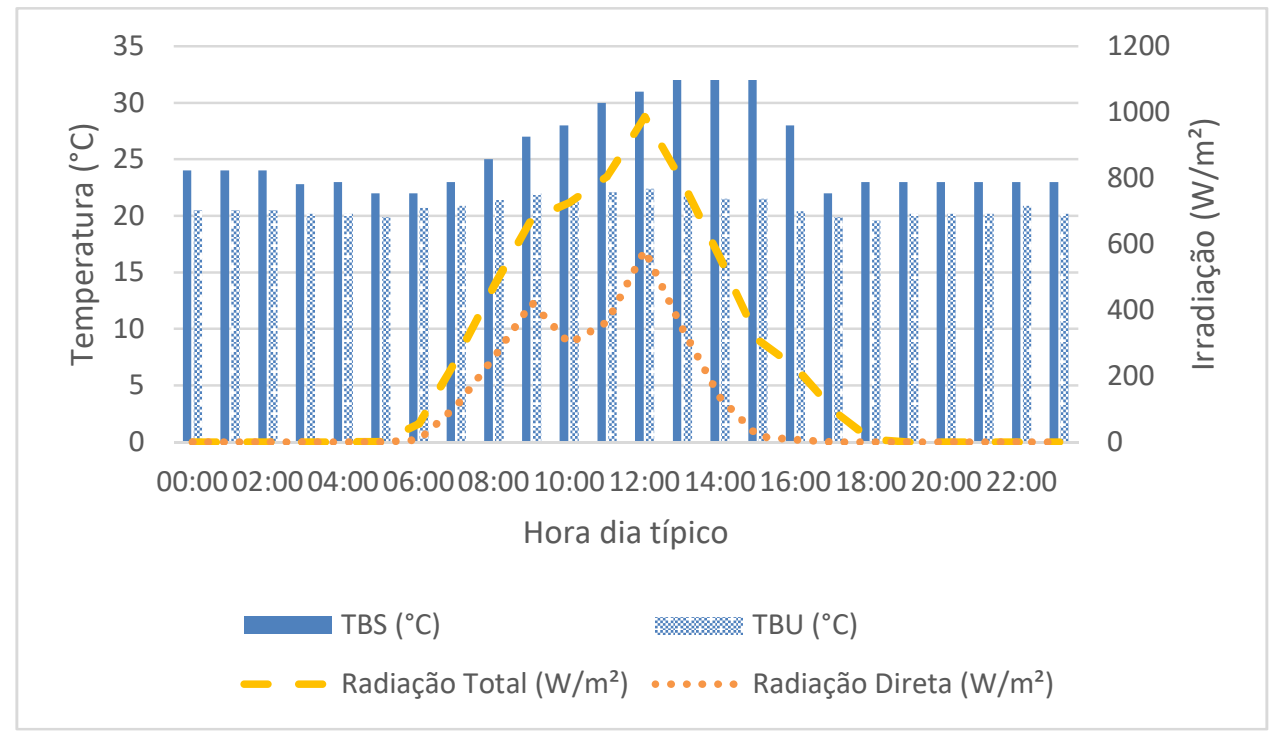

Figura 5.2. Irradiação típica e temperatura em dia típico de verão (04 de fevereiro) para São Paulo.

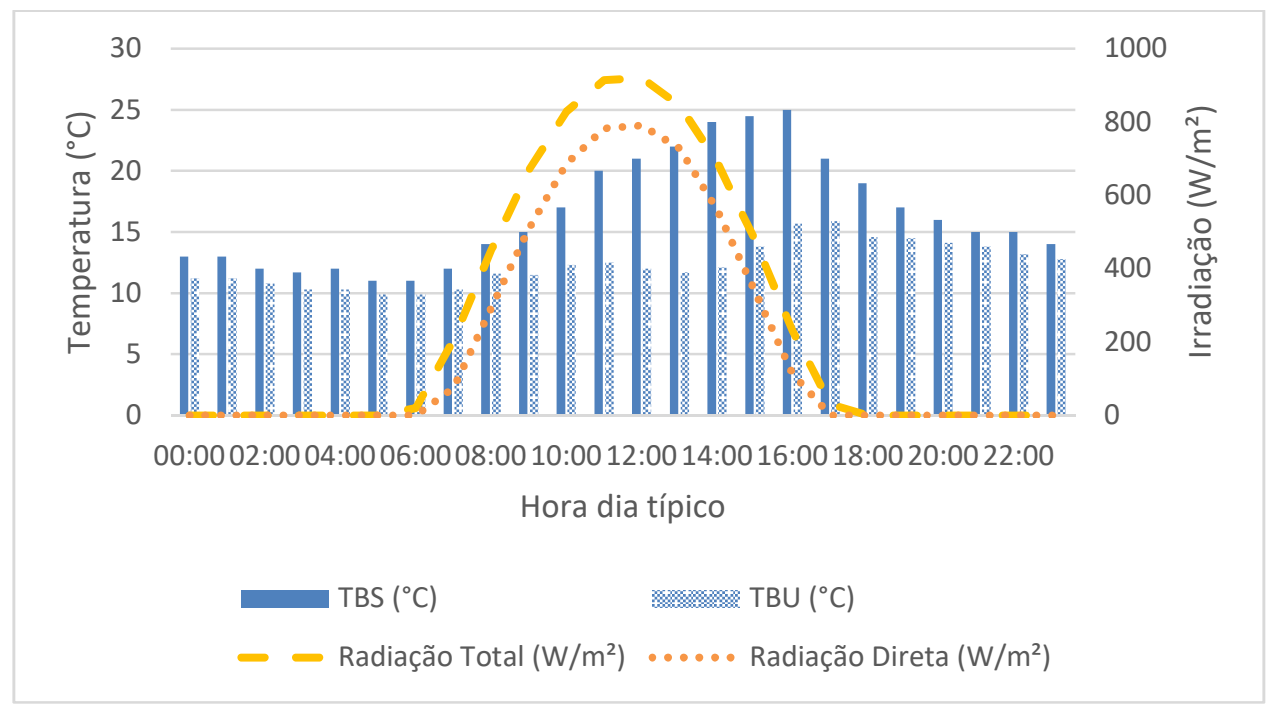

Figura 5.3. Irradiação típica e temperatura em dia típico de inverno (11 de setembro).

\footnotetext{
${ }^{18}$ Para obtenção de certificações do tipo Tier, explicadas no capítulo 2 desta tese, o Data Center deverá ser capaz de manter um ambiente condicionado dentro da faixa indicada no Thermal Guidelines 9.9 sob condição exterior de temperaturas iguais às maiores e menores temperaturas atingidas nos últimos 20 anos.(UPTIME-INSTITUTE, 2013)
} 
De posse destes dados e considerando a latitude local $-24,33^{\circ}$, inclinação de placas em $30^{\circ}$ e altitude de $780 \mathrm{~m}$, calcula-se a radiação do modelo de Liu e Jordan, apresentada na seção 4.2. A radiação para os dias típicos apresenta-se na Figura 5.4.

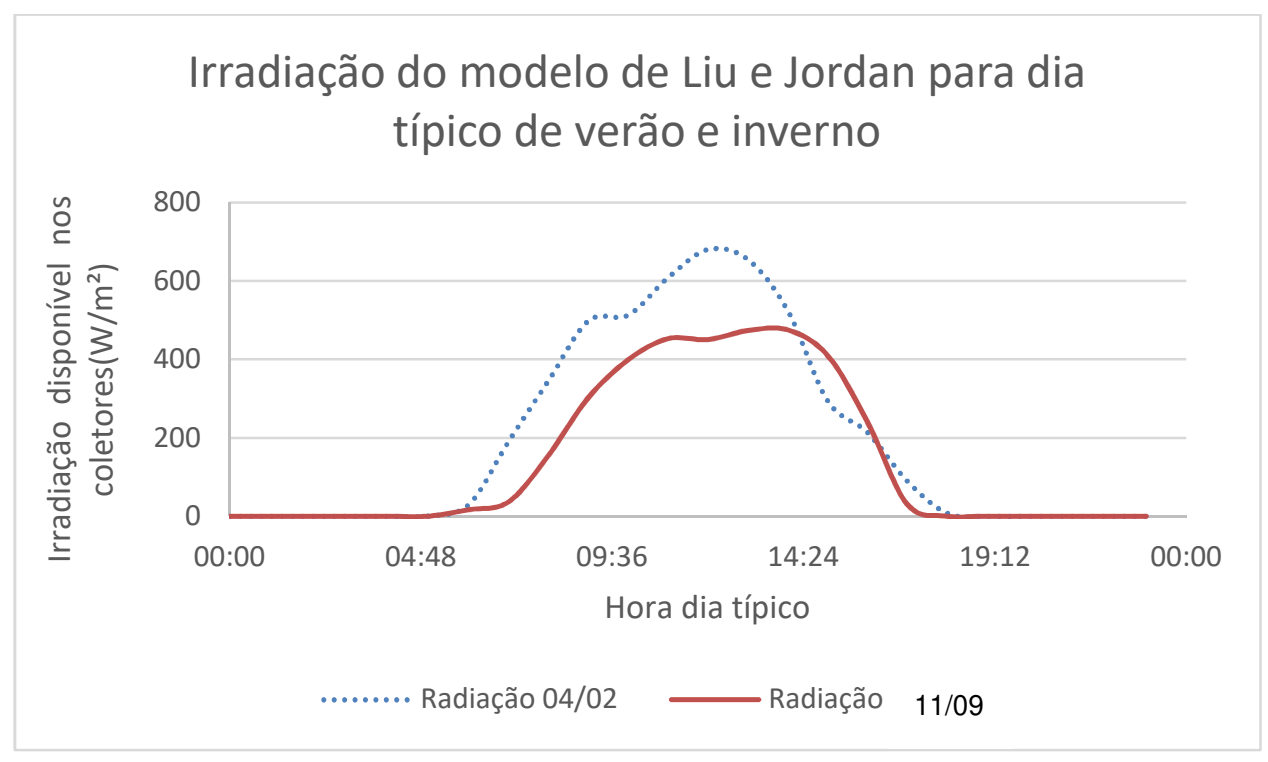

Figura 5.4. Irradiação do modelo de Liu e Jordan para a solução proposta em dias típicos de verão e inverno

Na sequência, calcula-se a eficiência de cada coletor solar indicado para cada instalação, apresentados nas seções 4.3.1 para absorção solar e 4.3.2 para resfriamento fotovoltaico. As Figuras 5.5 e 5.6 apresentam os rendimentos para dias típicos de verão e inverno respectivamente. Observa-se o rendimento superior dos coletores solares de tubo à vácuo em relação às células fotovoltaicas em horários de alta radiação. Nota-se também que em alguns períodos no alvorecer e no entardecer a eficiência das células fotovoltaicas é maior que os coletores. Isto ocorre devido a relação entre irradiação e temperatura exterior nestes horários favorecer esta utilização face aos coletores solares. 


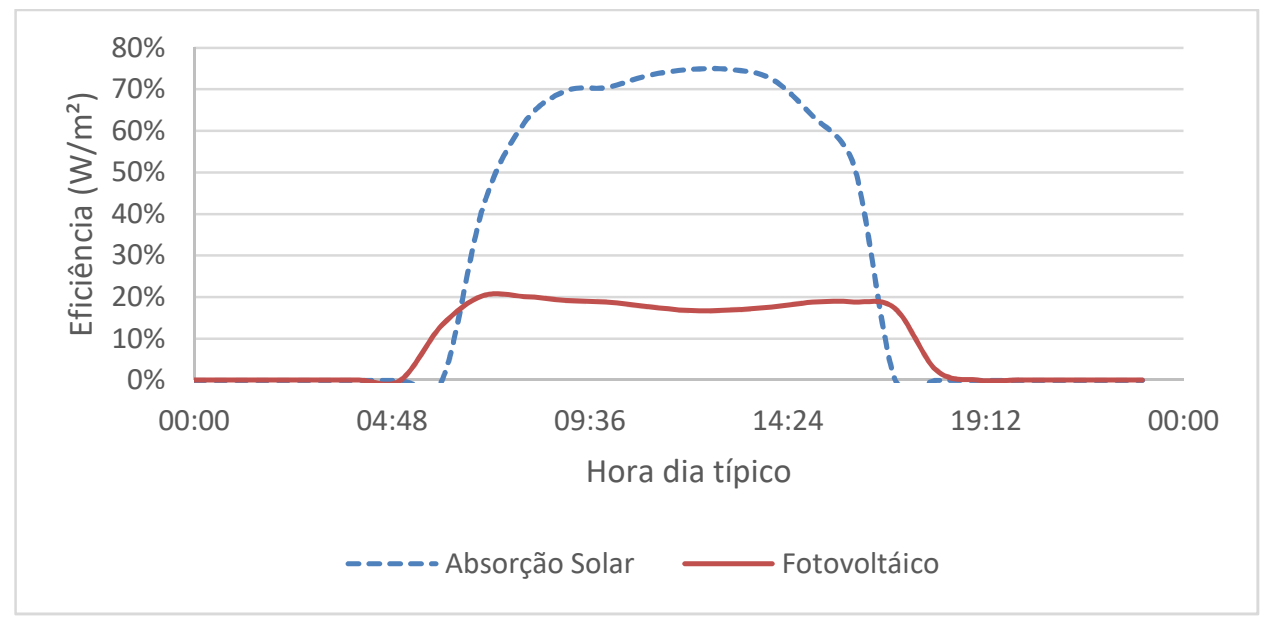

Figura 5.5. Eficiência de coletores solares em dia típico de verão (04/02)

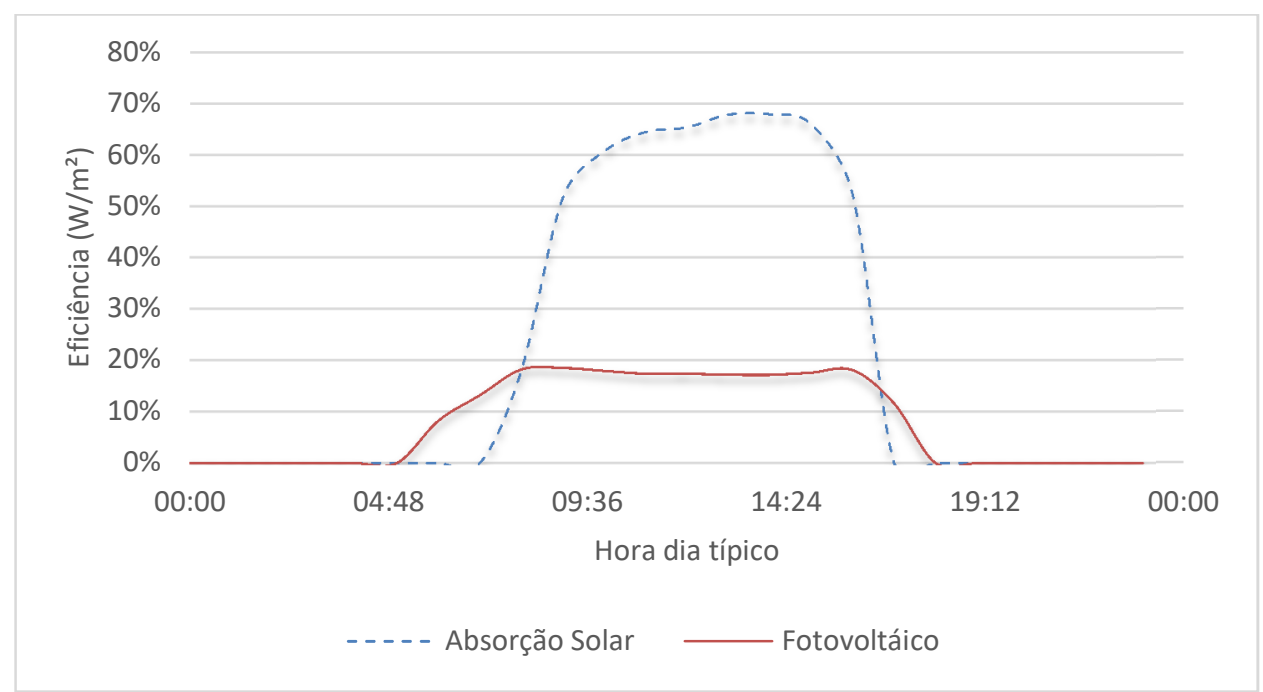

Figura 5.6. Eficiência de coletores em dias típicos de inverno (11/09)

Para o dimensionamento do equipamento de absorção é estimada a maior capacidade de utilização de absorção solar em um dia e seu resultado é diluído sua aplicação em 3 horas, para que a energia solar acumulada seja toda transformada em água gelada para a instalação e satisfaça toda a carga necessária para o horário de ponta.

No dia 04/12, maior capacidade anual, a energia absorvida é de $8282,3 \mathrm{~kW}$ para $625 \mathrm{~m}^{2}$, isto resultaria em um equipamento de 295 TR para aplicação em transformação 
de toda a carga acumulada nos reservatórios de água quente em 24 horas para utilização em 3 horas. Todavia em $90 \%$ do ano a energia absorvida é inferior a $6000 \mathrm{~kW} / \mathrm{m}^{2}$, o que resulta em um equipamento de 210 TR justificando a seleção deste equipamento para esta aplicação.

Para o cálculo da energia de resfriamento disponibilizada pelo sistema de absorção solar necessário multiplicar estes valores pelo COP para $100 \%$ de carregamento, considerando que há água quente reservada o suficiente para 0 funcionamento da UR de absorção em carga máxima durante uma hora. As Figuras 5.7 e 5.8 apresentam estes valores. Nota-se que a grande diferença de rendimento é compensada pela diferença de COP do equipamento de absorção de 1,5 (LG, 2017) e do equipamento de compressão de vapor em torno de 5,5 (FERREIRA; KIM, 2014). O COP do equipamento de compressão de vapor pode ser variável de acordo com a carga térmica aplicada, em alguns momentos, a carga de resfriamento fotovoltaico supera a absorção solar.

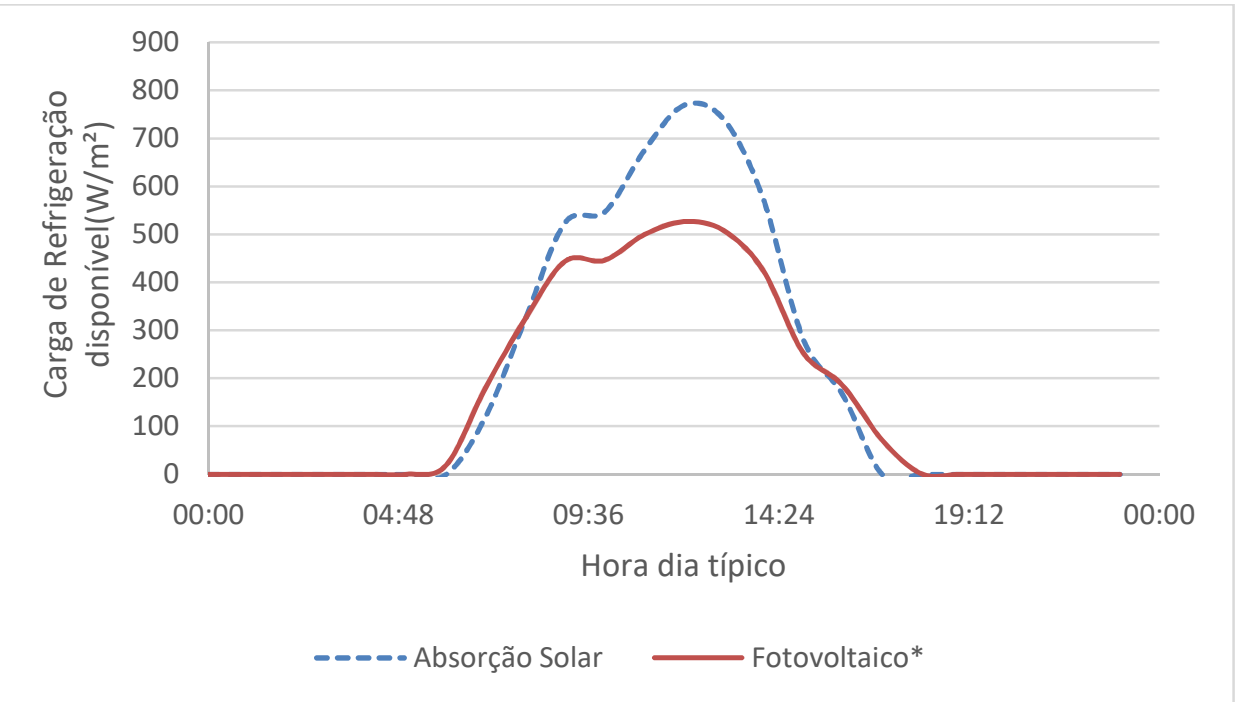

Figura 5.7. Capacidade de resfriamento disponível em $\mathrm{W} / \mathrm{m}^{2} \mathrm{em}$ dia típico de verão $(04 / 02)$ 


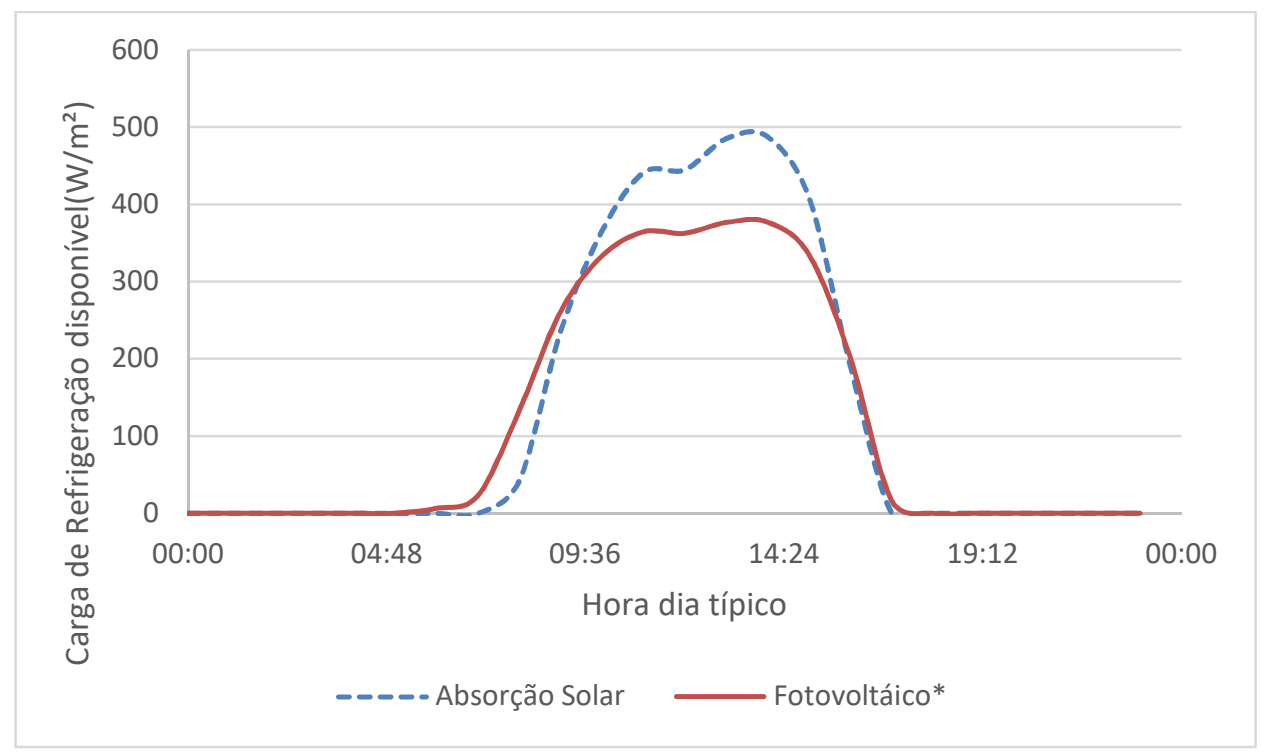

Figura 5.8. Capacidade de resfriamento disponível em $\mathrm{W} / \mathrm{m}^{2} \mathrm{em}$ dia típico de inverno (11/09)

Nota-se que quanto maior a irradiação, maior a vantagem do equipamento de absorção solar face a utilização de resfriamento fotovoltaico, devido à maior eficiência de coletores. Para baixas irradiações, o equipamento fotovoltaico apresenta vantagem pela maior eficiência instantânea dos equipamentos de resfriamento face aos resfriadores por absorção. Outro ponto a se destacar é o aumento da eficiência dos coletores fotovoltaicos a temperaturas mais baixas.

Nota-se que no primeiro caso (figura 5.7) a diferença em média entálpica entre o equipamento de absorção solar e resfriamento fotovoltaico é $18 \%$ e no segundo caso (figura 5.8) é de 10\%. Este valor deve-se a diferença de eficiência do compressor utilizado no equipamento de resfriamento a compressão de vapor, podendo ser maximizada ou reduzida, ressaltando que uma unidade de resfriamento de líquido do tipo compressor parafuso tem seu ponto ótimo ${ }^{19} \mathrm{em}$ cargas parciais e centrífugas próximas de sua carga total. Este cálculo será efetuado nas próximas seções. No caso de absorção solar temos a redução da carga a ser resfriada, que altera a eficiência do equipamento de compressão

\footnotetext{
19 Ponto ótimo de funcionamento, é o ponto de maior capacidade com o menor consumo.
} 
a vapor. No segundo caso de resfriamento acionado por painéis fotovoltaicos a energia é disponibilizada sem alterar a eficiência original.

\subsection{Economizadores}

O trabalho segue com a avaliação da utilização de economizadores, que neste caso poderão ser resfriadores naturais diretos e indiretos por fonte de água não resfriada, proveniente de torres de arrefecimento, doravante chamado de método de resfriamento natural indireto.

Os resfriadores naturais serão utilizados conforme a carga aplicada no data centere as restrições físicas da instalação.

\subsubsection{Resfriamento Natural Direto}

A primeira análise ocorre sobre equipamentos de resfriamento de resfriamento natural direto, pois sua contribuição ocorre diretamente no ar de retorno do ambiente, antes que este passe pelas unidades de ventilação. A Tabela 5.2 mostra a seleção de caixas de ventilação, exaustão e módulos de filtragem. Um ponto importante a observar é que para as cargas até $2 \mathrm{~kW} / \mathrm{m}^{2}$ a quantidade de módulos é selecionada pela carga térmica e a partir de $2 \mathrm{~kW} / \mathrm{m}^{2}$ as cargas são selecionadas pela limitação física, pois devido ao tamanho destas podemos ter somente 5 de um lado e 5 caixas de exaustão do lado oposto.

\begin{tabular}{|c|c|c|c|c|c|}
\hline Equipamento & $0,5 \mathrm{~kW} / \mathrm{m}^{2}$ & $1 \mathrm{~kW} / \mathrm{m}^{2}$ & $2 \mathrm{~kW} / \mathrm{m}^{2}$ & $4 \mathrm{~kW} / \mathrm{m}^{2}$ & $8 \mathrm{~kW} / \mathrm{m}^{2}$ \\
\hline $\begin{array}{l}\text { Quantidade de Caixas de } \\
\text { Ventilação }\end{array}$ & 2 & 4 & 5 & 5 & 5 \\
\hline Módulos de Filtragem & 2 & 4 & 5 & 5 & 5 \\
\hline Caixas de Exaustão & 2 & 4 & 5 & 5 & 5 \\
\hline Vazão de $\operatorname{Ar}\left(m^{3} / \mathbf{s}\right)$ & 22,22 & 44,44 & 55,55 & 55,55 & 55,55 \\
\hline Potência (kW) & 140 & 280 & 350 & 350 & 350 \\
\hline
\end{tabular}


Os resultados de economia de energia serão obtidos através da metodologia apresentada na seção 4.4.1. As Figuras 5.9 e 5.10 mostram a contribuição do resfriamento natural direto na carga total do sistema.

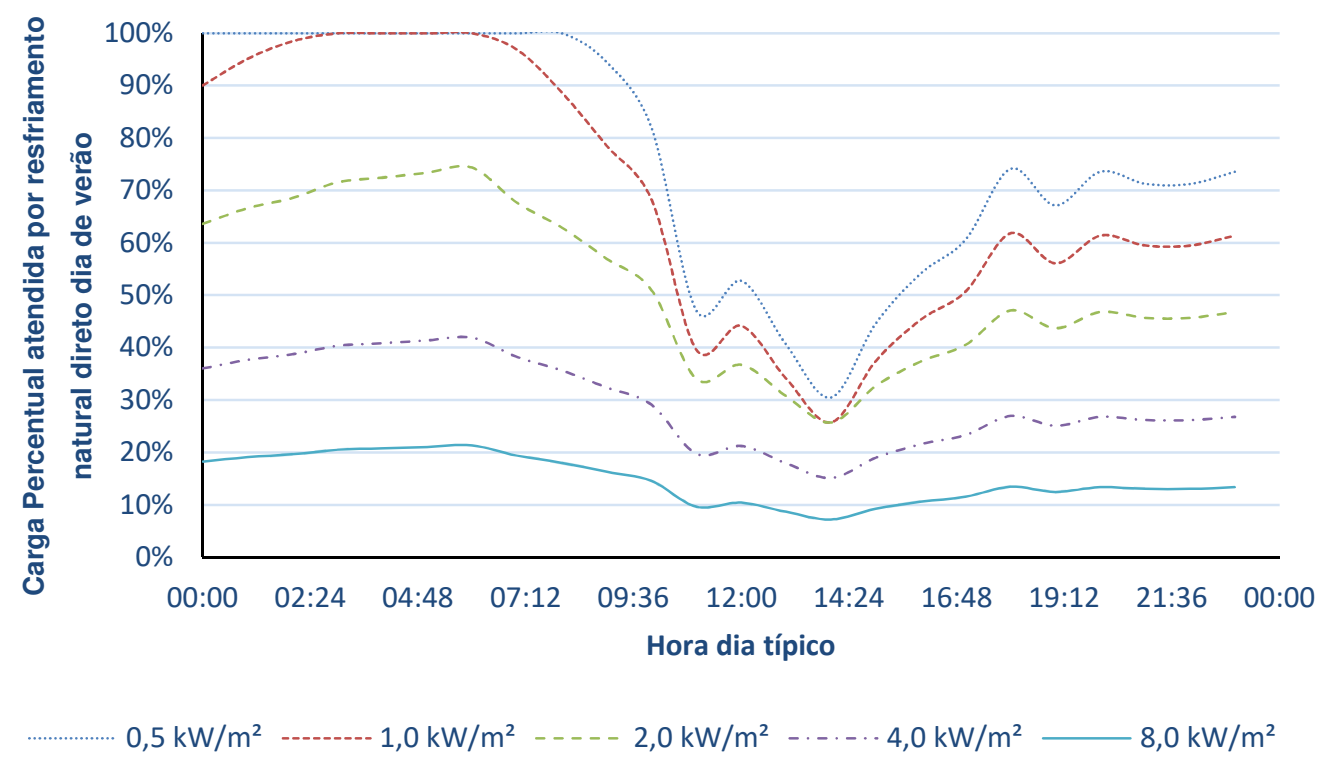

Figura 5.9. Contribuição de resfriamento natural direto face carga total em dia típico de verão

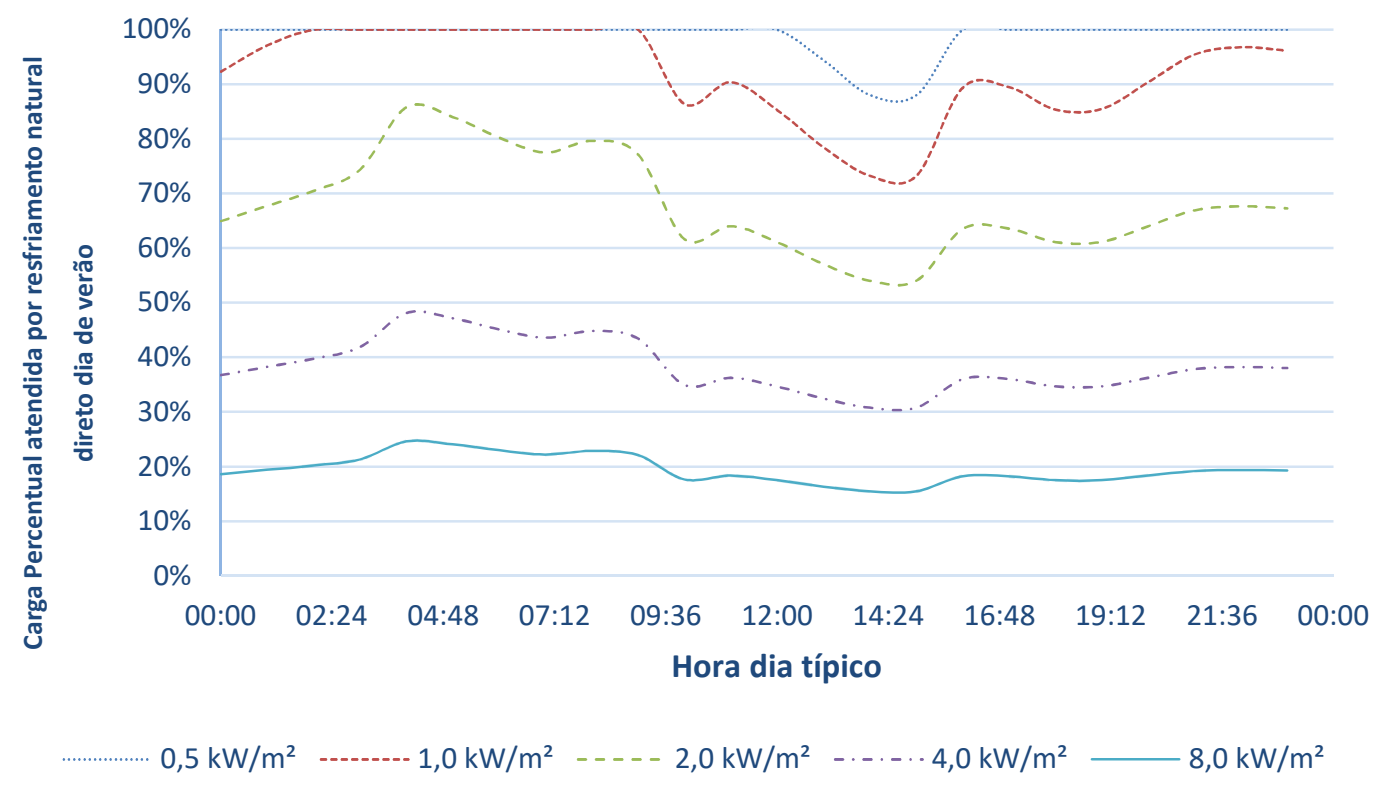

Figura 5.10 Contribuição de resfriamento natural direto face carga total em dia típico de inverno 
Pode-se observar que devido às regras de climatização de Data Centers, para baixas cargas, a carga é plenamente atendida em dias frios e horários noturnos, e para altas cargas há uma importante contribuição. Todavia deve ser avaliada sua utilização, haja visto que a energia gasta por caixas de ventilação em alguns casos é similar ou superior a energia gasta por uma UR e também, quase sempre há necessidade de complementaridade para o atendimento da carga total, com uma unidade de resfriamento trabalhando em faixas de baixo rendimento para atender baixas cargas.

\subsubsection{Resfriamento Natural Indireto}

A análise subsequente debruça-se sobre o resfriamento natural indireto por fontes de água não resfriada, neste caso por torres de arrefecimento. Este tipo de tecnologia atua no retorno da água das unidades de ventilação à unidade de resfriamento, aliviando a carga desta. A seleção do trocador de calor é feita através do fluxo de água, conforme apresentado na Tabela 5.3.

Tabela 5.3 - Seleção de trocadores de calor para resfriamento natural indireto

\begin{tabular}{|c|c|c|c|c|c|}
\hline Resfriamento Natural indireto & $0,5 \mathrm{~kW} / \mathrm{m}^{2}$ & $1 \mathrm{~kW} / \mathrm{m}^{2}$ & $2 \mathrm{~kW} / \mathrm{m}^{2}$ & $4 \mathrm{~kW} / \mathrm{m}^{2}$ & $8 \mathrm{~kW} / \mathrm{m}^{2}$ \\
\hline Trocador de Calor referência & aq4 & aq4 & aq8 & aq8 & $\mathrm{aq} 10$ \\
\hline Vazão (I/s) & 26,63 & 40,25 & 67,50 & 122,01 & 231,01 \\
\hline
\end{tabular}

Os resultados de economia de energia serão obtidos através da metodologia apresentada na Seção 4.4.2. As Figuras 5.11 e 5.12 mostram a contribuição do resfriamento natural direto na carga total do sistema. 


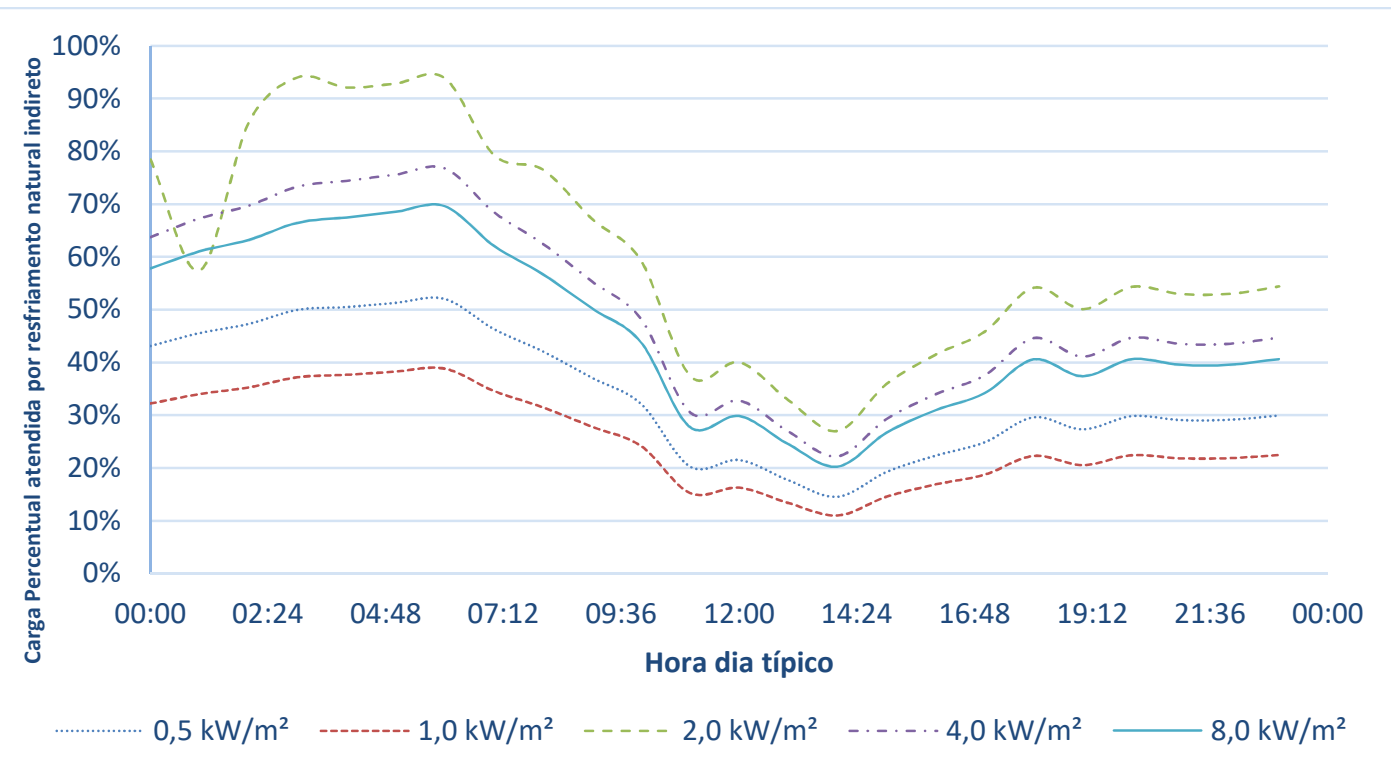

Figura 5.11. Contribuição de resfriamento natural indireto face carga total em dia típico de verão

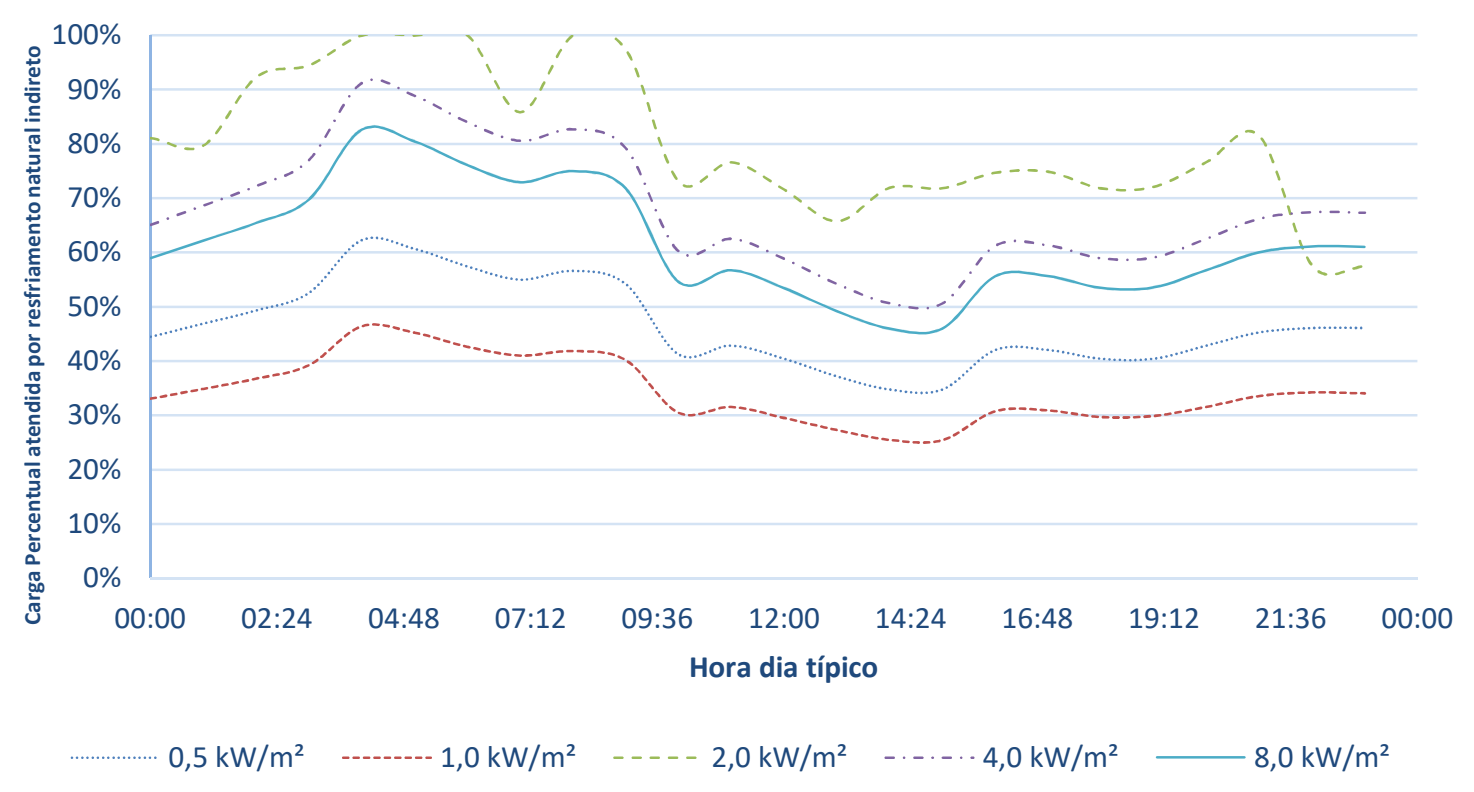

Figura 5.12. Contribuição de resfriamento natural indireto e dia típico de inverno

A contribuição do resfriamento natural indireto é observada em dias frios e períodos noturno. Uma vantagem em relação ao resfriamento natural direto, é a dispensa de adição de novos ventiladores ou bombas, somente de válvulas automatizadas e da 
automação na instalação da obra. A Figura 5.13 mostra a disponibilidade de cada método de resfriamento solar e economizadores de acordo com a densidade de carga, neste caso são considerados o aumento de consumo de energia elétrico causado por ventiladores.

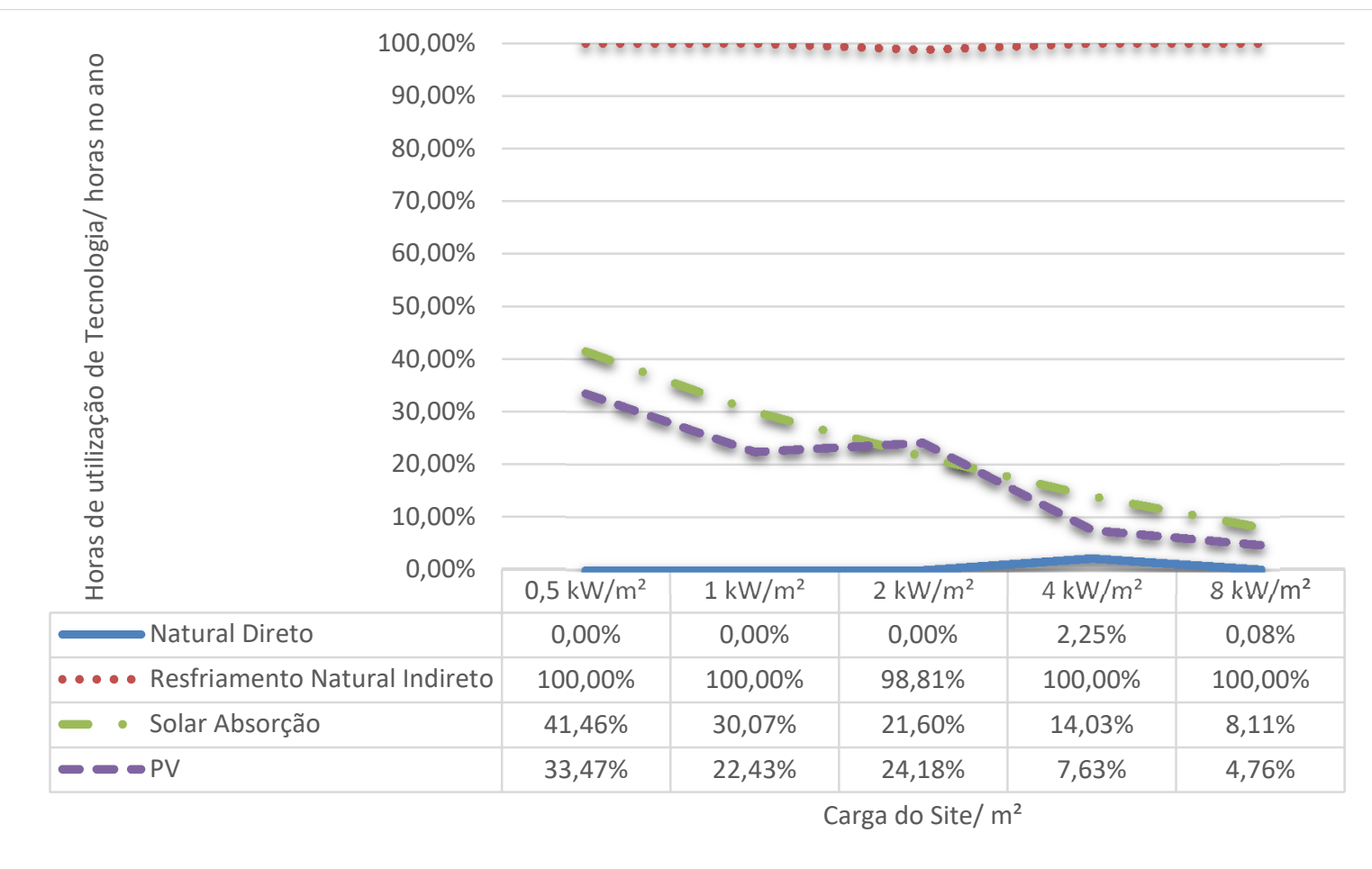

Figura 5.13. Percentual de utilização de economizadores e métodos de resfriamento solar sobre carga total para densidades de carga estudadas.

Nota-se, que quase não há contribuição do resfriamento natural direto, e geralmente esta é baixa, pois na maior parte do tempo convêm-se deixar os ventiladores de resfriamento natural direto desligados, pois a soma do consumo elétrico dos ventiladores e o residual da UR é superior ao consumo da UR sem esta contribuição.

O resfriamento natural indireto para esta condição climática é sempre utilizado, mesmo que de forma parcial é sempre utilizado, independente da carga aplicada. Os métodos de resfriamento solar também apresentam bom ganho energético, porém sua contribuição decresce com o aumento da carga. 
Os métodos não são utilizados de forma isolada, também podem ser utilizados de forma combinada. Os economizados podem ser utilizados com quais quer tecnologias solares e também é possível ter uma instalação com resfriamento natural direto e indireto associados.

A combinação de tecnologias solares não é possível, pois a área disponível para a colocação de captadores solares é a mesma.

\subsection{Seleção de unidades de resfriamento de líquido para caso base e consumo de energia}

Os equipamentos serão selecionados conforme a carga térmica máxima inicial apresentada na Tabela 5.1. Segue seleção na Tabela 5.4:

Tabela 5.4 - Seleção de unidades de resfriamento de líquido

\begin{tabular}{|c|c|c|}
\hline Instalação & Compressor Parafuso & Compressor Centrífugo \\
\hline $0,5 \mathrm{~kW} / \mathrm{m}^{2}$ & $180 \mathrm{TR}$ & $400 \mathrm{TR}$ \\
\hline $1,0 \mathrm{~kW} / \mathrm{m}^{2}$ & $260 \mathrm{TR}$ & $400 \mathrm{TR}$ \\
\hline $2,0 \mathrm{~kW} / \mathrm{m}^{2}$ & $500 \mathrm{TR}$ & $600 \mathrm{TR}$ \\
\hline $4,0 \mathrm{~kW} / \mathrm{m}^{2}$ & 2 equipamentos de $420 \mathrm{TR}$ & 840 TR \\
\hline $8,0 \mathrm{~kW} / \mathrm{m}^{2}$ & 4 equipamentos de 420 TR & $1680 \mathrm{TR}$ \\
\hline
\end{tabular}

Após a seleção do equipamento, aplica-se as equações características apresentadas na Tabela 4.8 e para cada carga térmica horária calcula-se o consumo elétrico correspondente.

Para cada método específico estudado, será calculado o consumo por meio da metodologia apresentada na Seção 4.5. A Tabela 5.5 apresenta os valores para cada tecnologia. 
Tabela 5.5 - Consumo de energia elétrica complementar para cada tecnologia

\begin{tabular}{|c|c|c|c|c|c|}
\hline \multicolumn{6}{|c|}{ Consumo Total (kWh) } \\
\hline & \multicolumn{5}{|c|}{ Carga (kW) } \\
\hline Tecnologia & $\begin{array}{c}0,5 \\
\mathrm{~kW} / \mathrm{m}^{2}\end{array}$ & $\begin{array}{c}1 \\
k W / m^{2}\end{array}$ & $\begin{array}{c}2 \\
\mathrm{~kW} / \mathrm{m}^{2}\end{array}$ & $\begin{array}{c}4 \\
k W / m^{2}\end{array}$ & $\begin{array}{c}8 \\
k W / m^{2}\end{array}$ \\
\hline $\begin{array}{c}\text { Caso Base } \\
\text { CON }_{\text {Base }}\end{array}$ & 887,24 & 1703,24 & 1549,49 & 4877,46 & 7544,06 \\
\hline $\begin{array}{l}\text { Natural Direto } \\
\text { CON }_{\boldsymbol{R} D}\end{array}$ & 887,24 & 1703,24 & 1549,49 & 4875,53 & 7544,02 \\
\hline $\begin{array}{l}\text { Resfriamento Natural Indireto } \\
\qquad \boldsymbol{C O N}_{\boldsymbol{R I}}\end{array}$ & 569,91 & 1133,04 & 1046,16 & 2529,77 & 4465,28 \\
\hline $\begin{array}{l}\text { Natural Direto e Indireto } \\
\qquad \boldsymbol{C O N}_{R \boldsymbol{D}+\boldsymbol{R I}}\end{array}$ & 887,24 & 1703,24 & 1549,49 & 4722,54 & 6718,48 \\
\hline $\begin{array}{c}\text { Solar Absorção } \\
\operatorname{CON}_{A S}\end{array}$ & 568,94 & 1294,24 & 1358,48 & 4486,68 & 7240,69 \\
\hline $\begin{array}{c}\text { Solar Absorção + Resfriamento Natural } \\
\text { Direto } \\
\boldsymbol{C O N}_{A S+R \boldsymbol{D}}\end{array}$ & 848,52 & 1641,24 & 1511,81 & 4699,57 & 7370,85 \\
\hline $\begin{array}{c}\text { Solar Absorção + Resfriamento Natural } \\
\text { Indireto } \\
\text { CON }_{A S+R I}\end{array}$ & 303,93 & 781,69 & 622,01 & 2002,88 & 3946,76 \\
\hline $\begin{array}{c}\text { Solar Absorção + Resfriamento Natural } \\
\text { Direto e Indireto } \\
\boldsymbol{C O N}_{A S+R \boldsymbol{R}+\boldsymbol{R I}}\end{array}$ & 848,40 & 1640,90 & 1515,21 & 3866,45 & 5731,41 \\
\hline $\begin{array}{l}\text { Fotovoltaica } \\
\operatorname{CON}_{P V}\end{array}$ & 690,15 & 1506,15 & 1352,39 & 4680,37 & 7346,95 \\
\hline $\begin{array}{l}\text { Fotovoltaica + Resfriamento Natural Direto } \\
\qquad \boldsymbol{C O N} N_{P V+R D}\end{array}$ & 842,53 & 1634,57 & 1497,11 & 4742,32 & 7414,51 \\
\hline $\begin{array}{c}\text { Fotovoltaica }+ \text { Resfriamento Natural } \\
\text { Indireto } \\
\boldsymbol{C O N}_{\boldsymbol{P V}+\boldsymbol{R I}}\end{array}$ & 517,55 & 1028,90 & 952,18 & 2297,41 & 4056,99 \\
\hline $\begin{array}{c}\text { Fotovoltaica + Resfriamento Natural Direto } \\
+ \text { Resfriamento Natural Indireto } \\
\qquad \boldsymbol{C O N}_{P V+R D+R I}\end{array}$ & 845,42 & 1639,37 & 1499,19 & 4731,53 & 7371,95 \\
\hline
\end{tabular}

A Tabela 5.6 apresenta a economia de energia percentual em relação ao caso base. Pelos resultados obtidos para as tecnologias estudadas, propõe-se que todos os processos onde há a utilização de resfriamento natural direto há tímida ou nenhuma economia de energia elétrica, devido ao consumo das caixas de ventilação e exaustão. Doravante, nos detalhamentos das soluções, estas proposições serão descartadas. Similarmente observa-se que o resfriamento natural indireto se viabiliza utilizado isoladamente e em conjunto com equipamentos solares. 
Tabela 5.6 - Economia de energia percentual

\begin{tabular}{|c|c|c|c|c|c|}
\hline \multicolumn{6}{|c|}{ Economia de Energia } \\
\hline & & & Carga & & \\
\hline Tecnologia & $\begin{array}{c}0,5 \\
\mathrm{~kW} / \mathrm{m}^{2}\end{array}$ & $\begin{array}{c}1 \\
k W / m^{2}\end{array}$ & $\stackrel{2}{\mathrm{~kW} / \mathrm{m}^{2}}$ & $\begin{array}{c}4 \\
k W / m^{2}\end{array}$ & $\begin{array}{c}8 \\
k W / m^{2}\end{array}$ \\
\hline Caso Base & - & - & - & - & - \\
\hline $\begin{array}{l}\text { Natural Direto } \\
\qquad \boldsymbol{E} \boldsymbol{A} \boldsymbol{E}_{\boldsymbol{B} D}\end{array}$ & $0 \%$ & $0 \%$ & $0 \%$ & $0 \%$ & $0 \%$ \\
\hline $\begin{array}{l}\text { Resfriamento Natural Indireto } \\
\qquad \boldsymbol{E} \boldsymbol{A} \boldsymbol{E}_{R I}\end{array}$ & $36 \%$ & $33 \%$ & $32 \%$ & $48 \%$ & $41 \%$ \\
\hline $\begin{array}{l}\text { Natural Direto e Indireto } \\
\qquad \boldsymbol{E A E _ { R \boldsymbol { D } } + \boldsymbol { R } \boldsymbol { I }}\end{array}$ & $0 \%$ & $0 \%$ & $0 \%$ & $3 \%$ & $11 \%$ \\
\hline $\begin{array}{c}\text { Solar Absorção } \\
\boldsymbol{E A E}_{A S}\end{array}$ & $36 \%$ & $24 \%$ & $12 \%$ & $8 \%$ & $4 \%$ \\
\hline $\begin{array}{l}\text { Solar Absorção + Resfriamento Natural Direto } \\
\qquad \boldsymbol{E A E _ { A S + R \boldsymbol { D } }}\end{array}$ & $4 \%$ & $4 \%$ & $2 \%$ & $4 \%$ & $2 \%$ \\
\hline $\begin{array}{c}\text { Solar Absorção + Resfriamento Natural } \\
\text { Indireto } \\
\boldsymbol{E} \boldsymbol{A} \boldsymbol{E}_{\boldsymbol{A} \boldsymbol{S}+\boldsymbol{R I}}\end{array}$ & $66 \%$ & $54 \%$ & $60 \%$ & $59 \%$ & $48 \%$ \\
\hline $\begin{array}{c}\text { Solar Absorção + } \\
\text { Resfriamento Natural Direto } \\
\text { e Indireto } \\
\qquad \boldsymbol{E} \boldsymbol{E}_{\boldsymbol{A S}+\boldsymbol{R} \boldsymbol{D}+\boldsymbol{R I}}\end{array}$ & $4 \%$ & $4 \%$ & $2 \%$ & $21 \%$ & $24 \%$ \\
\hline $\begin{array}{l}\text { Fotovoltaica } \\
\qquad \boldsymbol{E A E _ { P V }}\end{array}$ & $22 \%$ & $12 \%$ & $13 \%$ & $4 \%$ & $3 \%$ \\
\hline $\begin{array}{l}\text { Fotovoltaica + Resfriamento Natural Direto } \\
\qquad \boldsymbol{E A} \boldsymbol{E}_{P V+\boldsymbol{D} \boldsymbol{D}}\end{array}$ & $5 \%$ & $4 \%$ & $3 \%$ & $3 \%$ & $2 \%$ \\
\hline $\begin{array}{l}\text { Fotovoltaica + Resfriamento Natural Indireto } \\
\qquad \boldsymbol{E A E _ { P V + R I }}\end{array}$ & $42 \%$ & $40 \%$ & $39 \%$ & $53 \%$ & $46 \%$ \\
\hline $\begin{array}{l}\text { Fotovoltaica + Resfriamento Natural Direto + } \\
\text { Resfriamento Natural Indireto } \\
\qquad \boldsymbol{E A E _ { P V + R D + R I }}\end{array}$ & $5 \%$ & $4 \%$ & $3 \%$ & $3 \%$ & $2 \%$ \\
\hline
\end{tabular}

Todavia a utilização de resfriamento natural indireto, bem como absorção solar impacta diretamente na carga térmica e no COP das URs. As Figuras 5.14 e 5.15 para uma carga de $0,5 \mathrm{~kW} / \mathrm{m}^{2}$ e para $2,0 \mathrm{~kW} / \mathrm{m}^{2}$, apresentam a evolução diária do COP e utilização em um dia típico de verão e inverno. 


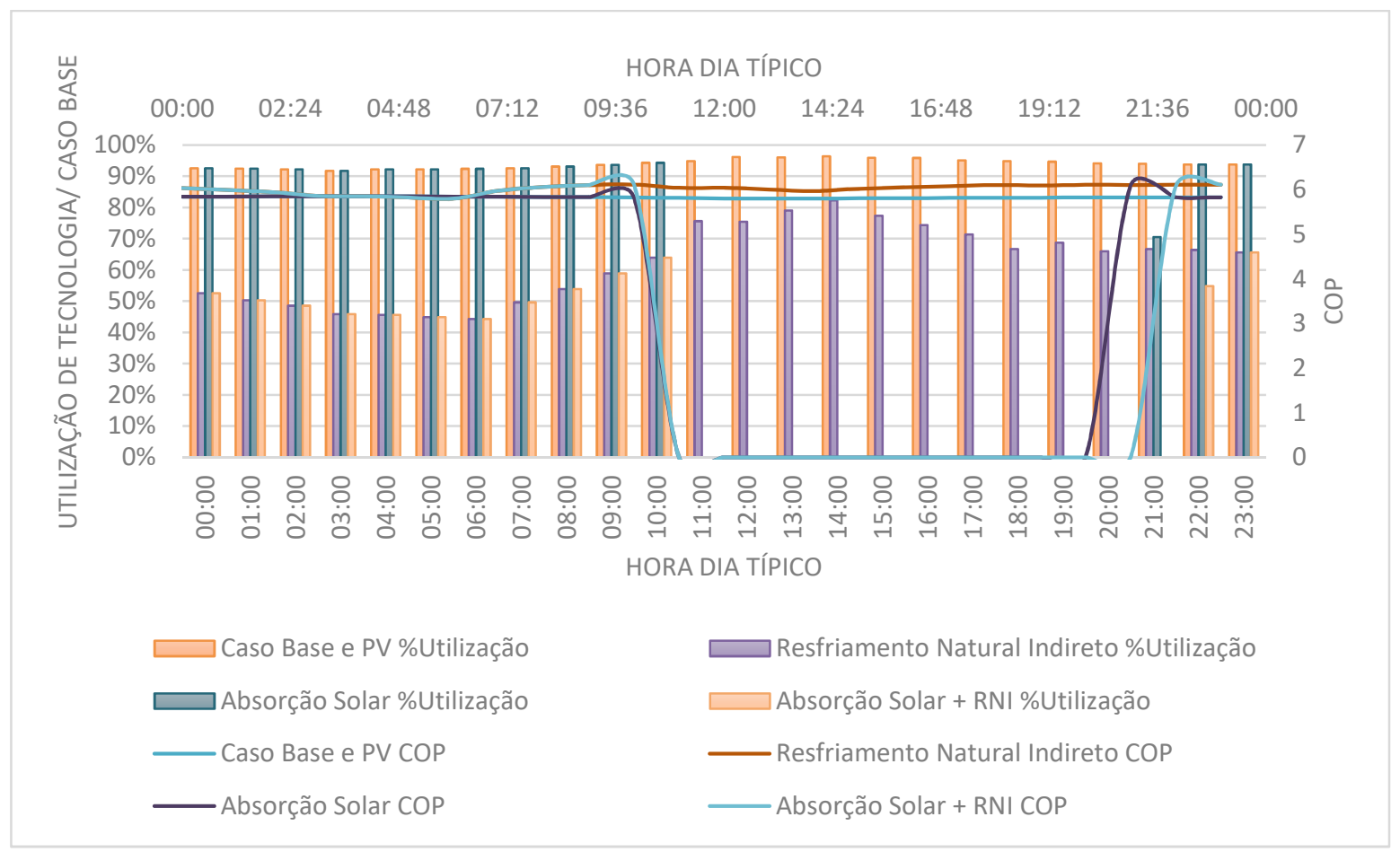

Figura 5.14. Evolução COP e Utilização dia típico de verão para carga de $0,5 \mathrm{~kW} / \mathrm{m}^{2}$

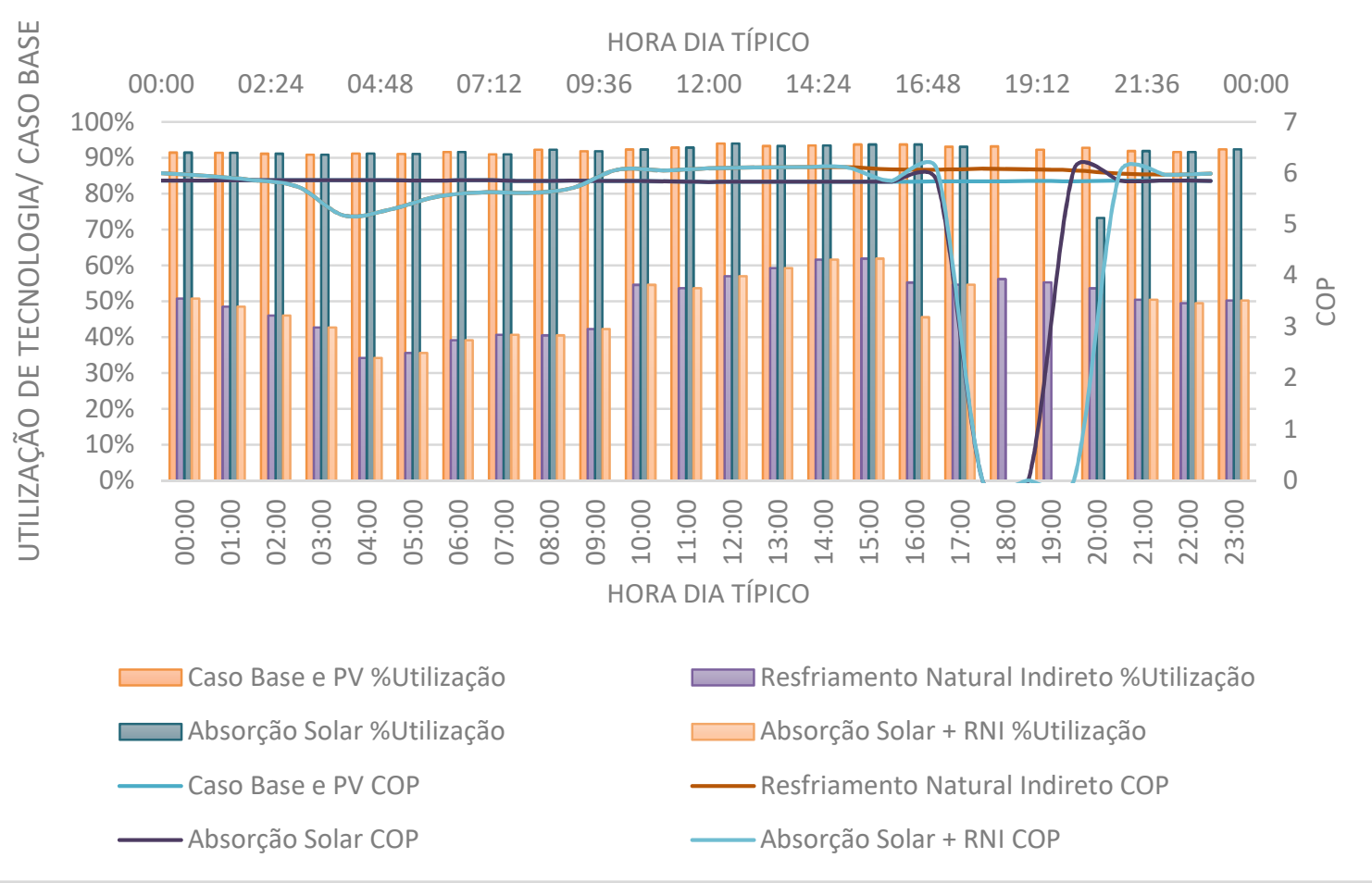

Figura 5.15. Evolução COP e Utilização dia típico de inverno para carga de $0,5 \mathrm{~kW} / \mathrm{m}^{2}$ 


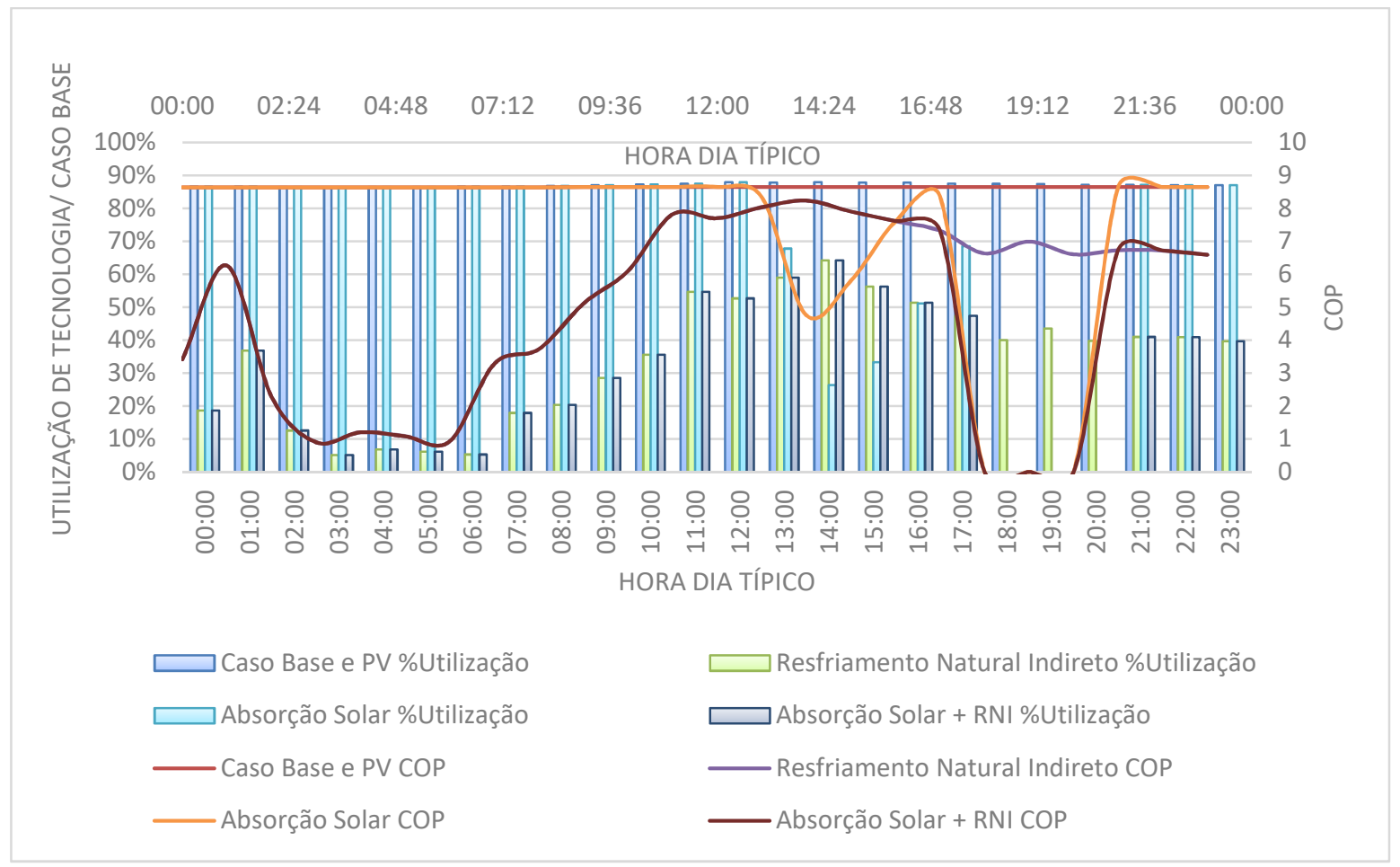

Figura 5.16. Evolução COP e Utilização dia típico de verão para carga de $2,0 \mathrm{~kW} / \mathrm{m}^{2}$

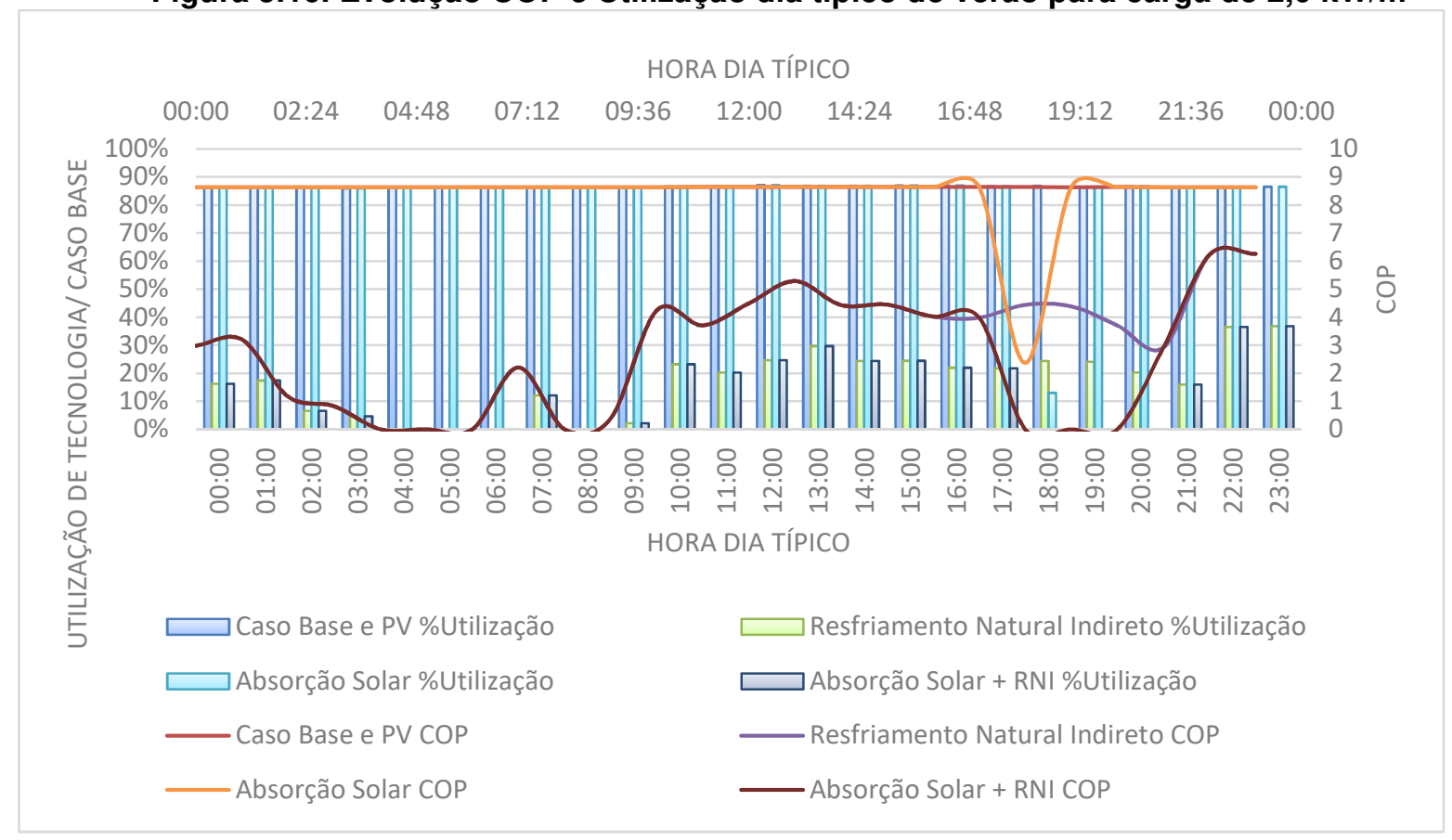

Figura 5.17. Evolução COP e Utilização dia típico de inverno para carga de $2,0 \mathrm{~kW} / \mathrm{m}^{2}$ 
Nota-se nas Figuras 5.14 e 5.15, a contribuição do resfriamento natural indireto e a absorção solar contribuem para o aumento do coeficiente de performance da unidade de resfriamento de líquido. Nas Figuras 5.16 e 5.17, a contribuição do resfriamento natural indireto e a absorção solar apresentam boa economia de energia, porém fazem a unidade de resfriamento trabalhar em cargas residuais de baixo rendimento, o que podem resultar em melhor economia para equipamentos fotovoltaicos.

\subsubsection{Influência da Curva do Equipamento sobre a economia de energia.}

Como visto na seção acima, um fator extremamente importante na seleção de um método solar é o estudo de sua curva de capacidades, haja visto que os métodos de absorção solar e os economizados por resfriamento natural atuam diretamente na carga a ser climatizada e o resfriamento fotovoltaico atua na compensação do consumo de energia.

A Figura 5.18, apresenta a curva de eficiência da unidade de resfriamento utilizada como base neste trabalho (TRANE, 2017). A linha de tendência, obtida no Microsoft Excel ${ }^{\circledR}$, com as capacidades levantadas em catálogo, indica a eficiência máxima da unidade de resfriamento de líquido de acordo com o seu percentil de utilização. O ponto ótimo será a derivada desta curva, segundo métodos de otimização paramétrica linear pelo modelo proposto de Anderson (1984) ${ }^{20}$, (Von Zuben, 1996). As equações de 5.1 a 5.3 apresentam estes valores para curvas características de coeficiente de performance (COP) levantadas de unidades de resfriamento acionadas por compressores do tipo parafuso.

\footnotetext{
20 Em aproximação paramétrica utilizando um número finito de dados amostrados, a distância entre a função a ser aproximada e sua aproximação é uma função apenas do vetor de parâmetros $\theta \in \Re P$. (VON ZUBEN, 1996)
} 


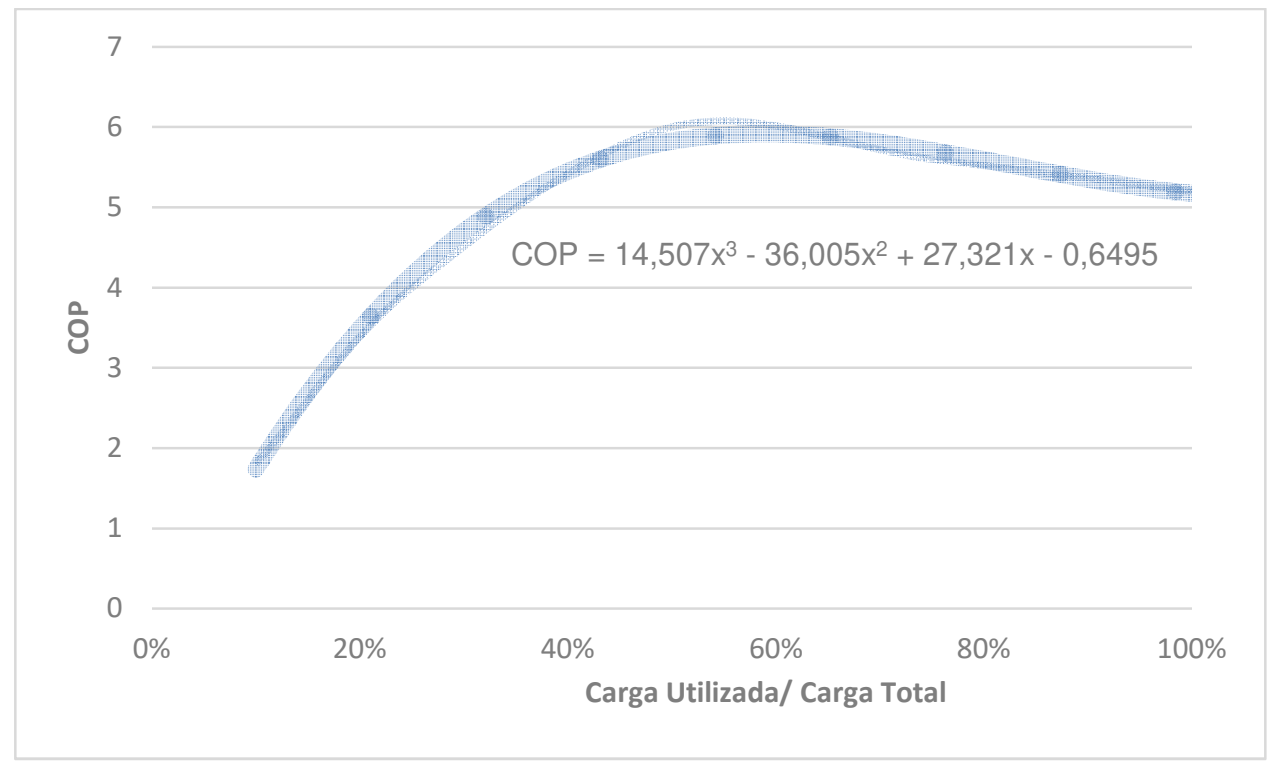

Figura 5.18. Curva de COP de unidade de resfriamento acionada por compressor do tipo parafuso

$$
\begin{aligned}
& \frac{\partial C O P}{\partial x}=0 \\
& C O P=14,507 \cdot x^{3}-36,005 \cdot x^{2}+27,321 \cdot x-0,6495 \\
& \frac{\partial C O P}{\partial x}=43,521 \cdot x^{2}-72,01 \cdot x+27,321=0 \\
& x^{\prime}=59 \% \\
& x^{\prime}=107 \%
\end{aligned}
$$

O resultado da equação 5.3 indica que para a utilização desta unidade de resfriamento deve-se trabalhar entre 50\% e 100\%. Para baixos valores de utilização há um baixo rendimento. No caso a utilização de sistemas de absorção solar faz com que a unidade de resfriamento trabalhe abaixo de $40 \%$ em alguns casos, tornando um sistema de resfriamento fotovoltaico mais viável.

Outra consideração utilizada neste trabalho, propõe-se que por meio de análise da carga base é possível avaliar pontualmente o método solar aplicável mais favorável, considerando a variação da irradiação disponível do modelo de Liu e Jordan, As 
equações 4.67 e 4.70 fornecem dados para obtenção de um índice que indica vantagem de absorção solar $\left(V_{A S}\right)$ ou vantagem fotovoltaica $\left(V_{P V}\right)$ para um dos métodos utilizados (Equações 5.4 e 5.5) e seus valores para diferentes irradiações são apresentados para as diferentes densidades dissipação térmica nas figuras de 5.19 a 5.21. O rendimento de células fotovoltaicas e tubos evacuado, foi considerado o rendimento médio deste para São Paulo em 1 ano, sendo respectivamente $16 \%$ e $60 \%$, calculado nesta tese.

Se $E_{P V}>E_{A S}$

$V_{A S}=\frac{E_{P V}-E_{A S}}{E_{P V}}$

Se $E_{P V}<E_{A S}$

$V_{P V}=\frac{E_{A S}-E_{P V}}{E_{A S}}$

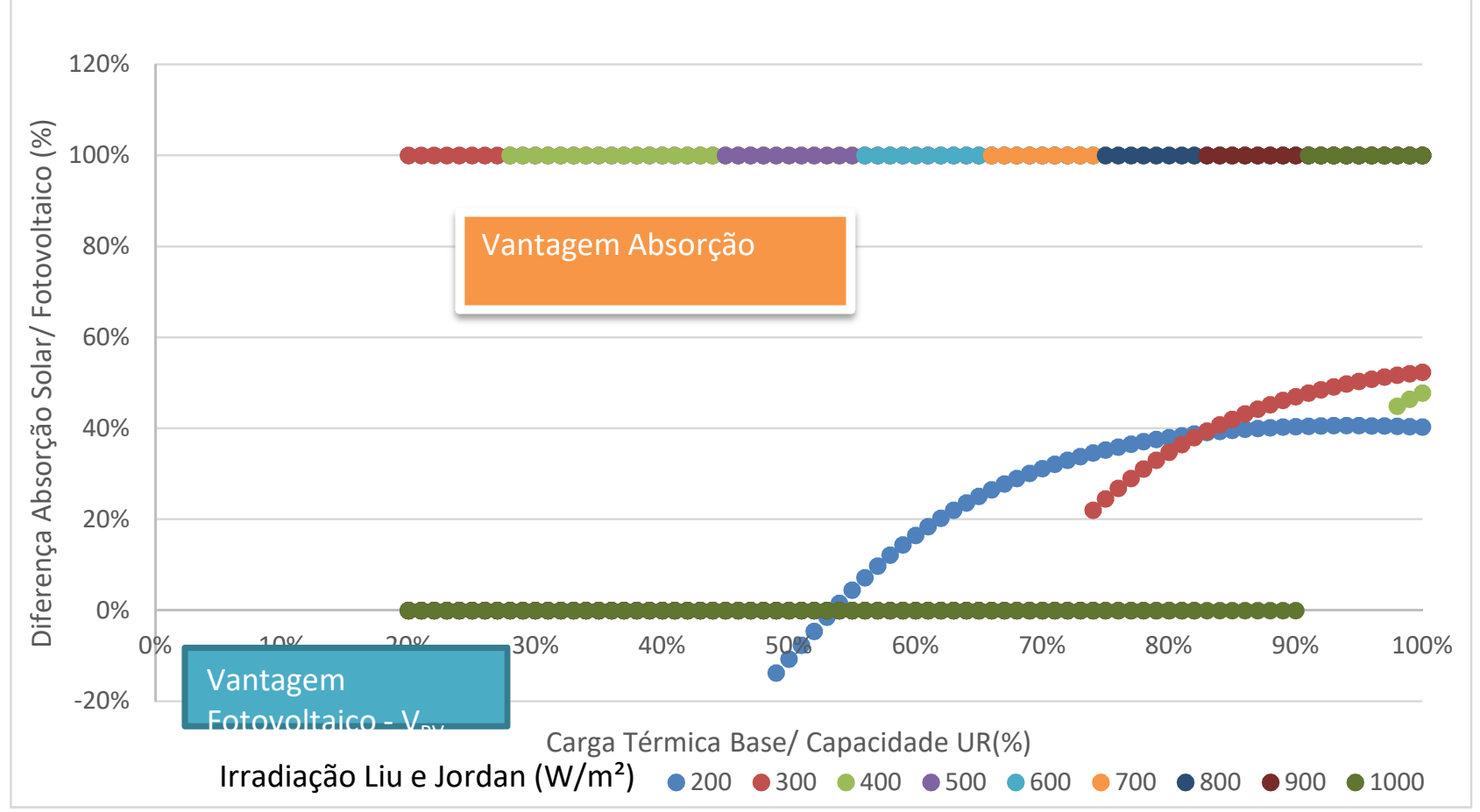

Figura 5.19. Indicação de utilização de tecnologia solar fotovoltaica ou de absorção solar pontual para rendimento médio de coletores em São Paulo, considerando $0,5 \mathrm{~kW} / \mathrm{m}^{2}$ 
$\mathrm{Na}$ Figura 5.19, nota-se que para este equipamento, nesta obra utilizado para cargas de $0,5 \mathrm{~kW} / \mathrm{m}^{2}$, grande vantagem do equipamento de absorção solar em face ao fotovoltaico, que se justifica somente para baixas irradiações de $200 \mathrm{~W} / \mathrm{m}^{2}$ e cargas e cargas superiores entre $42 \%$ e $50 \%$. Nos demais casos recomenda-se a utilização de absorção solar.

Já na unidade de $500 \mathrm{TR}$, que atende a carga de $2 \mathrm{~kW} / \mathrm{m}^{2}$, há uma maior participação dos equipamentos fotovoltaicos, haja visto que a influência na curva de consumo da unidade de resfriamento leva a valores não tão vantajosos para absorção solar. Esta justifica-se basicamente quando há alta incidência solar e altos carregamentos. A Figura 5.20 ilustra esta afirmação.

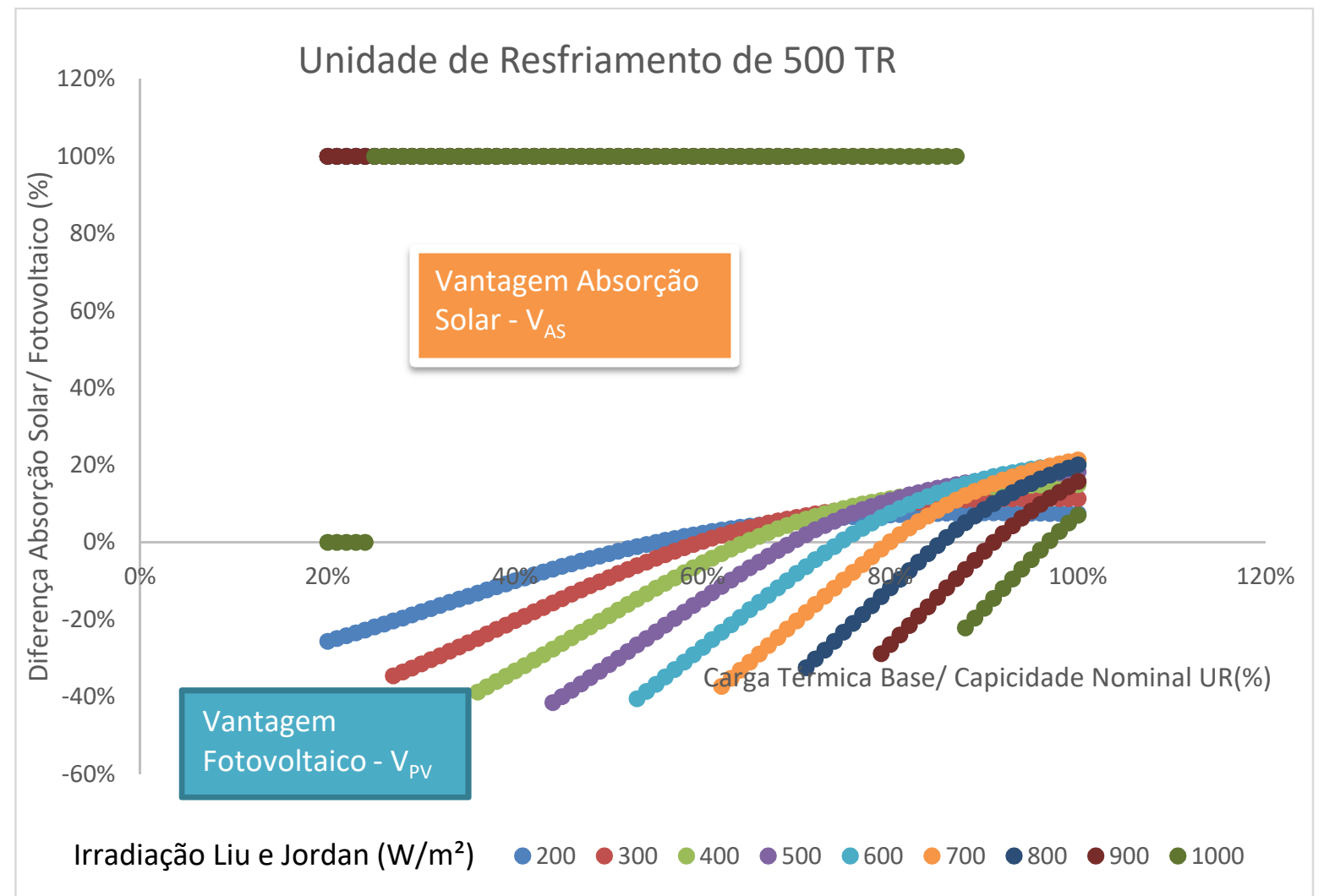

Figura 5.20. Indicação de utilização de tecnologia solar fotovoltaica ou de absorção solar pontual para rendimento médio de coletores em São Paulo, considerando $2,0 \mathrm{~kW} / \mathrm{m}^{2}$ 
$\mathrm{Na}$ maior unidade estudada para a carga de $8 \mathrm{~kW} / \mathrm{m}^{2}$, conclui-se que independente da radiação para altos carregamentos recomenda-se a absorção solar, ilustrado na Figura 5.21. No caso de utilização de resfriamento natural, a carga residual deverá ser utilizada como carga base para consulta dos gráficos.

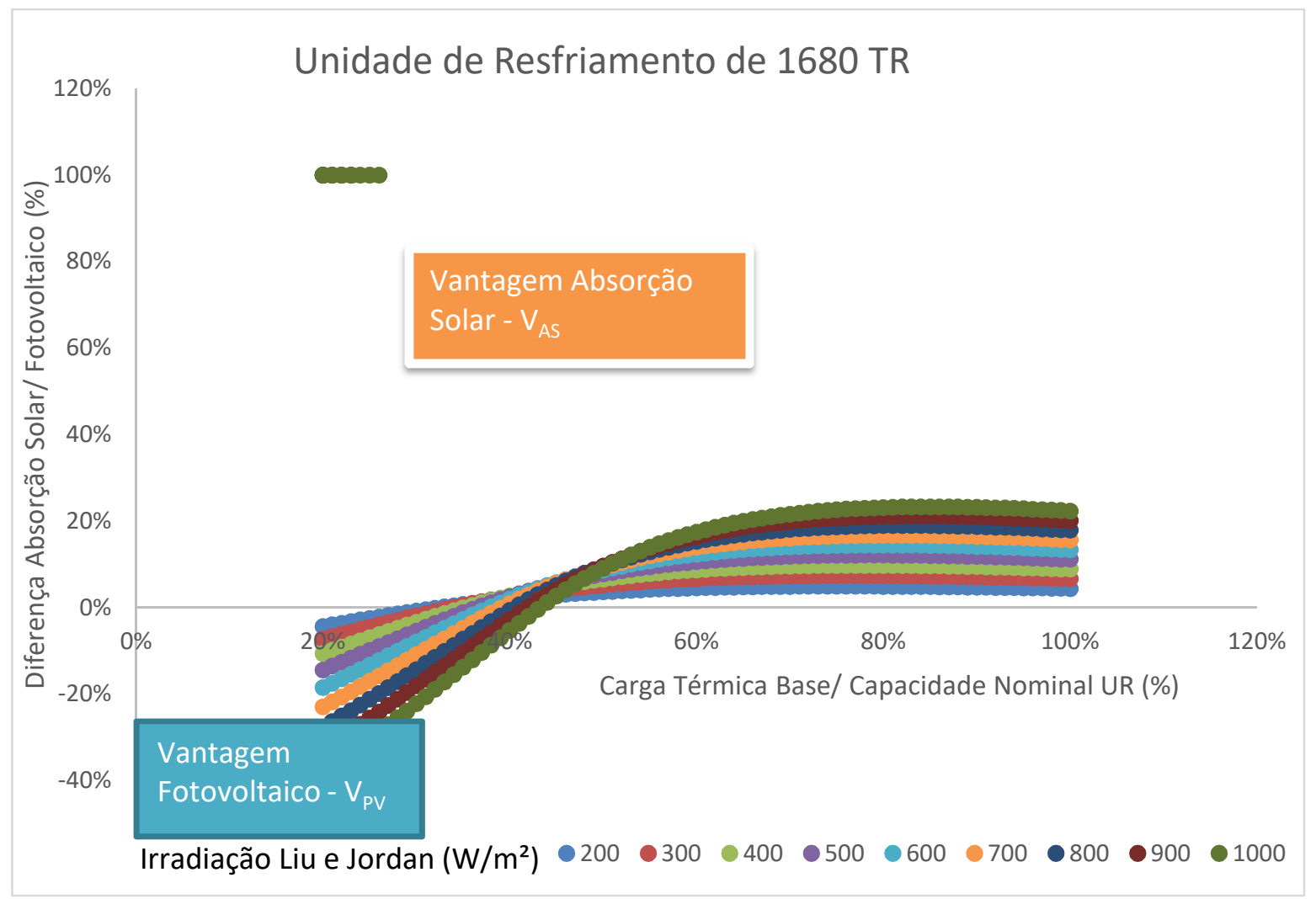

Figura 5.21. Indicação de utilização de tecnologia solar fotovoltaica ou de absorção solar pontual para rendimento médio de coletores em São Paulo, considerando $8,0 \mathrm{~kW} / \mathrm{m}^{2}$

A Figura 5.22 indica a utilização e COP anual para cada uma das tecnologias estudadas. As linhas indicam o percentil residual resfriado, pós aplicação de tecnologias solares e métodos de resfriamento natural para todas as densidades estudadas, as colunas indicam o COP médio da UR trabalhando com cargas residuais.

Nota-se que no caso de $2 \mathrm{~kW} / \mathrm{m}^{2}$, onde há vantagem na utilização de fotovoltaicas, o equipamento sem alterações em sua carga térmica trabalha mais próximo 
de seu ponto ótimo e isto se reflete em seu resultado face a absorção solar. Em outros casos há vantagem clara dos equipamentos de absorção solar.

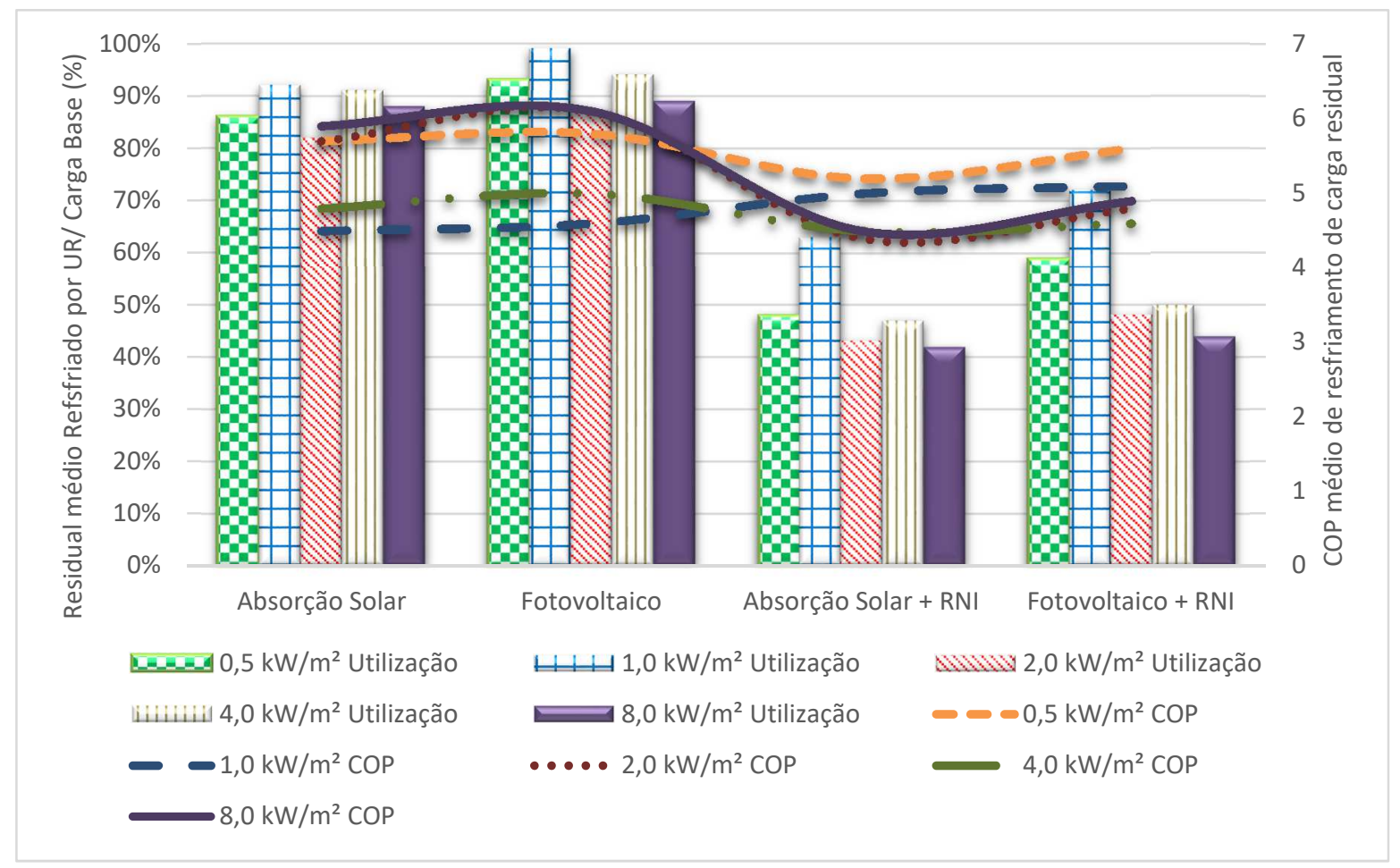

Figura 5.22. Indicação de utilização e COP para todas as densidades estudadas e tecnologias solares com e sem economizadores.

5.5. Tempo de retorno de investimento e taxa interna de retorno para 10 anos.

Outro aspecto de análise são os resultados financeiros, que incluem o preço de investimento inicial e a depreciação de equipamentos e coletores solares. Esta seção apresenta o tempo de retorno de investimento simples e a taxa interna de retorno das tecnologias solares aplicadas às mais vantajosas utilizações de tecnologias solares com e sem economizadores, considerando um período de utilização de 10 anos. Todos os cálculos relativos a tempo de retorno de investimento e taxa interna de retorno para 10 anos são apresentados no Anexo B desta tese.

A Tabela 5.7 apresenta amostralmente, o melhor método solar para cada uma das densidades de carga estudadas para diferentes variações de preço de tarifa regular 
e de ponta e utilização, sob o critério de economia de energia, tempo de retorno de investimento e taxa interna de retorno para 10 anos. Adicionalmente apresenta a pontuação que pode ser obtida no caso de certificação LEED $^{\odot}$ no critério economia de energia. Pontos adicionais referente a utilização de energia solar e inovação poderão ser obtidos conjuntamente, também neste cálculo serão excluídas cargas de processo dos servidores.

Tabela 5.7 - Seleção de método solar para economia de energia e taxa interna de retorno de investimento para a instalação desejada

\begin{tabular}{|c|c|c|c|c|c|c|c|c|}
\hline \multirow[b]{2}{*}{ Carga } & \multicolumn{4}{|c|}{ Tarifas } & \multicolumn{2}{|c|}{ Economia de Energia } & \multicolumn{2}{|c|}{ Taxa Interna de Retorno } \\
\hline & Tarif & & Tarif & & Melhor Método & $\mathrm{EAE} / \mathrm{CON}_{\text {Base }}$ & TIR 10A & Melhor Método2 \\
\hline $0,5 \mathrm{~kW} / \mathrm{m}^{2}$ & $\mathrm{R} S$ & 0,30 & $\mathrm{RS}$ & 0,30 & Absorção Solar & $38 \%$ & Inv & Caso Base \\
\hline $0,5 \mathrm{~kW} / \mathrm{m}^{2}$ & $\mathrm{RS}$ & 0,30 & RS & 0,56 & Absorção Solar & $31 \%$ & Inv & Caso Base \\
\hline $0,5 \mathrm{~kW} / \mathrm{m}^{2}$ & $\mathrm{RS}$ & 0,55 & $\mathrm{RS}$ & 0,69 & Absorção Solar & $36 \%$ & $\ln v$ & Caso Base \\
\hline $0,5 \mathrm{~kW} / \mathrm{m}^{2}$ & RS & 0,80 & $\mathrm{RS}$ & 1,20 & Absorção Solar & $34 \%$ & $7 \%$ & Absorção Solar \\
\hline $0,5 \mathrm{~kW} / \mathrm{m}^{2}$ & $\mathrm{RS}$ & 1,05 & RS & 1,84 & Absorção Solar & $32 \%$ & $18 \%$ & Absorção Solar \\
\hline $1 \mathrm{~kW} / \mathrm{m}^{2}$ & $\mathrm{RS}$ & 0,45 & $\mathrm{RS}$ & 0,45 & Absorção Solar & $52 \%$ & $\ln v$ & Caso Base \\
\hline $1 \mathrm{~kW} / \mathrm{m}^{2}$ & $\mathrm{R} \$$ & 0,45 & $\mathrm{R} \$$ & 0,85 & Absorção Solar & $42 \%$ & $2 \%$ & Absorção Solar \\
\hline $1 \mathrm{~kW} / \mathrm{m}^{2}$ & $\mathrm{R} \$$ & 0,70 & $\mathrm{R} \$$ & 0,88 & Absorção Solar & $49 \%$ & $10 \%$ & Absorção Solar \\
\hline $1 \mathrm{~kW} / \mathrm{m}^{2}$ & RS & 0,95 & $\mathrm{RS}$ & 1,43 & Absorção Solar & $46 \%$ & $23 \%$ & Absorção Solar \\
\hline $2 \mathrm{~kW} / \mathrm{m}^{2}$ & $\mathrm{RS}$ & 0,35 & $\mathrm{RS}$ & 0,61 & Resfriamento Fotovoltaico & $6 \%$ & $\ln v$ & Caso Base \\
\hline $2 \mathrm{~kW} / \mathrm{m}^{2}$ & RS & 0,60 & RS & 0,60 & Resfriamento Fotovoltaico & $3 \%$ & Inv & Caso Base \\
\hline $2 \mathrm{~kW} / \mathrm{m}^{2}$ & $\mathrm{RS}$ & 0,60 & $\mathrm{RS}$ & 1,13 & Resfriamento Fotovoltaico & $6 \%$ & Inv & Caso Base \\
\hline $2 \mathrm{~kW} / \mathrm{m}^{2}$ & $\mathrm{RS}$ & 0,85 & $\mathrm{RS}$ & 1,06 & Resfriamento Fotovoltaico & $4 \%$ & Inv & Caso Base \\
\hline $2 \mathrm{~kW} / \mathrm{m}^{2}$ & $\mathrm{RS}$ & 1,10 & RS & 1,65 & Resfriamento Fotovoltaico & $5 \%$ & $8 \%$ & Resfriamento Fotovoltaico \\
\hline $4 \mathrm{~kW} / \mathrm{m}^{2}$ & $\mathrm{RS}$ & 0,50 & RS & 0,88 & Absorção Solar & $43 \%$ & $8 \%$ & Absorção Solar \\
\hline $4 \mathrm{~kW} / \mathrm{m}^{2}$ & $\mathrm{R} \$$ & 0,75 & $\mathrm{R} \$$ & 0,75 & Absorção Solar & $50 \%$ & $8 \%$ & Absorção Solar \\
\hline $4 \mathrm{~kW} / \mathrm{m}^{2}$ & RS & 0,75 & RS & 1,41 & Absorção Solar & $43 \%$ & $23 \%$ & Absorção Solar \\
\hline $4 \mathrm{~kW} / \mathrm{m}^{2}$ & $\mathrm{RS}$ & 1,00 & $\mathrm{RS}$ & 1,25 & Absorção Solar & $47 \%$ & $23 \%$ & Absorção Solar \\
\hline $8 \mathrm{~kW} / \mathrm{m}^{2}$ & RS & 0,40 & RS & 0,60 & Absorção Solar & $32 \%$ & $\ln v$ & Caso Base \\
\hline $8 \mathrm{~kW} / \mathrm{m}^{2}$ & $\mathrm{R} \$$ & 0,65 & $\mathrm{R} \$$ & 1,14 & Absorção Solar & $31 \%$ & $19 \%$ & Absorção Solar \\
\hline $8 \mathrm{~kW} / \mathrm{m}^{2}$ & $\mathrm{RS}$ & 0,90 & $\mathrm{R} \$$ & 0,90 & Absorção Solar & $35 \%$ & $14 \%$ & Absorção Solar \\
\hline $8 \mathrm{~kW} / \mathrm{m}^{2}$ & $\mathrm{RS}$ & 0,90 & $\mathrm{R} \$$ & 1,69 & Absorção Solar & $31 \%$ & $25 \%$ & Absorção Solar \\
\hline
\end{tabular}

Neste caso, nota-se que em termos de economia de energia e pontuações para certificação ambiental, é sempre recomendada a utilização de algum método solar, todavia levando em consideração o investimento inicial, isto se reflete apenas em casos de alta densidade, tarifas não atrativas e aumento de tarifas no horário de pico. Em geral a absorção solar apresenta rendimentos superiores ao equipamento fotovoltaico, conforme apresentado na Figura 5.23. Neste caso o retorno do investimento inicial, nem sempre é garantido conforme é apresentado na Figura 5.24 em 38\% das proposições apresentadas não há retorno de investimento. Em 58\% utiliza-se absorção solar e somente em $4 \%$ dos casos utiliza-se resfriamento fotovoltaico. 


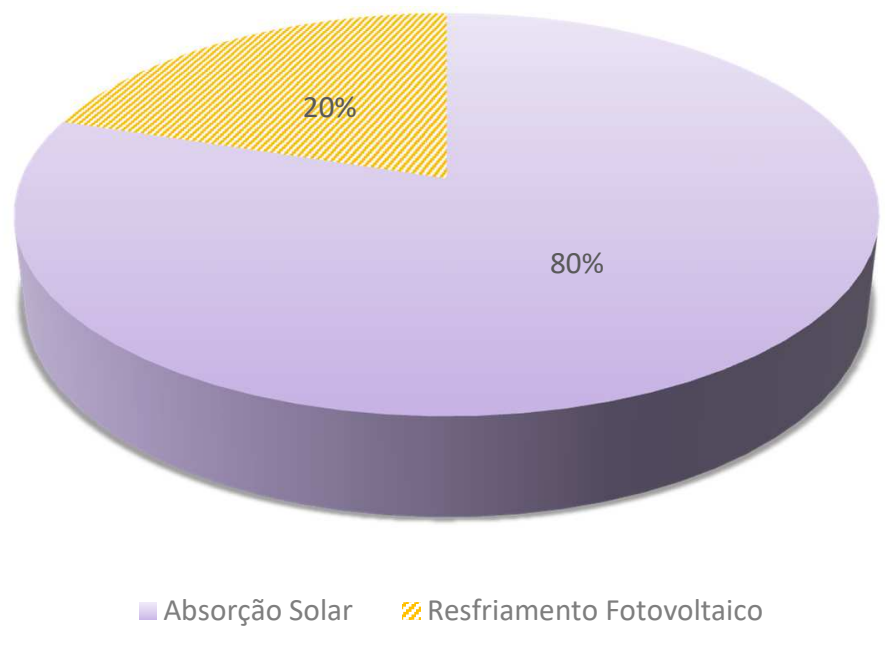

Figura 5.23. Melhor equipamento segundo critério de economia de energia

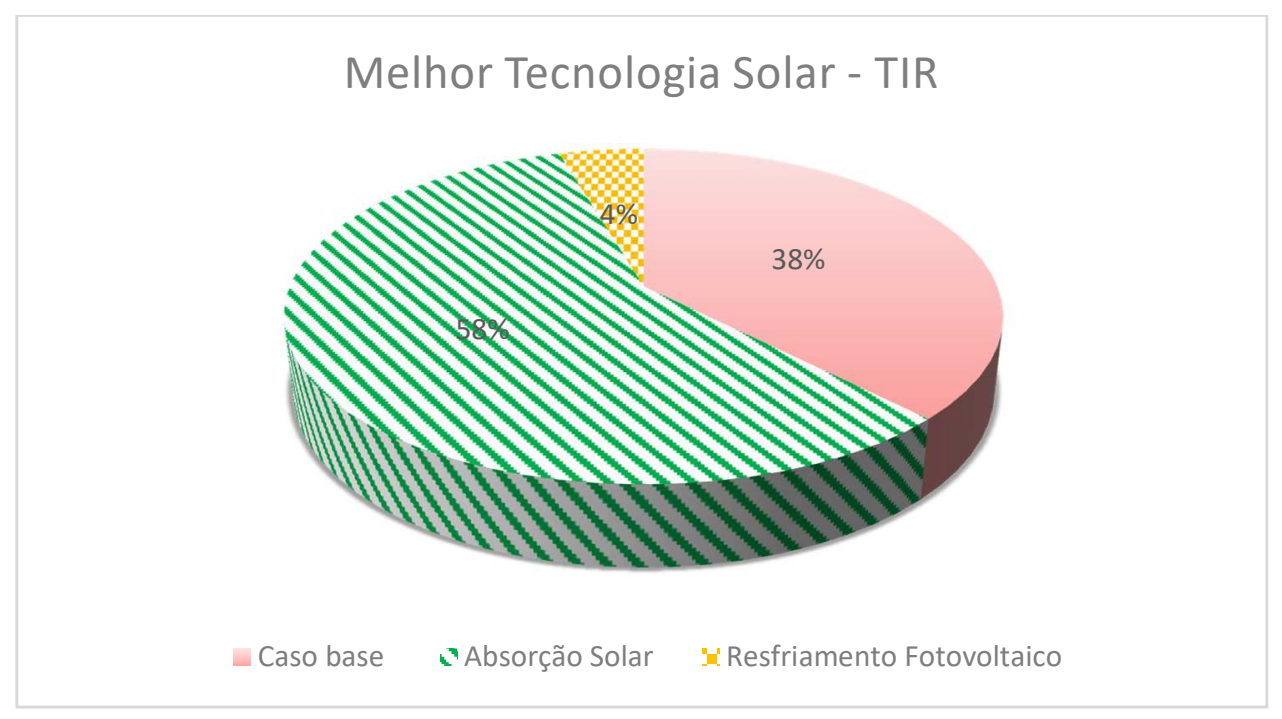

Figura 5.24. Melhor equipamento segundo critério de Taxa Interna de Retorno

Para a menor densidade estudada $\left(0,5 \mathrm{~kW} / \mathrm{m}^{2}\right)$, os resultados aparecem com tarifas superiores a $\mathrm{R} \$ 0,55$ e aumento de $88 \%$ desta no horário de ponta e para tarifas superiores a $R \$ 0,60$ centavos, quando não há diferenciação entre o horário de ponta e horário usual para absorção solar. 
Para densidades maiores percebem-se vantagens para tarifas mais baratas e maiores taxas de retorno. Para $1,0 \mathrm{~kW} / \mathrm{m}^{2}$ há vantagens em tarifas a partir de $\mathrm{R} \$ 0,45$ para uma relação tarifa de ponta sobre tarifa regular de 1,8, quando não há essa diferenciação as vantagens são evidentes a partir de $R \$ 0,55$. Para densidades de 4,0 $\mathrm{kW} / \mathrm{m}^{2}$ e $8,0 \mathrm{~kW} / \mathrm{m}^{2}$ há vantagens em tarifas a partir de $\mathrm{R} \$ 0,40$ para uma relação tarifa de ponta sobre tarifa regular de 1,8, quando não há essa diferenciação as vantagens são evidentes a partir de $\mathrm{R} \$ 0,60$ para absorção solar.

Nota-se que para uma densidade de $2,0 \mathrm{~kW} / \mathrm{m}^{2}$, o resfriamento fotovoltaico apresenta vantagens em relação a absorção solar. Isto ocorre porque o método de absorção solar infere diretamente na curva de rendimento do compressor. Isto é ilustrado nas figuras 5.25 e 5.26, que apresentam os resultados de taxa interna de retorno de investimento para 10 anos para todas as densidades estudadas e tarifa de $R \$ 1,10 \mathrm{com}$ variações da taxa de tarifa de ponta sobre regular entre 1 e 1,88 para absorção solar e resfriamento fotovoltaico respectivamente.

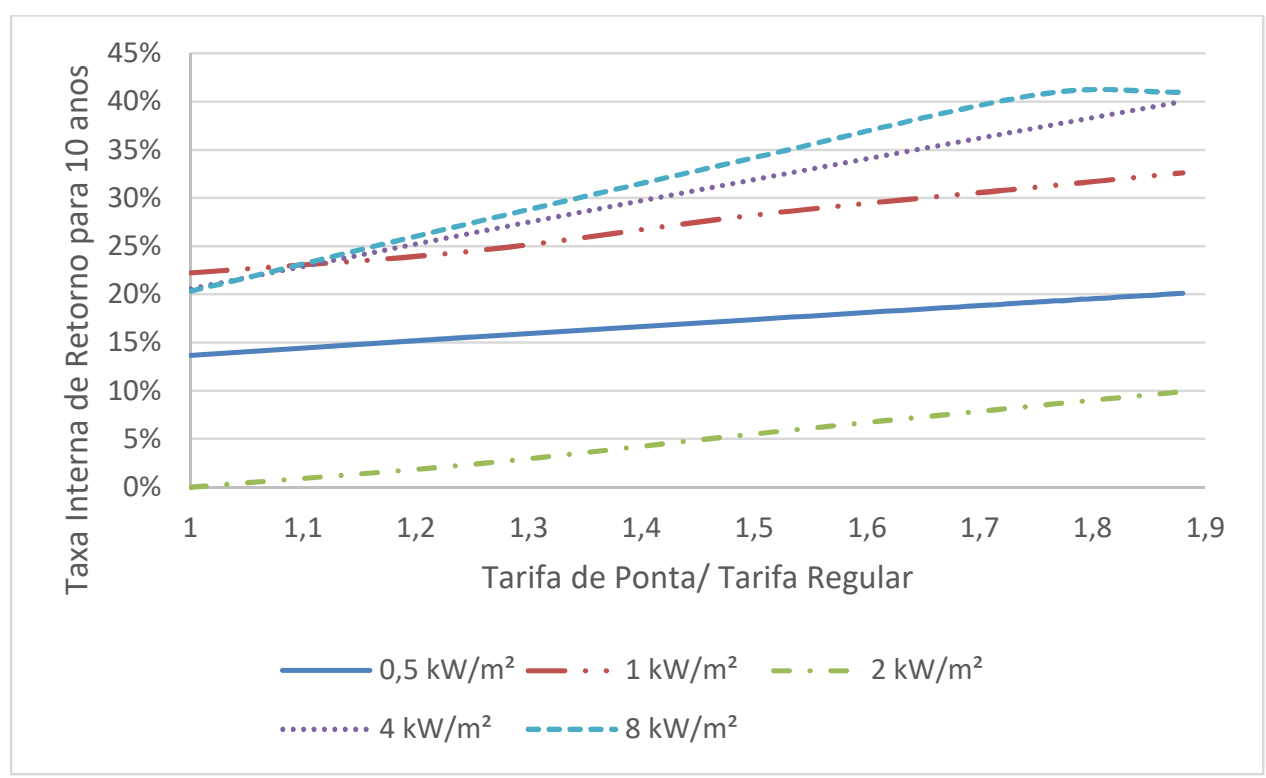

Figura 5.25. Taxa Interna de Retorno para Tarifa de R\$ 1,10 kWh para Absorção Solar 


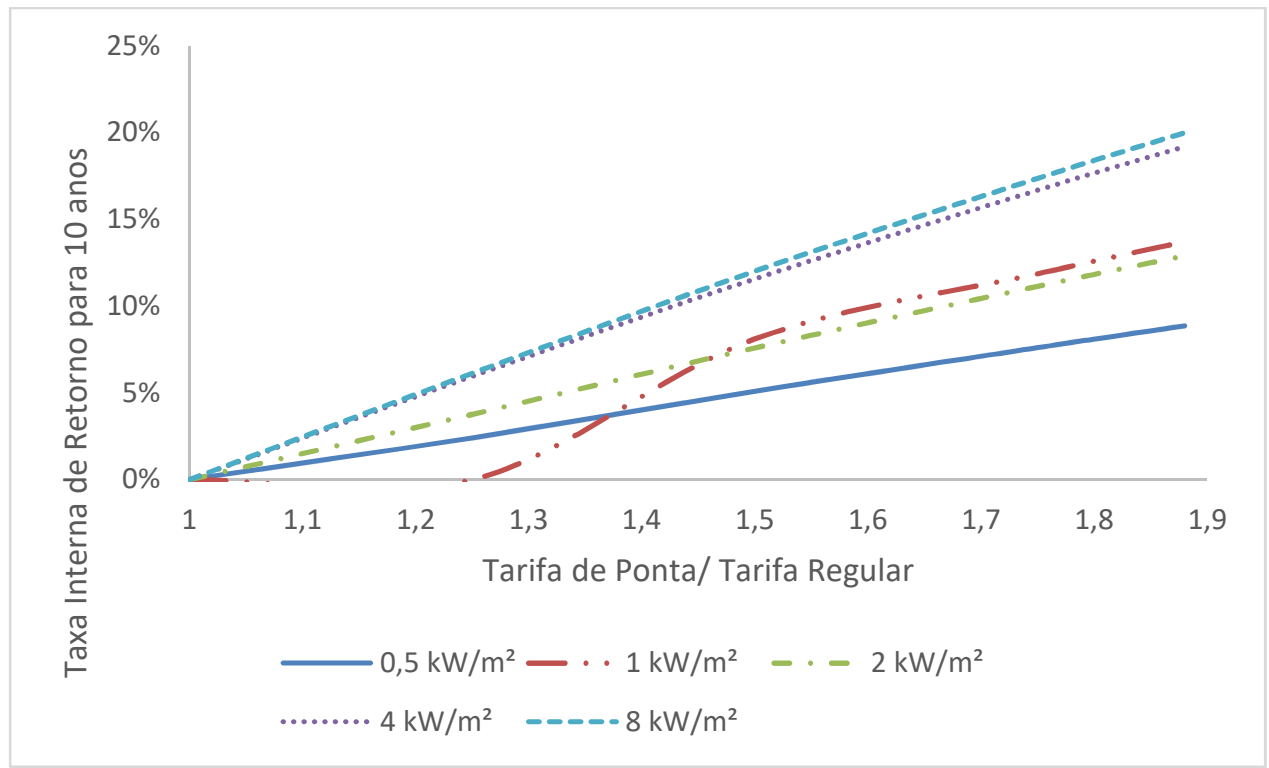

Figura 5.26. Taxa Interna de Retorno para Tarifa de $R \$ 1,10$ kWh para Resfriamento Fotovoltaico.

Neste caso a absorção solar faz com que o compressor opere em faixas de rendimento parciais baixas, conforme discutido na Seção 5.4 .

Outro ponto que deve ser avaliado é o melhor método com a inserção de economizadores. A Tabela 5.8 apresenta os dados de melhores métodos solares com a inserção de economizadores. 
Tabela 5.8 - Seleção de método solar com economizadores para economia de energia e taxa interna de retorno de investimento para a instalação desejada em São Paulo

\begin{tabular}{|c|c|c|c|c|c|c|c|c|}
\hline \multirow{3}{*}{$\begin{array}{l}\text { Carga } \\
0,5 \mathrm{~kW} / \mathrm{m}^{2}\end{array}$} & \multicolumn{4}{|c|}{ Tarifas } & \multicolumn{2}{|l|}{ Economia de Energia } & \multicolumn{2}{|r|}{ Taxa Interna de Retorno } \\
\hline & \multicolumn{2}{|c|}{ Tarifa FP } & \multicolumn{2}{|c|}{ Tarifa Ponta } & \multirow{2}{*}{\begin{tabular}{|l|} 
Melhor Método \\
Absorção Solar e Resfriamento Natural Indireto \\
\end{tabular}} & \multirow{2}{*}{\begin{tabular}{|r|} 
EAE/CON \\
$66 \%$
\end{tabular}} & \multirow{2}{*}{\begin{tabular}{|l|} 
TIR \\
Inv
\end{tabular}} & \multirow{2}{*}{\begin{tabular}{|l|} 
Melhor Método2 \\
Caso base e Economizadores \\
\end{tabular}} \\
\hline & $\mathrm{RS}$ & 0,30 & $\mathrm{RS}$ & 0,30 & & & & \\
\hline $0,5 \mathrm{~kW} / \mathrm{m}^{2}$ & $\mathrm{RS}$ & 0,30 & $\mathrm{RS}$ & 0,56 & Absorção Solar e Resfriamento Natural Indireto & $68 \%$ & Inv & Caso base e Economizadores \\
\hline $0,5 \mathrm{~kW} / \mathrm{m}^{2}$ & $\mathrm{RS}$ & 0,55 & RS & 0,69 & Absorção Solar e Resfriamento Natural Indireto & $66 \%$ & $11 \%$ & Absorção Solar e Resfriamento Natural Indireto \\
\hline $0,5 \mathrm{~kW} / \mathrm{m}^{2}$ & $\mathrm{R} \$$ & 0,80 & $\mathrm{R} S$ & 1,20 & Absorção Solar e Resfriamento Natural Indireto & $67 \%$ & $25 \%$ & Absorção Solar e Resfriamento Natural Indireto \\
\hline $0,5 \mathrm{~kW} / \mathrm{m}^{2}$ & RS & 1,05 & RS & 1,84 & Absorção Solar e Resfriamento Natural Indireto & $68 \%$ & $39 \%$ & Absorção Solar e Resfriamento Natural Indireto \\
\hline $1 \mathrm{~kW} / \mathrm{m}^{2}$ & RS & 0,45 & RS & 0,45 & Absorção Solar e Resfriamento Natural Indireto & $54 \%$ & $19 \%$ & Absorção Solar e Resfriamento Natural Indireto \\
\hline $1 \mathrm{~kW} / \mathrm{m}^{2}$ & RS & 0,45 & RS & 0,85 & Absorção Solar e Resfriamento Natural Indireto & $57 \%$ & $23 \%$ & Absorção Solar e Resfriamento Natural Indireto \\
\hline $1 \mathrm{~kW} / \mathrm{m}^{2}$ & $\mathrm{RS}$ & 0,70 & $\mathrm{RS}$ & 0,88 & Absorção Solar e Resfriamento Natural Indireto & $55 \%$ & $38 \%$ & Absorção Solar e Resfriamento Natural Indireto \\
\hline $1 \mathrm{~kW} / \mathrm{m}^{2}$ & RS & 0,95 & $\mathrm{RS}$ & 1,43 & Absorção Solar e Resfriamento Natural Indireto & $56 \%$ & $57 \%$ & Absorção Solar e Resfriamento Natural Indireto \\
\hline $2 \mathrm{~kW} / \mathrm{m}^{2}$ & $\mathrm{RS}$ & 0,35 & $\mathrm{R} \$$ & 0,61 & Absorção Solar e Resfriamento Natural Indireto & $62 \%$ & $13 \%$ & Absorção Solar e Resfriamento Natural Indireto \\
\hline $2 \mathrm{~kW} / \mathrm{m}^{2}$ & RS & 0,60 & $\mathrm{RS}$ & 0,60 & Absorção Solar e Resfriamento Natural Indireto & $60 \%$ & $29 \%$ & Absorção Solar e Resfriamento Natural Indireto \\
\hline $2 \mathrm{~kW} / \mathrm{m}^{2}$ & $\mathrm{RS}$ & 0,60 & $\mathrm{RS}$ & 1,13 & Absorção Solar e Resfriamento Natural Indireto & $63 \%$ & $34 \%$ & Absorção Solar e Resfriamento Natural Indireto \\
\hline $2 \mathrm{~kW} / \mathrm{m}^{2}$ & RS & 0,85 & $\mathrm{RS}$ & 1,06 & Absorção Solar e Resfriamento Natural Indireto & $61 \%$ & $47 \%$ & Absorção Solar e Resfriamento Natural Indireto \\
\hline $2 \mathrm{~kW} / \mathrm{m}^{2}$ & RS & 1,10 & $\mathrm{R} \$$ & 1,65 & Absorção Solar e Resfriamento Natural Indireto & $62 \%$ & $66 \%$ & Absorção Solar e Resfriamento Natural Indireto \\
\hline $4 \mathrm{~kW} / \mathrm{m}^{2}$ & RS & 0,50 & $\mathrm{RS}$ & 0,88 & Absorção Solar e Resfriamento Natural Indireto & $61 \%$ & $99 \%$ & Fotovoltaico + resfriamento Natural indireto \\
\hline $4 \mathrm{~kW} / \mathrm{m}^{2}$ & $\mathrm{RS}$ & 0,75 & $\mathrm{RS}$ & 0,75 & Absorção Solar e Resfriamento Natural Indireto & $59 \%$ & $134 \%$ & Absorção Solar e Resfriamento Natural Indireto \\
\hline $4 \mathrm{~kW} / \mathrm{m}^{2}$ & RS & 0,75 & RS & 1,41 & Absorção Solar e Resfriamento Natural Indireto & $62 \%$ & $154 \%$ & Fotovoltaico + resfriamento Natural indireto \\
\hline $4 \mathrm{~kW} / \mathrm{m}^{2}$ & $\mathrm{RS}$ & 1,00 & $\mathrm{R} S$ & 1,25 & Absorção Solar e Resfriamento Natural Indireto & $60 \%$ & $188 \%$ & Fotovoltaico + resfriamento Natural indireto \\
\hline $8 \mathrm{~kW} / \mathrm{m}^{2}$ & $\mathrm{R} \$$ & 0,40 & RS & 0,60 & Absorção Solar e Resfriamento Natural Indireto & $49 \%$ & $103 \%$ & Fotovoltaico + resfriamento Natural indireto \\
\hline $8 \mathrm{~kW} / \mathrm{m}^{2}$ & $\mathrm{RS}$ & 0,65 & $\mathrm{R} \$$ & 1,14 & Absorção Solar e Resfriamento Natural Indireto & $50 \%$ & $179 \%$ & Fotovoltaico + resfriamento Natural indireto \\
\hline $8 \mathrm{~kW} / \mathrm{m}^{2}$ & RS & 0,90 & $\mathrm{R} \$$ & 0,90 & Absorção Solar e Resfriamento Natural Indireto & $48 \%$ & $201 \%$ & Fotovoltaico + resfriamento Natural indireto \\
\hline $8 \mathrm{~kW} / \mathrm{m}^{2}$ & RS & 0,90 & $\mathrm{RS}$ & 1,69 & Fotovoltaico + resfriamento Natural indireto & $50 \%$ & $256 \%$ & Fotovoltaico + resfriamento Natural indireto \\
\hline
\end{tabular}

Nesse caso, com a inserção dos economizadores por resfriamento natural indireto, o método de absorção solar torna-se o principal método de resfriamento solar.

Neste caso há uma grande parcela da carga térmica que é atendida pelos economizadores. Nota-se que para cargas de 0,5, 1 e $2 \mathrm{~kW} / \mathrm{m}^{2}$, o melhor método é o de absorção solar associado ao resfriamento natural indireto. Para 4 e $8 \mathrm{~kW} / \mathrm{m}^{2}$ onde há baixas tarifas e baixa diferenciação entre tarifas regulares e tarifas de ponta. Para maiores tarifas regulares e de ponta utiliza-se resfriamento fotovoltaico. Isto ocorre pois nestes casos a economia apresentada é similar, e as vantagens de um método solar em face ao outro estão associadas ao custo de aquisição.

A Figura 5.27 apresenta os valores sobre melhor tecnologia solares associada ao uso de economizadores segundo economia de energia. A Figura 5.28 apresenta valores similares segundo critério de taxa interna de retorno para 10 anos. Comparando face a não utilização dos economizadores, segundo a taxa de interna de retorno apenas $2 \%$ dos casos apresenta inviabilidade. 


\section{Melhor utilização de Tecnologias Solares com \\ Economizadores - Critério Economia de Energia}

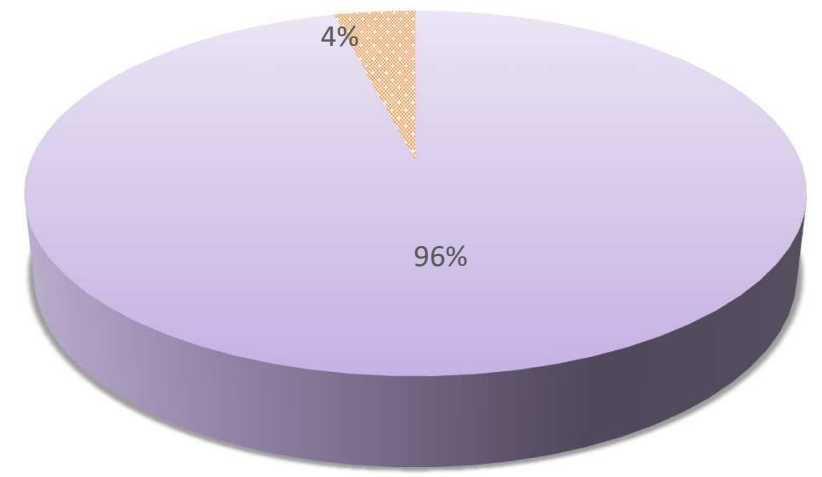

absorção Solar e Resfriamento Natural Indireto : Fotovoltáica + Resfriamento Natural indireto

Figura 5.27. Melhor tecnologia solar associada a economizadores segundo economia de energia.

Melhor utilização de Tecnologias Solares com

Economizadores - Critério TIR

Fotovoltáica +

Economizadores

Resfriamento Natural

indireto

$33 \%$

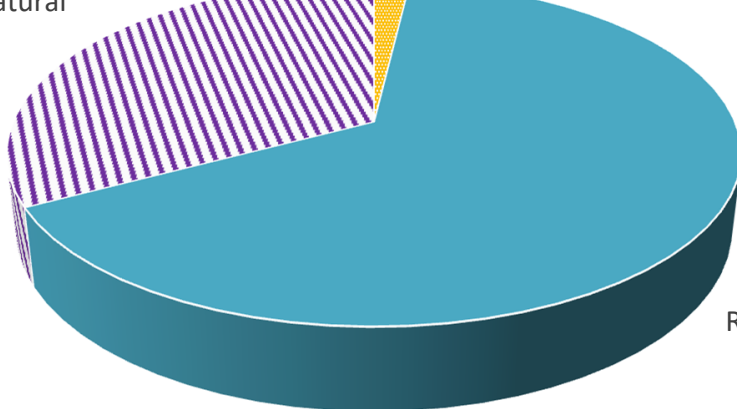

Absorção Solar e

Resfriamento Natural Indireto

$65 \%$

- Caso base e Economizadores

- Absorção Solar e Resfriamento Natural Indireto

、 Fotovoltáica + Resfriamento Natural indireto

Figura 5.28. Melhor tecnologia solar associada a economizadores segundo taxa interna de retorno para 10 anos. 
As Figuras 5.29 e 5.30, que apresentam os resultados de taxa interna de retorno de investimento para 10 anos para todas as densidades estudadas e tarifa de $R \$ 1,10$ com variações da taxa de tarifa de ponta sobre regular entre 1 e 1,88 para absorção solar com resfriamento natural indireto e resfriamento fotovoltaico com resfriamento natural indireto, respectivamente.

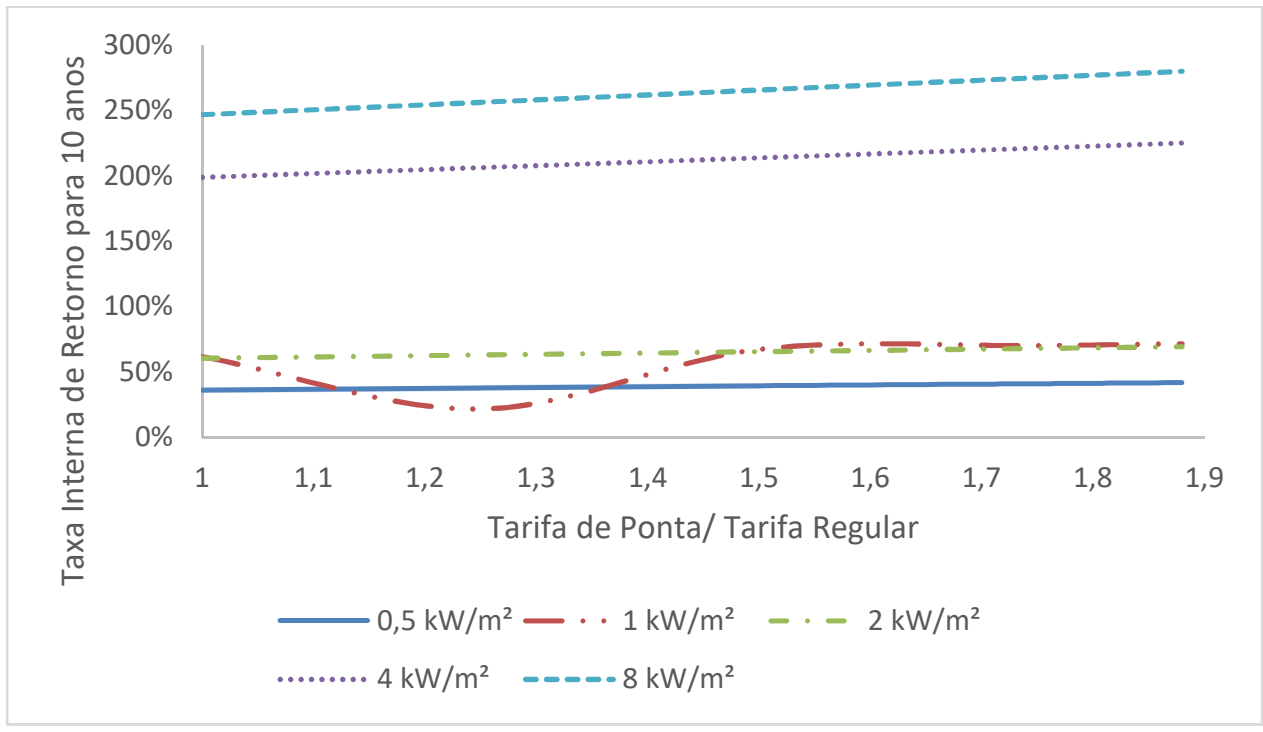

Figura 5.29. Taxa Interna de Retorno para Tarifa de $R \$ 1,10 \mathrm{kWh}$ para Absorção Solar com resfriamento natural indireto

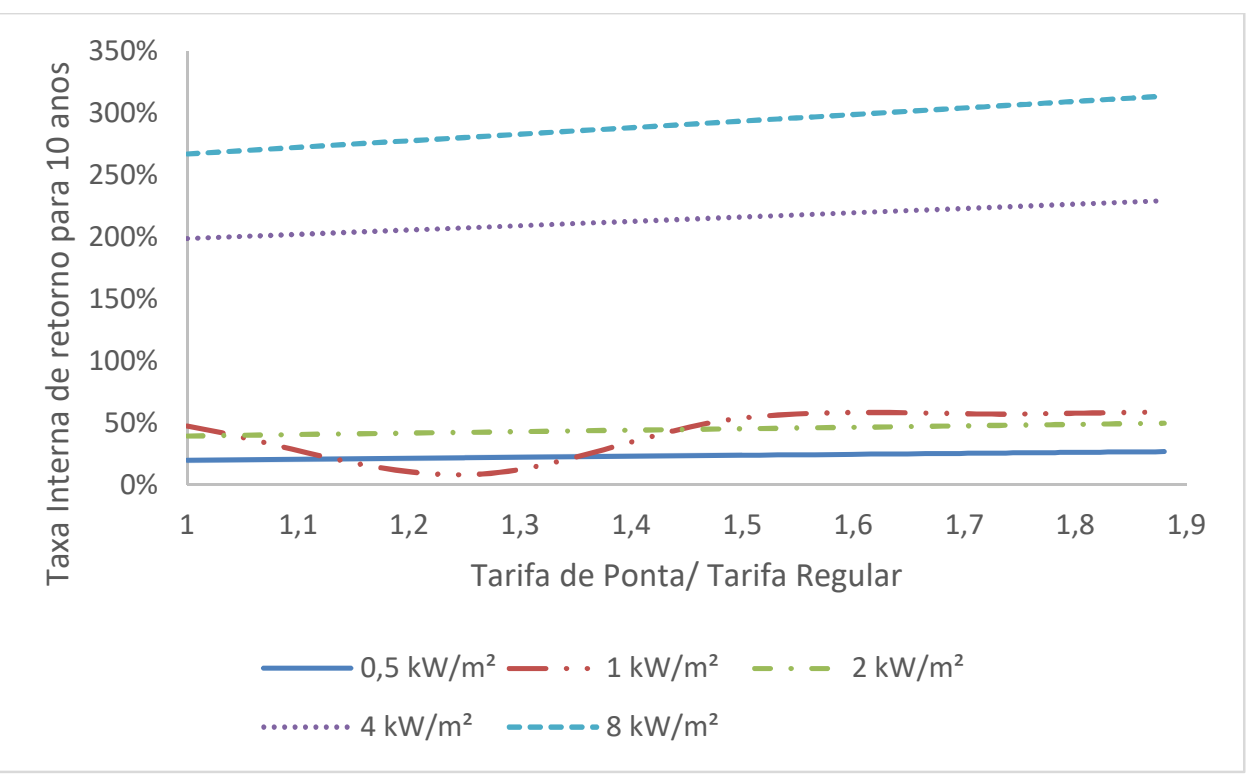

Figura 5.30. Taxa Interna de Retorno para Tarifa de $\mathbf{R} \$ 1,10 \mathrm{kWh}$ para Resfriamento Fotovoltaico com resfriamento natural indireto 
A Tabela 5.10 mostra a tarifa inicial cuja há vantagem demonstrada para a cidade de São Paulo e compressores parafusos. O melhor método é o de absorção solar, exceto para a carga de $2 \mathrm{~kW} / \mathrm{m}^{2}$, pois segundo o dimensionamento aqui proposto, opera próximo de seu ponto ótimo. Todavia só há retorno de investimento para 10 anos quando a tarifa é superior a $R \$ 0,60$ para o máximo proposto de aumento em horário de ponta (88\%) para $0,5 \mathrm{~kW} / \mathrm{m}^{2}$ e $\mathrm{R} \$ 0,70$ para quando não há diferencial entre horário de ponta e regular.

Quando associado a métodos de resfriamento natural, os resfriadores solares apresentam viabilidade para todas as tarifas. 


\section{CAPÍTULO 6 - DISCUSSÃO DE RESULTADOS - VARIAÇÃO DE ZONA CLIMÁTICA, TECNOLOGIA DE UR E UTILIZAÇÃO}

Este capítulo apresenta os valores de economia de energia e taxa interna de retorno para 10 anos para as demais localidades em regiões climáticas diferentes comparativamente ao caso base. Apresenta também a variação do caso base utilizando unidades de resfriamento acionadas por compressores do tipo centrífugo e a variação do caso base de data center para loja de departamentos. Ao final, juntamente com o capítulo 5 propicia o dados e discussões para as conclusões apresentadas a seguir. 


\subsection{Utilização do mesmo sistema em cidades de zonas climáticas distintas.}

Para efeitos de comparação aplicando ao mesmo modelo, será avaliado os resultados para mesma edificação característica em cidades de outras três regiões climáticas, sendo:

- Abu Dhabi, localizada nos Emirados Árabes Unidos, no Oriente Médio, zona climática I da ASHRAE, definida como muito quente e úmida (ASHRAE, 2006).

- Los Angeles, localizada nos Estados Unidos da América, zona climática III da ASHRAE, definida como quente e seca (ASHRAE, 2006).

- Nova York, localizada nos Estados Unidos da América, zona climática IV da ASHRAE, definida como quente e seca (ASHRAE, 2006).

\subsubsection{Zona 1 - Abu Dhabi}

Utilizando a mesma edificação e proposições para a Abu Dhabi, cidade localizada no Oriente médio, considerada Zona 1 pela $A S H R A E \AA$, sendo cidade quente e úmida. $A$ temperatura de bulbo seco máxima para Abu Dhabi nos últimos 20 anos é de $48,8^{\circ} \mathrm{C}$ com temperatura de bulbo úmido respectiva de $33,3^{\circ} \mathrm{C}$, a mínima é de $6,7^{\circ} \mathrm{C}$ e TBU 3 ${ }^{\circ} \mathrm{C}$. Para demais projetos utiliza-se $43,3{ }^{\circ} \mathrm{C}$ e $23,6^{\circ} \mathrm{C}$ (ASHRAE, 2017).

A Figura 6.1 apresenta um gráfico de dia típico de verão, onde as barras representam as temperaturas de bulbo seco e úmido e as linhas apresentam a radiação total e direta. Nota-se que é comum temperatura superiores a $40^{\circ} \mathrm{C}$ em dias de verão, e a temperatura de bulbo úmido apresenta números próximos a temperatura de bulbo seco, resultando em baixos índices de umidade. 


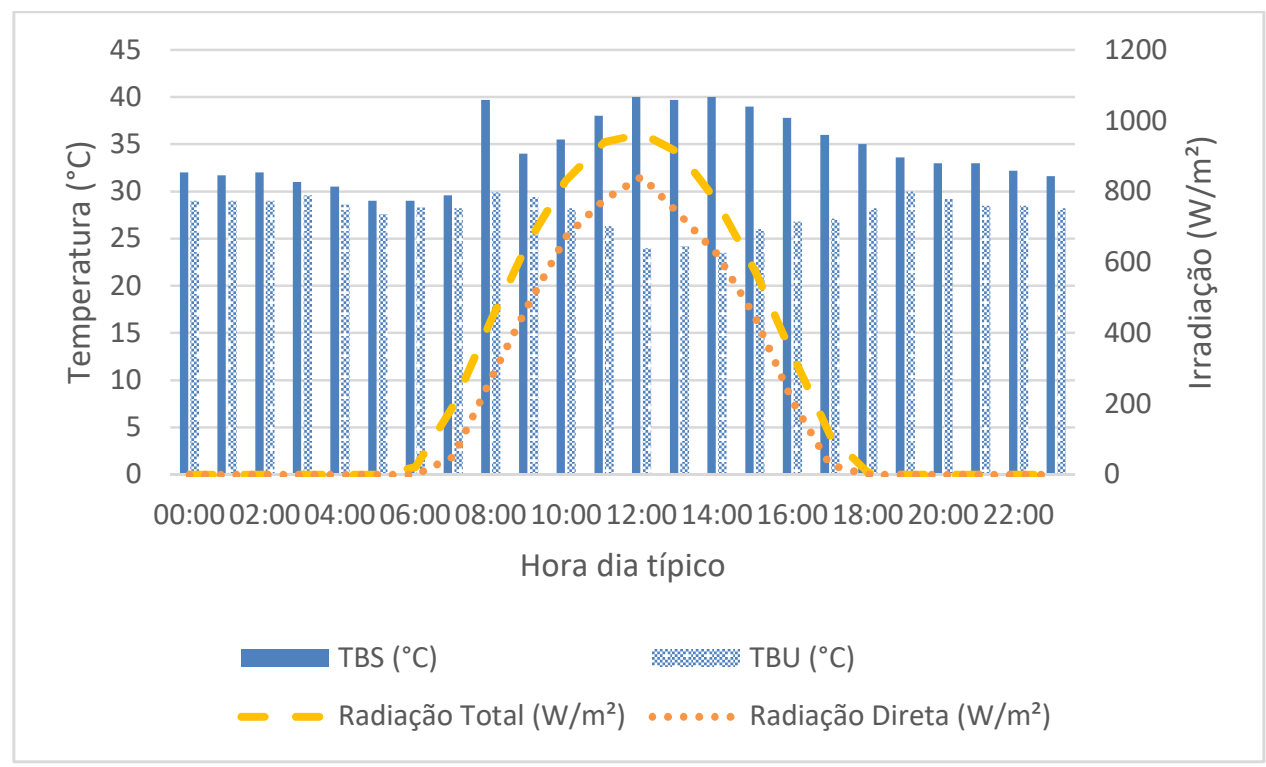

Figura 6.1 Irradiação típica e temperatura em dia típico de verão (11 de setembro).

Em um dia típico de inverno, apresentado na Figura 6.2, há alta variação de temperatura. A Temperatura de bulbo seco supera os $30^{\circ} \mathrm{C}$ durante o dia e durante a noite é inferior a $15^{\circ} \mathrm{C}$. Nota-se também dias geralmente secos pela alta diferença entre temperatura de bulbo úmido e bulbo seco.

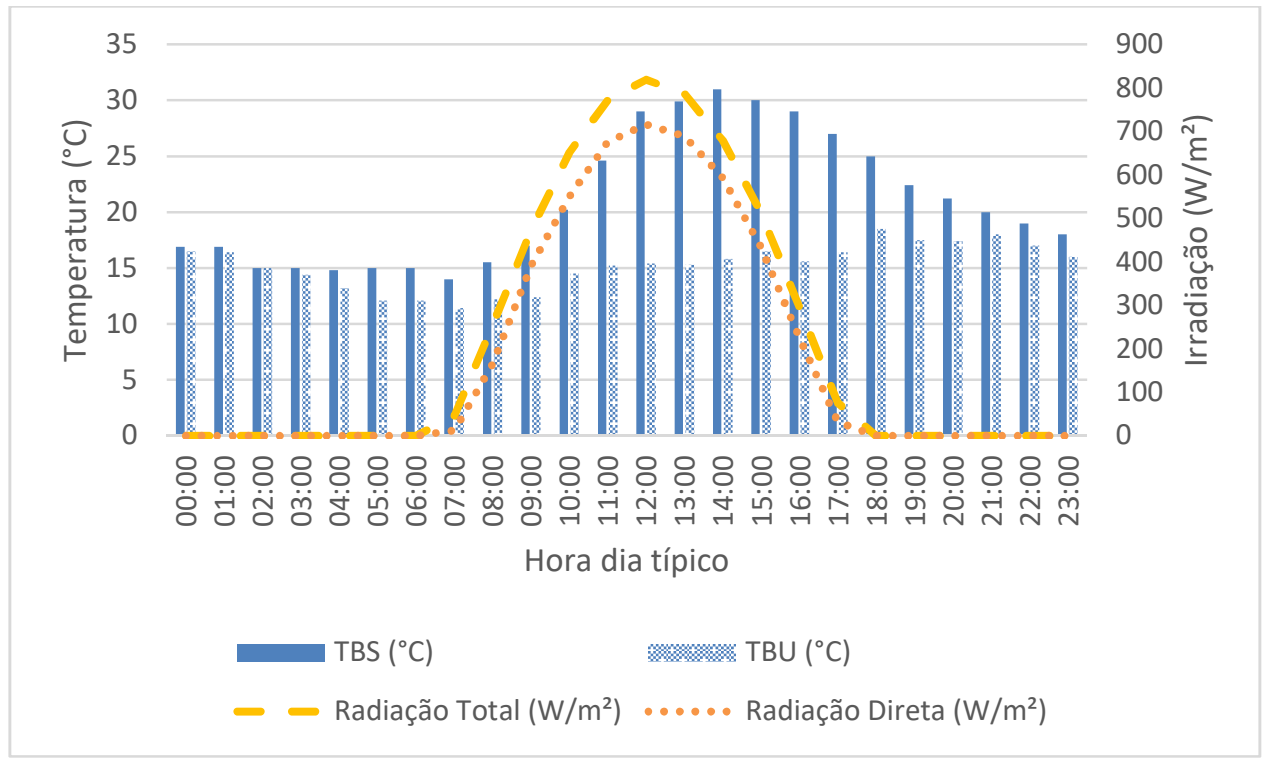

Figura 6.2. Irradiação típica e temperatura em dia típico de inverno (04 de fevereiro). 
Efetuando toda a mesma metodologia apresentada para São Paulo, nota-se que há um maior aproveitamento de tecnologias solares que na cidade base, todavia um menor aproveitamento de economizadores. A Figura 6.3 mostra a distribuição da disponibilidade de cada método de tecnologia solar ou economizador para cada densidade de carga por metro quadrado. Nota-se nesta figura a probabilidade de utilização de quase em todos os dias do ano de resfriamento natural, todavia esta carga em muitos casos pouco contribui no resfriamento da carga térmica, em muitos casos atingindo menos de $1 \%$ do valor requerido no caso de resfriamento natural indireto $\mathrm{e}$ completamente inviável no caso de resfriamento natural direto.

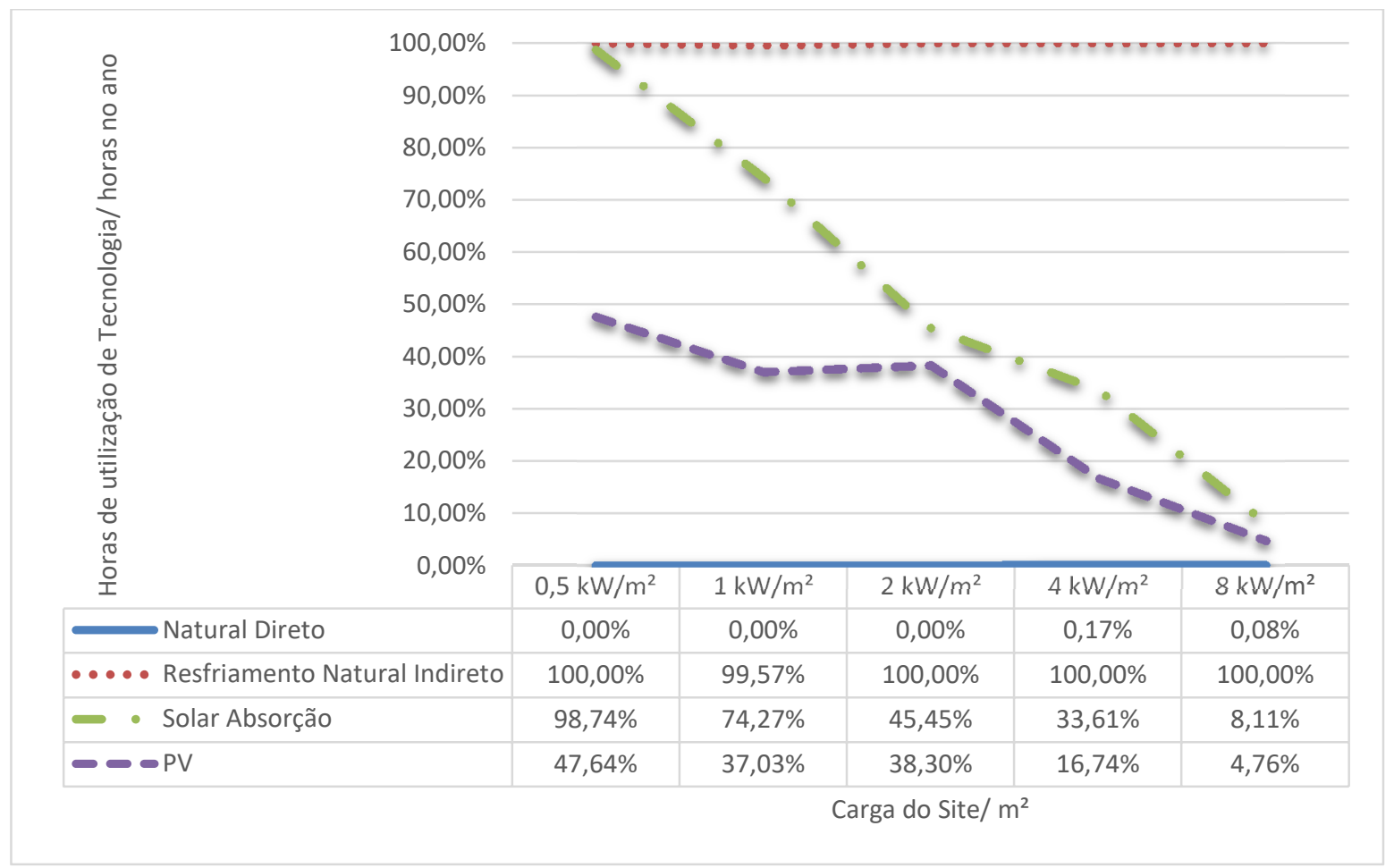

Figura 6.3. Utilização de Economizadores e métodos de resfriamento solar sobre carga total para densidades de carga estudadas para Abu Dhabi.

Um dado relevante apresentado na Figura 6.3 é a alta disponibilidade de resfriamento solar por absorção, o que significa que o horário de ponta é quase que em sua totalidade atendido por este sistema e ainda há sobra para realizar altas contribuições em horários regulares. 
A Figura 6.4 apresenta a evolução de COP nas barras e utilização residual em face a utilização total para cada uma das tecnologias e densidades de cargas aplicadas. Nota-se queda nos valores de COP quando há utilização de resfriamento natural indireto. Isto resulta em pouca vantagem na utilização de economizadores, sendo em alguns casos vantajosa a não aplicação destes.

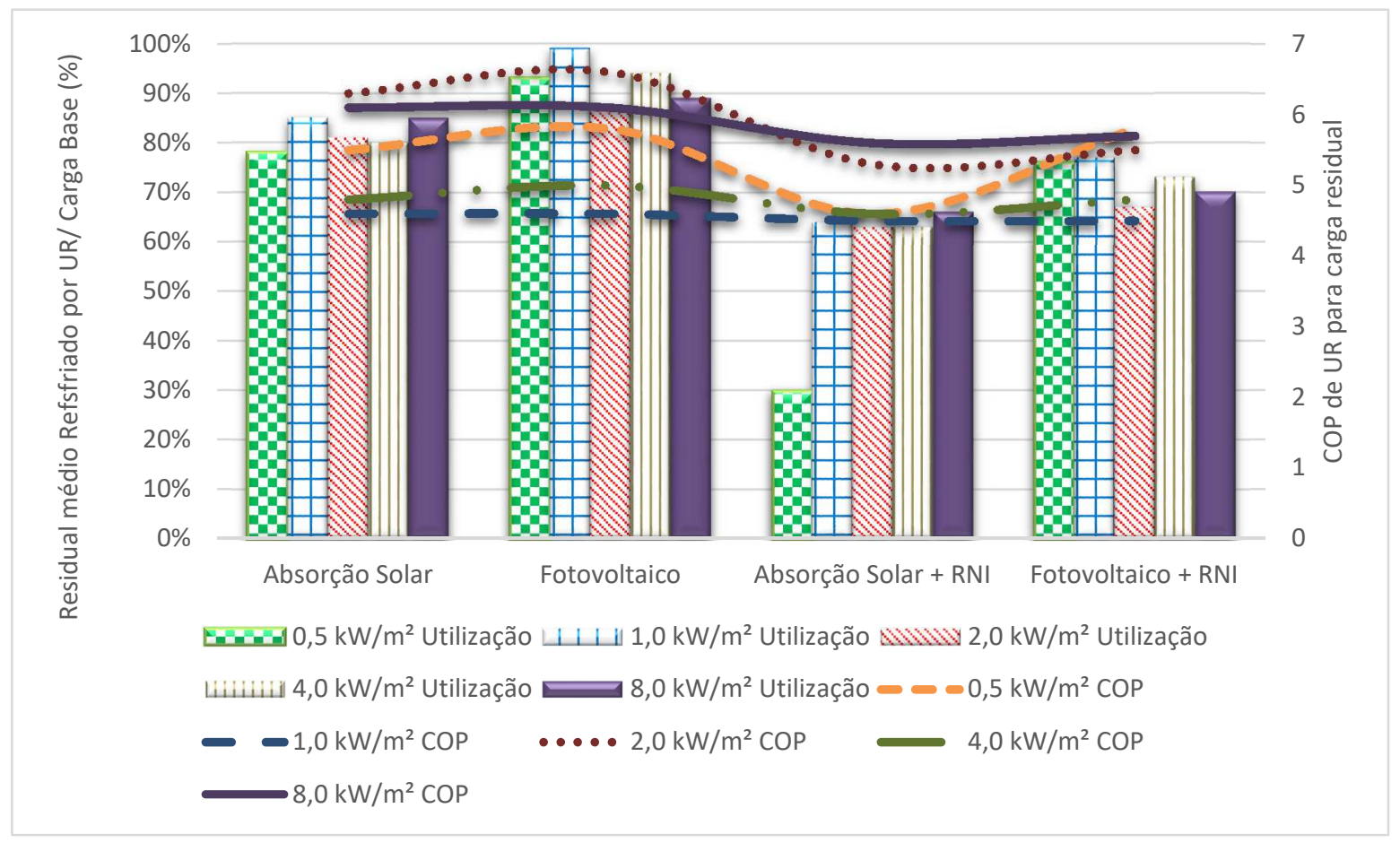

Figura 6.4 Indicação de utilização e COP para todas as densidades estudas e tecnologias solares com e sem economizadores para Abu Dhabi.

Outro ponto importante para esta localização e cidades de clima similar é a maior irradiação solar disponível, que resulta em melhores resultados para os sistemas de absorção solar comparativamente à São Paulo. Os coletores fornecem mais energia ao sistema e as eficiências de unidades de resfriamento de água se mantém, embora há relevantes ganhos em utilizações de células fotovoltaicas, todavia a alta temperatura reduz a eficiência destas. A Tabela 6.1, apresenta melhor método segundo economia de energia em sua quarta coluna e respectiva economia percentual subsequentemente, além da pontuação atingida para uma edificação que deseja obter uma certificação do 
tipo LEED $^{\odot}$. A taxa interna de retorno atingida em 10 anos e melhor método segundo este critério para tecnologias solares é apresentada na sétima e oitava coluna.

Tabela 6.1 - Seleção de método solar para economia de energia e taxa interna de retorno de investimento para a instalação desejada em Abu Dhabi

\begin{tabular}{|c|c|c|c|c|c|c|c|c|}
\hline \multirow{3}{*}{$\begin{array}{l}\text { Carga } \\
0,5 \mathrm{~kW} / \mathrm{m}^{2}\end{array}$} & \multicolumn{4}{|c|}{ Tarifas } & \multicolumn{2}{|c|}{ Economia de Energia } & \multicolumn{2}{|c|}{ Taxa Interna de Retorno } \\
\hline & \multicolumn{2}{|c|}{ Tarifa FP } & \multicolumn{2}{|c|}{ Tarifa Ponta } & \multirow{2}{*}{$\begin{array}{l}\text { Melhor Método } \\
\text { Absorção Solar }\end{array}$} & \multirow{2}{*}{$\begin{array}{r}\mathrm{EAE} / \mathrm{CON}_{\text {Base }} \\
56 \% \\
\end{array}$} & \multirow{2}{*}{$\begin{array}{l}\text { TIR } \\
5 \% \\
\end{array}$} & \multirow{2}{*}{\begin{tabular}{|l} 
Melhor Método2 \\
Absorção Solar \\
\end{tabular}} \\
\hline & $\mathrm{R} \$$ & 0,30 & $\mathrm{R} \$$ & 0,30 & & & & \\
\hline $0,5 \mathrm{~kW} / \mathrm{m}^{2}$ & $\mathrm{R} \$$ & 0,30 & $\mathrm{R} \$$ & 0,56 & Absorção Solar & $52 \%$ & $12 \%$ & Absorção Solar \\
\hline $0,5 \mathrm{~kW} / \mathrm{m}^{2}$ & $\mathrm{R} \$$ & 0,55 & $\mathrm{R} \$$ & 0,69 & Absorção Solar & $55 \%$ & $26 \%$ & Absorção Solar \\
\hline $0,5 \mathrm{~kW} / \mathrm{m}^{2}$ & $\mathrm{R} \$$ & 0,80 & $\mathrm{R} \$$ & 1,20 & Absorção Solar & $54 \%$ & $44 \%$ & Absorção Solar \\
\hline $0,5 \mathrm{~kW} / \mathrm{m}^{2}$ & $\mathrm{R} \$$ & 1,05 & $\mathrm{R} \$$ & 1,84 & Absorção Solar & $53 \%$ & $61 \%$ & Absorção Solar \\
\hline $1 \mathrm{~kW} / \mathrm{m}^{2}$ & $\mathrm{R} \$$ & 0,45 & $\mathrm{R} \$$ & 0,45 & Absorção Solar & $67 \%$ & $28 \%$ & Absorção Solar \\
\hline $1 \mathrm{~kW} / \mathrm{m}^{2}$ & $\mathrm{R} \$$ & 0,45 & $\mathrm{R} \$$ & 0,85 & Absorção Solar & $60 \%$ & $33 \%$ & Absorção Solar \\
\hline $1 \mathrm{~kW} / \mathrm{m}^{2}$ & $\mathrm{R} \$$ & 0,70 & $\mathrm{R} \$$ & 0,88 & Absorção Solar & $65 \%$ & $52 \%$ & Absorção Solar \\
\hline $1 \mathrm{~kW} / \mathrm{m}^{2}$ & $\mathrm{R} \$$ & 0,95 & $\mathrm{R} \$$ & 1,43 & Absorção Solar & $63 \%$ & $75 \%$ & Absorção Solar \\
\hline $2 \mathrm{~kW} / \mathrm{m}^{2}$ & $\mathrm{R} \$$ & 0,35 & $\mathrm{R} \$$ & 0,61 & Absorção Solar & $32 \%$ & $3 \%$ & Absorção Solar \\
\hline $2 \mathrm{~kW} / \mathrm{m}^{2}$ & $\mathrm{R} \$$ & 0,60 & $\mathrm{R} \$$ & 0,60 & Absorção Solar & $37 \%$ & $15 \%$ & Absorção Solar \\
\hline $2 \mathrm{~kW} / \mathrm{m}^{2}$ & $\mathrm{R} \$$ & 0,60 & $\mathrm{R} \$$ & 1,13 & Absorção Solar & $31 \%$ & $21 \%$ & Absorção Solar \\
\hline $2 \mathrm{~kW} / \mathrm{m}^{2}$ & $\mathrm{R} \$$ & 0,85 & $\mathrm{R} \$$ & 1,06 & Absorção Solar & $35 \%$ & $30 \%$ & Absorção Solar \\
\hline $2 \mathrm{~kW} / \mathrm{m}^{2}$ & $\mathrm{R} \$$ & 1,10 & $\mathrm{R} \$$ & 1,65 & Absorção Solar & $33 \%$ & $44 \%$ & Absorção Solar \\
\hline $4 \mathrm{~kW} / \mathrm{m}^{2}$ & $\mathrm{R} \$$ & 0,50 & $\mathrm{R} \$$ & 0,88 & Absorção Solar & $55 \%$ & $40 \%$ & Absorção Solar \\
\hline $4 \mathrm{~kW} / \mathrm{m}^{2}$ & $\mathrm{R} \$$ & 0,75 & $\mathrm{R} \$$ & 0,75 & Absorção Solar & $64 \%$ & $48 \%$ & Absorção Solar \\
\hline $4 \mathrm{~kW} / \mathrm{m}^{2}$ & $\mathrm{R} \$$ & 0,75 & $\mathrm{R} \$$ & 1,41 & Absorção Solar & $54 \%$ & $67 \%$ & Absorção Solar \\
\hline $4 \mathrm{~kW} / \mathrm{m}^{2}$ & $\mathrm{R} \$$ & 1,00 & $\mathrm{R} \$$ & 1,25 & Absorção Solar & $60 \%$ & $73 \%$ & Absorção Solar \\
\hline $8 \mathrm{~kW} / \mathrm{m}^{2}$ & $\mathrm{R} \$$ & 0,40 & $\mathrm{R} \$$ & 0,60 & Absorção Solar & $32 \%$ & $\ln v$ & Caso Base \\
\hline $8 \mathrm{~kW} / \mathrm{m}^{2}$ & $\mathrm{R} \$$ & 0,65 & $\mathrm{R} \$$ & 1,14 & Absorção Solar & $31 \%$ & $11 \%$ & Absorção Solar \\
\hline $8 \mathrm{~kW} / \mathrm{m}^{2}$ & $\mathrm{R} \$$ & 0,90 & $\mathrm{R} \$$ & 0,90 & Absorção Solar & $35 \%$ & $6 \%$ & Absorção Solar \\
\hline $8 \mathrm{~kW} / \mathrm{m}^{2}$ & $\mathrm{R} \$$ & 0,90 & $\mathrm{R} \$$ & 1,69 & Absorção Solar & $31 \%$ & $25 \%$ & Absorção Solar \\
\hline
\end{tabular}

Tratando-se de economia de energia, o melhor método é o de absorção solar em todos os casos, conforme mostra a Figura 6.5. Todavia em poucos casos de alta carga e baixa tarifa (em torno de 8\%), o sistema de inviabiliza, como visto na Figura 6.6. 
Percebe-se que para as densidades de $0,5 \mathrm{~kW} / \mathrm{m}^{2}, 1 \mathrm{~kW} / \mathrm{m}^{2}$ e $4 \mathrm{~kW} / \mathrm{m}^{2}$ há vantagem em todas as tarifas. A diferenciação do horário de ponta faz com que o valor de taxa interna de retorno aumenta.

Para $2,0 \mathrm{~kW} / \mathrm{m}^{2}$ há vantagens a partir de $\mathrm{R} \$ 0,35$ com diferenciação de 1,88 de tarifa de ponta para regular. Quando estas se igualam, estas apresentam vantagens de $\mathrm{R} \$ 0,40$. Para $8,0 \mathrm{~kW} / \mathrm{m}^{2}$ há taxa interna de retorno a partir de $\mathrm{R} \$ 0,45$ para 1,88 de tarifa de ponta sobre regular e $R \$ 0,75$ quando há tarifa de ponta igual à tarifa regular.

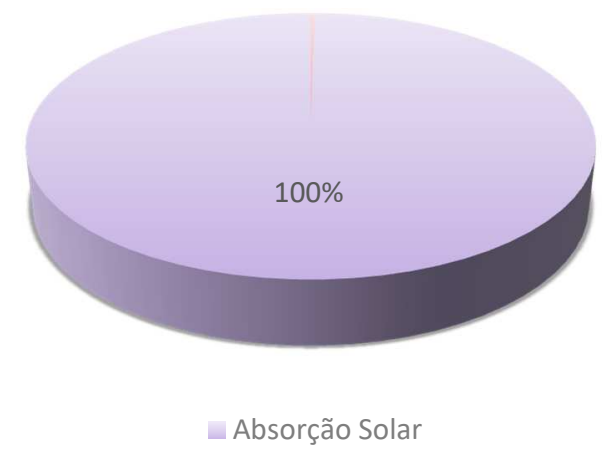

Figura 6.5 Melhor equipamento segundo critério de economia de energia para Abu Dhabi

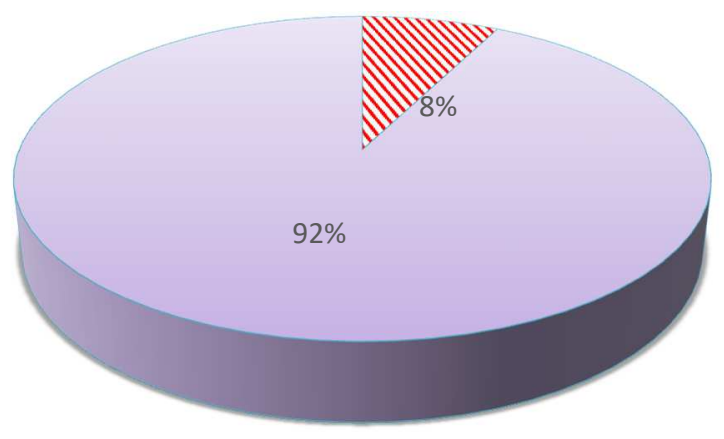

』 Caso base $\square$ Absorção Solar

Figura 6.6 Melhor equipamento segundo critério de taxa interna de retorno para Abu Dhabi 
Quando associado a economizadores, observa-se que para baixas cargas $(0,5$ $\mathrm{kW} / \mathrm{m}^{2}$ ) recomenda-se a não utilização de economizadores, segundo taxa interna de retorno. Isto ocorre pois, a carga residual é resfriada nas URs em faixas pouco eficientes em face a não utilização desta tecnologia, não se justificando o investimento em trocadores de calor, para este caso.

Para cargas de 1, 2 e 4 kW/m², recomenda-se a utilização de absorção solar em conjunto com resfriamento natural direto. Para $8 \mathrm{~kW} / \mathrm{m}^{2}$ pela inferência do resfriamento natural indireto na curva das unidades de resfriamento conjuntamente com a absorção solar, gerando trabalhos em baixa eficiência das unidades de resfriamento, é recomendada a utilização do resfriamento fotovoltaico. Isto é mostrado na Tabela $6.2 \mathrm{e}$ na Figura 6.7. Em se tratando de economia de energia recomenda-se em quase todos os casos utiliza-se absorção solar e resfriamento natural direto.

Tabela 6.2 - Seleção de método solar com economizadores para economia de energia e taxa interna de retorno de investimento para a instalação desejada em Abu Dhabi

\begin{tabular}{|c|c|c|c|c|c|c|c|}
\hline \multirow[b]{2}{*}{ Carga } & \multicolumn{3}{|c|}{ Tarifas } & \multicolumn{2}{|l|}{ Economia de Energia } & \multicolumn{2}{|r|}{ Taxa Interna de Retorno } \\
\hline & Tarifa FP & Tarif & Ponta & Melhor Método & EAE/CON & TIR & Melhor Método2 \\
\hline $0,5 \mathrm{~kW} / \mathrm{m}^{2}$ & $\mathrm{R} \$ 0^{0}, 30$ & $\mathrm{R} \$$ & 0,30 & Absorção Solar e Resfriamento Natural Indireto & $100 \%$ & $5 \%$ & Absorção Solar \\
\hline $0,5 \mathrm{~kW} / \mathrm{m}^{2}$ & $\mathrm{R} \$ 0_{0}, 30$ & $\mathrm{R} \$$ & 0,56 & Absorção Solar e Resfriamento Natural Indireto & $100 \%$ & $12 \%$ & Absorção Solar \\
\hline $0,5 \mathrm{~kW} / \mathrm{m}^{2}$ & $\mathrm{R} \$ \mathbf{0} 0,55$ & $\mathrm{R} \$$ & 0,69 & Absorção Solar e Resfriamento Natural Indireto & $100 \%$ & $26 \%$ & Absorção Solar \\
\hline $0,5 \mathrm{~kW} / \mathrm{m}^{2}$ & $\mathrm{R} \${ }^{0}, 80$ & $\mathrm{R} \$$ & 1,20 & Absorção Solar e Resfriamento Natural Indireto & $100 \%$ & $44 \%$ & Absorção Solar \\
\hline $0,5 \mathrm{~kW} / \mathrm{m}^{2}$ & $\mathrm{R} \$ 1,05$ & $\mathrm{R} \$$ & 1,84 & Absorção Solar e Resfriamento Natural Indireto & $100 \%$ & $61 \%$ & Absorção Solar \\
\hline $1 \mathrm{~kW} / \mathrm{m}^{2}$ & $\mathrm{R} \$ \mathbf{0 , 4 5}$ & $\mathrm{R} \$$ & 0,45 & Absorção Solar e Resfriamento Natural Indireto & $83 \%$ & $36 \%$ & Absorção Solar e Resfriamento Natural Indireto \\
\hline $1 \mathrm{~kW} / \mathrm{m}^{2}$ & $\mathrm{R} \$ \mathbf{0 , 4 5}$ & $\mathrm{R} \$$ & 0,85 & Absorção Solar e Resfriamento Natural Indireto & $84 \%$ & $40 \%$ & Absorção Solar e Resfriamento Natural Indireto \\
\hline $1 \mathrm{~kW} / \mathrm{m}^{2}$ & $\mathrm{R} \$ \mathbf{0 , 7 0}$ & $\mathrm{R} \$$ & 0,88 & Absorção Solar e Resfriamento Natural Indireto & $84 \%$ & $62 \%$ & Absorção Solar e Resfriamento Natural Indireto \\
\hline $1 \mathrm{~kW} / \mathrm{m}^{2}$ & $\mathrm{R} \$ \mathbf{0 , 9 5}$ & $\mathrm{R} \$$ & 1,43 & Absorção Solar e Resfriamento Natural Indireto & $84 \%$ & $89 \%$ & Absorção Solar e Resfriamento Natural Indireto \\
\hline $2 \mathrm{~kW} / \mathrm{m}^{2}$ & $\mathrm{R} \$ \$ 0,35$ & $\mathrm{R} \$$ & 0,61 & Absorção Solar e Resfriamento Natural Indireto & $59 \%$ & $11 \%$ & Absorção Solar e Resfriamento Natural Indireto \\
\hline $2 \mathrm{~kW} / \mathrm{m}^{2}$ & $\mathrm{R} \$ 0^{0,60}$ & $\mathrm{R} \$$ & 0,60 & Absorção Solar e Resfriamento Natural Indireto & $56 \%$ & $26 \%$ & Absorção Solar e Resfriamento Natural Indireto \\
\hline $2 \mathrm{~kW} / \mathrm{m}^{2}$ & $\mathrm{R} \$ 0^{0,60}$ & $\mathrm{R} \$$ & 1,13 & Absorção Solar e Resfriamento Natural Indireto & $59 \%$ & $31 \%$ & Absorção Solar e Resfriamento Natural Indireto \\
\hline $2 \mathrm{~kW} / \mathrm{m}^{2}$ & $\mathrm{R} \$ \mathbf{0 , 8 5}$ & $\mathrm{R} \$$ & 1,06 & Absorção Solar e Resfriamento Natural Indireto & $57 \%$ & $44 \%$ & Absorção Solar e Resfriamento Natural Indireto \\
\hline $2 \mathrm{~kW} / \mathrm{m}^{2}$ & $\mathrm{R} \$ 1,10$ & $\mathrm{R} \$$ & 1,65 & Absorção Solar e Resfriamento Natural Indireto & $58 \%$ & $61 \%$ & Absorção Solar e Resfriamento Natural Indireto \\
\hline $4 \mathrm{~kW} / \mathrm{m}^{2}$ & $\mathrm{R} \$ \mathbf{0 , 5 0}$ & $\mathrm{R} \$$ & 0,88 & Absorção Solar e Resfriamento Natural Indireto & $49 \%$ & $78 \%$ & Absorção Solar e Resfriamento Natural Indireto \\
\hline $4 \mathrm{~kW} / \mathrm{m}^{2}$ & $\mathrm{R} \${ }^{2}, 75$ & $\mathrm{R} \$$ & 0,75 & Absorção Solar e Resfriamento Natural Indireto & $46 \%$ & $103 \%$ & Absorção Solar e Resfriamento Natural Indireto \\
\hline $4 \mathrm{~kW} / \mathrm{m}^{2}$ & $\mathrm{R} \$ 0,75$ & $\mathrm{R} \$$ & 1,41 & Absorção Solar e Resfriamento Natural Indireto & $50 \%$ & $122 \%$ & Absorção Solar e Resfriamento Natural Indireto \\
\hline $4 \mathrm{~kW} / \mathrm{m}^{2}$ & $\mathrm{R} \${ }^{1,00}$ & $\mathrm{R} \$$ & 1,25 & Absorção Solar e Resfriamento Natural Indireto & $47 \%$ & $146 \%$ & Absorção Solar e Resfriamento Natural Indireto \\
\hline $8 \mathrm{~kW} / \mathrm{m}^{2}$ & $\mathrm{R} \$ 0,40$ & $\mathrm{R} \$$ & 0,60 & Absorção Solar e Resfriamento Natural Indireto & $49 \%$ & $103 \%$ & Fotovoltaico + Resfriamento Natural indireto \\
\hline $8 \mathrm{~kW} / \mathrm{m}^{2}$ & $\mathrm{R} \$ 0,65$ & $\mathrm{R} \$$ & 1,14 & Absorção Solar e Resfriamento Natural Indireto & $50 \%$ & $179 \%$ & Fotovoltaico + Resfriamento Natural indireto \\
\hline $8 \mathrm{~kW} / \mathrm{m}^{2}$ & $\mathrm{R} \$ 0,90$ & $\mathrm{R} \$$ & 0,90 & Absorção Solar e Resfriamento Natural Indireto & $48 \%$ & $201 \%$ & Fotovoltaico + Resfriamento Natural indireto \\
\hline $8 \mathrm{~kW} / \mathrm{m}^{2}$ & $\mathrm{R} \$ 0^{0,90}$ & $\mathrm{R} \$$ & 1,69 & Fotovoltaico + resfriamento Natural indireto & $50 \%$ & $256 \%$ & Fotovoltaico + Resfriamento Natural indireto \\
\hline
\end{tabular}

A Figura 6.7 apresenta que em somente $4 \%$ dos casos onde há alta carga e alta tarifa, recomenda-se a utilização de resfriamento natural direto com células fotovoltaicas. 
Nos demais casos utiliza-se absorção solar com resfriamento natural indireto. A figura 6.8 indica que o sistema de absorção solar é em $20 \%$ mais vantajoso, justamente onde há a carga mais baixa de $0,5 \mathrm{~kW} / \mathrm{m}^{2}$. Nos casos de $1 \mathrm{~kW} / \mathrm{m}^{2}, 2 \mathrm{~kW} / \mathrm{m}^{2}$ e $4 \mathrm{~kW} / \mathrm{m}^{2}$ o sistema de absorção solar com resfriamento natural indireto. Em $8 \mathrm{~kW} / \mathrm{m}^{2}$, há pouca diferença de economia energia entre fotovoltaicas e absorção solar, porém devido há um menor investimento inicial, o equipamento fotovoltaico é mais vantajoso.

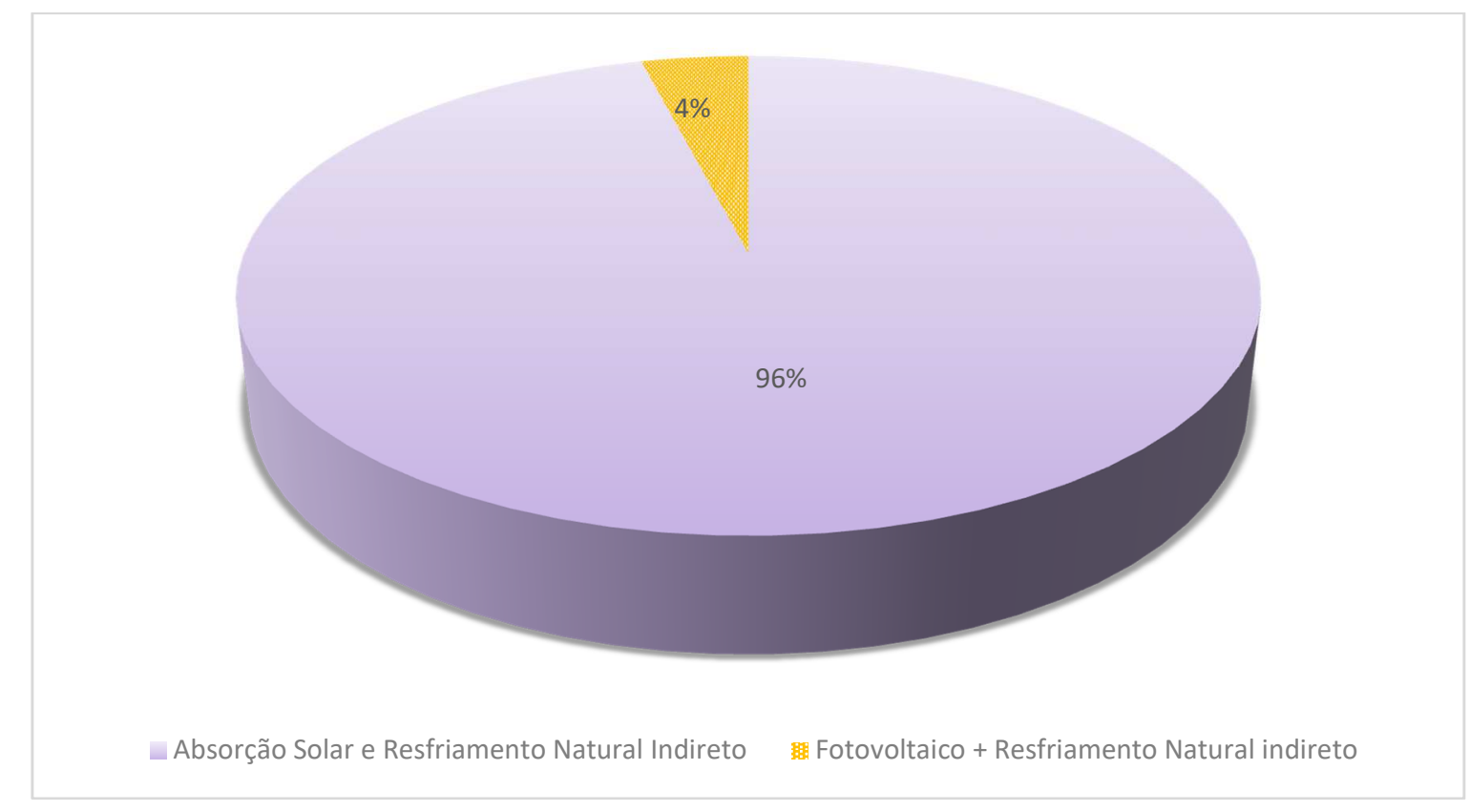

Figura 6.7 Melhor tecnologia solar associada a economizadores segundo economia de energia em Abu Dhabi. 


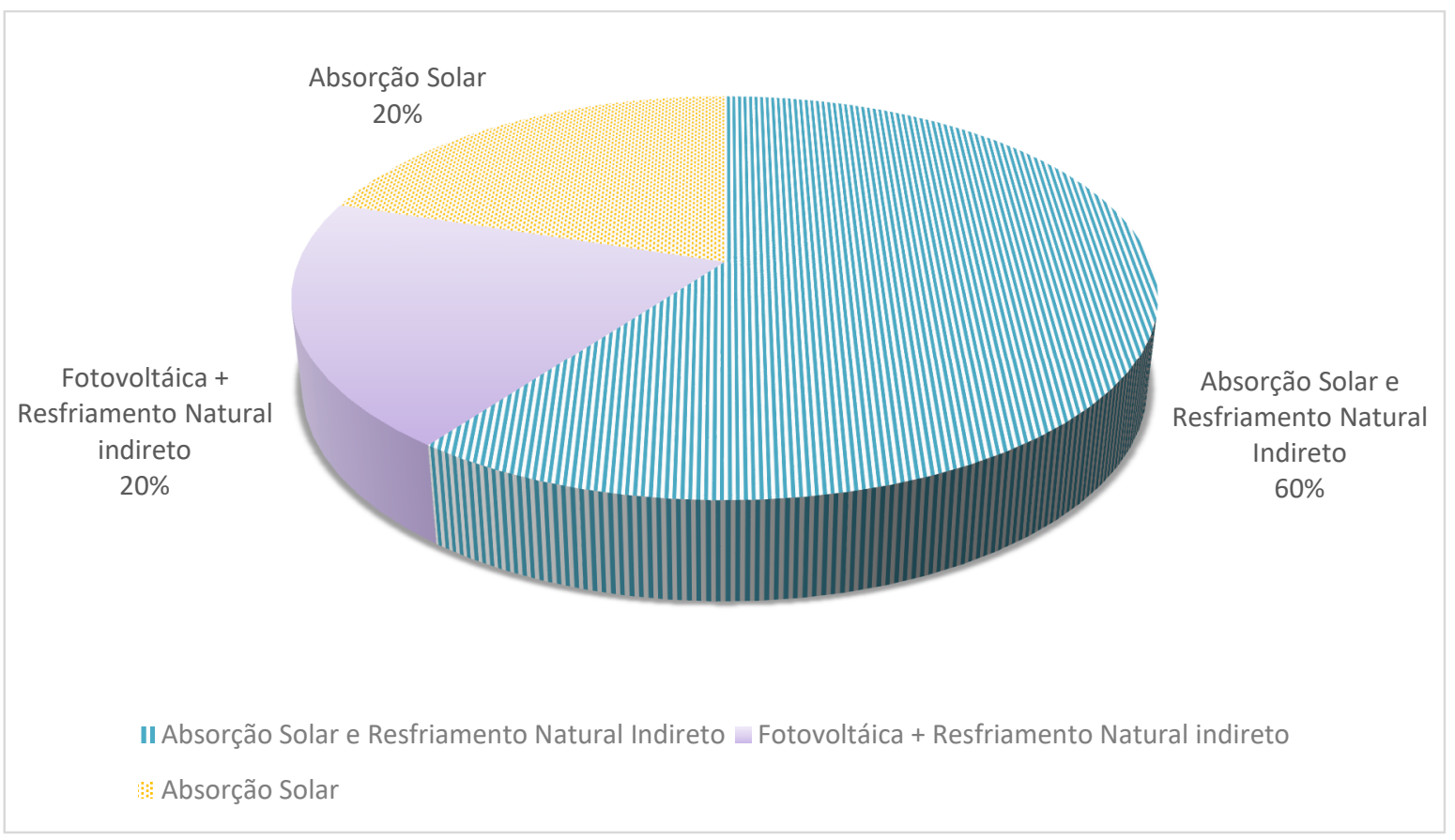

Figura 6.8. Melhor tecnologia solar associada a economizadores segundo taxa interna de retorno em Abu Dhabi.

$\mathrm{Na}$ associação com resfriamento natural, as tecnologias solares apresentam vantagens para todas as tarifas de ponta e regular aplicadas, conforme Figura 6.8.

\subsubsection{Zona 3 - Los Angeles}

Utilizando a mesma edificação e proposições para a Los Angeles, cidade localizada no estado da Califórnia, nos Estados Unidos da América, considerada Zona 3 pela $A S H R A E^{\circledR}$, sendo cidade de clima temperado, tendo característica inverno não severo, especialmente Los Angeles está na região $3 \mathrm{C}$ da $\mathrm{ASHRAE}^{\circledR}$ para cidades litorâneas, muito em função de seu alto diferencial de temperatura diário. A temperatura de bulbo seco máxima para Los Angeles nos últimos 20 anos é de $44,5{ }^{\circ} \mathrm{C}$ com temperatura de bulbo úmido respectiva de $27,1^{\circ} \mathrm{C}$, a mínima é de $-4,0^{\circ} \mathrm{C}$ e TBU $-5,5^{\circ} \mathrm{C}$. Para demais projetos utiliza-se $36,4^{\circ} \mathrm{C}$ e $20,2^{\circ} \mathrm{C}$ (ASHRAE, 2017).

A Figura 6.9 apresenta um gráfico de dia típico de verão, onde as barras representam as temperaturas de bulbo seco e úmido e as linhas apresentam a radiação 
total e direta. Nota-se que é comum temperatura entre 18 e $24^{\circ} \mathrm{C}$ em dias de verão e alta umidade.

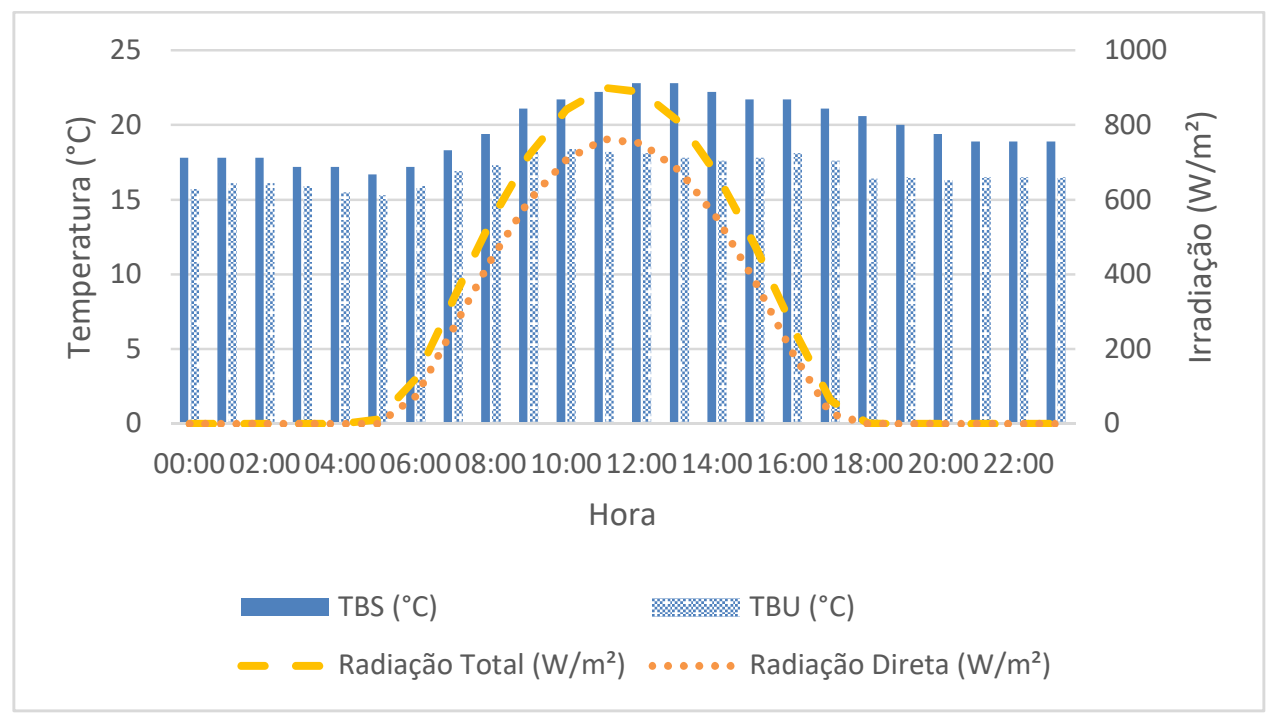

Figura 6.9 Irradiação típica e temperatura em dia típico de verão (11 de setembro) em Los Angeles.

Em um dia típico de inverno, apresentado na figura 6.10, há alta variação de temperatura. A Temperatura de bulbo seco gira em torno de $17^{\circ} \mathrm{C}$ durante o dia e durante a noite é inferior a $7{ }^{\circ} \mathrm{C}$. Nota-se também dias geralmente secos pela alta diferença entre temperatura de bulbo úmido e bulbo seco. Esta região costuma apresentar grandes variações de temperatura durante o dia e noite, em torno de $16^{\circ} \mathrm{C}$ (ASHRAE, 2017). 


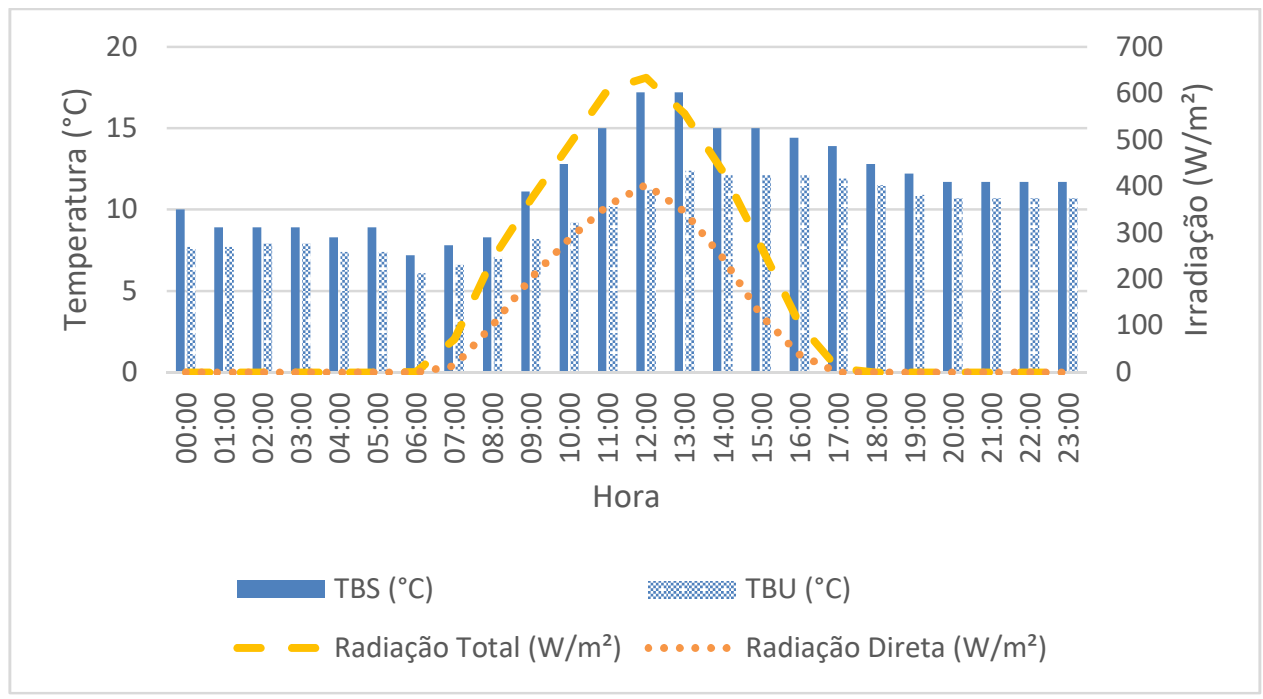

Figura 6.10. Irradiação típica e temperatura em dia típico de inverno (11 de setembro) em Los Angeles.

Efetuando toda a mesma metodologia apresentada para São Paulo, nota-se que há um maior aproveitamento de tecnologias solares que na cidade de São Paulo, com bom aproveitamento de economizadores, como não se verifica em Abu Dhabi. A Figura 6.11 mostra a distribuição da disponibilidade de cada método de tecnologia solar ou economizador para cada densidade de carga por metro quadrado. 


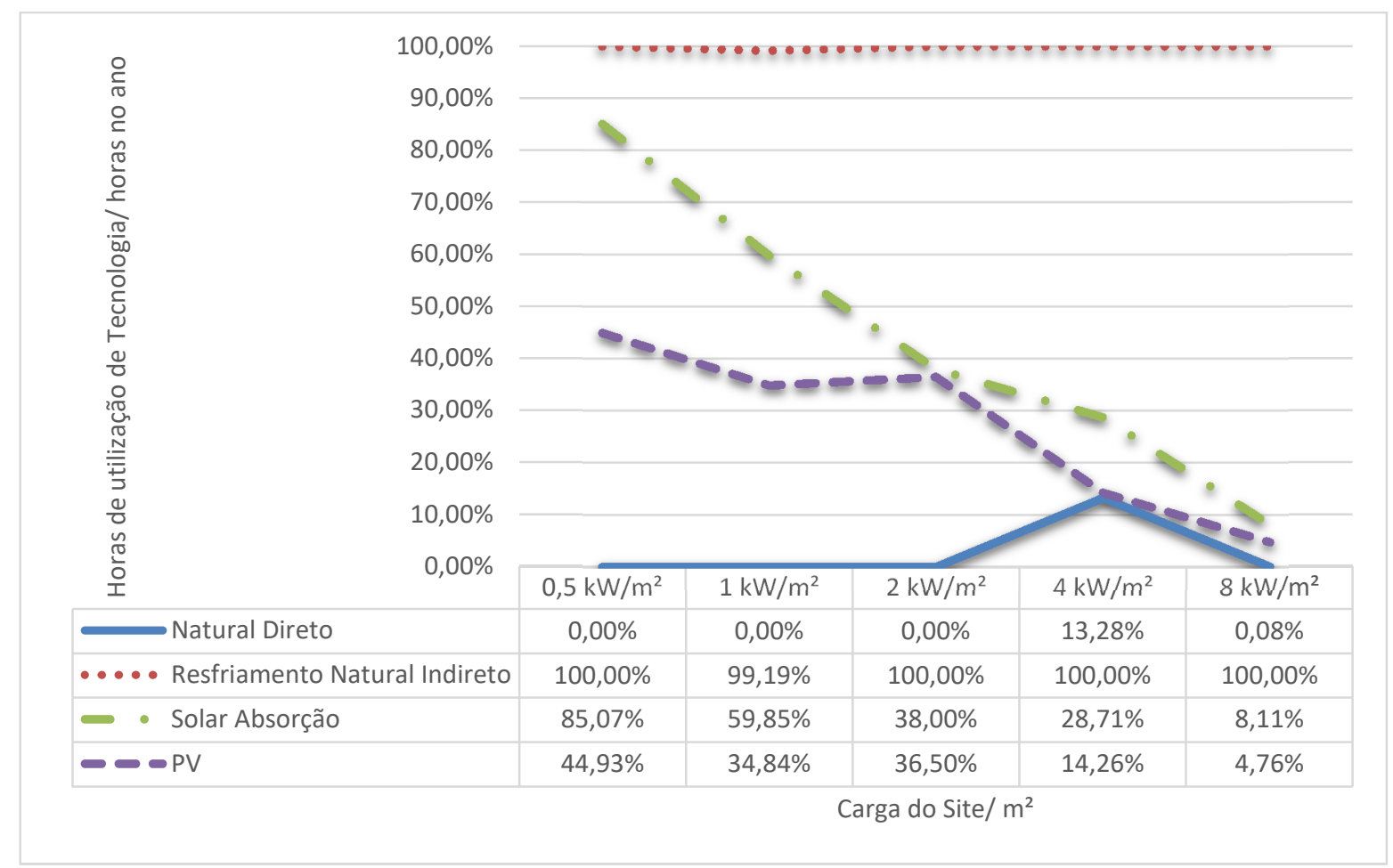

Figura 6.11 Utilização de Economizadores e métodos de resfriamento solar sobre carga total para densidades de carga estudadas para Los Angeles.

A Figura 6.12 apresenta a evolução de COP e disponibilidade para cada uma das utilizações. Nota-se queda mais acentuada que nos casos anteriores, nos valores de COP quando há utilização de resfriamento natural indireto. Isto resulta em pouca vantagem na utilização de economizadores, sendo em alguns casos vantajosa a não aplicação destes. 


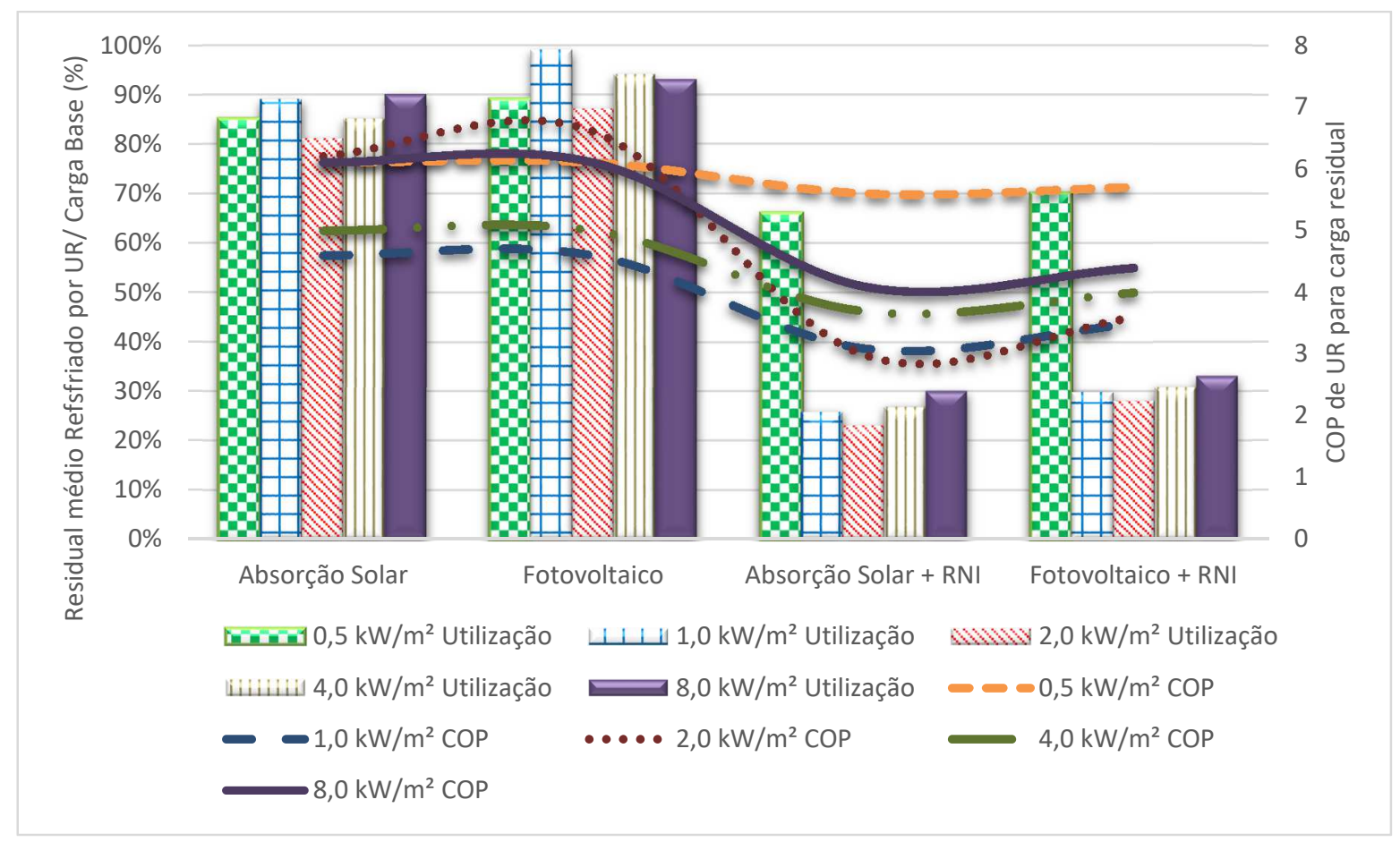

Figura 6.12. Indicação de utilização e COP para todas as densidades estudas e tecnologias solares com e sem economizadores para Los Angeles.

Neste caso, o sistema de absorção solar apresenta vantagem em todas as densidades de carga em economia de energia, como apresentado na Figura 6.13 e também é o mais vantajoso em relação a taxa de retorno de investimento para 10 anos, exceto em casos de baixa tarifa para 2 e $8 \mathrm{~kW} / \mathrm{m}^{2}$, independente da variação de tarifa nos horários de ponta, como visto na Figura 6.14. A Tabela 6.3 apresenta parte destes valores, isto deve-se a alta irradiação nos horários de alta incidência (10:00 às 14:00 Hs). 
Tabela 6.3 - Seleção de método solar para economia de energia e taxa interna de retorno de investimento para a instalação desejada em Los Angeles

\begin{tabular}{|c|c|c|c|c|c|c|c|c|}
\hline \multirow{3}{*}{$\begin{array}{l}\text { Carga } \\
0,5 \mathrm{~kW} / \mathrm{m}^{2} \\
\end{array}$} & \multicolumn{4}{|c|}{ Tarifas } & \multicolumn{2}{|c|}{ Economia de Energia } & \multicolumn{2}{|c|}{ Taxa Interna de Retorno } \\
\hline & \multicolumn{2}{|c|}{ Tarifa FP } & \multicolumn{2}{|c|}{ Tarifa Ponta } & \multirow{2}{*}{\begin{tabular}{|l} 
Melhor Método \\
Absorção Solar \\
\end{tabular}} & \multirow{2}{*}{\begin{tabular}{|r|} 
EAE/CON $_{\text {Base }}$ \\
$55 \%$ \\
\end{tabular}} & \multirow{2}{*}{\begin{tabular}{|r|} 
TIR \\
$0 \%$ \\
\end{tabular}} & \multirow{2}{*}{\begin{tabular}{|l} 
Melhor Método2 \\
Absorção Solar \\
\end{tabular}} \\
\hline & $\mathrm{R} \$$ & 0,30 & $\mathrm{R} \$$ & 0,30 & & & & \\
\hline $0,5 \mathrm{~kW} / \mathrm{m}^{2}$ & $\mathrm{R} \$$ & 0,30 & $\mathrm{R} \$$ & 0,56 & Absorção Solar & $50 \%$ & $7 \%$ & Absorção Solar \\
\hline $0,5 \mathrm{~kW} / \mathrm{m}^{2}$ & $\mathrm{R} \$$ & 0,55 & $\mathrm{R} \$$ & 0,69 & Absorção Solar & $53 \%$ & $19 \%$ & Absorção Solar \\
\hline $0,5 \mathrm{~kW} / \mathrm{m}^{2}$ & $\mathrm{R} \$$ & 0,80 & $\mathrm{R} \$$ & 1,20 & Absorção Solar & $52 \%$ & $35 \%$ & Absorção Solar \\
\hline $0,5 \mathrm{~kW} / \mathrm{m}^{2}$ & $\mathrm{R} \$$ & 1,05 & $\mathrm{R} \$$ & 1,84 & Absorção Solar & $50 \%$ & $51 \%$ & Absorção Solar \\
\hline $1 \mathrm{~kW} / \mathrm{m}^{2}$ & $\mathrm{R} \$$ & 0,45 & $\mathrm{RS}$ & 0,45 & Absorção Solar & $64 \%$ & $20 \%$ & Absorção Solar \\
\hline $1 \mathrm{~kW} / \mathrm{m}^{2}$ & $\mathrm{R} \$$ & 0,45 & $\mathrm{R} \$$ & 0,85 & Absorção Solar & $56 \%$ & $24 \%$ & Absorção Solar \\
\hline $1 \mathrm{~kW} / \mathrm{m}^{2}$ & $\mathrm{R} \$$ & 0,70 & $\mathrm{R} \$$ & 0,88 & Absorção Solar & $62 \%$ & $40 \%$ & Absorção Solar \\
\hline $1 \mathrm{~kW} / \mathrm{m}^{2}$ & R\$ & 0,95 & $\mathrm{R} \$$ & 1,43 & Absorção Solar & $59 \%$ & $59 \%$ & Absorção Solar \\
\hline $2 \mathrm{~kW} / \mathrm{m}^{2}$ & $\mathrm{R} \$$ & 0,35 & $\mathrm{R} \$$ & 0,61 & Absorção Solar & $23 \%$ & $\operatorname{lnv}$ & Caso Base \\
\hline $2 \mathrm{~kW} / \mathrm{m}^{2}$ & $\mathrm{R} \$$ & 0,60 & $\mathrm{R} \$$ & 0,60 & Absorção Solar & $29 \%$ & $7 \%$ & Absorção Solar \\
\hline $2 \mathrm{~kW} / \mathrm{m}^{2}$ & $\mathrm{R} \$$ & 0,60 & $\mathrm{R} \$$ & 1,13 & Absorção Solar & $23 \%$ & $14 \%$ & Absorção Solar \\
\hline $2 \mathrm{~kW} / \mathrm{m}^{2}$ & $\mathrm{R} \$$ & 0,85 & $\mathrm{R} \$$ & 1,06 & Absorção Solar & $27 \%$ & $20 \%$ & Absorção Solar \\
\hline $2 \mathrm{~kW} / \mathrm{m}^{2}$ & $\mathrm{R} \$$ & 1,10 & $\mathrm{R} \$$ & 1,65 & Absorção Solar & $25 \%$ & $33 \%$ & Absorção Solar \\
\hline $4 \mathrm{~kW} / \mathrm{m}^{2}$ & $\mathrm{R} \$$ & 0,50 & $\mathrm{R} \$$ & 0,88 & Absorção Solar & $53 \%$ & $33 \%$ & Absorção Solar \\
\hline $4 \mathrm{~kW} / \mathrm{m}^{2}$ & $\mathrm{R} \$$ & 0,75 & $\mathrm{R} \$$ & 0,75 & Absorção Solar & $61 \%$ & $37 \%$ & Absorção Solar \\
\hline $4 \mathrm{~kW} / \mathrm{m}^{2}$ & $\mathrm{R} \$$ & 0,75 & $\mathrm{R} \$$ & 1,41 & Absorção Solar & $52 \%$ & $57 \%$ & Absorção Solar \\
\hline $4 \mathrm{~kW} / \mathrm{m}^{2}$ & $\mathrm{R} \$$ & 1,00 & $\mathrm{R} \$$ & 1,25 & Absorção Solar & $58 \%$ & $60 \%$ & Absorção Solar \\
\hline $8 \mathrm{~kW} / \mathrm{m}^{2}$ & $\mathrm{R} \$$ & 0,40 & $\mathrm{R} \$$ & 0,60 & Absorção Solar & $32 \%$ & $\ln v$ & Caso Base \\
\hline $8 \mathrm{~kW} / \mathrm{m}^{2}$ & $\mathrm{R} \$$ & 0,65 & $\mathrm{R} \$$ & 1,14 & Absorção Solar & $31 \%$ & $11 \%$ & Absorção Solar \\
\hline $8 \mathrm{~kW} / \mathrm{m}^{2}$ & $\mathrm{R} \$$ & 0,90 & $\mathrm{R} \$$ & 0,90 & Absorção Solar & $35 \%$ & $6 \%$ & Absorção Solar \\
\hline $8 \mathrm{~kW} / \mathrm{m}^{2}$ & $\mathrm{R} \$$ & 0,90 & $\mathrm{R} \$$ & 1,69 & Absorção Solar & $31 \%$ & $25 \%$ & Absorção Solar \\
\hline
\end{tabular}




\section{Melhor Tecnologia Solar - Economia de Energia}

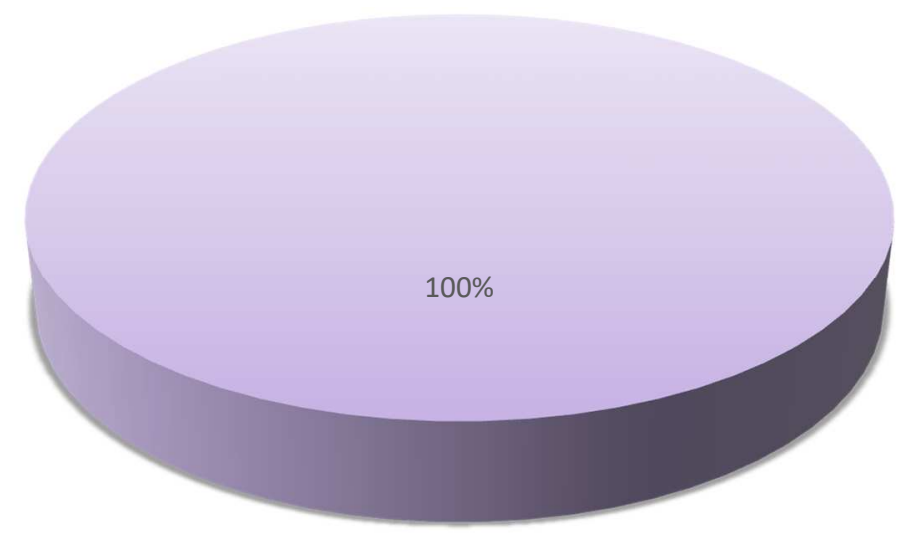

Absorção Solar

Figura 6.13. Melhor equipamento segundo critério de economia de energia para Los Angeles

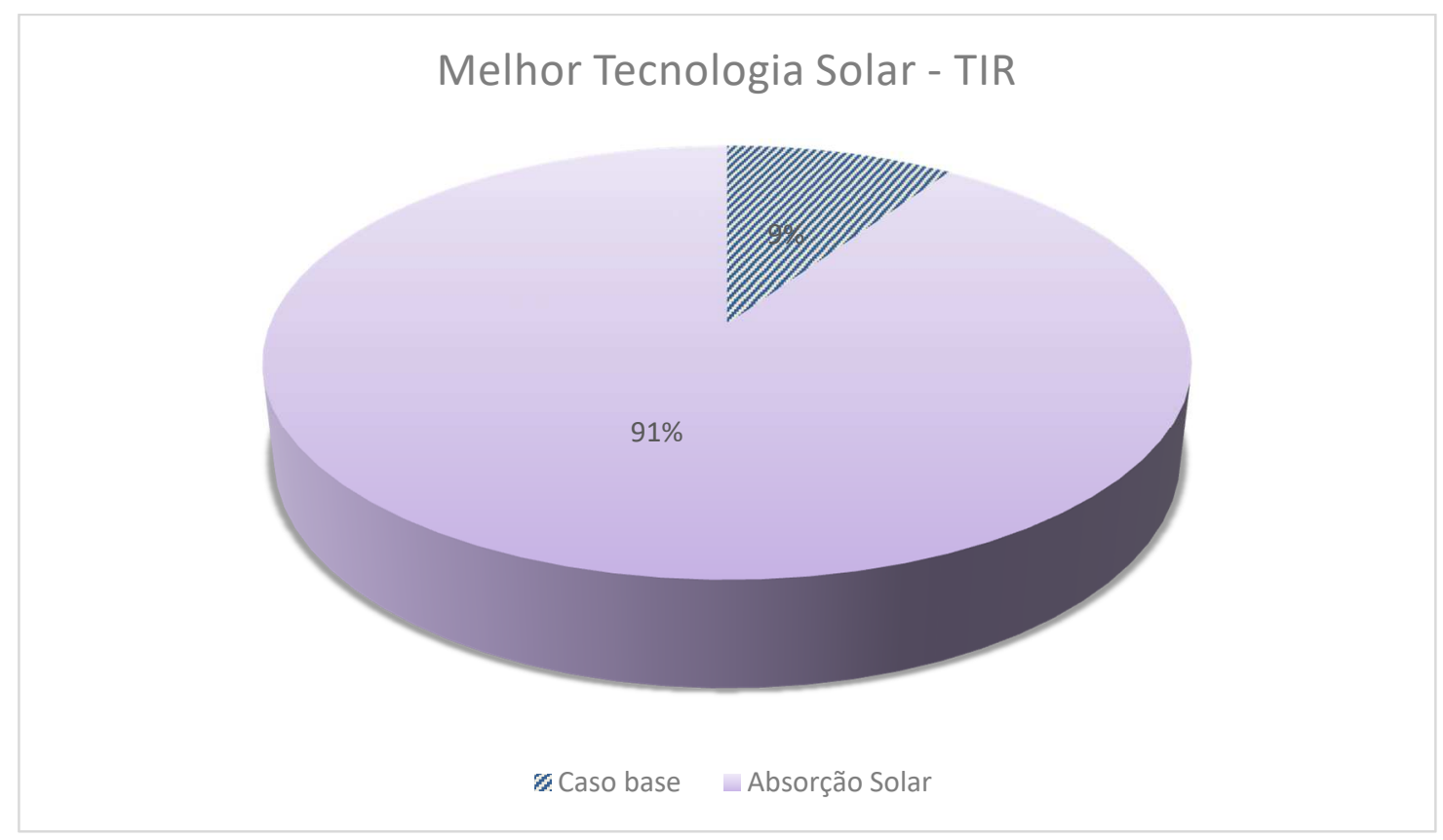

Figura 6.14. Melhor equipamento segundo critério de taxa interna de retorno para Los Angeles

Percebe-se que para as densidades de $0,5 \mathrm{~kW} / \mathrm{m}^{2}, 1 \mathrm{~kW} / \mathrm{m}^{2}$ e $4 \mathrm{~kW} / \mathrm{m}^{2}$ há vantagem em todas as tarifas. A diferenciação do horário de ponta faz com que o valor de taxa interna de retorno aumenta. 
Para $2,0 \mathrm{~kW} / \mathrm{m}^{2}$ há vantagens a partir de $\mathrm{R} \$ 0,45$ com diferenciação de 1,88 de tarifa de ponta para regular. Quando estas se igualam, estas apresentam vantagens de $\mathrm{R} \$ 0,50$. Para $8,0 \mathrm{~kW} / \mathrm{m}^{2}$ há taxa interna de retorno a partir de $\mathrm{R} \$ 0,45$ para 1,88 de tarifa de ponta sobre regular e $R \$ 0,80$ quando há tarifa de ponta igual à tarifa regular.

Quando combinados com método de resfriamento natural, absorção solar apresenta grande vantagem. Em economia de energia os resfriadores fotovoltaicos combinados possuem melhor desempenho somente em casos de alta carga e alta tarifa e alta diferenciação de tarifa, conforme apresentado na Tabela 6.4 e Figura 6.15. No caso de taxa de retorno de investimento para 10 anos, a absorção solar apresenta superioridade, exceto para as condições simuladas em $8 \mathrm{~kW} / \mathrm{m}^{2}$ conforme Tabela $6.4 \mathrm{e}$ Figura 6.16. 
Tabela 6.4 - Seleção de método solar com economizadores para economia de energia e taxa interna de retorno de investimento para a instalação desejada em Los Angeles

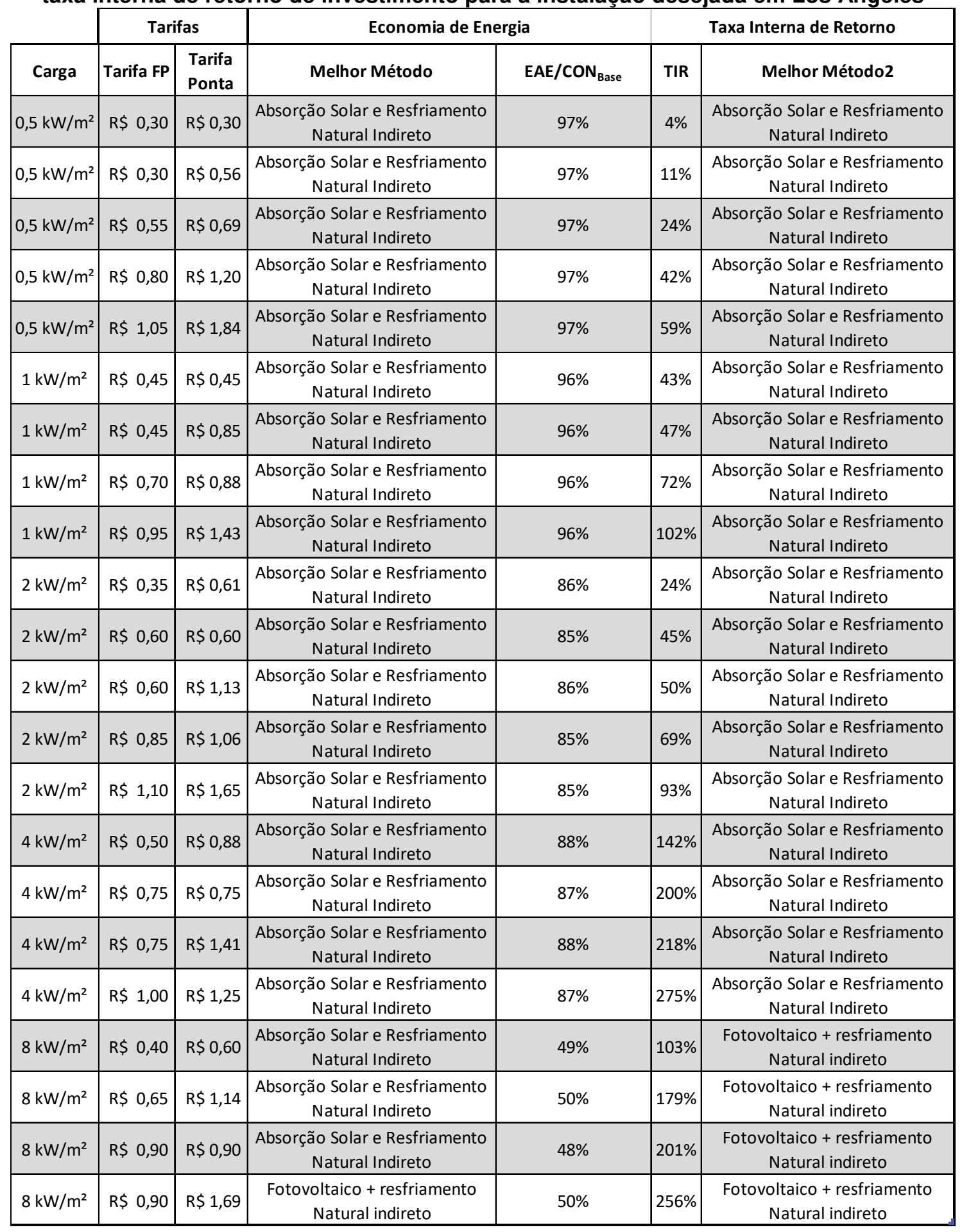




\section{Melhor utilização de Tecnologias Solares com Economizadores - Critério Economia de Energia}

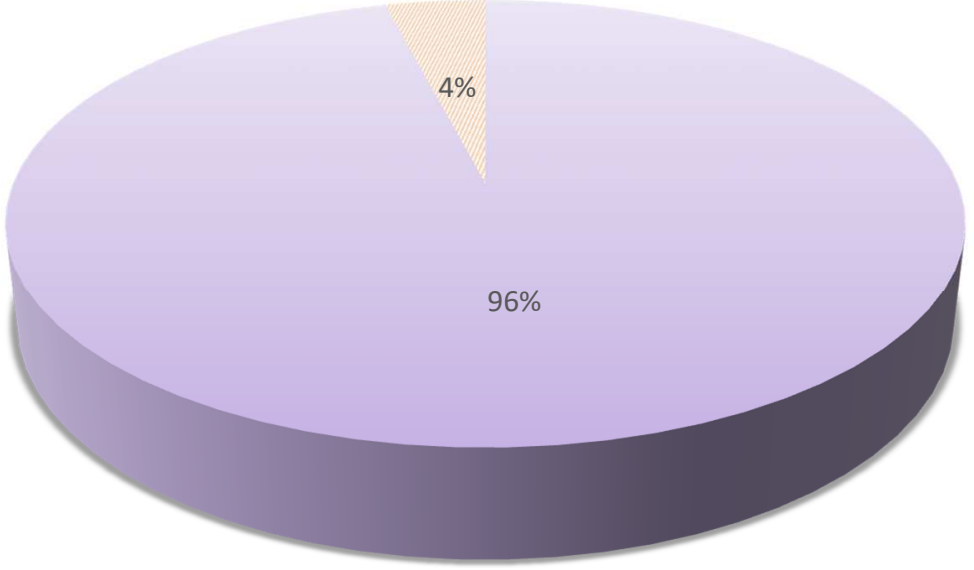

Figura 6.15. Melhor tecnologia solar associada a economizadores segundo economia de energia em Los Angeles.

Melhor utilização de Tecnologias Solares com Economizadores - Critério TIR Fotovoltaico + Resfriamento Natural

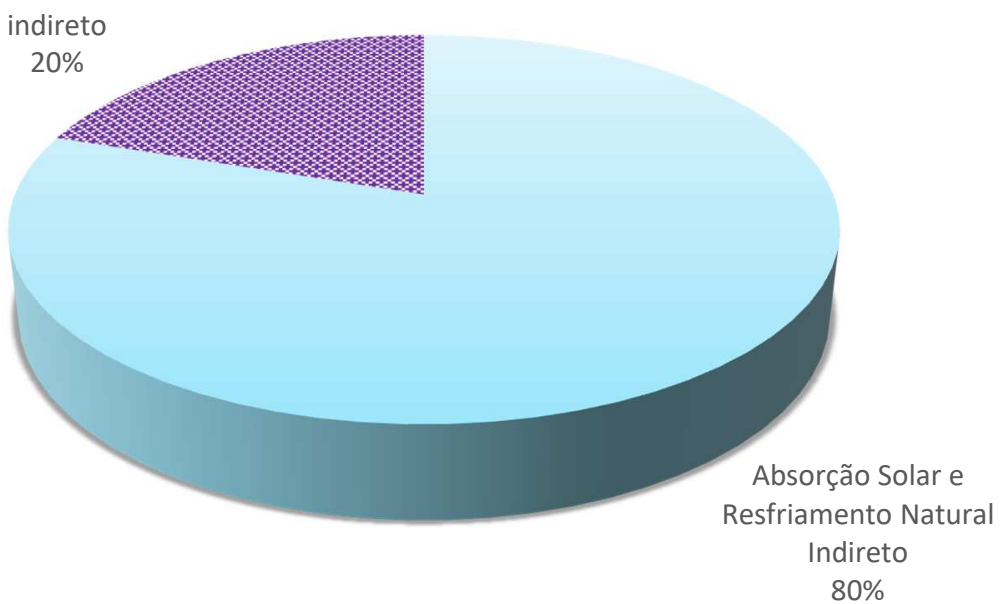

Figura 6.16. Melhor tecnologia solar associada a economizadores segundo taxa interna de retorno em Los Angeles. 
Percebe-se que para as todas as densidades há vantagens em todas as tarifas estudadas, porém para maiores tarifas e maior diferenciação ponta sobre regular a TIR é maior.

\subsubsection{Zona 4 - Nova York}

Nesta tese é verificada a utilização de edificação partindo de mesmas condições de contorno para a Nova York, cidade localizada nos Estados Unidos da América, considerada Zona 4 pela ASHRAE ${ }^{\circledR}$, sendo cidade de clima temperado. A temperatura de bulbo seco máxima para Nova York nos últimos 20 anos é de $39,3^{\circ} \mathrm{C}$ com temperatura de bulbo úmido respectiva de $27,9{ }^{\circ} \mathrm{C}$, a mínima é de $-17,4{ }^{\circ} \mathrm{C}$ e TBU $-18,2{ }^{\circ} \mathrm{C}$. Para demais projetos utiliza-se $30,3^{\circ} \mathrm{C}$ e $22,1^{\circ} \mathrm{C}$ (ASHRAE, 2017).

A Figura 6.17 apresenta um gráfico de dia típico de verão, onde as barras representam as temperaturas de bulbo seco e úmido e as linhas apresentam a radiação total e direta. Nota-se que é comum temperatura entre 17 e $24^{\circ} \mathrm{C}$ em dias de verão e baixa umidade.

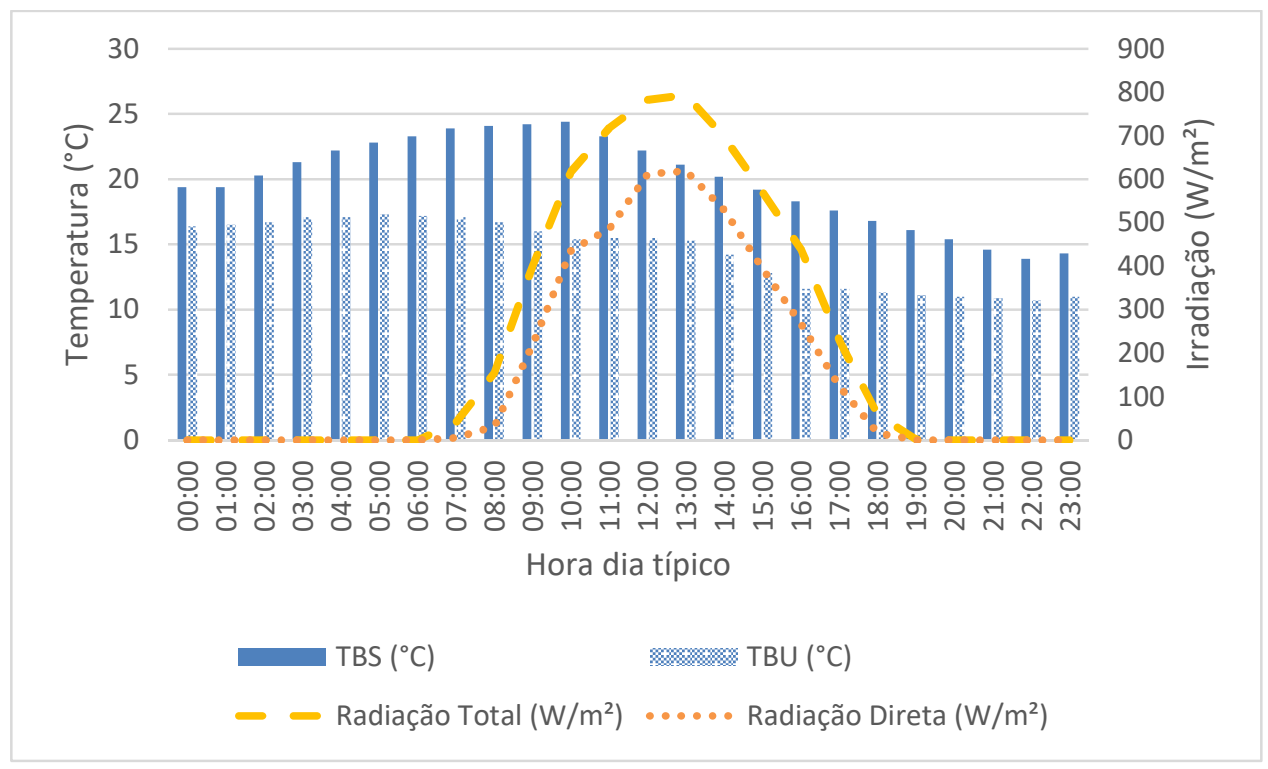

Figura 6.17 Irradiação típica e temperatura em dia típico de verão (11 de setembro) em Nova York. 
Em um dia típico de inverno, registra baixas temperaturas. A Temperatura varia ente $-2 \mathrm{e}-14{ }^{\circ} \mathrm{C}$, com alta umidade relativa, conforme Figura 6.18

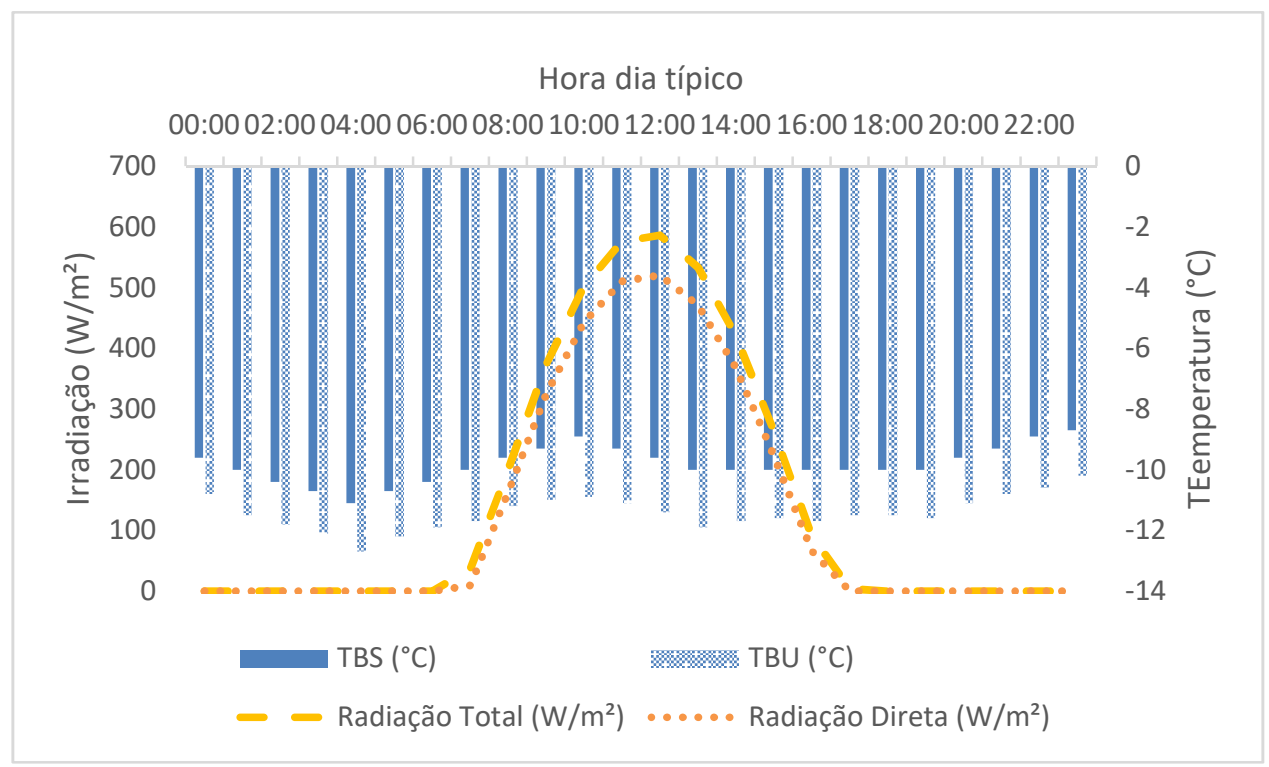

Figura 6.18. Irradiação típica e temperatura em dia típico de verão (4 de fevereiro) em Nova York.

Efetuando toda a mesma metodologia apresentada para São Paulo, nota-se que há aproveitamento superior de tecnologias solares que na cidade base, devido aos picos propiciados no verão, com bom grande aproveitamento de ar resfriado proveniente de economizadores, o que pouco se verificou em Abu Dhabi e em maior intensidade que em Los Angeles. A Figura 6.19 mostra a distribuição da disponibilidade de cada método de tecnologia solar ou economizador para cada densidade de carga por metro quadrado. 


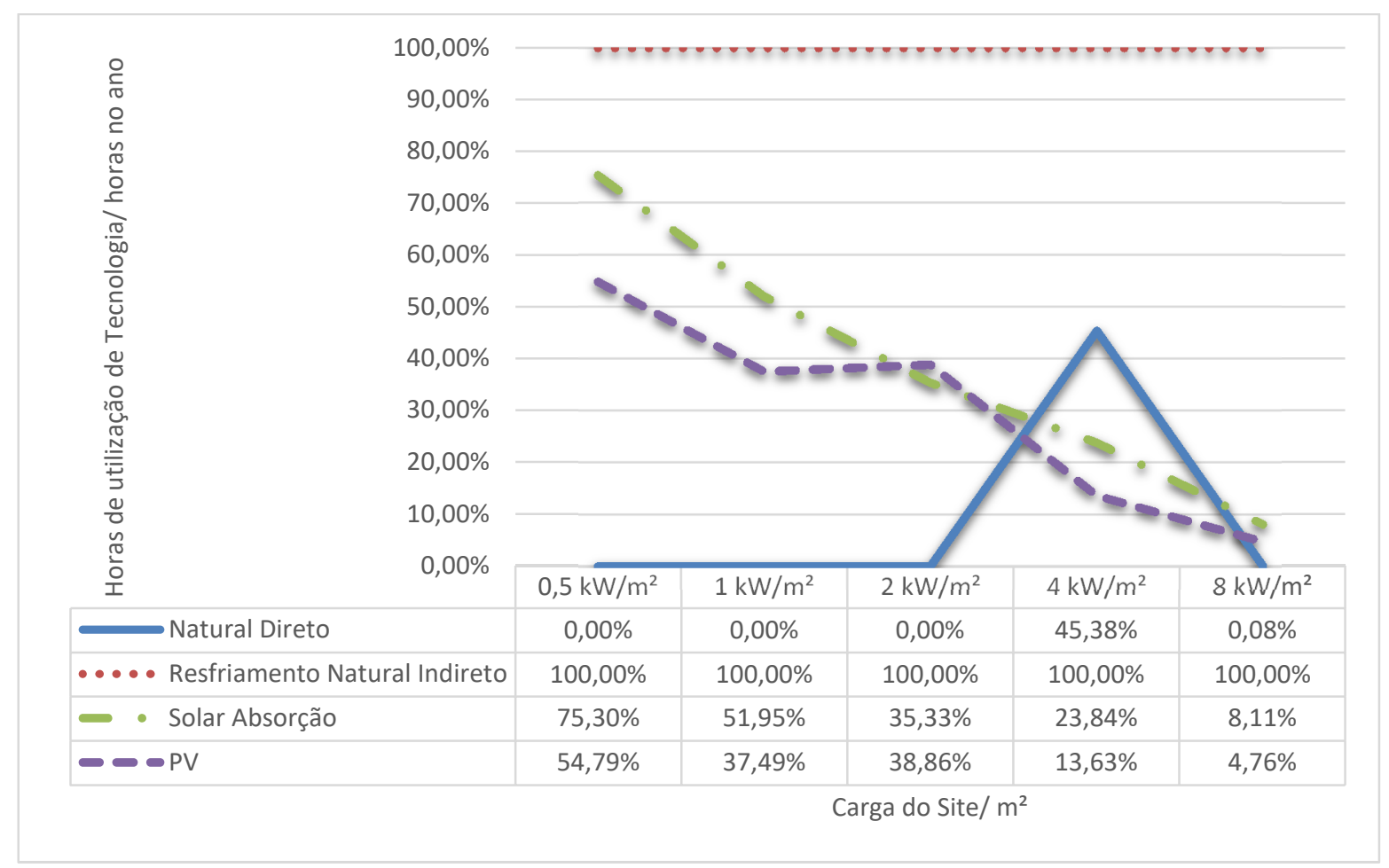

Figura 6.19. Utilização de Economizadores e métodos de resfriamento solar sobre carga total para densidades de carga estudadas para Nova York.

A Figura 6.20 apresenta a evolução de COP e disponibilidade para cada uma das utilizações. Nota-se, neste caso a maior queda em relação aos anteriores nos valores de COP quando há utilização de resfriamento natural indireto. Isto resulta em pouca vantagem na utilização de economizadores, sendo em alguns casos vantajosa a não aplicação destes. 


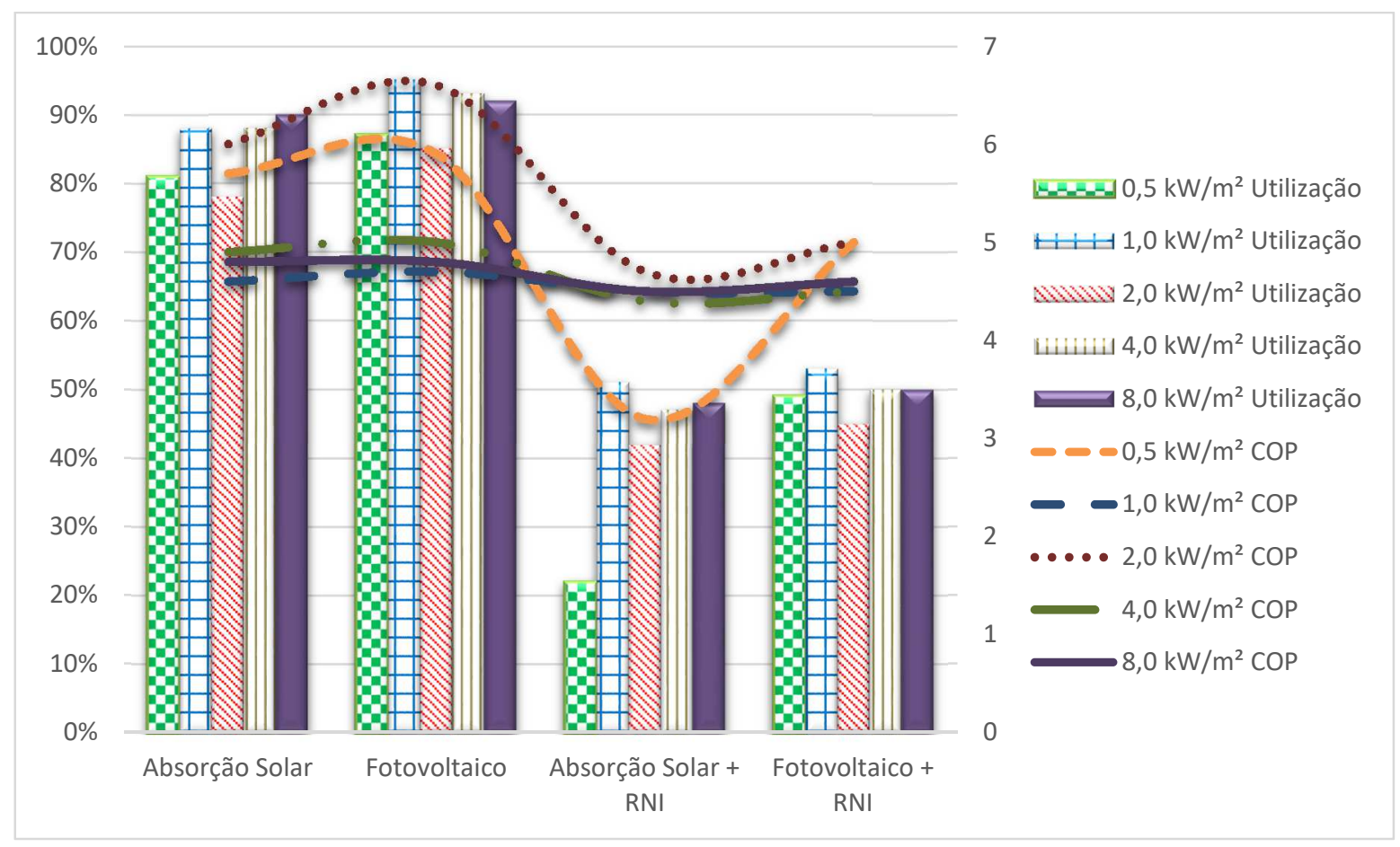

Figura 6.20 Indicação de utilização e COP para todas as densidades estudas e tecnologias solares com e sem economizadores para Nova York.

Neste caso, o sistema de absorção solar apresenta vantagem em todas as cargas em economia de energia, como apresentado na Figura 6.21 e também é o mais vantajoso em relação a taxa de retorno de investimento para 10 anos na maioria dos casos, exceto em casos de baixa tarifa onde se inviabiliza e em $2 \mathrm{~kW} / \mathrm{m}^{2}$ onde há pouca diferença entre absorção solar e fotovoltaico, como visto na Figura 6.22. A Tabela 6.5 apresenta parte destes valores. Neste caso, pela baixa temperatura há ganho de rendimentos nas células fotovoltaicas. 
Tabela 6.5 - Seleção de método solar para economia de energia e taxa interna de retorno de investimento para a instalação desejada em Nova York

\begin{tabular}{|c|c|c|c|c|c|c|c|}
\hline & \multirow{2}{*}{\multicolumn{3}{|c|}{ Tarifas }} & \multirow{2}{*}{\multicolumn{2}{|c|}{ Economia de Energia }} & & \\
\hline & & & & & & \multicolumn{2}{|c|}{ Taxa Interna de Retorno } \\
\hline & Tarifa FP & \multicolumn{2}{|c|}{ Tarifa Ponta } & \multirow{2}{*}{$\begin{array}{c}\text { Melhor Método } \\
\text { Absorção Solar }\end{array}$} & \multirow{2}{*}{\begin{tabular}{|c|} 
EAE/CON \\
0,403470172
\end{tabular}} & \multirow{2}{*}{$\frac{\text { TIR 10A }}{\ln v}$} & \multirow{2}{*}{$\begin{array}{c}\text { Melhor Método2 } \\
\text { Caso Base }\end{array}$} \\
\hline $0,5 \mathrm{~kW} / \mathrm{m}^{2}$ & $\mathrm{R} \$ 0,30$ & $\mathrm{R} \$$ & 0,30 & & & & \\
\hline $0,5 \mathrm{~kW} / \mathrm{m}^{2}$ & $\mathrm{R} \$ 0,30$ & $\mathrm{R} \$$ & 0,56 & Absorção Solar & 0,362864373 & Inv & Caso Base \\
\hline $0,5 \mathrm{~kW} / \mathrm{m}^{2}$ & $R \$ 0,55$ & $\mathrm{R} \$$ & 0,69 & Absorção Solar & 0,391119979 & $13 \%$ & Absorção Solar \\
\hline $0,5 \mathrm{~kW} / \mathrm{m}^{2}$ & $\mathrm{R} \$ 0,80$ & $\mathrm{R} \$$ & 1,20 & Absorção Solar & 0,379442955 & $27 \%$ & Absorção Solar \\
\hline $0,5 \mathrm{~kW} / \mathrm{m}^{2}$ & $\mathrm{R} \$ 1,05$ & $\mathrm{R} \$$ & 1,84 & Absorção Solar & 0,368385523 & $40 \%$ & Absorção Solar \\
\hline $1 \mathrm{~kW} / \mathrm{m}^{2}$ & $\mathrm{R} \$ \quad 0,45$ & $\mathrm{R} \$$ & 0,45 & Absorção Solar & 0,523610965 & $13 \%$ & Absorção Solar \\
\hline $1 \mathrm{~kW} / \mathrm{m}^{2}$ & $\mathrm{R} \$ \quad 0,45$ & $\mathrm{R} \$$ & 0,85 & Absorção Solar & 0,456091002 & $17 \%$ & Absorção Solar \\
\hline $1 \mathrm{~kW} / \mathrm{m}^{2}$ & $\mathrm{R} \$ \quad 0,70$ & $\mathrm{R} \$$ & 0,88 & Absorção Solar & 0,502403442 & $30 \%$ & Absorção Solar \\
\hline $1 \mathrm{~kW} / \mathrm{m}^{2}$ & $\mathrm{R} \$ 0,95$ & $\mathrm{R} \$$ & 1,43 & Absorção Solar & 0,48290192 & $47 \%$ & Absorção Solar \\
\hline $2 \mathrm{~kW} / \mathrm{m}^{2}$ & $\mathrm{R} \$ 0,35$ & $\mathrm{R} \$$ & 0,61 & Absorção Solar & 0,021923548 & Inv & Caso Base \\
\hline $2 \mathrm{~kW} / \mathrm{m}^{2}$ & $\mathrm{R} \$ 0,60$ & $\mathrm{R} \$$ & 0,60 & Absorção Solar & 0,049227501 & $1 \%$ & Absorção Solar \\
\hline $2 \mathrm{~kW} / \mathrm{m}^{2}$ & $\mathrm{R} \$ \quad 0,60$ & $\mathrm{R} \$$ & 1,13 & Absorção Solar & 0,018170872 & $8 \%$ & Resfriamento Fotovoltaico \\
\hline $2 \mathrm{~kW} / \mathrm{m}^{2}$ & $\mathrm{R} \$ 0,85$ & $\mathrm{R} \$$ & 1,06 & Absorção Solar & 0,038868996 & $13 \%$ & Absorção Solar \\
\hline $2 \mathrm{~kW} / \mathrm{m}^{2}$ & $\mathrm{R} \$ 1,10$ & $\mathrm{R} \$$ & 1,65 & Absorção Solar & 0,029848898 & $26 \%$ & Resfriamento Fotovoltaico \\
\hline $4 \mathrm{~kW} / \mathrm{m}^{2}$ & $\mathrm{R} \$ \quad 0,50$ & $R \$$ & 0,88 & Absorção Solar & 0,452979263 & $25 \%$ & Absorção Solar \\
\hline $4 \mathrm{~kW} / \mathrm{m}^{2}$ & $\mathrm{R} \$ \quad 0,75$ & $\mathrm{R} \$$ & 0,75 & Absorção Solar & 0,507945152 & $30 \%$ & Absorção Solar \\
\hline $4 \mathrm{~kW} / \mathrm{m}^{2}$ & $\mathrm{R} \$ \quad 0,75$ & $\mathrm{R} \$$ & 1,41 & Absorção Solar & 0,446025338 & $45 \%$ & Absorção Solar \\
\hline $4 \mathrm{~kW} / \mathrm{m}^{2}$ & $\mathrm{R} \$ 1,00$ & $\mathrm{R} \$$ & 1,25 & Absorção Solar & 0,486137112 & $49 \%$ & Absorção Solar \\
\hline $8 \mathrm{~kW} / \mathrm{m}^{2}$ & $\mathrm{R} \$ 0,40$ & $R \$$ & 0,60 & Absorção Solar & 0,321425167 & Inv & Caso Base \\
\hline $8 \mathrm{~kW} / \mathrm{m}^{2}$ & $\mathrm{R} \$ \quad 0,65$ & $\mathrm{R} \$$ & 1,14 & Absorção Solar & 0,312650937 & $11 \%$ & Absorção Solar \\
\hline $8 \mathrm{~kW} / \mathrm{m}^{2}$ & $\mathrm{R} \$ \quad 0,90$ & $\mathrm{R} \$$ & 0,90 & Absorção Solar & 0,350258049 & $6 \%$ & Absorção Solar \\
\hline $8 \mathrm{~kW} / \mathrm{m}^{2}$ & $\mathrm{R} \$ \quad 0,90$ & $\mathrm{R} \$$ & 1,69 & Absorção Solar & 0,308935604 & $25 \%$ & Absorção Solar \\
\hline
\end{tabular}




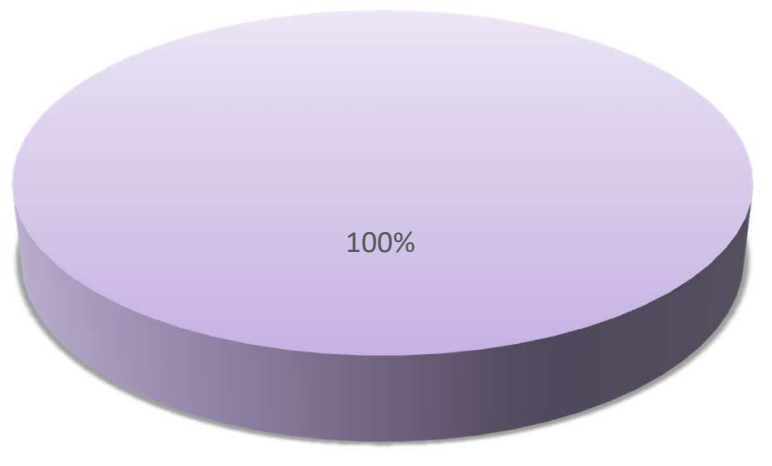

Absorção Solar

Figura 6.21. Melhor equipamento segundo critério de economia de energia para Nova York

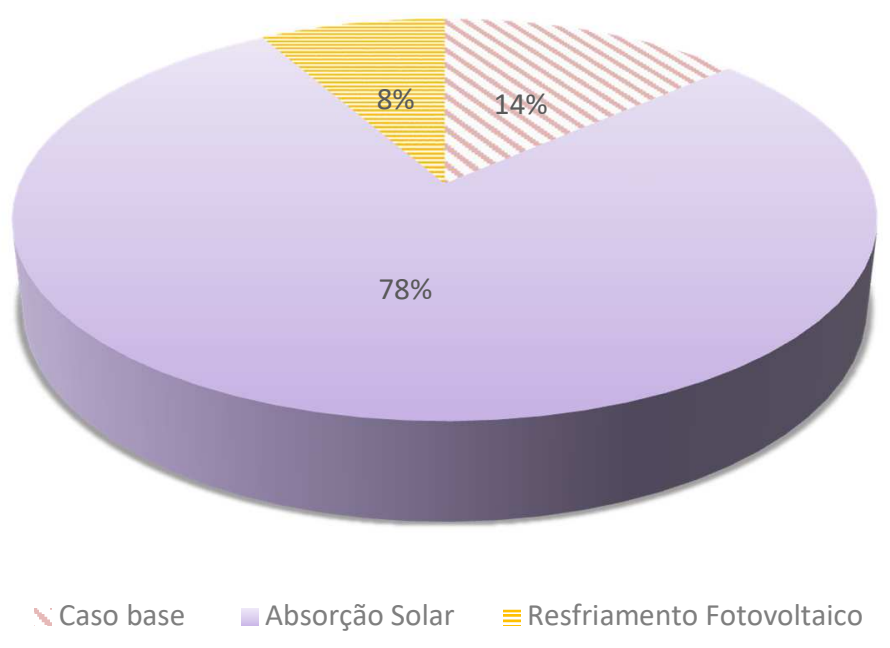

Figura 6.22. Melhor equipamento segundo critério de taxa interna de retorno Nova York

Percebe-se que para menor densidade de $0,5 \mathrm{~kW} / \mathrm{m}^{2}$ há vantagens a partir de $\mathrm{R} \$$

0,35 para a maior relação ponta regular, para a menor as vantagens se dão a partir de $\mathrm{R} \$ 0,40$. Para densidades de $1 \mathrm{~kW} / \mathrm{m}^{2}$ e $4 \mathrm{~kW} / \mathrm{m}^{2}$ há vantagem em todas as tarifas. $A$ diferenciação do horário de ponta faz com que o valor de taxa interna de retorno aumenta.

Para $2,0 \mathrm{~kW} / \mathrm{m}^{2}$ há vantagens a partir de $\mathrm{R} \$ 0,50$ com diferenciação de 1,88 de tarifa de ponta para regular. Quando estas se igualam, estas apresentam vantagens de $\mathrm{R} \$ 0,60$. Para $8,0 \mathrm{~kW} / \mathrm{m}^{2}$ há taxa interna de retorno a partir de $\mathrm{R} \$ 0,45$ para 1,88 de tarifa de ponta sobre regular e $R \$ 0,80$ quando há tarifa de ponta igual à tarifa regular. 
Quando combinados com método de resfriamento natural, absorção solar apresenta grande vantagem. Em economia de energia os resfriadores fotovoltaicos combinados possuem melhor desempenho somente em casos de alta carga e alta tarifa e alta diferenciação de tarifa, conforme apresentado na Tabela 6.6 e Figura 6.23. No caso de taxa de retorno de investimento para 10 anos, a absorção solar apresenta superioridade, exceto para as condições simuladas em $8 \mathrm{~kW} / \mathrm{m}^{2}$ conforme Tabela $6.6 \mathrm{e}$ Figura 6.24. 


\section{Tabela 6.6 - Seleção de método solar com economizadores para economia de energia e taxa interna de retorno de investimento para a instalação desejada em Nova York}

\begin{tabular}{|c|c|c|c|c|c|c|c|c|}
\hline \multirow[b]{2}{*}{ Carga } & \multicolumn{4}{|c|}{ Tarifas } & \multicolumn{2}{|c|}{ Economia de Energia } & \multicolumn{2}{|r|}{ Taxa Interna de Retorno } \\
\hline & Tarifa & fa FP & Tarifa & Ponta & Melhor Método & EAE/CON Base & TIR 10A & Melhor Método2 \\
\hline $0,5 \mathrm{~kW} / \mathrm{m}^{2}$ & $\mathrm{R} \$ \mathrm{C}$ & 0,30 & $\mathrm{R} \$$ & 0,30 & $\begin{array}{c}\text { Absorção Solar e Resfriamento } \\
\text { Natural Indireto }\end{array}$ & $99 \%$ & $3 \%$ & $\begin{array}{c}\text { Absorção Solar e Resfriamento } \\
\text { Natural Indireto }\end{array}$ \\
\hline $0,5 \mathrm{~kW} / \mathrm{m}^{2}$ & $\mathrm{R} \$ \mathrm{C}$ & 0,30 & $\mathrm{R} \$$ & 0,56 & $\begin{array}{c}\text { Absorção Solar e Resfriamento } \\
\text { Natural Indireto }\end{array}$ & $99 \%$ & $9 \%$ & $\begin{array}{c}\text { Absorção Solar e Resfriamento } \\
\text { Natural Indireto }\end{array}$ \\
\hline $0,5 \mathrm{~kW} / \mathrm{m}^{2}$ & $\mathrm{R} \$ \mathrm{C}$ & 0,55 & $\mathrm{R} \$$ & 0,69 & $\begin{array}{l}\text { Absorção Solar e Resfriamento } \\
\text { Natural Indireto }\end{array}$ & $99 \%$ & $22 \%$ & $\begin{array}{c}\text { Absorção Solar e Resfriamento } \\
\text { Natural Indireto }\end{array}$ \\
\hline $0,5 \mathrm{~kW} / \mathrm{m}^{2}$ & $\mathrm{R} \$ \mathrm{C}$ & 0,80 & $\mathrm{R} \$$ & 1,20 & $\begin{array}{l}\text { Absorção Solar e Resfriamento } \\
\text { Natural Indireto }\end{array}$ & $99 \%$ & $39 \%$ & $\begin{array}{c}\text { Absorção Solar e Resfriamento } \\
\text { Natural Indireto }\end{array}$ \\
\hline $0,5 \mathrm{~kW} / \mathrm{m}^{2}$ & $\mathrm{R} \$ 1$ & 1,05 & $\mathrm{R} \$$ & 1,84 & $\begin{array}{l}\text { Absorção Solar e Resfriamento } \\
\text { Natural Indireto }\end{array}$ & $99 \%$ & $55 \%$ & $\begin{array}{c}\text { Absorção Solar e Resfriamento } \\
\text { Natural Indireto }\end{array}$ \\
\hline $1 \mathrm{~kW} / \mathrm{m}^{2}$ & $\mathrm{R} \$ \mathrm{C}$ & 0,45 & $\mathrm{R} \$$ & 0,45 & $\begin{array}{c}\text { Absorção Solar e Resfriamento } \\
\text { Natural Indireto }\end{array}$ & $83 \%$ & $33 \%$ & $\begin{array}{l}\text { Absorção Solar e Resfriamento } \\
\text { Natural Indireto }\end{array}$ \\
\hline $1 \mathrm{~kW} / \mathrm{m}^{2}$ & $\mathrm{R} \$ \mathrm{C}$ & 0,45 & $\mathrm{R} \$$ & 0,85 & $\begin{array}{c}\text { Absorção Solar e Resfriamento } \\
\text { Natural Indireto } \\
\end{array}$ & $84 \%$ & 0,37 & $\begin{array}{c}\text { Absorção Solar e Resfriamento } \\
\text { Natural Indireto }\end{array}$ \\
\hline $1 \mathrm{~kW} / \mathrm{m}^{2}$ & $\mathrm{R} \$ \mathrm{C}$ & 0,70 & $\mathrm{R} \$$ & 0,88 & $\begin{array}{l}\text { Absorção Solar e Resfriamento } \\
\text { Natural Indireto }\end{array}$ & $83 \%$ & $58 \%$ & $\begin{array}{c}\text { Absorção Solar e Resfriamento } \\
\text { Natural Indireto }\end{array}$ \\
\hline $1 \mathrm{~kW} / \mathrm{m}^{2}$ & $\mathrm{R} \$ \mathrm{C}$ & 0,95 & $\mathrm{R} \$$ & 1,43 & $\begin{array}{l}\text { Absorção Solar e Resfriamento } \\
\text { Natural Indireto }\end{array}$ & $84 \%$ & $83 \%$ & $\begin{array}{l}\text { Absorção Solar e Resfriamento } \\
\text { Natural Indireto }\end{array}$ \\
\hline $2 \mathrm{~kW} / \mathrm{m}^{2}$ & $\mathrm{R} \$ \mathrm{C}$ & 0,35 & $\mathrm{R} \$$ & 0,61 & $\begin{array}{c}\text { Absorção Solar e Resfriamento } \\
\text { Natural Indireto }\end{array}$ & $84 \%$ & 0,23 & $\begin{array}{l}\text { Absorção Solar e Resfriamento } \\
\text { Natural Indireto }\end{array}$ \\
\hline $2 \mathrm{~kW} / \mathrm{m}^{2}$ & $\mathrm{R} \$ \mathrm{C}$ & 0,60 & $\mathrm{R} \$$ & 0,60 & $\begin{array}{c}\text { Absorção Solar e Resfriamento } \\
\text { Natural Indireto }\end{array}$ & $83 \%$ & $42 \%$ & $\begin{array}{c}\text { Absorção Solar e Resfriamento } \\
\text { Natural Indireto }\end{array}$ \\
\hline $2 \mathrm{~kW} / \mathrm{m}^{2}$ & $\mathrm{R} \$ \mathrm{C}$ & 0,60 & $\mathrm{R} \$$ & 1,13 & $\begin{array}{c}\text { Absorção Solar e Resfriamento } \\
\text { Natural Indireto } \\
\end{array}$ & $84 \%$ & $47 \%$ & $\begin{array}{c}\text { Absorção Solar e Resfriamento } \\
\text { Natural Indireto } \\
\end{array}$ \\
\hline $2 \mathrm{~kW} / \mathrm{m}^{2}$ & $\mathrm{R} \$ \mathrm{C}$ & 0,85 & $\mathrm{R} \$$ & 1,06 & $\begin{array}{c}\text { Absorção Solar e Resfriamento } \\
\text { Natural Indireto }\end{array}$ & $83 \%$ & $65 \%$ & $\begin{array}{l}\text { Absorção Solar e Resfriamento } \\
\text { Natural Indireto }\end{array}$ \\
\hline $2 \mathrm{~kW} / \mathrm{m}^{2}$ & $\mathrm{R} \$ 1$ & 1,10 & $\mathrm{R} \$$ & 1,65 & $\begin{array}{c}\text { Absorção Solar e Resfriamento } \\
\text { Natural Indireto }\end{array}$ & $83 \%$ & $89 \%$ & $\begin{array}{l}\text { Absorção Solar e Resfriamento } \\
\text { Natural Indireto }\end{array}$ \\
\hline $4 \mathrm{~kW} / \mathrm{m}^{2}$ & $\mathrm{R} \$ \mathrm{C}$ & 0,50 & $\mathrm{R} \$$ & 0,88 & $\begin{array}{c}\text { Absorção Solar e Resfriamento } \\
\text { Natural Indireto }\end{array}$ & $85 \%$ & $135 \%$ & $\begin{array}{l}\text { Absorção Solar e Resfriamento } \\
\text { Natural Indireto }\end{array}$ \\
\hline $4 \mathrm{~kW} / \mathrm{m}^{2}$ & $\mathrm{R} \$ \mathrm{C}$ & 0,75 & $\mathrm{R} \$$ & 0,75 & $\begin{array}{c}\text { Absorção Solar e Resfriamento } \\
\text { Natural Indireto }\end{array}$ & $84 \%$ & $190 \%$ & $\begin{array}{l}\text { Absorção Solar e Resfriamento } \\
\text { Natural Indireto }\end{array}$ \\
\hline $4 \mathrm{~kW} / \mathrm{m}^{2}$ & $\mathrm{R} \$ \mathrm{C}$ & 0,75 & $\mathrm{R} \$$ & 1,41 & $\begin{array}{c}\text { Absorção Solar e Resfriamento } \\
\text { Natural Indireto }\end{array}$ & $85 \%$ & $208 \%$ & $\begin{array}{l}\text { Absorção Solar e Resfriamento } \\
\text { Natural Indireto }\end{array}$ \\
\hline $4 \mathrm{~kW} / \mathrm{m}^{2}$ & $\mathrm{R} \$ 1$ & 1,00 & $\mathrm{R} \$$ & 1,25 & $\begin{array}{c}\text { Absorção Solar e Resfriamento } \\
\text { Natural Indireto }\end{array}$ & $84 \%$ & $261 \%$ & $\begin{array}{c}\text { Absorção Solar e Resfriamento } \\
\text { Natural Indireto }\end{array}$ \\
\hline $8 \mathrm{~kW} / \mathrm{m}^{2}$ & $\mathrm{R} \$ \mathrm{C}$ & 0,40 & $\mathrm{R} \$$ & 0,60 & $\begin{array}{c}\text { Absorção Solar e Resfriamento } \\
\text { Natural Indireto }\end{array}$ & $49 \%$ & $103 \%$ & $\begin{array}{c}\text { Fotovoltaico + resfriamento Natural } \\
\text { indireto }\end{array}$ \\
\hline $8 \mathrm{~kW} / \mathrm{m}^{2}$ & $\mathrm{R} \$ \mathrm{C}$ & 0,65 & $\mathrm{R} \$$ & 1,14 & $\begin{array}{c}\text { Absorção Solar e Resfriamento } \\
\text { Natural Indireto }\end{array}$ & $50 \%$ & $179 \%$ & $\begin{array}{c}\text { Fotovoltaico + resfriamento Natural } \\
\text { indireto }\end{array}$ \\
\hline $8 \mathrm{~kW} / \mathrm{m}^{2}$ & $\mathrm{R} \$ \mathrm{C}$ & 0,90 & $\mathrm{R} \$$ & 0,90 & $\begin{array}{c}\text { Absorção Solar e Resfriamento } \\
\text { Natural Indireto } \\
\end{array}$ & $48 \%$ & $201 \%$ & $\begin{array}{c}\text { Fotovoltaico }+ \text { resfriamento Natural } \\
\text { indireto }\end{array}$ \\
\hline $8 \mathrm{~kW} / \mathrm{m}^{2}$ & $\mathrm{R} \$ \mathrm{C}$ & 0,90 & $\mathrm{R} \$$ & 1,69 & $\begin{array}{c}\text { Fotovoltaico + resfriamento } \\
\text { Natural indireto }\end{array}$ & $50 \%$ & $256 \%$ & $\begin{array}{c}\text { Fotovoltaico }+ \text { resfriamento Natural } \\
\text { indireto }\end{array}$ \\
\hline
\end{tabular}




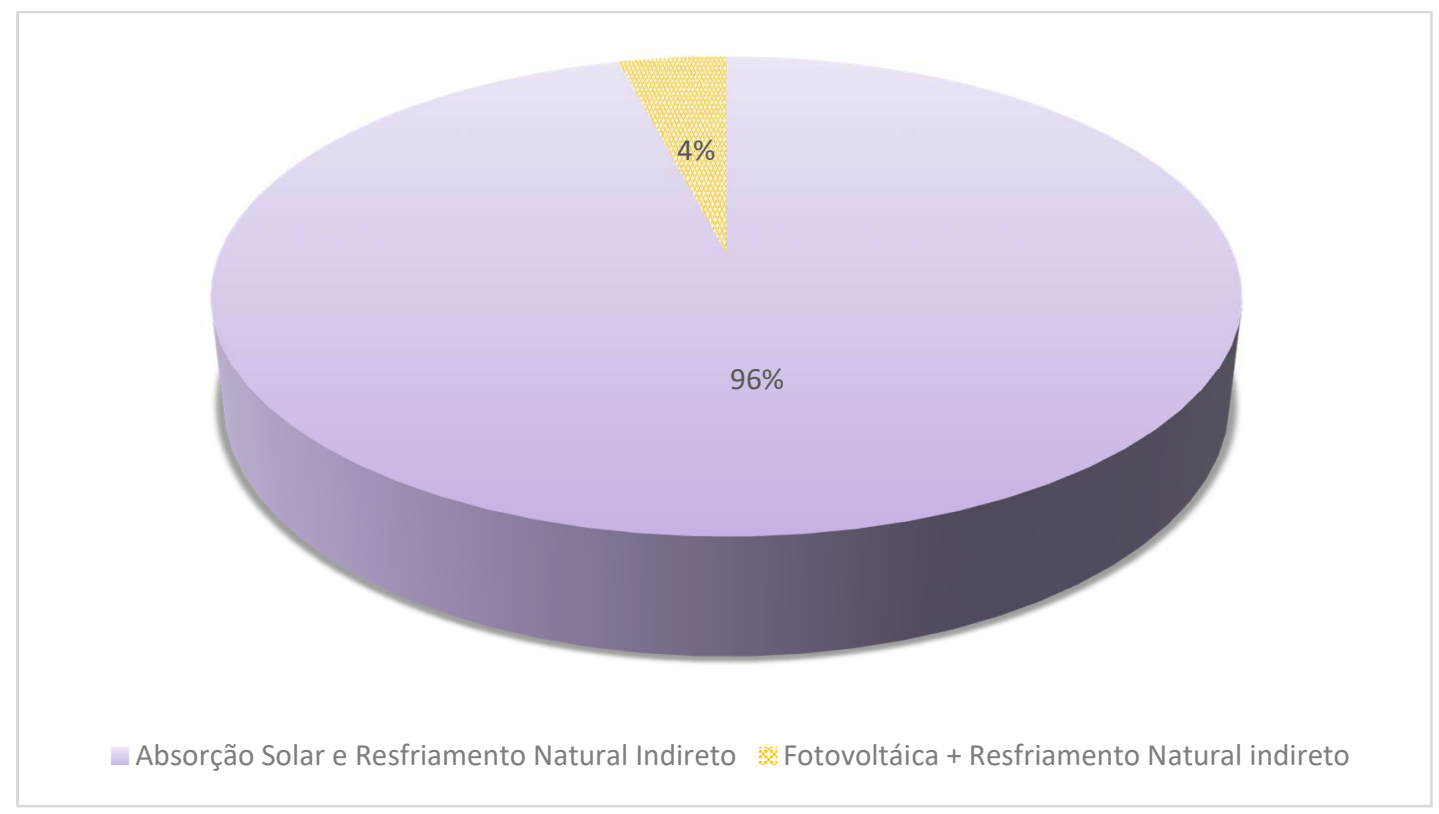

Figura 6.23. Melhor tecnologia solar associada a economizadores segundo economia de energia em Nova York.

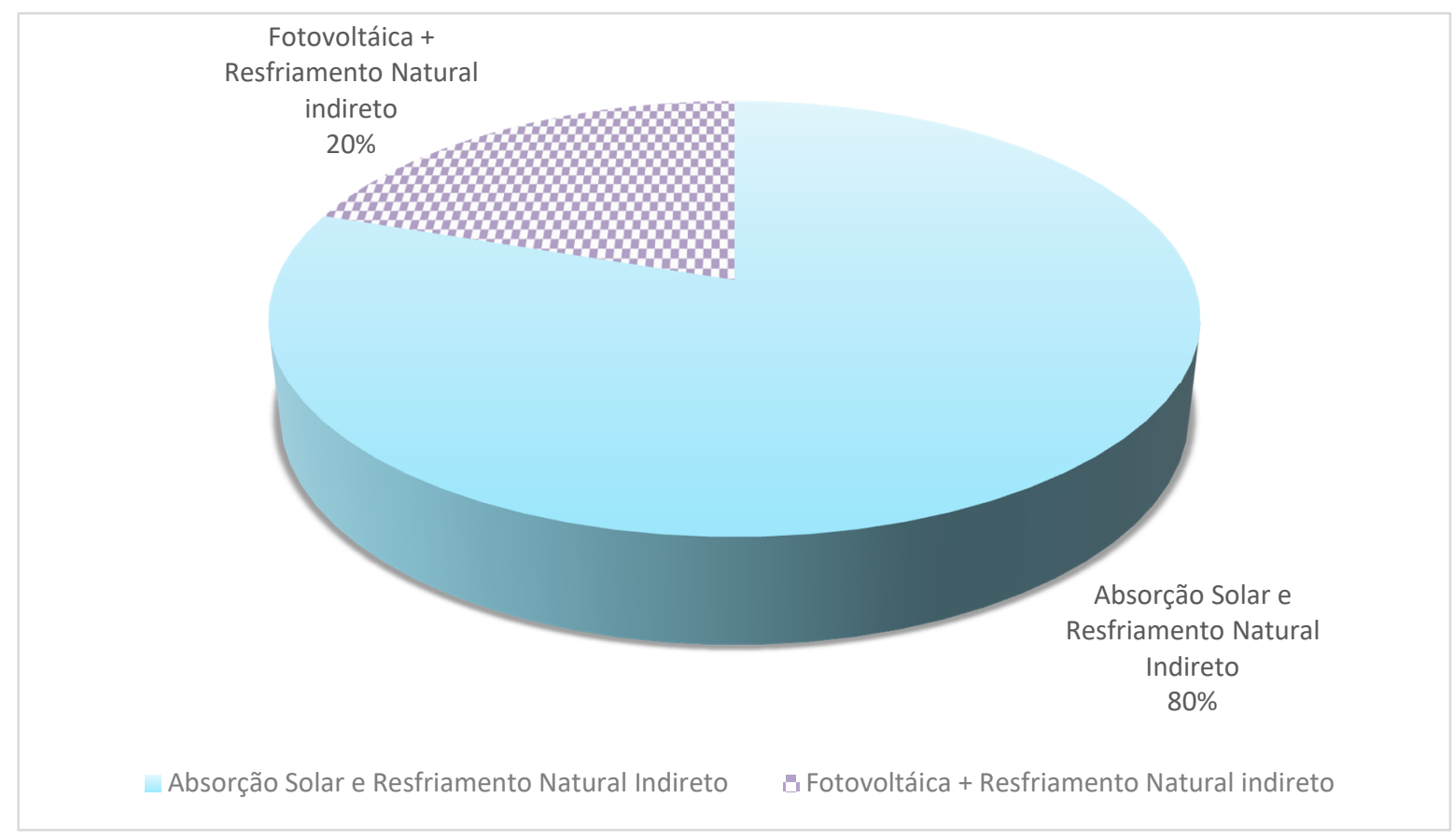

Figura 6.24. Melhor tecnologia solar associada a economizadores segundo taxa interna de retorno em Nova York. 
Percebe-se que para as todas as densidades há vantagens em todas as tarifas estudadas, porém para maiores tarifas e maior diferenciação ponta sobre regular a TIR é maior.

\subsection{Utilização do mesmo sistema tendo como equipamento complementar unidades de resfriamento de líquido do tipo centrífuga}

A próxima etapa desta é avaliar a aplicação de tecnologias solares na cidade de São Paulo alterando os compressores na unidade de resfriamento de líquido para equipamentos do tipo centrífuga, mais eficientes.

A seleção das centrífugas, de maneira análoga a seleção das unidades de resfriamento de líquido com compressores do tipo parafuso, é obtida por meio da carga térmica máxima apresentada na Tabela 5.4, Seção 5.4, desta Tese. A curva de eficiência da Figura 6.25 foi obtida de acordo com o dados fornecidos pelo fabricante (CARRIER, 2014), e através de interpolações polinomiais no Microsoft Excel ${ }^{\circledR}$, resultando em um polinômio de segunda ordem.

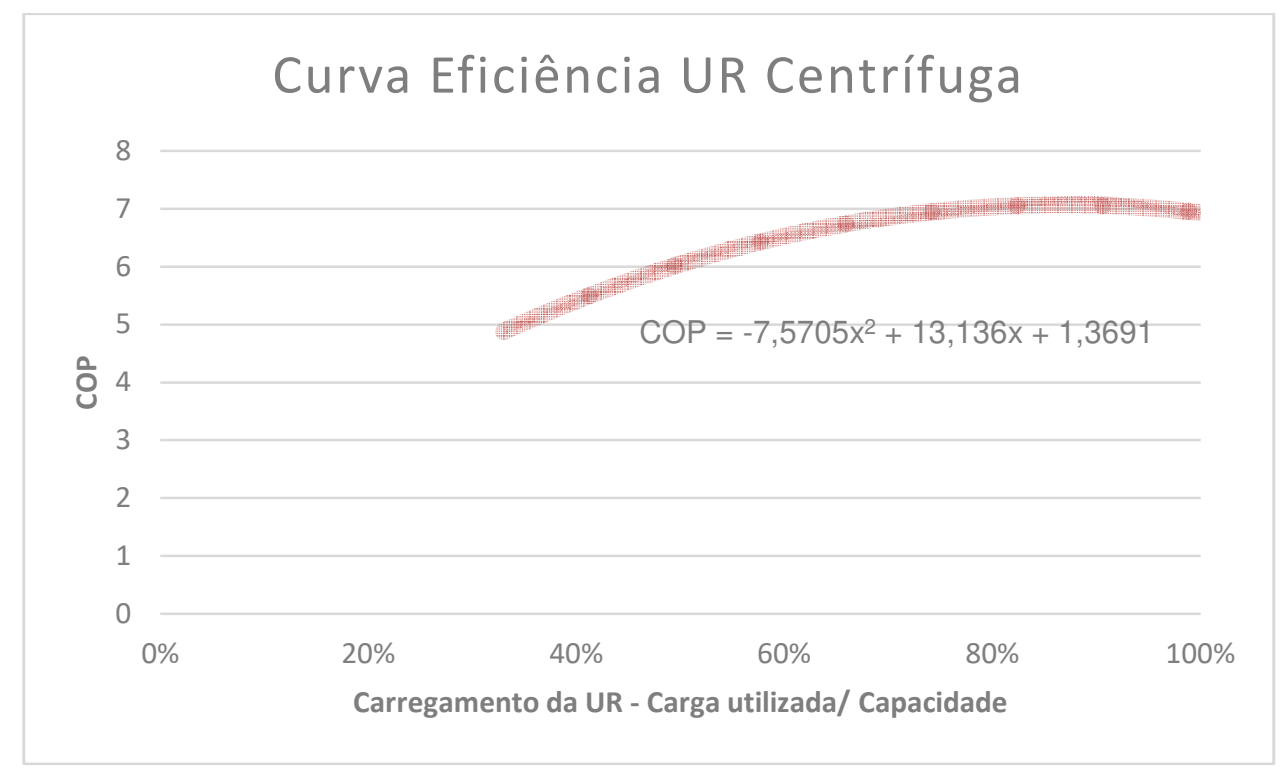

Figura 6.25 Curva de eficiência de Unidade de Resfriamento centrífuga 
A linha de tendência indica a eficiência máxima da unidade de resfriamento de líquido de acordo com o seu percentil de utilização. O ponto ótimo será a derivada desta curva, conforme equações de 6.1 a 6.4 .

$$
\begin{aligned}
& \frac{\partial C O P}{\partial x}=0 \\
& C O P=-7,5705 \cdot x^{2}+13,136 \cdot x+1,3691 \\
& \frac{\partial C O P}{\partial x}=15,141 \cdot x+13,136=0 \\
& x^{\prime}=87 \%
\end{aligned}
$$

A melhor utilização desta unidade de resfriamento ocorre com 87\%, próximo de seu carregamento máximo, diferentemente do equipamento de parafuso, que ocorre em cargas parciais.

A Figura 6.26 apresenta a evolução de COP e disponibilidade para cada uma das utilizações. Neste caso, os métodos de absorção solar e economizadores influenciam negativamente de forma drástica o COP. Isto indica vantagem dos resfriadores fotovoltaicos, quando a UR está dimensionada para utilização próxima de sua capacidade máxima.

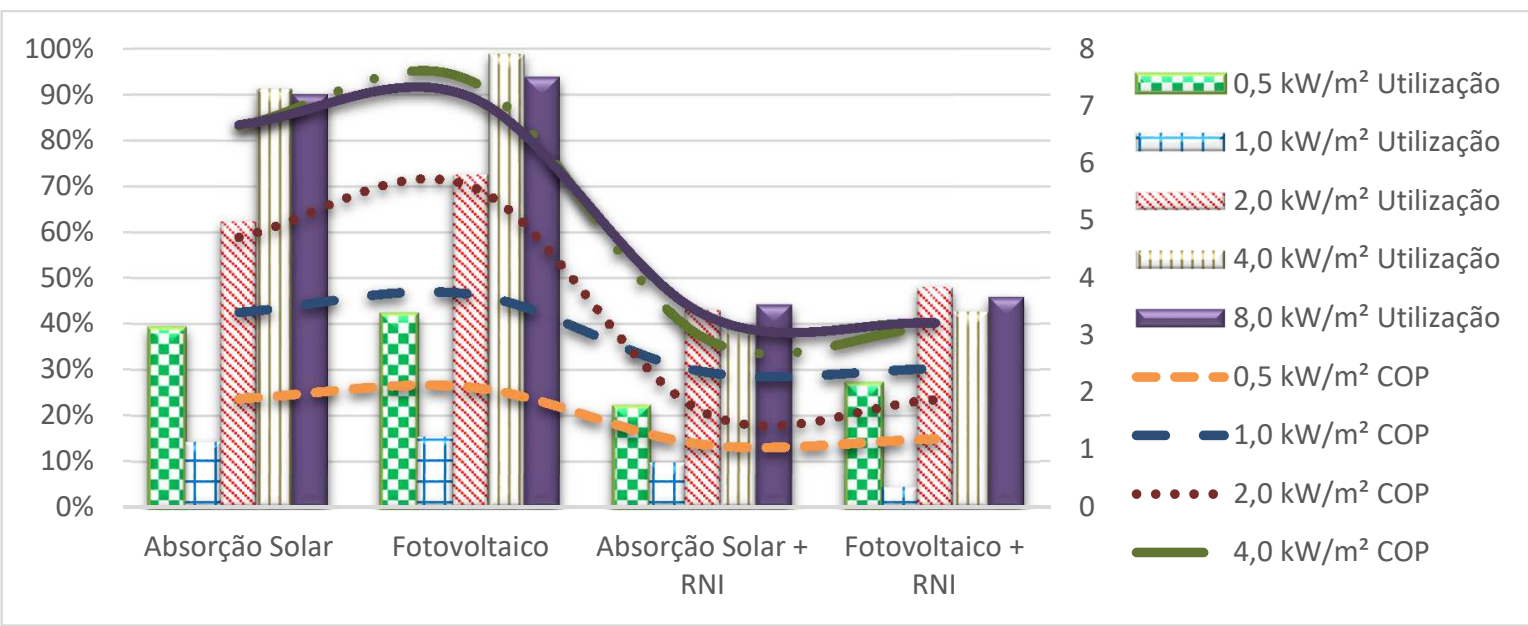

Figura 6.26. Indicação de utilização e COP para todas as densidades estudas e tecnologias solares com e sem economizadores para compressores centrífugos em São Paulo. 
Tratando-se de economias, a absorção solar leva vantagem nas cargas de 0,5, 1 e $2 \mathrm{~kW} / \mathrm{m}^{2}$ e o resfriamento fotovoltaico é superior em 4 e $8 \mathrm{~kW} / \mathrm{m}^{2}$. A Tabela 6.7 apresenta estes valores.

Ocorre que nos casos de 0,5 e $1,0 \mathrm{~kW} / \mathrm{m}^{2}$, as unidades de resfriamento jamais trabalharão em cargas totais, pois a capacidade da menor centrífuga disponível é superior à sua carga total. No caso de $2 \mathrm{~kW} / \mathrm{m}^{2}$, a centrífuga selecionada é superior em $16 \%$ ao carregamento máximo.

Nestes casos a centrífuga parte com seu rendimento abaixo do ótimo, e a absorção solar pode em alguns momentos desligar a unidade, o que geraria grande economia. Nas demais densidades quando há redução da carga térmica, a perda de rendimento da UR, favorecendo a tecnologia fotovoltaica. A Figura 6.27 apresenta a melhor tecnologia solar a ser utilizada segundo economia de energia. 
Tabela 6.7 - Seleção de método solar para economia de energia e taxa interna de retorno de investimento para a instalação desejada em São Paulo com Centrífugas

\begin{tabular}{|c|c|c|c|c|c|c|c|c|}
\hline \multirow{3}{*}{\begin{tabular}{|l|} 
Carga \\
$0,5 \mathrm{~kW} / \mathrm{m}^{2}$ \\
\end{tabular}} & \multicolumn{4}{|c|}{ Tarifas } & \multicolumn{2}{|c|}{ Economia de Energia } & \multicolumn{2}{|c|}{ Taxa Interna de Retorno } \\
\hline & \multicolumn{2}{|c|}{ Tarifa FP } & \multicolumn{2}{|c|}{ Tarifa Ponta } & \multirow{2}{*}{$\begin{array}{l}\text { Melhor Método } \\
\text { Absorção Solar } \\
\end{array}$} & \multirow{2}{*}{\begin{tabular}{|r|} 
EAE/CONBase \\
$74 \%$ \\
\end{tabular}} & \multirow{2}{*}{$\begin{array}{l}\text { TIR } \\
\text { Inviável } \\
\end{array}$} & \multirow{2}{*}{\begin{tabular}{|l|} 
Melhor Método2 \\
Caso Base \\
\end{tabular}} \\
\hline & $\mathrm{R} \$$ & 0,30 & $\mathrm{R} \$$ & 0,30 & & & & \\
\hline $0,5 \mathrm{~kW} / \mathrm{m}^{2}$ & $\mathrm{R} \$$ & 0,30 & $\mathrm{R} \$$ & 0,56 & Absorção Solar & $65 \%$ & $12 \%$ & Absorção Solar \\
\hline $0,5 \mathrm{~kW} / \mathrm{m}^{2}$ & $\mathrm{R} \$$ & 0,55 & $\mathrm{R} \$$ & 0,69 & Absorção Solar & $71 \%$ & $22 \%$ & Absorção Solar \\
\hline $0,5 \mathrm{~kW} / \mathrm{m}^{2}$ & $\mathrm{R} \$$ & 0,80 & $\mathrm{R} \$$ & 1,20 & Absorção Solar & $69 \%$ & $41 \%$ & Absorção Solar \\
\hline $0,5 \mathrm{~kW} / \mathrm{m}^{2}$ & $\mathrm{R} \$$ & 1,05 & $\mathrm{R} \$$ & 1,84 & Absorção Solar & $67 \%$ & $61 \%$ & Absorção Solar \\
\hline $1 \mathrm{~kW} / \mathrm{m}^{2}$ & $\mathrm{R} \$$ & 0,45 & $\mathrm{R} \$$ & 0,45 & Absorção Solar & $48 \%$ & $\operatorname{lnv}$ & Caso Base \\
\hline $1 \mathrm{~kW} / \mathrm{m}^{2}$ & $\mathrm{R} \$$ & 0,45 & $\mathrm{R} \$$ & 0,85 & Absorção Solar & $38 \%$ & $2 \%$ & Absorção Solar \\
\hline $1 \mathrm{~kW} / \mathrm{m}^{2}$ & $\mathrm{R} \$$ & 0,70 & $\mathrm{R} \$$ & 0,88 & Absorção Solar & $44 \%$ & $8 \%$ & Absorção Solar \\
\hline $1 \mathrm{~kW} / \mathrm{m}^{2}$ & $\mathrm{R} \$$ & 0,95 & $\mathrm{R} \$$ & 1,43 & Absorção Solar & $41 \%$ & $21 \%$ & Absorção Solar \\
\hline $2 \mathrm{~kW} / \mathrm{m}^{2}$ & $\mathrm{R} \$$ & 0,35 & $\mathrm{R} \$$ & 0,61 & Absorção Solar & $1 \%$ & Inv & Caso Base \\
\hline $2 \mathrm{~kW} / \mathrm{m}^{2}$ & $\mathrm{R} \$$ & 0,60 & $\mathrm{R} \$$ & 0,60 & Absorção Solar & $1 \%$ & Inv & Caso Base \\
\hline $2 \mathrm{~kW} / \mathrm{m}^{2}$ & $\mathrm{R} \$$ & 0,60 & $\mathrm{R} \$$ & 1,13 & Absorção Solar & $1 \%$ & Inv & Caso Base \\
\hline $2 \mathrm{~kW} / \mathrm{m}^{2}$ & $\mathrm{R} \$$ & 0,85 & $\mathrm{R} \$$ & 1,06 & Absorção Solar & $1 \%$ & Inv & Caso Base \\
\hline $2 \mathrm{~kW} / \mathrm{m}^{2}$ & $\mathrm{R} \$$ & 1,10 & $\mathrm{R} \$$ & 1,65 & Absorção Solar & $1 \%$ & $10 \%$ & Resfriamento Fotovoltaico \\
\hline $4 \mathrm{~kW} / \mathrm{m}^{2}$ & $\mathrm{R} \$$ & 0,50 & $\mathrm{R} \$$ & 0,88 & Resfriamento Fotovoltaico & $34 \%$ & Inv & Caso Base \\
\hline $4 \mathrm{~kW} / \mathrm{m}^{2}$ & $\mathrm{R} \$$ & 0,75 & $\mathrm{R} \$$ & 0,75 & Resfriamento Fotovoltaico & $44 \%$ & $\operatorname{lnv}$ & Caso Base \\
\hline $4 \mathrm{~kW} / \mathrm{m}^{2}$ & $\mathrm{R} \$$ & 0,75 & $\mathrm{R} \$$ & 1,41 & Resfriamento Fotovoltaico & $33 \%$ & $5 \%$ & Resfriamento Fotovoltaico \\
\hline $4 \mathrm{~kW} / \mathrm{m}^{2}$ & $\mathrm{R} \$$ & 1,00 & $\mathrm{R} \$$ & 1,25 & Resfriamento Fotovoltaico & $39 \%$ & $2 \%$ & Resfriamento Fotovoltaico \\
\hline $8 \mathrm{~kW} / \mathrm{m}^{2}$ & $\mathrm{R} \$$ & 0,40 & $R \$$ & 0,60 & Resfriamento Fotovoltaico & $27 \%$ & Inv & Caso Base \\
\hline $8 \mathrm{~kW} / \mathrm{m}^{2}$ & $\mathrm{R} \$$ & 0,65 & $\mathrm{R} \$$ & 1,14 & Resfriamento Fotovoltaico & $27 \%$ & $0 \%$ & Resfriamento Fotovoltaico \\
\hline $8 \mathrm{~kW} / \mathrm{m}^{2}$ & $\mathrm{R} \$$ & 0,90 & $\mathrm{R} \$$ & 0,90 & Resfriamento Fotovoltaico & $28 \%$ & Inv & Caso Base \\
\hline $8 \mathrm{~kW} / \mathrm{m}^{2}$ & $\mathrm{R} \$$ & 0,90 & $\mathrm{R} \$$ & 1,69 & Resfriamento Fotovoltaico & $26 \%$ & $13 \%$ & Resfriamento Fotovoltaico \\
\hline
\end{tabular}




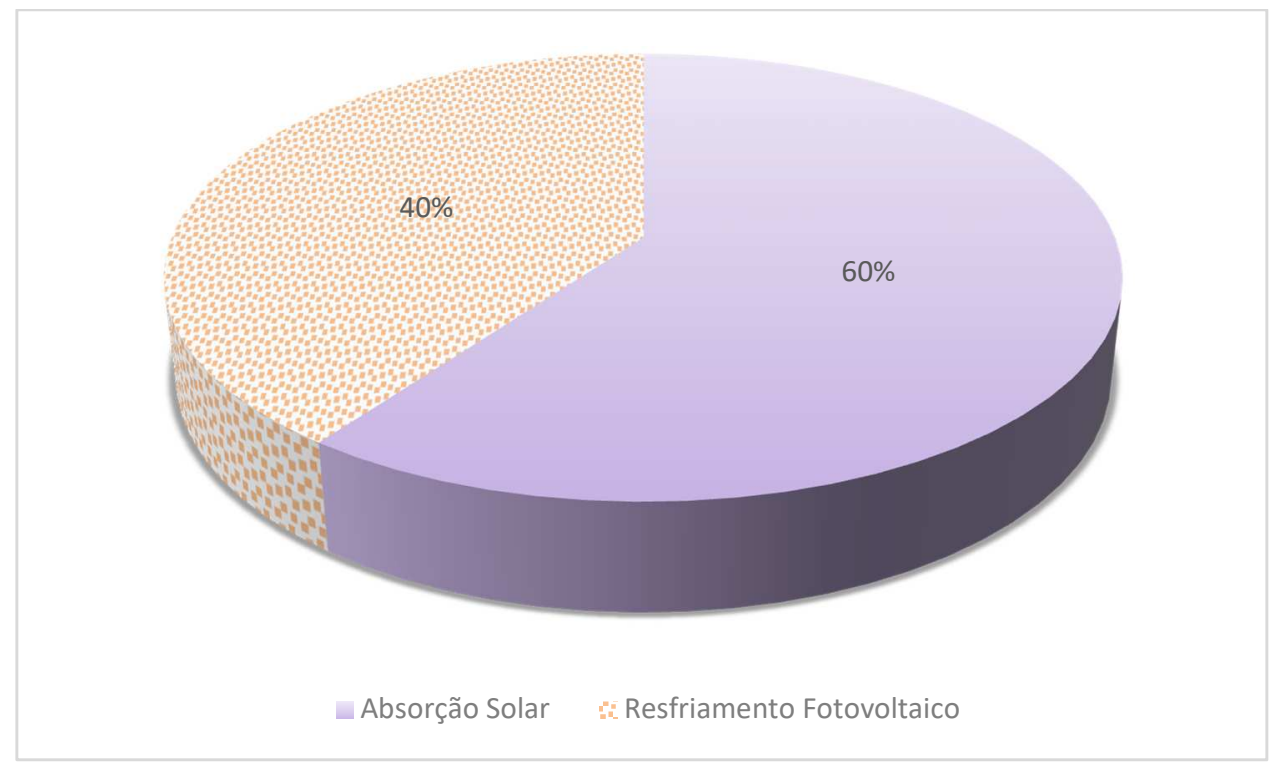

Figura 6.27 - Melhor tecnologia solar para instalação com centrífugas em São Paulo, segundo critério de Economia de energia

No tangente a taxa de retorno de investimento, justifica-se em instalações de 0,5 e $1 \mathrm{~kW} / \mathrm{m}^{2}$ o equipamento de absorção solar pelos mesmos motivos citados acima. Para os casos de 4 e $8 \mathrm{~kW} / \mathrm{m}^{2}$, as tecnologias de resfriamento fotovoltaico justificam em casos de tarifa superior a $R \$ 0,75$ e razão de tarifa de ponta por tarifa regular superior a 1,5. Em outras situações e em densidades de $2 \mathrm{~kW} / \mathrm{m}^{2}$ não se justifica a utilização de tecnologias solares. A Figura 6.28 apresenta estes valores, bem como a Tabela 5.16.

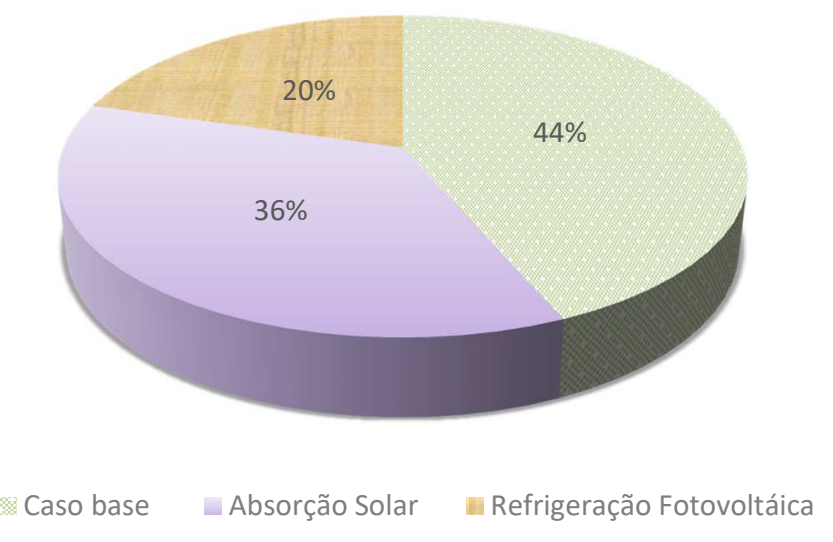

Figura 6.28 - Melhor tecnologia solar para instalação com centrífugas em São Paulo, segundo critério de taxa interna de retorno para 10 anos. 
Percebe-se que para menor densidade de $0,5 \mathrm{~kW} / \mathrm{m}^{2}$ há vantagens em todas as densidades. Para densidades de $1 \mathrm{~kW} / \mathrm{m}^{2}$ as vantagens aparecem a partir de $R \$ 0,45$ para relação ponta regular de 1,88 , quando a relação é 1 a tarifa inicial é $R \$ 0,60$. Para $2,0 \mathrm{~kW} / \mathrm{m}^{2}, 4,0 \mathrm{~kW} / \mathrm{m}^{2}$ e $8,0 \mathrm{~kW} / \mathrm{m}^{2}$ há vantagens com diferenciação de 1,88 de tarifa de ponta para regular a partir de $R \$ 0,70, R \$ 0,65$ e $R \$ 0,65$ respectivamente.

Quando os economizadores são inseridos, há grande vantagem da absorção solar com o resfriamento natural indireto sobre as demais proposições em todos os casos, pela possibilidade de desligamento das unidades de resfriamento em alguns períodos conforme apresenta a Tabela 6.8. A Figura 6.29 apresenta graficamente estes resultados no tangente à escolha do melhor método segundo economias. 


\section{Tabela 6.8 - Seleção de método solar com economizadores para economia de energia e taxa interna de retorno de investimento para a instalação desejada em São Paulo com Centrífugas}

\begin{tabular}{|c|c|c|c|c|c|c|c|c|}
\hline \multirow[b]{2}{*}{ Carga } & \multicolumn{4}{|c|}{ Tarifas } & \multicolumn{2}{|c|}{ Economia de Energia } & \multicolumn{2}{|r|}{ Taxa Interna de Retorno } \\
\hline & Ta! & a FP & Tar & onta & Melhor Método & EAE/CONBase & TIR & Melhor Método2 \\
\hline $0,5 \mathrm{~kW} / \mathrm{m}^{2}$ & $\mathrm{R} \$$ & 0,30 & $\mathrm{R} \$$ & 0,30 & $\begin{array}{c}\text { Absorção Solar e Resfriamento } \\
\text { Natural Indireto }\end{array}$ & $37 \%$ & $7 \%$ & $\begin{array}{c}\text { Absorção Solar e Resfriamento } \\
\text { Natural Indireto }\end{array}$ \\
\hline $0,5 \mathrm{~kW} / \mathrm{m}^{2}$ & $\mathrm{R} \$$ & 0,30 & $\mathrm{R} \$$ & 0,56 & $\begin{array}{c}\text { Absorção Solar e Resfriamento } \\
\text { Natural Indireto }\end{array}$ & $42 \%$ & $17 \%$ & $\begin{array}{c}\text { Absorção Solar e Resfriamento } \\
\text { Natural Indireto }\end{array}$ \\
\hline $0,5 \mathrm{~kW} / \mathrm{m}^{2}$ & $\mathrm{R} \$$ & 0,55 & $\mathrm{R} \$$ & 0,69 & $\begin{array}{c}\text { Absorção Solar e Resfriamento } \\
\text { Natural Indireto }\end{array}$ & $39 \%$ & $29 \%$ & $\begin{array}{c}\text { Absorção Solar e Resfriamento } \\
\text { Natural Indireto }\end{array}$ \\
\hline $0,5 \mathrm{~kW} / \mathrm{m}^{2}$ & $\mathrm{R} \$$ & 0,80 & $\mathrm{R} \$$ & 1,20 & $\begin{array}{c}\text { Absorção Solar e Resfriamento } \\
\text { Natural Indireto }\end{array}$ & $40 \%$ & $50 \%$ & $\begin{array}{c}\text { Absorção Solar e Resfriamento } \\
\text { Natural Indireto }\end{array}$ \\
\hline $0,5 \mathrm{~kW} / \mathrm{m}^{2}$ & $\mathrm{R} \$$ & 1,05 & $\mathrm{R} \$$ & 1,84 & $\begin{array}{c}\text { Absorção Solar e Resfriamento } \\
\text { Natural Indireto }\end{array}$ & $41 \%$ & $72 \%$ & $\begin{array}{c}\text { Absorção Solar e Resfriamento } \\
\text { Natural Indireto }\end{array}$ \\
\hline $1 \mathrm{~kW} / \mathrm{m}^{2}$ & $\mathrm{R} \$$ & 0,45 & $\mathrm{R} \$$ & 0,45 & $\begin{array}{c}\text { Absorção Solar e Resfriamento } \\
\text { Natural Indireto }\end{array}$ & $21 \%$ & Inv & Caso base e Economizadores \\
\hline $1 \mathrm{~kW} / \mathrm{m}^{2}$ & $\mathrm{R} \$$ & 0,45 & $\mathrm{R} \$$ & 0,85 & $\begin{array}{c}\text { Absorção Solar e Resfriamento } \\
\text { Natural Indireto }\end{array}$ & $27 \%$ & $6 \%$ & $\begin{array}{c}\text { Absorção Solar e Resfriamento } \\
\text { Natural Indireto }\end{array}$ \\
\hline $1 \mathrm{~kW} / \mathrm{m}^{2}$ & $\mathrm{R} \$$ & 0,70 & $\mathrm{R} \$$ & 0,88 & $\begin{array}{c}\text { Absorção Solar e Resfriamento } \\
\text { Natural Indireto }\end{array}$ & $23 \%$ & $13 \%$ & $\begin{array}{c}\text { Absorção Solar e Resfriamento } \\
\text { Natural Indireto }\end{array}$ \\
\hline $1 \mathrm{~kW} / \mathrm{m}^{2}$ & $\mathrm{R} \$$ & 0,95 & $\mathrm{R} \$$ & 1,43 & $\begin{array}{c}\text { Absorção Solar e Resfriamento } \\
\text { Natural Indireto }\end{array}$ & $25 \%$ & $27 \%$ & $\begin{array}{c}\text { Absorção Solar e Resfriamento } \\
\text { Natural Indireto }\end{array}$ \\
\hline $2 \mathrm{~kW} / \mathrm{m}^{2}$ & $\mathrm{R} \$$ & 0,35 & $\mathrm{R} \$$ & 0,61 & $\begin{array}{c}\text { Absorção Solar e Resfriamento } \\
\text { Natural Indireto }\end{array}$ & $44 \%$ & $16 \%$ & $\begin{array}{c}\text { Absorção Solar e Resfriamento } \\
\text { Natural Indireto }\end{array}$ \\
\hline $2 \mathrm{~kW} / \mathrm{m}^{2}$ & $\mathrm{R} \$$ & 0,60 & $\mathrm{R} \$$ & 0,60 & $\begin{array}{c}\text { Absorção Solar e Resfriamento } \\
\text { Natural Indireto }\end{array}$ & $40 \%$ & $30 \%$ & $\begin{array}{c}\text { Absorção Solar e Resfriamento } \\
\text { Natural Indireto } \\
\end{array}$ \\
\hline $2 \mathrm{~kW} / \mathrm{m}^{2}$ & $\mathrm{R} \$$ & 0,60 & $\mathrm{R} \$$ & 1,13 & $\begin{array}{c}\text { Absorção Solar e Resfriamento } \\
\text { Natural Indireto }\end{array}$ & $45 \%$ & $38 \%$ & $\begin{array}{c}\text { Absorção Solar e Resfriamento } \\
\text { Natural Indireto }\end{array}$ \\
\hline $2 \mathrm{~kW} / \mathrm{m}^{2}$ & $\mathrm{R} \$$ & 0,85 & $\mathrm{R} \$$ & 1,06 & $\begin{array}{c}\text { Absorção Solar e Resfriamento } \\
\text { Natural Indireto }\end{array}$ & $42 \%$ & $50 \%$ & $\begin{array}{c}\text { Absorção Solar e Resfriamento } \\
\text { Natural Indireto }\end{array}$ \\
\hline $2 \mathrm{~kW} / \mathrm{m}^{2}$ & $\mathrm{R} \$$ & 1,10 & $\mathrm{R} \$$ & 1,65 & $\begin{array}{c}\text { Absorção Solar e Resfriamento } \\
\text { Natural Indireto }\end{array}$ & $43 \%$ & $71 \%$ & $\begin{array}{c}\text { Absorção Solar e Resfriamento } \\
\text { Natural Indireto }\end{array}$ \\
\hline $4 \mathrm{~kW} / \mathrm{m}^{2}$ & $\mathrm{R} \$$ & 0,50 & $\mathrm{R} \$$ & 0,88 & $\begin{array}{c}\text { Absorção Solar e Resfriamento } \\
\text { Natural Indireto }\end{array}$ & $25 \%$ & $20 \%$ & $\begin{array}{c}\text { Absorção Solar e Resfriamento } \\
\text { Natural Indireto }\end{array}$ \\
\hline $4 \mathrm{~kW} / \mathrm{m}^{2}$ & $\mathrm{R} \$$ & 0,75 & $\mathrm{R} \$$ & 0,75 & $\begin{array}{c}\text { Absorção Solar e Resfriamento } \\
\text { Natural Indireto }\end{array}$ & $21 \%$ & $25 \%$ & $\begin{array}{c}\text { Absorção Solar e Resfriamento } \\
\text { Natural Indireto } \\
\end{array}$ \\
\hline $4 \mathrm{~kW} / \mathrm{m}^{2}$ & $\mathrm{R} \$$ & 0,75 & $\mathrm{R} \$$ & 1,41 & $\begin{array}{c}\text { Absorção Solar e Resfriamento } \\
\text { Natural Indireto }\end{array}$ & $26 \%$ & $38 \%$ & $\begin{array}{c}\text { Absorção Solar e Resfriamento } \\
\text { Natural Indireto } \\
\end{array}$ \\
\hline $4 \mathrm{~kW} / \mathrm{m}^{2}$ & $\mathrm{R} \$$ & 1,00 & $\mathrm{R} \$$ & 1,25 & $\begin{array}{c}\text { Absorção Solar e Resfriamento } \\
\text { Natural Indireto }\end{array}$ & $22 \%$ & $42 \%$ & $\begin{array}{c}\text { Absorção Solar e Resfriamento } \\
\text { Natural Indireto }\end{array}$ \\
\hline $8 \mathrm{~kW} / \mathrm{m}^{2}$ & $\mathrm{R} \$$ & 0,40 & $\mathrm{R} \$$ & 0,60 & $\begin{array}{c}\text { Absorção Solar e Resfriamento } \\
\text { Natural Indireto }\end{array}$ & $17 \%$ & $15 \%$ & $\begin{array}{c}\text { Absorção Solar e Resfriamento } \\
\text { Natural Indireto } \\
\end{array}$ \\
\hline $8 \mathrm{~kW} / \mathrm{m}^{2}$ & $\mathrm{R} \$$ & 0,65 & $\mathrm{R} \$$ & 1,14 & $\begin{array}{c}\text { Absorção Solar e Resfriamento } \\
\text { Natural Indireto }\end{array}$ & $17 \%$ & $39 \%$ & $\begin{array}{c}\text { Fotovoltaico + resfriamento } \\
\text { Natural indireto } \\
\end{array}$ \\
\hline $8 \mathrm{~kW} / \mathrm{m}^{2}$ & $\mathrm{R} \$$ & 0,90 & $\mathrm{R} \$$ & 0,90 & $\begin{array}{c}\text { Absorção Solar e Resfriamento } \\
\text { Natural Indireto }\end{array}$ & $16 \%$ & $39 \%$ & $\begin{array}{c}\text { Absorção Solar e Resfriamento } \\
\text { Natural Indireto }\end{array}$ \\
\hline $8 \mathrm{~kW} / \mathrm{m}^{2}$ & $\mathrm{R} \$$ & 0,90 & $\mathrm{R} \$$ & 1,69 & $\begin{array}{c}\text { Absorção Solar e Resfriamento } \\
\text { Natural Indireto }\end{array}$ & $18 \%$ & $63 \%$ & $\begin{array}{c}\text { Fotovoltaico + resfriamento } \\
\text { Natural indireto }\end{array}$ \\
\hline
\end{tabular}




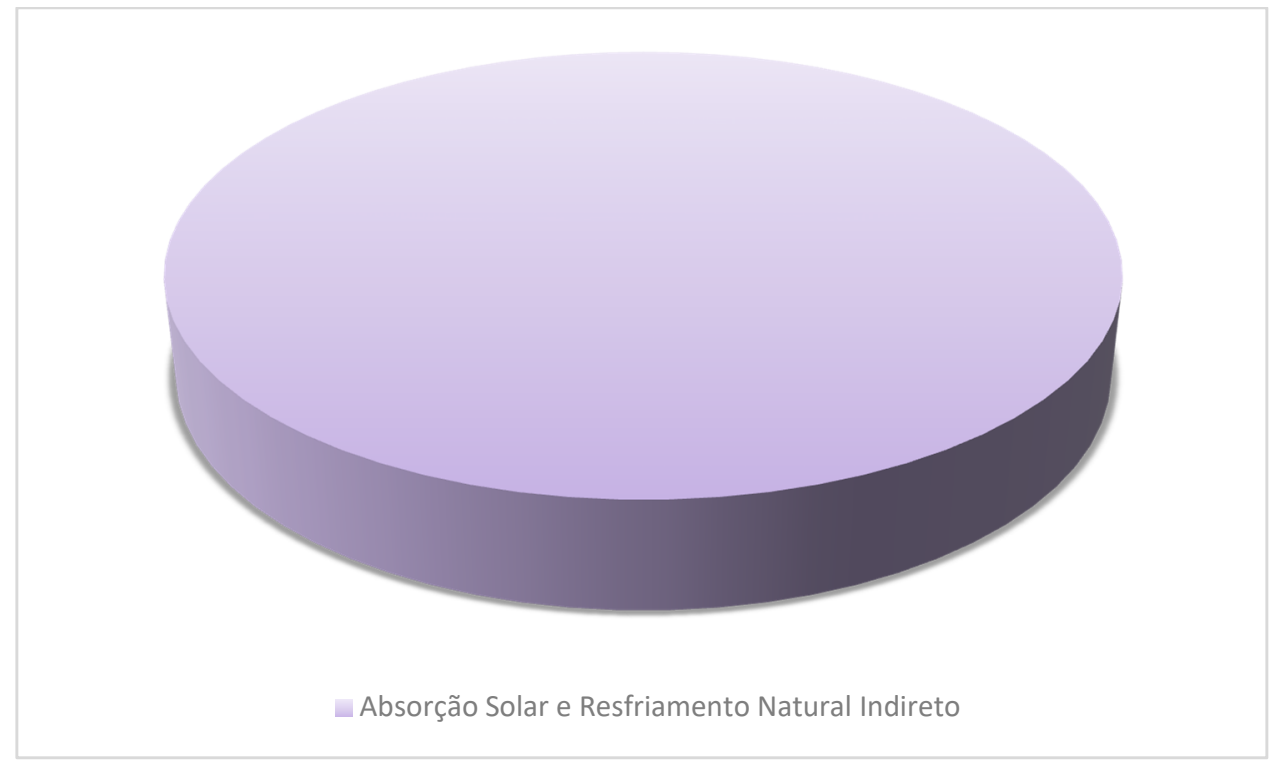

Figura 6.29 - Melhor tecnologia solar com economizadores para instalação com centrífugas em São Paulo, segundo critério de Economia de energia

Em se tratando de taxa de retorno de investimento, a solução acima é a melhor na maioria dos casos exceto em cargas de $8 \mathrm{~kW} / \mathrm{m}^{2}$ e em baixas tarifas. Isto é apresentado na Tabela 6.8 e na Figura 2.30.

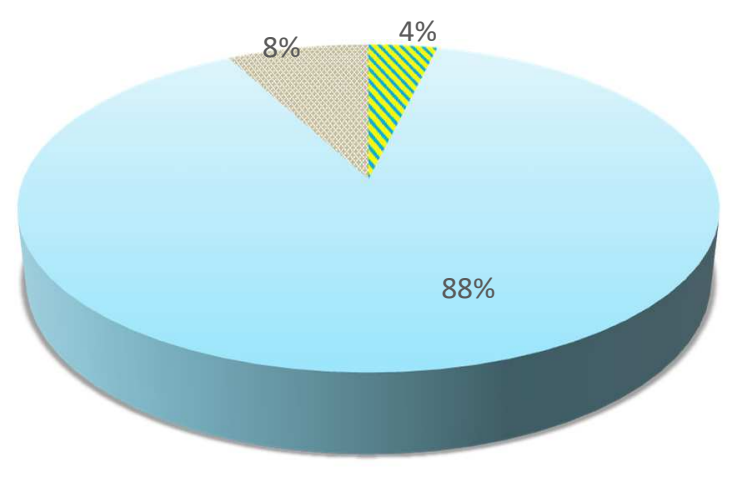

$\checkmark$ Caso base e Economizadores

Absorção Solar e Resfriamento Natural Indireto

Fotovoltáica + Resfriamento Natural indireto

Figura 6.30 Melhor tecnologia solar associada a economizadores segundo taxa interna de retorno em São Paulo para compressores centrífugos. 
Percebe-se que para as todas as densidades há vantagens na utilização dos métodos solares associados ao resfriamento natural indireto, nota-se que quanto maior a tarifa, maior a diferenciação.

\subsection{Fatores para seleção}

Em resumo, para se selecionar um método de resfriamento solar deve se levar em consideração 6 fatores: investimento inicial, aplicação, região de instalação, tarifa base, diferenciação de ponta e inferência na curva do equipamento base $e$ consequentemente alteração de rendimento. Quando o critério é somente economia de energia, sem retorno financeiro, a tarifa base, a aplicação e a diferenciação de tarifa no horário de ponta são os principais critérios que deverão ser levados em consideração. Considerando pesos de 0 a 10 e classificando de acordo com os resultados obtidos nesta tese a Figura 6.31 aponta o peso de cada um dos 6 fatores.

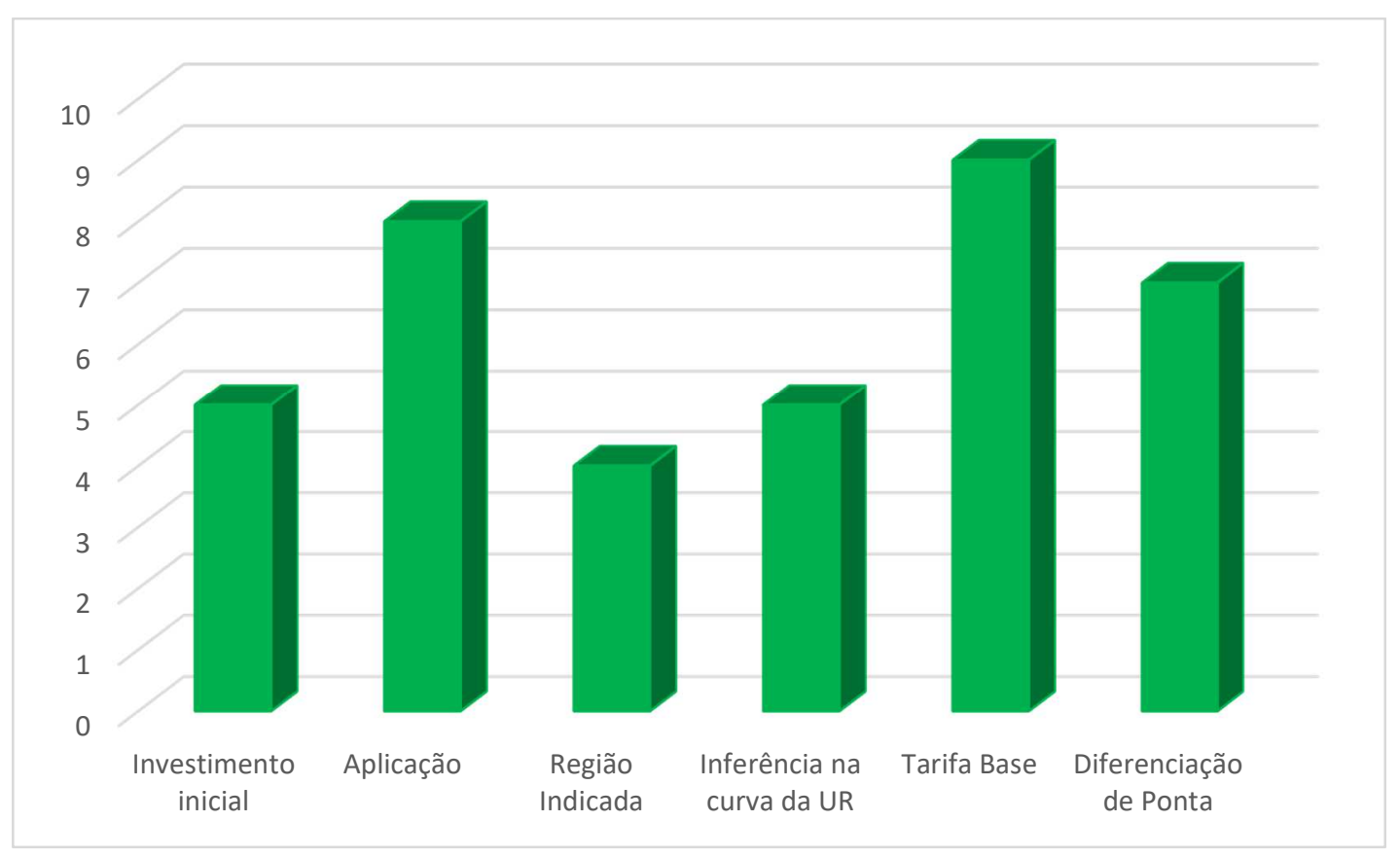

Figura 6.31 - Ponderações de critérios para utilização de métodos solares e economizadores segundo economia de energia 
Tratando de retorno financeiro, os critérios de investimento inicial, aplicação e inferência na curva da UR apresentam maior peso que se pensarmos somente em economia de energia. A Figura 6.32 apresenta estas ponderações.

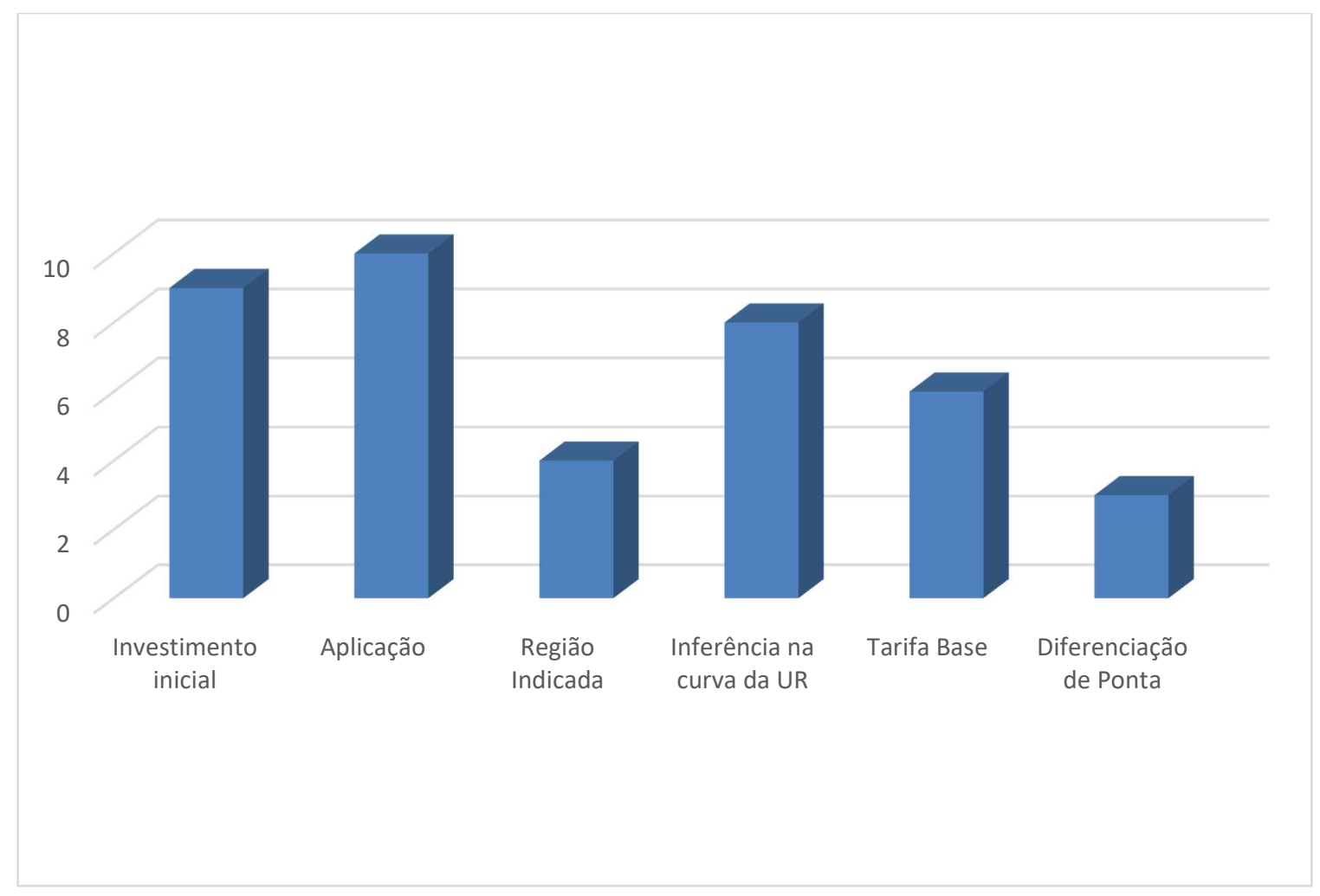

Figura 6.32 - Ponderações de critérios para utilização de métodos solares e economizadores segundo retorno de investimento

De modo resumido para todos os casos estudados o método de resfriamento solar por absorção associado a resfriamento natural indireto apresenta boa vantagem, quando se utiliza o critério de economia de energia. A Figura 6.33 ilustra a vantagem deste método face ao caso base com associação de economizadores, dos métodos fotovoltaicos e do sistema de absorção solar sem economizadores. 


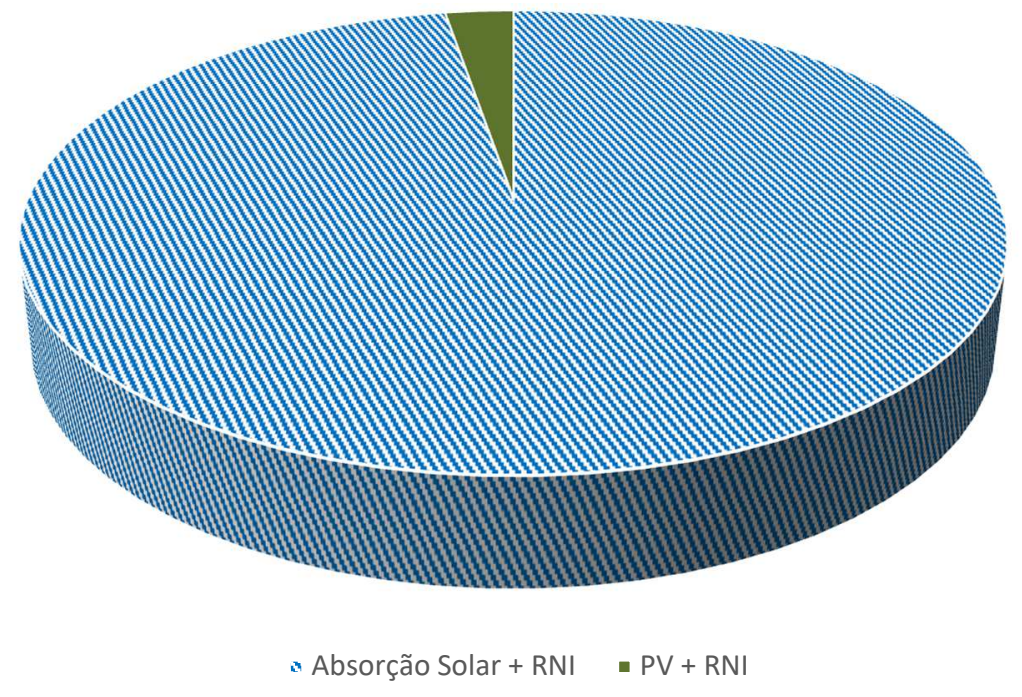

Figura 6.33 - Percentual de casos onde há maior vantagem de um método face os outros, segundo economia de energia.

Quando pensamos em retorno financeiro, esta vantagem sobre os demais não é tão clara quando falamos em economia de energia. Os valores relativos a utilização de fotovoltaicos aumentam, bem como os valores, em que o melhor é não utilizar nada ou somente economizadores. Ainda existem alguns casos onde somente a absorção solar sem economizadores deve ser utilizada. A Figura 6.34 ilustra esta afirmação.

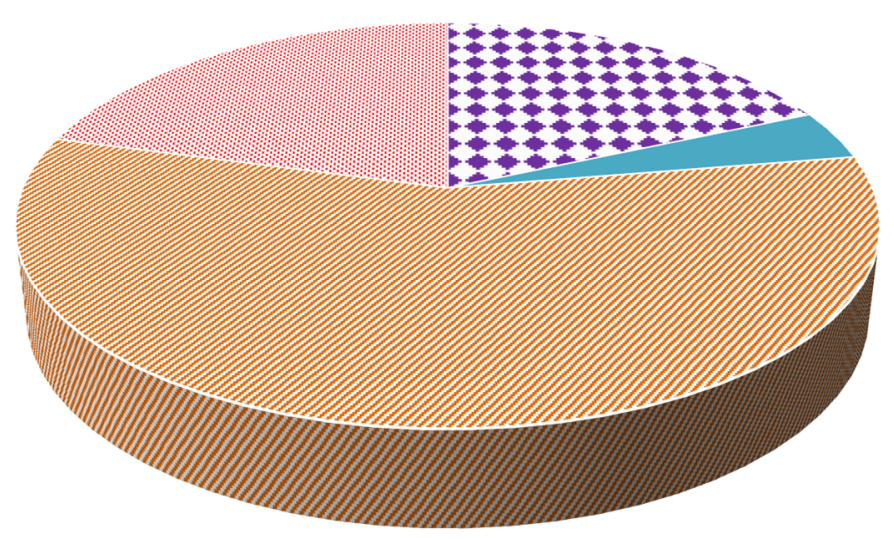

m. Caso Base + Economizadores - Absorção Solar * Absorção Solar + RNI : PV + RNI

Figura 6.34 - Percentual de casos onde há maior vantagem de um método face os outros, segundo retorno de investimento 


\section{CAPÍTULO 7 - CONCLUSÕES}

Este capítulo apresenta as conclusões da tese relatando o trabalho desenvolvido, consolida os resultados apresentados no Capítulo 5 e 6 indicando as melhores oportunidades para utilização de tecnologias solares e economizadores e sugere trabalhos futuros, os quais este poderá ser tomado como referência. 


\subsection{Desenvolvimento realizado}

Este trabalho avaliou a utilização de sistemas de condicionamento de ar baseados em tecnologias de resfriamento solar com a utilização em uma sala de servidores de um Data Center.

Para tal, foi necessário inicialmente entender as regras de climatização para este tipo de edificação, e se aproveitando de avanços nas últimas revisões de normas regulatórias, aplicar os métodos de resfriamento solar e métodos de resfriamento natural. Discorreu-se sobre as regras de funcionamento de uma edificação e seus sistemas básicos de funcionamento.

Outro ponto citado nesta obra foi a possibilidade de ganho de pontos na certificação Leed $^{\circ}$ através da economia de energia, onde-se ganha pontos adicionais com descontos na conta.

Na sequência, discorreu-se sobre métodos de resfriamento solar, onde citou-se às principais tecnologias empregadas atualmente e selecionou os métodos de resfriamento fotovoltaico e absorção solar para a aplicação na edificação modelo.

O Capítulo 4 apresentou a metodologia empregada através de diagramas e formulas. Pode-se percorrer como fora proposto, todos os cálculos e arranjos para se obter os resultados. A partir de bancos de dados consolidados calcula-se a carga térmica durante um ano hora a hora e aplica-se a esta a influência de métodos de resfriamento solar partindo do cálculo dos principais ângulos para a cidade modelo e rendimento de coletores através de condições externas.

Este capítulo na sequência, prosseguiu às formas de cálculo de contribuição dos economizadores nos sistemas através de condições de temperatura e umidades exteriores. Não obstante, são visualizou-se os métodos de cálculo de tempo de retorno de investimento e taxa interna de retorno, partindo de orçamentos obtidos em fabricantes de equipamentos e prestadores de serviços. 
No capítulo 5 obteve-se todos os resultados obtidos para a cidade modelo com seu tipo de equipamento base e os resultados de economia de energia para as tecnologias solares com e sem economizadores. No capítulo 6, subsequente, extrapolase o modelo para cidades de outras regiões climáticas do mundo, e também, analisa-se a instalação proposta com a utilização de equipamentos mais eficientes. Ao final deste apresentou-se um comparativo entre taxa interna de retorno e economia de energia entre os modelos proposto. Como comparativo, em sua última seção apresenta os resultados para uma instalação de conforto, aplicada em loja de departamentos, apresenta resultados para a aplicação desta tecnologia.

Este capítulo consolida os resultados apresentados no capítulo anterior e sugere novas pesquisas, que possam tomar esta como referência. O capítulo subsequente apresenta a bibliografia de referência e os anexos necessários para entendimento desta obra.

\subsection{Considerações finais}

Pode-se afirmar para a utilização em Data Centers, o condicionamento de ar baseado em resfriadores solares possui boa viabilidade financeira e em economia de energia nas 4 regiões estudadas, tendo como base compressores do tipo parafuso. Notadamente quanto mais quente se torna a região, maior a viabilidade destes, haja visto que na região I, este aplica-se para todos os casos de tarifa estudadas. Comprova-se que quanto maior a tarifa e maior a diferenciação ponta-regular melhor o resultado financeiro da tecnologia solar.

Quando há variação de carga, cada tecnologia solar deverá ser estudada de acordo como a carga térmica base se insere no carregamento total do compressor. As tecnologias solares auxiliam em alguns casos a operar em melhor faixa, como no caso de São Paulo para $1 \mathrm{~kW} / \mathrm{m}^{2}$, porém podem fazer com que a UR opere em faixas mais desfavoráveis, como no caso de São Paulo com $2 \mathrm{~kW} / \mathrm{m}^{2}$. Para menores cargas, consegue-se uma maior economia de energia através de métodos solares, e consequente maior pontuação em certificação ambiental. 
Pode-se notar que na maioria dos casos há grande vantagem na utilização de resfriamento solar por absorção, que é crescente de acordo com a disponibilidade solar devido ao maior rendimento dos coletores. Entretanto, existem alguns casos onde é vantajosa a utilização de resfriamento fotovoltaico, onde há o primeiro forçará a UR a trabalhar em condições de pouca eficiência. Em alguns casos recomenda-se a não utilização de nenhum método solar, geralmente em regiões de baixa irradiação associadas a tarifas mais baratas.

A utilização deste em compressores centrífugos possui maior restrição por se tratar de equipamento mais eficientes que os de parafuso e sua economia através deste não é significativa. Outro ponto a salientar é que estes compressores possuem ponto ótimo próximo do carregamento total, reduzindo sua eficiência em cargas parciais o que é altamente prejudicial para os equipamentos de absorção solar. As técnicas solares neste caso são recomendadas em altas tarifas. Em equipamentos que trabalham com folga em relação à sua carga nominal, utiliza-se absorção solar e quando trabalham próximo a sua carga nominal recomenda-se resfriamento fotovoltaico.

Em relação aos economizadores, pode-se notar que os métodos de resfriamento natural direto não representam vantagem em relação ao consumo base devido ao consumo elétrico dos ventiladores das caixas de ventilação. Isto pouco viabiliza qualquer utilização destes ou destes combinados com outro método de resfriamento natural ou tecnologia solar.

O resfriamento natural indireto mostrou-se altamente viável para quase todos os casos, exceto para baixas cargas na região 1 ASHRAE, representada aqui por Abu Dhabi. As altas temperaturas de bulbo seco e bulbo úmido dificultam a economia de energia por estes métodos.

Em contraponto às vantagens do resfriamento natural indireto, surge a necessidade de avaliação criteriosa da curva de desempenho do equipamento, principalmente na hora de associá-lo há um método solar. Não obstante, em alguns casos que embora o método de absorção solar fornece maior capacidade de resfriamento 
associado ao resfriamento natural indireto, é vantajosa a utilização de células fotovoltaicas devido ao impacto na curva do mesmo.

Verifica-se pouca viabilidade financeira em instalações de conforto de tecnologias solares, devido a alto custo de investimento e economizadores de resfriamento natural indireto devido à menor temperatura requerida pela instalação, provida pelas unidades de resfriamento. Em termos de economia de energia e pontuação para certificação, todos os métodos solares, mostram-se viáveis.

\subsection{Sugestões para trabalhos futuros.}

Este trabalho contribui para futuras pesquisas associadas ao mercado de resfriamento/ refrigeração solar e Data Centers e visa incentivar provedores, projetistas, engenheiros que utilizem tais técnicas como economia de energia, e operação sustentável, haja visto a característica da carga térmica tendendo a constante durante o tempo.

A sequência deste trabalho seria a validação prática deste estudo em algum provedor de serviços que aplique tecnologias de resfriamento solar para a economia de energia da planta, através de sua apresentação de contas de consumo

Outra necessidade é a constante atualização deste trabalho, haja visto a constante evolução de equipamentos e coletores. Como exemplo, a eficiência disponível para um resfriador de absorção solar para a pesquisa de Kim \& Ferreira em 2008 era de 0,7 (KIM \& FERREIRA, 2008), em sua mais recente revisão em 2014 fora constatado 1,29 (FERREIRA \& KIM, 2014; BELIZÁRIO \& SIMÕES-MOREIRA, 2017). Em 2017 fora apresentado pela LG equipamentos com eficiência de 1,51 da linha WC2HX(LG, 2017).

Outra possibilidade é verificar a viabilidade de sistemas análogos de células de refrigeração comercial, como mercados e entrepostos, em suas câmaras frigorificas.

Outra análise que futuramente toma este trabalho como base é a utilização de sistemas heliotérmicos para climatização e refrigeração, com a evolução tecnológica e 
maior viabilidade deste. Também a muito o que se pesquisar em equipamentos de adsorção e dissecantes. 


\section{CAPÍTULO 8 - BIBLIOGRAFIA}

Este capítulo apresenta bibliografia de referência para a construção desta obra. 


\subsection{Bibliografia}

ACCA SOFTWARE. Desenho de uma usina fotovoltaica: requisitos e tipos - BibLus - PTB. Disponível em: <http://biblus.accasoftware.com/ptb/desenho-de-uma-usina-fotovoltaica/>. Acesso em: 28 nov. 2017.

AHMED, Y.; TAHA, A.-Z. Solar Air Conditioning and Refrigeration with Absorption Chillers Technology in Australia - An Overview on Researches and Applications. Journal of Advanced Science and Engineering Research, v. 1, p. 23-41, 2011.

ALFA LAVAL. Heating and cooling solutions from Alfa Laval. Disponível em: <http://www.comfort.alfalaval.com/hvac-handbook_enus/files/assets/basichtml/index.html\#1>. Acesso em: 6 dez. 2017a.

ANEEL. RESOLUÇÃO NORMATIVA N 414, DE 9 DE SETEMBRO DE 2010. Brasília: Agência Nacional de Energia Elétrica, 2010. Disponível em: <http://www.aneel.gov.br/documents/656877/14486448/bren2010414.pdf/3bd33297-26f94ddf-94c3-f01d76d6f14a?version=1.0>. Acesso em: 7 dez. 2017.

ANEEL. Entendendo a Tarifa - ANEEL. Disponível em: <http://www.aneel.gov.br/entendendo-atarifa>. Acesso em: 21 nov. 2017.

ANEEL. RESOlUÇÃo NORMATIVA No 733, DE 06 DE SETEMBRO DE 2016. Brasília: Agência Nacional de Energia Elétrica, 2016. Disponível em: <http://www2.aneel.gov.br/aplicacoes/audiencia/arquivo/2013/043/resultado/ren2016733.pdf >. Acesso em: 7 dez. 2017.

ANEEL. Ranking das Tarifas - ANEEL. Disponível em: <http://www.aneel.gov.br/ranking-dastarifas>. Acesso em: 7 dez. 2017.

ANSI. S20.20-2007, ANSI/ESD -Electrostatic Discharge CertificationAmerican National Standards Institute, , 2007. .

ASHRAE. A History of Refrigeration. Ashrae Journal, p. 531-534, 2004.

ASHRAE. ANSI/ASHRAE Standard 169-2006 - Weather Data for Building Design StandardsAtlantaAmerican Society of Heating, Refrigeration and Air Conditioning Engineering, , 2006. .

ASHRAE. ASHRAE HVAC Apllications. Atlanta: American Society of Heating, Refrigeration and Air Conditioning Engineering, 2015.

ASHRAE. THERMAL GUIDELINES FOR DATA PROCESSING ENVIRONMENTS,. [s.I: s.n.].

ASHRAE. Ashrae Fundamentals Handbook. Atlanta: American Society of Heating, Refrigeration and Air Conditioning Engineering, 2017. 
ATS SOLUTION. ATS SolutionsSwichted on IT, 2015. . Disponível em: <http://atswa.com.au/>.

ATWOOD, D.; MINER, J. G. Reducing data center cost with an air economizer. Intel Information Technology, 2008.

BALARAS, C. A.; GROSSMAN, G.; HENNING, H. M.; FERREIRA, C. A. I.; PODESSER, E.; WANG, L.; WIEMKEN, E. Solar Air Conditioning in Europe-An Overview. Renewable and Sustainable Energy Reviews, p. 299-314, 2007.

BALGHOUTHI, M.; CHAHBANI, M. H.; GUIZANI, A. Feasibility of solar absorption air conditioning in Tunisia. Building and Environment, v. 43, n. 9, p. 1459-1470, 1 set. 2008. Disponível em: <https://www.sciencedirect.com/science/article/pii/S0360132307001497>. Acesso em: 21 nov. 2018.

BELIZÁRIO, A. C. Comparação entre Chiller Solar por Absorção e Chiller Fotovoltaico. [s.l: s.n.].

BELIZÁRIO, A. C.; SIMÕES-MOREIRA, J. R. Evaluation of Absorption Solar Cooling Application to a Data Center. In: ECOS 2017, San Diego - CA. Anais... San Diego - CA: ECOS Conference, 2017.

BOILIGER JR., R.; MARIANI, A. C. PsicrometriaAulas de Engenharia Termo AmbientalSão PauloEscola Politécnica da Universidade de São Paulo, , 2005. .

BRITO, E. H. G. de. Tarifas de distribuição de energia elétrica no Brasil: Aperfeiçoamento da metodologia tarifária a partir de parâmetros de continuidade de serviço, sustentabilidade econômico-finaceira e simplicidade regulatória. 2017. Escola Politécnica da Universidade de São Paulo, 2017.

CARRIER. Global Chiller - Catálogo TécnicoSão PauloCarrier, , 2014. . Disponível em: <http://cdn.carrierdobrasil.com.br/downloads_docs/ca0ab-Cat--logo-T--cnico---ct30hx-gxfaseiii-f-10.12-view-.pdf>. Acesso em: 6 dez. 2017.

CHEN, Y.; ZHANG, Y.; MENG, Q. Study of ventilation cooling technology for telecommunication base stations in Guangzhou. Energy Build, p. 738-744, 2009.

CHOULDHURY, B.; CHATTERJEE, P. K.; SAKTAR, J. P. Review Papaer on solar-powered air conditioning through adsorpition route. Renewable and Sustainable Energy Reviews, p. 21892195, 2010.

CRÉDER, H. Instalações de Ar Condicionado. São Paulo: LTC, 2004.

DAI, J.; DAS, D.; PECHT, M. Prognostics-based risk mitigation for telecom equipment under free cooling conditions. Applied Thermal Engineering, v. 89, p. 423-429, 2012.

DARAGHMEH, H. M.; WANG, C.-C. A review of current status of free cooling in datacenters. Applied Thermal Engineering, 2016. 
DATACENTER DYNAMICS. Matrix Data Center: Negócios de Missão Crítica Exigem Serviços de TI com alta disponibilidade. Uma pequena falha pode ser fatal. Disponível em: <http://www.datacenterdynamics.com.br/focus/archive/2017/04/matrix-data-center-negóciosde-missão-crítica-exigem-serviços-de-ti-com-alta-d>. Acesso em: 13 abr. 2018.

DE CASTRO, N.; RAMOS, D.; BRANDÃO, R.; PRADO, F.; DE MORAIS, P.; GALVÃO, P.; ARNAU, A.; DORADO, P. AS TARIFAS DE ENERGIA ELÉTRICA NO BRASIL E EM OUTROS PAISES: O PORQUE DAS DIFERENÇAS. Rio de Janeiro: CPFL, 2015.

DUFFIE, J. A.; BECKMAN, W. A. Solar Engineering of Thermal Process. [s.I.] Wiley, John \& Sons, In. 6 Edição, 2006.

ENERGY SAGE. Solar Power History: Timeline and Invention of Solar Panels. Disponível em: <https://news.energysage.com/the-history-and-invention-of-solar-panel-technology/>. Acesso em: 7 dez. 2017.

FERREIRA, C. I.; KIM, D.-S. Techno-economic review of solar cooling technologies based on location-specific data. International Journal of Refrigeration, v. 39, p. 23-37, 2014.

FIRJAN. Quanto custa a energia elétrica para a pequena e média indústria no Brasil? [s.I: s.n.]. Disponível em: <http://www.firjan.com.br/lumis/portal/>.

FONSECA JR., J. A. Ciclo básico de refrigeração por absorção e seus componentes principaisSão PauloDomínio Público, , 2009. .

GANTZ, J. 40 Years of IT: Looking Back, Looking Ahead. IDC, v. 20, 2004.

GATTO, O. A.; SILVA, M. A. ESTUDO DE VIDAS ÚTEIS PARA MÁQUINAS E EQUIPAMENTOS. [s.I: s.n.]. Disponível em: <http://www.ibapesp.org.br/arquivos/estudo_de_vidas_uteis.apresentacao.pdf>. Acesso em: 7 dez. 2017.

GERBRESLASSIE, B. H.; GUILLEN-GOSALBEZ, G.; JIMENEZ, L.; BOER, D. A systematic tool for the minimization life cicle impact of solar assisted absorption cooling system. Energy, v. 35, p. 38493862, 2010.

HENNING, H.-M.; JAKOB, U. What are the chances for solar cooling? Energy reserarch for application, p. 2, 2015. Disponível em: <http://www.bine.info/en/topics/publikation/mit-solarerwaerme-kuehlen-1/standpunkte-en-passant-

1/?cHash=a338b42d9182ca78bf7e046e71ad3ddb\&type=333>.

HULD, T.; GOTTSCHALG, R.; BEYER, H.-G.; TOPIC, M. Mapping the performance of PV modules, effects of module type and data averaging. Solar Energy, v. 84, p. 324-338, 2010.

HYDEMAN, M.; SWENSON, D. Humidity Control for Data Center - Are they necessary? Ashrae Journal, v. Março, 2010. 
INCROPERA, F. P.; DEWITT, D. P.; BERGMAN, T. L.; LAVINE, A. S. Fundamentos de Transferência de Calor e Massa. $7^{\mathrm{a}}$ ed. ed. New York: LTC, 2014.

JESUS, G. J. V. Data Center Automation: A necessidade de gerir mais com menos. [s.I: s.n.].

KALOGIROU, S. A. Solar Thermal collectors and applications. Prog. Energy Combust., p. 231-295, 2004.

KIM, D.-S.; FERREIRA, C. I. Solar Refrigeration Options - A state of art Review. International Journal of Refrigeration, v. 21, p. 89-99, 2008.

KIM, D.-S.; FERREIRA, C. I. Techno-economic review of solar cooling technologies based on location-specific data. International Journal of Refrigeration XXX, p. 1-15, 2013a.

KIM, D.-S.; FERREIRA, C. I. Solar Cooling: Overview and RecomendationsEurope, 2013b. .

KOHLENBACH, P.; JAKOB, U. Solar Cooling. 1 ed. ed. Glasgow, Scotland: Earthscan from Routledge, 2014.

KREITH, F.; KREIDER, J. F. Principles of Solar Engineering. New York: Mc Graw-Hill, 1978.

LAZARIN, R. M. Solar Cooling: PV or thermal? A thermodynamic and economical analysis. International Journal of Refrigeration, v. 39, p. 38-47, 2014.

LAZZARIN, R. M.; NORO, M. Past, present, future of solar cooling: Technical and economical considerations. Solar Energy, n. December 2017, p. 0-1, 2018. Disponível em: <http://linkinghub.elsevier.com/retrieve/pii/S0038092X17311374>.

LG. LG HVAC Solution - Absorption Chillers: HVAC Solution. [s.l: s.n.].

LIN, P.; NIENMANN, J.; LONG., L. Choosing between direct and indirect air economization for data centers. APC - Schneider Electric White Paper 215, 2015.

LOPES, R. P.; SILVA, J. de S. e; REZENDE, C. R. Pricípios Básicos de Psicrometria. In: Secagem e Armazenamento de Produtos Agrícolas. Viçosa - MG: Universidade Federal de Viçosa, 2010. p. 39-62.

MAGGI, F. O.; POSSÃO, B. D.; SILVA, A. W.; SILVA, B. D. Sistema de Cogeração no estado de São Paulo: Análise de Vaibilidade Técnico - Econômica. 2014. UMC, Mogi das Cruzes, 2014.

MATOS, R. S. Apostila do curso de sistemas de refrigeraçãoCuritiba - PRUFPR, , 2010. . Disponível em: <https://docs.ufpr.br/ rudmar/refri/material/4_ABSORCAO.pdf>.

MILLER, R. Ar Condicionado e Refrigeração. $2^{\text {a }}$ Edição ed. [s.I: s.n.] 
MMA; PNUD; GIZ. Programa Brasileiro de Eliminação dos HCFCsBrasília, DFMMA, , 2011. . Disponível em: <http://www.mma.gov.br/publicacoes/clima/category/110-protecao-dacamada-de-ozonio?download=1456:programa-brasileiro-de-eliminação-dos-hcfcs-pbh-etapa$1>$.

MOKHTAR, M.; ALI, M. T.; BRÄUNIGER, S.; AFSHARI, A.; SGOURIDIS, S.; ARMSTRONG, P.; CHIESA, $M$. Systematic comprehensive techno-economic assessmente of solar cooling technologies using location-specific climate data. Applied Energy, p. 3766-3778, 2010.

MONTAGNINO, F. M. Solar cooling technologies. Design, application and performance of existing projects. Solar Energy, v. 154, p. 144-157, 2017. Disponível em: <http://dx.doi.org/10.1016/j.solener.2017.01.033>.

MORADIAN, M.; PATNAIK, A.; HAN, Y.; WAN, F.; GAO, X.; POMMERENKE, D.; SWENSON, D. Determination of the Effect of Humidity on the Probability of ESD Failure or Upset in Data Centers. ASHRAE Transactions, v. 210, p. 25-41, 2014.

MORAN, M. J.; SHAPIRO, H. N.; BOETTNER, D. D.; BALEY, M. B. Princípio da Termodinâmica. Rio de Janeiro: LTC, 2018.

ORGILL, J. F.; HOLLANDS, K. G. T. Correlation equation for hourly diffuse radiation on a horizontal surface. Solar Energy, v. 19, n. 4, p. 357-359, 1977. Disponível em: <https://www.sciencedirect.com/science/article/pii/0038092X77900068>.

ORÓ, E.; DEPOORTER, V.; PFLUGRADT, N.; SALOM, J. Overview of direct air free cooling and thermal storage potential energy savings in data centers. Applied Thermal Engineering, 2015.

OTANICAR, T.; TAYLORB, R. A.; PHELANC, P. Prospec of a solar cooling - An economic and environmental assessment. Solar Energy, v. 86, p. 1287-1299, 2012.

PACHECO, C. R. de F. Fundamentos da Utilização de Energia Solar. In: SIMÕES-MOREIRA, J. R. (Ed.). Energias Renováveis, Geração Distribuída e Eficiência Energética. São Paulo: LTC, 2017. p. 187221.

PAPADOPOULOS, A. M.; OXIDIS, S.; KYRIAKIS, N. Perspective of Solar Cooling in view of the development in the air conditionig sector. Renewable and Sustanable Energy Reviews, v. 7, p. 419-438, 2003.

PARENTE, V. Análise de Investimentos aplicada a projetos de Energia. In: SIMÕES-MOREIRA, J. R. (Ed.). Energias Renováveis, Geração Distribuída e Eficiência Energética. $1^{a}$ Ed ed. São Paulo: LTC, 2017. p. 337-353.

PORTAL SOLAR. QUANTO CUSTA A ENERGIA SOLAR FOTOVOLTAICA | Portal Solar - Tudo sobre Energia Solar Fotovoltaica. Disponível em: <https://www.portalsolar.com.br/quanto-custa-aenergia-solar-fotovoltaica.html>. Acesso em: 7 dez. 2017. 
PORUMB, R.; PORUMB, B.; BALAN, M. Baseline evalution of potential to use solar radiation in air conditioning applications. Energy Procedia, v. 85, p. 442-451, 2016.

PROCEL. Manual de Tarifação da Energia Elétrica. [s.l: s.n.]. Disponível em: <www.eletrobras.com>. Acesso em: 7 dez. 2017.

RAMOS BALLESTÉ, R. O IMPACTO DAS TARIFAS DE ENERGIA ELÉTRICA NO CONSUMO RESIDENCIAL. 2016. Pontifícia Universidade Católica do Rio de Janeiro, Rio de Janeiro, 2016. Disponível em: <http://www.econ.pucrio.br/uploads/adm/trabalhos/files/Renata_Ramos_Balleste.pdf>. Acesso em: 7 dez. 2017.

RAPOZA, J. Moving Past Backup To True Disaster Recovery. [s.l: s.n.]. Disponível em: <http://v1.aberdeen.com/launch/report/research_report/16773-RR-recover-backupdisaster.asp>. Acesso em: 21 nov. 2017.

SAIDEL, M. A. Investimentos Aplicados à Eficiência EnergéticaSão PauloGEPEA - USP, , 2017. .

SANTAMARIA. Painel de ClimatizaçãoClimatização de corredores confinados. Práticas de Eficiência EnergéticaSão Paulo, São PauloABRAVA, , 2016. .

SANTOS, K. Análise do desempenho térmico do enclausuramento de corredores em ambientes de Data Centers. 2014. Univesidade de Brasília, Brasília, 2014.

SARBU, I.; SERBACHIEVI, C. Review of a Solar Refrigeration and Cooling System. Energy and Buildings, p. 286-297, 2013.

SCHIAVON ARA, P. J. Desempenho se distemas de condicionamento de ar com utilização de energia solar em edifícios de escritórios. 2010. Universidade de São Paulo, São Paulo, 2010.

SEBRAE. Análise e Planejamento Financeiro - Manual do ParticipanteBrasiliaSEBRAE - Serviço Brasileiro de Apoio às Micro e Pequenas Empresa, , 2011. . Disponível em: <http://www.sebrae.com.br/Sebrae/Portal Sebrae/Anexos/0_fluxo-de-caixa.pdf>. Acesso em: 8 dez. 2017.

SILVA, F. D. J. Análise de Viabilidade Financeira de um Sistema de Climatização Solar em um Hipermercado. [s.I: s.n.].

SIMÕES-MOREIRA, J. R. Fundamentos e Aplicações da Psicrometria. $1^{\text {a }}$ edição ed. São Paulo: RPA Editorial, 1999.

SOBRAL, M. Sistema de Ar Condicionado. Disponível em: <http://www.sistemasdearcondicionado.com.br/2008/11/carga-termica-definicao.html>. Acesso em: 17 jan. 2018. 
STRUTT, S.; KELLEY, C.; HARKEERET SINGH, C.; REUTERS VIC SMITH, T. Data Center Efficiency and IT Equipment Reliability at Wider Operating Temperature and Humidity Ranges. The Green Grid, 2012. Disponível

em: <https://energy.gov/sites/prod/files/2013/12/f5/data_center_efficiency_and_reliabilit_at_wide r_operating_ranges.pdf>. Acesso em: 20 nov. 2017.

TIAN, Y.; ZHAO, C. Y. A review of solar collectors and thermal energy storage in solar thermal applications. Applied Energy, v. 104, 2013.

TORRE CARAVELA. Catálogos TécnicosSantana do Parnaíba - SPTorre Caravela, , 2014. . Disponível em: <http://www.torre-caravela.com.br/pdf/catalogo_espec_enge_WTD.pdf>. Acesso em: 6 dez. 2017.

TRANE. Manual de Instalação, Operação e Manutenção - Caixas de Ventilação linha Wavelngersol Rand, 2013. Disponível em: <https://www.trane.com/content/dam/Trane/Commercial/lar/br/produtossistemas/equipamentos/Climatizadores/Wave_Doble/Catalogo_IOM-Wave(WAVE-SVN002GPT0113).pdf>. Acesso em: 4 dez. 2017.

TRANE. Resfriadores de Líquido Tipo Parafuso Série RAraucária, PRTrane, , 2017a. . Disponível em: $\quad<$ http://www.trane.com/content/dam/Trane/Commercial/lar/br/produtossistemas/equipamentos/Chillers/Chillers_Parafuso/Condensacao_Agua/RTWD_RTUD-

Serie_R/Catalogo_Produto-RTWD(RLC-PRC029-PT).pdf>. Acesso em: 6 dez. 2017.

UDAGAWA, Y.; WARAGAI, S.; YANAGI, M.; FUKUMITSU, W. Study on Free Cooling Systems for Data Centers in Japan. In: Intelec, 32nd Annu. Int. Telecommun, Urbana-Champaign. IL, USA. Anais... Urbana-Champaign. IL, USA: University of Illinois, 2010.

UPTIME-INSTITUTE. Accredited Tier Specialist. New York: Uptime Institute, 2013.

VAN WYLEN, G.; SONNTAG, R.; BORGNAKKE, C. Fundamentos da Termodinâmica Clássica. $8^{a}$ Edição ed. New York: Edgard Blucher, 2013.

VERAS, M. Datacenter: Componente central da infraestrutura de TI. Rio de Janeiro: Braspot, 2009.

VERGE, J.; SMITH, J. What will the data center of 2025 look like?Data Center Knowledge, 2014. - Disponível em: <http://www.datacenterknowledge.com/archieves/2014/04/29/will-datacenter-2025-look-like/>.

VERTIV CO. Liebert CW BrochureColumbus, Ohio, 2016. . Disponível em: <https://www.vertivco.com/globalassets/products/thermal-management/room-cooling/liebertcw-brochure.pdf>. Acesso em: 4 dez. 2017.

VON ZUBEN, F. J. Métodos de otimização paramétrica não-linear irrestrita. 1996. 1996. 
WANG, S. K. Handbook of air conditioning and refrigeration. United States of America: McGrawHill, 2010.

ZHANG, H.; SHAO, S.; XU, H.; ZOU, H.; TIAN, C. Free cooling of datacenters: Areview. Renewable and Sustainable Energy Reviews, p. 171-182, 2014. 
Air System Information

Air System Name

Equipment Class

Air System Type

Aizing Calculation Information

Calculation Months

Sizing Data
Fan Coils

CW AHU

SZCAV
Number of zones

Floor Area

Location
1

$625,0 \mathrm{~m}$ Paulo, Brazil

\section{Zone Sizing Data}

\begin{tabular}{|c|c|c|c|c|c|c|c|}
\hline Zone Name & $\begin{array}{l}\text { Maximum } \\
\text { Cooling } \\
\text { Sensible } \\
\text { (kW) }\end{array}$ & $\begin{array}{c}\text { Design } \\
\text { Airflow } \\
(\mathrm{L} / \mathrm{s})\end{array}$ & $\begin{array}{l}\text { Minimum } \\
\text { Airflow } \\
\text { (L/s) }\end{array}$ & $\begin{array}{c}\text { Time of } \\
\text { Peak Load }\end{array}$ & $\begin{array}{c}\text { Maximum } \\
\text { Heating } \\
\text { Load } \\
\text { (kW) }\end{array}$ & $\begin{array}{c}\text { Zone } \\
\text { Floor } \\
\text { Area } \\
\left(\mathrm{m}^{2}\right) \\
\end{array}$ & $\begin{array}{c}\text { Zone } \\
\mathrm{L} /\left(\mathrm{s}-\mathrm{m}^{2}\right)\end{array}$ \\
\hline Zone 1 & 1266,5 & 164981 & 164981 & $\operatorname{Jan} 1400$ & $\begin{array}{r}0,0 \\
\end{array}$ & 625,0 & 263,97 \\
\hline
\end{tabular}

Zone Terminal Sizing Data

No Zone Terminal Sizing Data required for this system.

Space Loads and Airflows

\begin{tabular}{|c|c|c|c|c|c|c|c|}
\hline $\begin{array}{l}\text { Zone Name / } \\
\text { Space Name }\end{array}$ & Mult. & $\begin{array}{r}\text { Cooling } \\
\text { Sensible } \\
(\mathrm{kW})\end{array}$ & $\begin{array}{r}\text { Time } \\
\text { of } \\
\text { Load }\end{array}$ & $\begin{array}{r}\text { Air } \\
\text { Flow } \\
(\mathrm{L} / \mathrm{s})\end{array}$ & $\begin{array}{r}\text { Heating } \\
\text { Load } \\
(\mathrm{kW})\end{array}$ & $\begin{array}{r}\text { Floor } \\
\text { Area } \\
\left(\mathrm{m}^{2}\right) \\
\end{array}$ & $\begin{array}{r}\text { Space } \\
L /\left(s-m^{2}\right)\end{array}$ \\
\hline \multicolumn{8}{|l|}{ Zone 1} \\
\hline Área de TI & & 1266,5 & Jan 1400 & 164981 & 0,0 & 625,0 & 263,97 \\
\hline
\end{tabular}

1. Summary

Ventilation Sizing Method

Jan to Dec

Zone L/s Sizing

Sum of space airflow rates

Space U/s Sizing Individual peak space loads

Design Ventilation Airflow Rate

Sum of Space OA Airflows

. Space Ventilation Analysis Table

\begin{tabular}{|c|c|c|c|c|c|c|c|c|c|}
\hline Zone Name / Space Name & Mult. & $\begin{array}{r}\text { Floor } \\
\text { Area } \\
\left(\mathrm{m}^{2}\right)\end{array}$ & $\begin{array}{r}\text { Maximum } \\
\text { Occupants }\end{array}$ & $\begin{array}{r}\text { Maximum } \\
\text { Supply Air } \\
(\mathrm{L} / \mathrm{s})\end{array}$ & $\begin{array}{r}\text { Required } \\
\text { Outdoor Air } \\
\text { (L/s/person) }\end{array}$ & $\begin{array}{r}\text { Required } \\
\text { Outdoor Air } \\
\left(\mathrm{L} /\left(\mathrm{s}-\mathrm{m}^{2}\right)\right) \\
\end{array}$ & $\begin{array}{r}\text { Required } \\
\text { Outdoor Air } \\
(\mathrm{L} / \mathrm{s})\end{array}$ & $\begin{array}{r}\text { Required } \\
\text { Outdoor Air } \\
(\% \text { of supply) }\end{array}$ & $\begin{array}{r}\text { Uncorrected } \\
\text { Outdoor Air } \\
(\mathrm{L} / \mathrm{s})\end{array}$ \\
\hline \multicolumn{10}{|l|}{ Zone 1} \\
\hline \begin{tabular}{|c|} 
Area de TI \\
\end{tabular} & 1 & 625,0 & 3,1 & 164980,5 & 2,50 & 0,30 & 0,0 & 0,0 & 195,3 \\
\hline Totals (incl. Space Multipliers) & & & & 164980,5 & & & & & 195,3 \\
\hline
\end{tabular}




\begin{tabular}{|c|c|c|c|c|c|c|}
\hline & & $\sqrt{\mathrm{C} \text { COOLINC }}$ & & & N HEATINC & \\
\hline & COOLING DAT & an 1300 & & HEATING DATA & ES HTG & \\
\hline & COOLING OA D & B $30,8^{\circ} \mathrm{C}$ & & HEATING OA DE & B $8,9^{\circ} \mathrm{C}$ & \\
\hline ZONE LOADS & Details & $\begin{array}{r}\text { Sensible } \\
\text { (W) }\end{array}$ & $\begin{array}{r}\text { Latent } \\
\text { (W) }\end{array}$ & Details & $\begin{array}{r}\text { Sensible } \\
\text { (W) }\end{array}$ & $\begin{array}{l}\text { Latent } \\
\text { (W) }\end{array}$ \\
\hline Window \& Skylight Solar Loads & $0 \mathrm{~m}^{2}$ & 0 & - & $0 \mathrm{~m}^{2}$ & - & - \\
\hline Wall Transmission & $250 \mathrm{~m}^{2}$ & 2703 & - & $250 \mathrm{~m}^{2}$ & 0 & - \\
\hline Roof Transmission & $625 \mathrm{~m}^{2}$ & 44418 & - & $625 \mathrm{~m}^{2}$ & 0 & - \\
\hline Window Transmission & $0 \mathrm{~m}^{2}$ & 0 & - & $0 \mathrm{~m}^{2}$ & 0 & - \\
\hline Skylight Transmission & $0 \mathrm{~m}^{2}$ & 0 & - & $0 \mathrm{~m}^{2}$ & 0 & - \\
\hline Door Loads & $0 \mathrm{~m}^{2}$ & 0 & - & $0 \mathrm{~m}^{2}$ & 0 & - \\
\hline Floor Transmission & $625 \mathrm{~m}^{2}$ & 0 & - & $625 \mathrm{~m}^{2}$ & 0 & - \\
\hline Partitions & $250 \mathrm{~m}^{2}$ & -2505 & - & $250 \mathrm{~m}^{2}$ & 0 & - \\
\hline Ceiling & $0 \mathrm{~m}^{2}$ & 0 & - & $0 \mathrm{~m}^{2}$ & 0 & - \\
\hline Overhead Lighting & $0 \mathrm{~W}$ & 0 & - & 0 & 0 & - \\
\hline Task Lighting & $11250 \mathrm{~W}$ & 11249 & - & 0 & 0 & - \\
\hline Electric Equipment & $1250000 \mathrm{~W}$ & 1249942 & 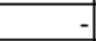 & 0 & 0 & - \\
\hline People & 3 & 270 & 417 & 0 & 0 & 0 \\
\hline Infiltration & - & 181 & 432 & - & 0 & 193 \\
\hline Miscellaneous & & 0 & 0 & - & 0 & 0 \\
\hline Safety Factor & $0 \% / 0 \%$ & 0 & 0 & $0 \%$ & 0 & 0 \\
\hline >> Total Zone Loads & & 1266258 & 848 & - & 0 & 193 \\
\hline Zone Conditioning & & 1266111 & 848 & - & 0 & 193 \\
\hline Plenum Wall Load & $0 \%$ & 0 & - & 0 & 0 & - \\
\hline Plenum Roof Load & $70 \%$ & 10308 & - & 0 & 0 & - \\
\hline Plenum Lighting Load & $30 \%$ & 0 & - & 0 & 0 & - \\
\hline Return Fan Load & $164981 \mathrm{~L} / \mathrm{s}$ & 0 & - & $164981 \mathrm{~L} / \mathrm{s}$ & 0 & - \\
\hline Ventilation Load & $195 \mathrm{~L} / \mathrm{s}$ & 940 & 2432 & $195 \mathrm{~L} / \mathrm{s}$ & -833 & 1088 \\
\hline Supply Fan Load & $164981 \mathrm{~L} / \mathrm{s}$ & 258036 & - & $164981 \mathrm{~L} / \mathrm{s}$ & -258036 & - \\
\hline Space Fan Coil Fans & - & 0 & - & - & 0 & - \\
\hline Duct Heat Gain / Loss & $0 \%$ & 0 & - & $0 \%$ & 0 & - \\
\hline > Total System Loads & & 1535394 & 3280 & & -258868 & 1281 \\
\hline Central Cooling Coil & - & 1535395 & 0 & & 0 & 0 \\
\hline Central Heating Coil & & 0 & - & & 2274034 & - \\
\hline > Total Conditioning & & 1535395 & 0 & & 2274034 & 0 \\
\hline Key: & $\begin{array}{l}\text { Positiv } \\
\text { Negati }\end{array}$ & $\begin{array}{l}\text { Jes are clg } \\
\text { Jes are htg }\end{array}$ & & $\begin{array}{l}\text { Positiv } \\
\text { Negativ }\end{array}$ & $\begin{array}{l}\text { ues are htg } \\
\text { ues are clg }\end{array}$ & \\
\hline
\end{tabular}




\begin{tabular}{|c|c|c|c|c|c|c|}
\hline \multirow[t]{3}{*}{ Zone 1} & \multicolumn{3}{|c|}{ DESIGN COOLING } & \multicolumn{3}{|c|}{ DESIGN HEATING } \\
\hline & \multicolumn{3}{|c|}{ COOLING DATA AT Jan 1400} & \multicolumn{3}{|c|}{ HEATING DATA AT DES HTG } \\
\hline & \multicolumn{3}{|c|}{ COOLING OA DB / WB $\quad 31,4^{\circ} \mathrm{C} / 20,5^{\circ} \mathrm{C}$} & \multicolumn{3}{|c|}{ HEATING OA DB / WB $8,9^{\circ} \mathrm{C} / 4,4^{\circ} \mathrm{C}$} \\
\hline & \multicolumn{3}{|c|}{ OCCUPIED T-STAT $26,0^{\circ} \mathrm{C}$} & \multicolumn{3}{|c|}{ OCCUPIED T-STAT $5,0^{\circ} \mathrm{C}$} \\
\hline ZONE LOADS & Details & $\begin{array}{r}\text { Sensible } \\
(\mathrm{W})\end{array}$ & $\begin{array}{r}\text { Latent } \\
(\mathrm{W})\end{array}$ & Details & \begin{tabular}{r|} 
Sensible \\
$(W)$ \\
\end{tabular} & $\begin{array}{r}\text { Latent } \\
\text { (W) }\end{array}$ \\
\hline Window \& Skylight Solar Loads & $0 \mathrm{~m}^{2}$ & 0 & - & $0 \mathrm{~m}^{2}$ & - & - \\
\hline Wall Transmission & $250 \mathrm{~m}^{2}$ & 2915 & - & $250 \mathrm{~m}^{2}$ & 0 & - \\
\hline Roof Transmission & $625 \mathrm{~m}^{2}$ & 4285 & - & $625 \mathrm{~m}^{2}$ & 0 & - \\
\hline Window Transmission & $0 \mathrm{~m}^{2}$ & 0 & - & $0 \mathrm{~m}^{2}$ & 0 & - \\
\hline Skylight Transmission & $0 \mathrm{~m}^{2}$ & 0 & - & $0 \mathrm{~m}^{2}$ & 0 & - \\
\hline Door Loads & $0 \mathrm{~m}^{2}$ & 0 & - & $0 \mathrm{~m}^{2}$ & 0 & - \\
\hline Floor Transmission & $625 \mathrm{~m}^{2}$ & 0 & - & $625 \mathrm{~m}^{2}$ & 0 & - \\
\hline Partitions & $250 \mathrm{~m}^{2}$ & -2416 & - & $250 \mathrm{~m}^{2}$ & 0 & - \\
\hline Ceiling & $0 \mathrm{~m}^{2}$ & 0 & - & $0 \mathrm{~m}^{2}$ & 0 & - \\
\hline Overhead Lighting & $0 \mathrm{~W}$ & 0 & - & 0 & 0 & - \\
\hline Task Lighting & $11250 \mathrm{~W}$ & 11249 & - & 0 & 0 & - \\
\hline Electric Equipment & $1250000 \mathrm{~W}$ & 1249942 & - & 0 & 0 & - \\
\hline People & 3 & 270 & 417 & 0 & 0 & 0 \\
\hline Infiltration & - & 206 & 430 & - & 0 & 193 \\
\hline Miscellaneous & - & 0 & 0 & - & 0 & 0 \\
\hline Safety Factor & $0 \% / 0 \%$ & 0 & 0 & $0 \%$ & 0 & 0 \\
\hline >> Total Zone Loads & -1 & 1266452 & 847 & -1 & 0 & 193 \\
\hline
\end{tabular}




\begin{tabular}{|c|c|c|c|c|c|c|}
\hline TABLE 1.1.A. & COMPONENT L & S FOR SP & Área de & TI" IN ZONE & e1" & \\
\hline & & N COOLIN & & & N HEATINC & \\
\hline & \begin{tabular}{|l} 
COOLING DATA \\
COOLING OA D \\
OCCUPIED T-S
\end{tabular} & $\begin{array}{l}\operatorname{Jan} 1400 \\
\mathrm{~B} \quad 31,4^{\circ} \\
6,0^{\circ} \mathrm{C}\end{array}$ & $5^{\circ} \mathrm{C}$ & $\begin{array}{l}\text { HEATING DATA } \\
\text { HEATING OA D } \\
\text { OCCUPIED T-S }\end{array}$ & $\begin{array}{l}\text { ES HTG } \\
\text { B } \quad 8,9^{\circ} \mathrm{C} \\
, 0^{\circ} \mathrm{C}\end{array}$ & \\
\hline & & Sensible & Latent & & Sensible & Latent \\
\hline SPACE LOADS & Details & $(\mathrm{W})$ & $(\mathrm{W})$ & Details & (W) & $(W)$ \\
\hline Window \& Skylight Solar Loads & $0 \mathrm{~m}^{2}$ & 0 & - & $0 \mathrm{~m}^{2}$ & - & - \\
\hline Wall Transmission & $250 \mathrm{~m}^{2}$ & 2915 & - & $250 \mathrm{~m}^{2}$ & 0 & - \\
\hline Roof Transmission & $625 \mathrm{~m}^{2}$ & 4285 & - & $625 \mathrm{~m}^{2}$ & 0 & - \\
\hline Window Transmission & $0 \mathrm{~m}^{2}$ & 0 & - & $0 \mathrm{~m}^{2}$ & 0 & - \\
\hline Skylight Transmission & $0 \mathrm{~m}^{2}$ & 0 & - & $0 \mathrm{~m}^{2}$ & 0 & - \\
\hline Door Loads & $0 \mathrm{~m}^{2}$ & 0 & - & $0 \mathrm{~m}^{2}$ & 0 & - \\
\hline Floor Transmission & $625 \mathrm{~m}^{2}$ & 0 & - & $625 \mathrm{~m}^{2}$ & 0 & \\
\hline Partitions & $250 \mathrm{~m}^{2}$ & -2416 & - & $250 \mathrm{~m}^{2}$ & 0 & - \\
\hline Ceiling & $0 \mathrm{~m}^{2}$ & 0 & - & $0 \mathrm{~m}^{2}$ & 0 & - \\
\hline Overhead Lighting & $0 \mathrm{~W}$ & 0 & - & 0 & 0 & \\
\hline Task Lighting & $11250 \mathrm{~W}$ & 11249 & - & 0 & 0 & - \\
\hline Electric Equipment & $1250000 \mathrm{~W}$ & 1249942 & - & 0 & 0 & - \\
\hline People & 3 & 270 & 417 & 0 & 0 & 0 \\
\hline Infiltration & - & 206 & 430 & - & 0 & 193 \\
\hline Miscellaneous & - & 0 & 0 & - & 0 & 0 \\
\hline Safety Factor & $0 \% / 0 \%$ & 0 & 0 & $0 \%$ & 0 & 0 \\
\hline > Total Zone Loads & -1 & 1266452 & 847 & 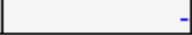 & 0 & 193 \\
\hline
\end{tabular}

\begin{tabular}{|c|c|c|c|c|c|c|c|}
\hline \multirow{2}{*}{\multicolumn{2}{|c|}{\begin{tabular}{|l} 
TABLE 1.1.B. \\
\end{tabular}}} & \multicolumn{2}{|c|}{ ENVELOPE LOADS FOR SPACE } & Área de $\mathrm{Tl}$ " & \multicolumn{3}{|c|}{ IN ZONE "Zone 1" } \\
\hline & & & & & COOLING & COOLING & HEATING \\
\hline & & Area & U-Value & Shade & TRANS & SOLAR & TRANS \\
\hline & & $\left(\mathrm{m}^{2}\right)$ & $\left(W /\left(m^{2}-{ }^{\circ} K\right)\right)$ & Coeff. & (W) & (W) & (W) \\
\hline \multicolumn{8}{|l|}{ N EXPOSURE } \\
\hline WALL & & 125 & 1,280 & - & 672 & & 0 \\
\hline \multicolumn{8}{|l|}{ E EXPOSURE } \\
\hline WALL & & 125 & 1,280 & - & 2244 & & 0 \\
\hline \multicolumn{8}{|l|}{ H $\quad$ EXPOSURE } \\
\hline ROOF & & 625 & 0,685 & - & 4285 & - & 0 \\
\hline
\end{tabular}


TABLE 1: SYSTEM DATA

\begin{tabular}{|c|c|c|c|c|c|c|c|}
\hline Component & Location & $\begin{array}{r}\text { Dry-Bulb } \\
\text { Temp } \\
\left({ }^{\circ} \mathrm{C}\right)\end{array}$ & $\begin{array}{r}\text { Specific } \\
\text { Humidity } \\
(\mathrm{kg} / \mathrm{kg})\end{array}$ & $\begin{array}{r}\text { Airflow } \\
(\mathrm{L} / \mathrm{s})\end{array}$ & $\begin{array}{r}\text { CO2 Level } \\
\text { (ppm) }\end{array}$ & $\begin{array}{r}\text { Sensible } \\
\text { Heat } \\
(\mathrm{W})\end{array}$ & $\begin{array}{r}\text { Latent } \\
\text { Heat } \\
(\mathrm{W})\end{array}$ \\
\hline Ventilation Air & Inlet & 30,8 & 0,01213 & 195 & 400 & 940 & 2432 \\
\hline Vent - Retum Mixing & Outlet & 26,4 & 0,00749 & 164981 & 800 & - & - \\
\hline Central Cooling Coil & Outlet & 17,9 & 0,00749 & 164981 & 800 & 1535395 & 0 \\
\hline Central Heating Coil & Outlet & 17,9 & 0,00749 & 164981 & 800 & 0 & - \\
\hline Supply Fan & Outlet & 19,3 & 0,00749 & 164981 & 800 & 258036 & - \\
\hline Cold Supply Duct & Outlet & 19,3 & 0,00749 & 164981 & 800 & - & - \\
\hline Zone Air & - & 26,3 & 0,00749 & 164981 & 800 & 1266111 & 848 \\
\hline Return Plenum & Outlet & 26,4 & 0,00749 & 164981 & 800 & 10308 & - \\
\hline
\end{tabular}

Air Density $x$ Heat Capacity $x$ Conversion Factor: At sea level = 1,207; At site altitude $=1,097 \mathrm{~W} /(\mathrm{L} / \mathrm{s}-\mathrm{K})$

Air Density x Heat of Vaporization x Conversion Factor. At sea level $=2947,6$; At site altitude $=2677,6 \mathrm{~W} /(\mathrm{L} / \mathrm{s})$

Site Altitude $=802,8 \mathrm{~m}$

TABLE 2: ZONE DATA

\begin{tabular}{|c|c|c|c|c|c|c|c|c|}
\hline Zone Name & $\begin{array}{r}\text { Zone } \\
\text { Sensible } \\
\text { Load } \\
(\mathrm{W})\end{array}$ & $\begin{array}{l}\text { T-stat } \\
\text { Mode }\end{array}$ & $\begin{array}{r}\text { Zone } \\
\text { Cond } \\
(\mathrm{W})\end{array}$ & $\begin{array}{r}\text { Zone } \\
\text { Temp } \\
\left({ }^{\circ} \mathrm{C}\right)\end{array}$ & $\begin{array}{r}\text { Zone } \\
\text { Airflow } \\
(\mathrm{L} / \mathrm{s})\end{array}$ & $\begin{array}{r}\mathrm{CO} 2 \\
\text { Level } \\
(\mathrm{ppm})\end{array}$ & $\begin{array}{r}\text { Terminal } \\
\text { Heating } \\
\text { Coil } \\
(\mathrm{W}) \\
\end{array}$ & $\begin{array}{r}\text { Zone } \\
\text { Heating } \\
\text { Unit } \\
\text { (W) }\end{array}$ \\
\hline Zone 1 & 1266258 & Cooling & 1266111 & 26,3 & 164981 & 800 & 0 & 0 \\
\hline
\end{tabular}

WINTER DESIGN HEATING

TABLE 1: SYSTEM DATA

\begin{tabular}{|c|c|c|c|c|c|c|c|}
\hline Component & Location & $\begin{array}{r}\text { Dry-Bulb } \\
\text { Temp } \\
\left({ }^{\circ} \mathrm{C}\right)\end{array}$ & $\begin{array}{r}\text { Specific } \\
\text { Humidity } \\
(\mathbf{k g} / \mathbf{k g})\end{array}$ & $\begin{array}{r}\text { Airflow } \\
(\mathrm{L} / \mathrm{s})\end{array}$ & $\begin{array}{r}\text { CO2 Level } \\
\text { (ppm) }\end{array}$ & $\begin{array}{r}\text { Sensible } \\
\text { Heat } \\
(W)\end{array}$ & $\begin{array}{r}\text { Latent } \\
\text { Heat } \\
(\mathrm{W})\end{array}$ \\
\hline Ventilation Air & Inlet & 8,9 & 0,00387 & 195 & 400 & 833 & -1088 \\
\hline Vent - Return Mixing & Outlet & 5,0 & 0,00595 & 164981 & 800 & - & - \\
\hline Central Cooling Coil & Outlet & 5,0 & 0,00595 & 164981 & 800 & 0 & 0 \\
\hline Central Heating Coil & Outlet & 17,6 & 0,00595 & 164981 & 800 & 2274034 & - \\
\hline Supply Fan & Outlet & 19,0 & 0,00595 & 164981 & 800 & 258036 & - \\
\hline Cold Supply Duct & Outlet & 5,0 & 0,00595 & 164981 & 800 & - & - \\
\hline Zone Air & - & 5,0 & 0,00595 & 164981 & 800 & 0 & -193 \\
\hline Return Plenum & Outlet & 5,0 & 0,00595 & 164981 & 800 & 0 & - \\
\hline
\end{tabular}

Air Density x Heat Capacity x Conversion Factor: At sea level = 1,207; At site altitude $=1,097 \mathrm{~W} /(\mathrm{L} / \mathrm{s}-\mathrm{K})$

Air Density x Heat of Vaporization x Conversion Factor. At sea level $=2947,6$; At site altitude $=2677,6 \mathrm{~W} /(\mathrm{L} / \mathrm{s})$

Site Altitude $=802,8 \mathrm{~m}$

\section{TABLE 2: ZONE DATA}

\begin{tabular}{|c|c|c|c|c|c|c|c|c|}
\hline Zone Name & $\begin{array}{r}\text { Zone } \\
\text { Sensible } \\
\text { Load } \\
(\mathrm{W})\end{array}$ & $\begin{array}{l}\text { T-stat } \\
\text { Mode }\end{array}$ & $\begin{array}{r}\text { Zone } \\
\text { Cond } \\
(\mathrm{W})\end{array}$ & $\begin{array}{r}\text { Zone } \\
\text { Temp } \\
\left({ }^{\circ} \mathrm{C}\right)\end{array}$ & $\begin{array}{r}\text { Zone } \\
\text { Airflow } \\
(\mathrm{L} / \mathrm{s})\end{array}$ & $\begin{array}{r}\mathrm{CO} 2 \\
\text { Level } \\
(\mathrm{ppm})\end{array}$ & $\begin{array}{r}\text { Terminal } \\
\text { Heating } \\
\text { Coil } \\
\text { (W) }\end{array}$ & $\begin{array}{r}\text { Zone } \\
\text { Heating } \\
\text { Unit } \\
\text { (W) }\end{array}$ \\
\hline Zone 1 & 0 & Deadband & 0 & 5,0 & 164981 & 800 & 0 & 0 \\
\hline
\end{tabular}


Location: Sao Paulo, Brazil

Altitude: $802,8 \mathrm{~m}$

Data for: January DESIGN COOLING DAY, 1300

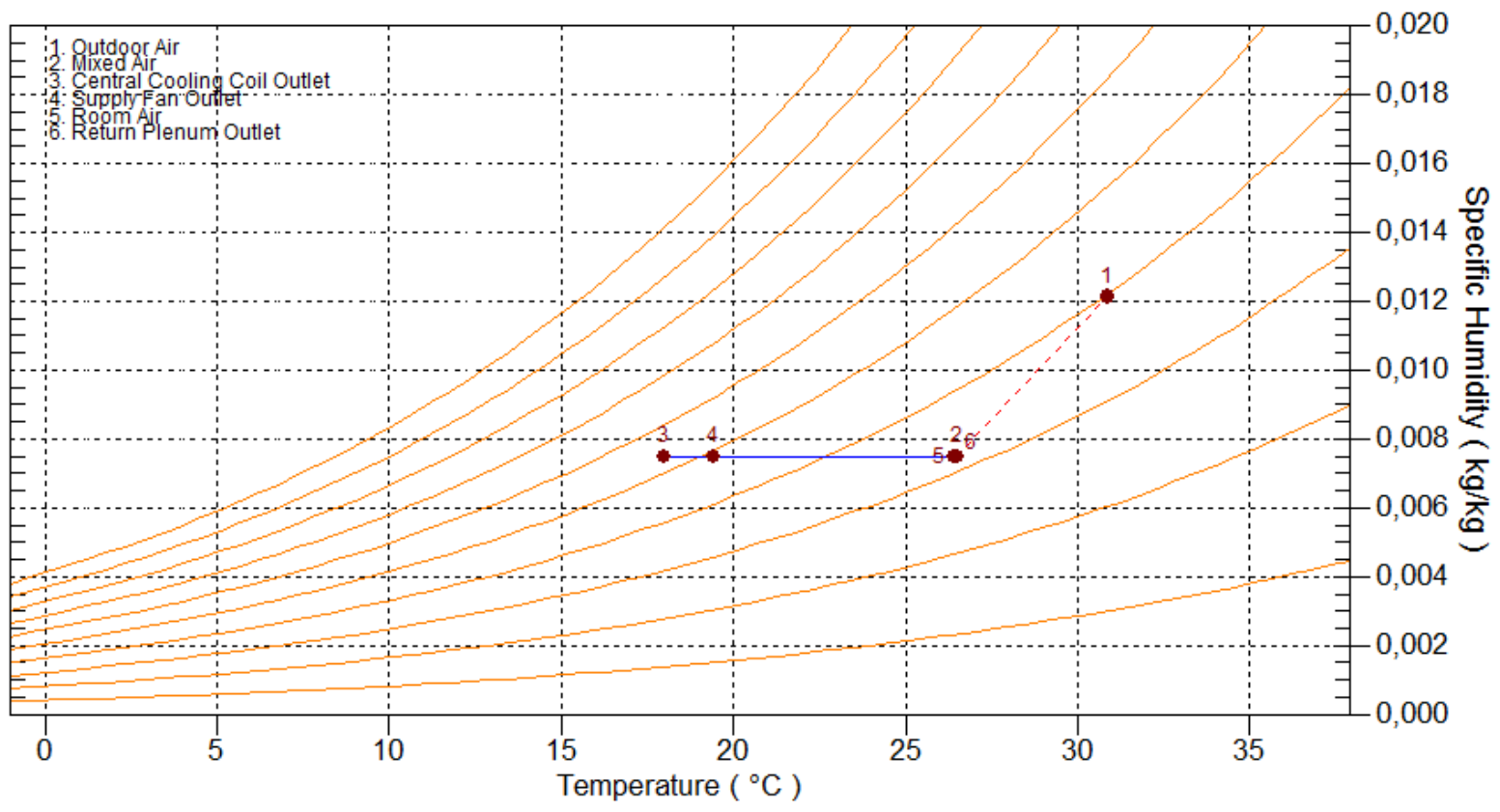




\section{Anexo B - Tabelas de Tempo e Taxa interna de investimento para São Paulo}

RN Direto

\begin{tabular}{|r|r|r|r|r|r|}
\hline \multicolumn{7}{|c|}{ RN Direto - Tarifa Básica R\$ 0,30 - Payback + Depreciação } \\
\hline $\begin{array}{c}\text { Carga } \\
\left(\mathrm{kW} / \mathrm{m}^{2}\right)\end{array}$ & 1 & 1,25 & 1,5 & 1,75 & 1,88 \\
\hline 0,5 & 0 & 0 & 0 & 0 & 0 \\
\hline 1 & 0 & 0 & 0 & 0 & 0 \\
\hline 2 & 0 & 0 & 0 & 0 & 0 \\
\hline 4 & 0 & 0 & 0 & 0 & 0 \\
\hline 8 & 0 & 0 & 0 & 0 & 0 \\
\hline
\end{tabular}

\begin{tabular}{|c|c|c|c|c|c|}
\hline \multicolumn{6}{|c|}{ RN Direto - Tarifa Básica R\$ 0,30 - TIR } \\
\hline \multirow{2}{*}{$\begin{array}{c}\text { Carga } \\
\left(\mathrm{kW} / \mathrm{m}^{2}\right)\end{array}$} & \multicolumn{5}{|c|}{ Tarifa Ponta/ Tarifa Regular } \\
\hline & 1 & 1,25 & 1,5 & 1,75 & 1,88 \\
\hline 0,5 & Inviável & Inviável & Inviável & Inviável & Inviável \\
\hline 1 & Inviável & Inviável & Inviável & Inviável & Inviável \\
\hline 2 & Inviável & Inviável & Inviável & Inviável & Inviável \\
\hline 4 & Inviável & Inviável & Inviável & Inviável & Inviável \\
\hline 8 & Inviável & Inviável & Inviável & Inviável & Inviável \\
\hline
\end{tabular}

\begin{tabular}{|c|c|c|c|c|c|}
\hline \multicolumn{7}{|c|}{ RN Direto - Tarifa Básica R\$ 0,60 - Payback + Depreciação } \\
\hline $\begin{array}{c}\text { Carga } \\
\left(\mathrm{kW} / \mathrm{m}^{2}\right)\end{array}$ & 1 & 1,25 & 1,5 & 1,75 & 1,88 \\
\hline 0,5 & 0 & 0 & 0 & 0 & 0 \\
\hline 1 & 0 & 0 & 0 & 0 & 0 \\
\hline 2 & 0 & 0 & 0 & 0 & 0 \\
\hline 4 & 0 & 0 & 0 & 0 & 0 \\
\hline 8 & 0 & 0 & 0 & 0 & 0 \\
\hline
\end{tabular}

\begin{tabular}{|c|c|c|c|c|c|}
\hline \multicolumn{7}{|c|}{ RN Direto - Tarifa Básica R\$ 0,60 - TIR } \\
\hline \multirow{2}{*}{$\begin{array}{c}\text { Carga } \\
\left(\mathrm{kW} / \mathrm{m}^{2}\right)\end{array}$} & 1 & 1,25 & 1,5 & 1,75 & 1,88 \\
\hline 0,5 & Inviável & Inviável & Inviável & Inviável & Inviável \\
\hline & Inviável & Inviável & Inviável & Inviável & Inviável \\
\hline 1 & Inviável & Inviável & Inviável & Inviável & Inviável \\
\hline 2 & Inviável & Inviável & Inviável & Inviável & Inviável \\
\hline 4 & Inviável & Inviável & Inviável & Inviável & Inviável \\
\hline 8 & \multicolumn{7}{|c}{}
\end{tabular}




\begin{tabular}{|c|c|c|c|c|c|}
\hline \multicolumn{7}{|c|}{ RN Direto - Tarifa Básica R\$ 1,10 - Payback + Depreciação } \\
\hline \multirow{2}{*}{$\begin{array}{c}\text { Carga } \\
\left(\mathrm{kW} / \mathrm{m}^{2}\right)\end{array}$} & 1 & 1,25 & 1,5 & 1,75 & 1,88 \\
\hline 0,5 & 0 & 0 & 0 & 0 & 0 \\
\hline 1 & 0 & 0 & 0 & 0 & 0 \\
\hline 2 & 0 & 0 & 0 & 0 & 0 \\
\hline 4 & 0 & 0 & 0 & 0 & 0 \\
\hline 8 & 0 & 0 & 0 & 0 & 0 \\
\hline
\end{tabular}

\begin{tabular}{|c|c|c|c|c|c|}
\hline \multicolumn{7}{|c|}{ RN Direto - Tarifa Básica R\$ 1,10 - TIR } \\
\hline \multirow{2}{*}{$\begin{array}{c}\text { Carga } \\
\left(\mathrm{kW} / \mathrm{m}^{2}\right)\end{array}$} & 1 & 1,25 & 1,5 & 1,75 & 1,88 \\
\cline { 2 - 6 } & Inviável & Inviável & Inviável & Inviável & Inviável \\
\hline 0,5 & Inviável & Inviável & Inviável & Inviável & Inviável \\
\hline 1 & Inviável & Inviável & Inviável & Inviável & Inviável \\
\hline 2 & Inviável & Inviável & Inviável & Inviável & Inviável \\
\hline 4 & 0,042928042 & 0,047152892 & 0,051335092 & 0,055476304 & 0,057614061 \\
\hline 8
\end{tabular}

RN Indireto

\begin{tabular}{|c|c|c|c|c|c|}
\hline \multirow{7}{*}{$\begin{array}{c}\text { Carga } \\
\left(\mathrm{kW} / \mathrm{m}^{2}\right)\end{array}$} & \multicolumn{5}{|c|}{ RN Indireto - Tarifa Básica R\$ 0,30 - Payback + Depreciação } \\
\cline { 2 - 6 } & 1 & 1,25 & 1,5 & 1,75 & 1,88 \\
\hline 0,5 & 0,315126635 & 0,308546571 & 0,302235679 & 0,296177773 & 0,293122645 \\
\hline 1 & 0,233835062 & 0,228987103 & 0,22433608 & 0,219870233 & 0,21761754 \\
\hline 2 & 0,529813949 & 0,518336916 & 0,50734658 & 0,496812625 & 0,491505994 \\
\hline 4 & 0,113586479 & 0,111174027 & 0,108861919 & 0,106644023 & 0,105526058 \\
\hline 8 & 0,108268008 & 0,105977719 & 0,10378232 & 0,101676033 & 0,100614199 \\
\hline
\end{tabular}

\begin{tabular}{|c|c|c|c|c|c|}
\hline \multirow{2}{*}{$\begin{array}{c}\text { Carga } \\
\left(\mathrm{kW} / \mathrm{m}^{2}\right)\end{array}$} & \multicolumn{5}{|c|}{ RN Indireto - Tarifa Básica R\$ 0,30 - TIR } \\
\cline { 2 - 6 } & 1 & 1,25 & 1,5 & 1,75 & 1,88 \\
\hline 0,5 & $317 \%$ & $324 \%$ & $331 \%$ & $338 \%$ & $341 \%$ \\
\hline 1 & $428 \%$ & $437 \%$ & $446 \%$ & $455 \%$ & $460 \%$ \\
\hline 2 & $189 \%$ & $193 \%$ & $197 \%$ & $201 \%$ & $203 \%$ \\
\hline 4 & $880 \%$ & $899 \%$ & $919 \%$ & $938 \%$ & $948 \%$ \\
\hline 8 & $924 \%$ & $944 \%$ & $964 \%$ & $984 \%$ & $994 \%$ \\
\hline
\end{tabular}




\begin{tabular}{|c|c|c|c|c|c|}
\hline \multirow{7}{*}{$\begin{array}{c}\text { Carga } \\
\left(\mathrm{kW} / \mathrm{m}^{2}\right)\end{array}$} & \multicolumn{5}{|c|}{ RN Indireto - Tarifa Básica R\$0,60 - Payback + Depreciação } \\
\cline { 2 - 6 } & 1 & 1,25 & 1,5 & 1,75 & 1,88 \\
\hline 0,5 & 0,157563317 & 0,154273285 & 0,151117839 & 0,148088887 & 0,146561322 \\
\hline 1 & 0,116917531 & 0,114493551 & 0,11216804 & 0,109935117 & 0,10880877 \\
\hline 2 & 0,264906975 & 0,259168458 & 0,25367329 & 0,248406313 & 0,245752997 \\
\hline 4 & 0,056793239 & 0,055587013 & 0,05443096 & 0,053322011 & 0,052763029 \\
\hline 8 & 0,054134004 & 0,05298886 & 0,05189116 & 0,050838017 & 0,050307099 \\
\hline
\end{tabular}

\begin{tabular}{|c|c|c|c|c|c|}
\hline \multicolumn{5}{|c|}{ RN Indireto - Tarifa Básica R\$ 0,60 - TIR } \\
\hline \multirow{2}{*}{$\begin{array}{c}\text { Carga } \\
\left(\mathrm{kW} / \mathrm{m}^{2}\right)\end{array}$} & \multicolumn{5}{|c|}{ Tarifa Ponta/ Tarifa Regular } \\
\cline { 2 - 6 } & 1 & 1,25 & 1,5 & 1,75 & 1,88 \\
\hline 0,5 & $635 \%$ & $648 \%$ & $662 \%$ & $675 \%$ & $682 \%$ \\
\hline 1 & $855 \%$ & $873 \%$ & $892 \%$ & $910 \%$ & $919 \%$ \\
\hline 2 & $377 \%$ & $386 \%$ & $394 \%$ & $403 \%$ & $407 \%$ \\
\hline 4 & $1761 \%$ & $1799 \%$ & $1837 \%$ & $1875 \%$ & $1895 \%$ \\
\hline 8 & $1847 \%$ & $1887 \%$ & $1927 \%$ & $1967 \%$ & $1988 \%$ \\
\hline
\end{tabular}

\begin{tabular}{|c|c|c|c|c|c|}
\hline \multicolumn{7}{|c|}{ RN Indireto - Tarifa Básica R\$ 1,10 - Payback + Depreciação } \\
\hline \multirow{2}{*}{$\begin{array}{c}\text { Carga } \\
\left.\mathrm{kW} / \mathrm{m}^{2}\right)\end{array}$} & \multicolumn{5}{|c|}{ Tarifa Ponta/ Tarifa Regular } \\
\cline { 2 - 6 } & 1 & 1,25 & 1,5 & 1,75 & 1,88 \\
\hline 0,5 & 0,085943628 & 0,084149065 & 0,082427912 & 0,080775756 & 0,079942539 \\
\hline 1 & 0,063773199 & 0,31788837 & 0,061182567 & 0,059964609 & 0,059350238 \\
\hline 2 & 0,144494713 & 0,141364614 & 0,138367249 & 0,135494352 & 0,134047089 \\
\hline 4 & 0,030978131 & 0,030320189 & 0,029689614 & 0,029084734 & 0,028779834 \\
\hline 8 & 0,029527639 & 0,028903014 & 0,028304269 & 0,027729827 & 0,027440236 \\
\hline
\end{tabular}

\begin{tabular}{|c|c|c|c|c|c|}
\hline \multicolumn{7}{|c|}{ RN Indireto - Tarifa Básica R\$ 1,10 - TIR } \\
\hline \multirow{2}{*}{$\begin{array}{c}\text { Carga } \\
\left(\mathrm{kW} / \mathrm{m}^{2}\right)\end{array}$} & \multicolumn{5}{|c|}{ Tarifa Ponta/ Tarifa Regular } \\
\cline { 2 - 6 } & 1 & 1,25 & 1,5 & 1,75 & 1,88 \\
\hline 0,5 & $1164 \%$ & $1188 \%$ & $1213 \%$ & $1238 \%$ & $1251 \%$ \\
\hline 1 & $1568 \%$ & $315 \%$ & $1634 \%$ & $1668 \%$ & $1685 \%$ \\
\hline 2 & $692 \%$ & $707 \%$ & $723 \%$ & $738 \%$ & $746 \%$ \\
\hline 4 & $3228 \%$ & $3298 \%$ & $3368 \%$ & $3438 \%$ & $3475 \%$ \\
\hline 8 & $3387 \%$ & $3460 \%$ & $3533 \%$ & $3606 \%$ & $3644 \%$ \\
\hline
\end{tabular}


RN Direto + Indireto

\begin{tabular}{|c|c|c|c|c|c|}
\hline \multicolumn{7}{|c|}{ RN Direto + Ind - Tarifa Básica R\$ 0,30 - Payback + Depreciação } \\
\hline \multirow{2}{*}{$\begin{array}{c}\text { Carga } \\
\left(\mathrm{kW} / \mathrm{m}^{2}\right)\end{array}$} & \multicolumn{5}{|c|}{ Tarifa Ponta/ Tarifa Regular } \\
\cline { 2 - 6 } & 1 & 1,25 & 1,5 & 1,75 & 1,88 \\
\hline 0,5 & 0 & 0 & 0 & 0 & 0 \\
\hline 1 & 0 & 0 & 0 & 0 & 0 \\
\hline 2 & 0 & 0 & 0 & 0 & 0 \\
\hline 4 & 6,917684347 & 6,745928607 & 6,582495113 & 6,426793305 & 6,348704005 \\
\hline 8 & 1,24134696 & 1,213987155 & 1,187807384 & 1,162732916 & 1,150108024 \\
\hline
\end{tabular}

\begin{tabular}{|c|c|c|c|c|c|}
\hline \multicolumn{7}{|c|}{ RN Direto + Ind - Tarifa Básica R\$ 0,30 - TIR } \\
\hline \multirow{2}{*}{$\begin{array}{c}\text { Carga } \\
\left(\mathrm{kW} / \mathrm{m}^{2}\right)\end{array}$} & 1 & 1,25 & 1,5 & 1,75 & 1,88 \\
\hline & \multicolumn{5}{c|}{ Tarifa Ponta/ Tarifa Regular } \\
\hline 0,5 & Inviável & Inviável & Inviável & Inviável & Inviável \\
\hline 1 & Inviável & Inviável & Inviável & Inviável & Inviável \\
\hline 2 & Inviável & Inviável & Inviável & Inviável & Inviável \\
\hline 4 & $7 \%$ & $8 \%$ & $8 \%$ & $17 \%$ & $9 \%$ \\
\hline 8 & $80 \%$ & $82 \%$ & $84 \%$ & $86 \%$ & $87 \%$ \\
\hline
\end{tabular}

\begin{tabular}{|c|c|c|c|c|c|}
\hline \multicolumn{7}{|c|}{ RN Direto + Ind - Tarifa Básica R\$ 0,60 - Payback + Depreciação } \\
\hline $\begin{array}{c}\text { Carga } \\
\left(\mathrm{kW} / \mathrm{m}^{2}\right)\end{array}$ & 1 & 1,25 & 1,5 & 1,75 & 1,88 \\
\cline { 2 - 6 } & 0 & 0 & 0 & 0 & 0 \\
\hline 0,5 & 0 & 0 & 0 & 0 & 0 \\
\hline 1 & 0 & 0 & 0 & 0 & 0 \\
\hline 2 & 3,2201695 & 3,145606748 & 3,074418839 & 3,006381718 & 2,972178955 \\
\hline 4 & 0,613063238 & 0,599713137 & 0,586932069 & 0,574684413 & 0,56851547 \\
\hline 8 &
\end{tabular}

\begin{tabular}{|c|c|c|c|c|c|}
\hline \multicolumn{6}{|c|}{ RN Direto + Ind - Tarifa Básica R\$ 0,60 - TIR } \\
\hline \multirow{2}{*}{$\begin{array}{c}\text { Carga } \\
\left(\mathrm{kW} / \mathrm{m}^{2}\right)\end{array}$} & \multicolumn{5}{|c|}{ Tarifa Ponta/ Tarifa Regular } \\
\cline { 2 - 6 } & 1 & 1,25 & 1,5 & 1,75 & 1,88 \\
\hline 0,5 & Inviável & Inviável & Inviável & Inviável & Inviável \\
\hline 1 & Inviável & Inviável & Inviável & Inviável & Inviável \\
\hline 2 & Inviável & Inviável & Inviável & Inviável & Inviável \\
\hline 4 & $29 \%$ & $29 \%$ & $30 \%$ & $31 \%$ & $31 \%$ \\
\hline 8 & $163 \%$ & $167 \%$ & $170 \%$ & $174 \%$ & $176 \%$ \\
\hline
\end{tabular}




\begin{tabular}{|c|c|c|c|c|c|}
\hline \multicolumn{7}{|c|}{ RN Direto + Ind - Tarifa Básica R\$ 1,10 - Payback + Depreciação } \\
\hline \multirow{2}{*}{$\begin{array}{c}\text { Carga } \\
\left(\mathrm{kW} / \mathrm{m}^{2}\right)\end{array}$} & 1 & 1,25 & 1,5 & 1,75 & 1,88 \\
\hline 0,5 & 0 & 0 & 0 & 0 & 0 \\
\hline 1 & 0 & 0 & 0 & 0 & 0 \\
\hline 2 & 0 & 0 & 0 & 0 & 0 \\
\hline 4 & 1,70303976 & 1,664778311 & 1,628198294 & 1,593191252 & 1,575575921 \\
\hline 8 & 0,332544758 & 0,325342509 & 0,31844562 & 0,311835073 & 0,308504894 \\
\hline
\end{tabular}

\begin{tabular}{|c|c|c|c|c|c|}
\hline \multicolumn{7}{|c|}{ RN Direto + Ind - Tarifa Básica R\$ 1,10 - TIR } \\
\hline \multirow{2}{*}{$\begin{array}{c}\text { Carga } \\
\left(\mathrm{kW} / \mathrm{m}^{2}\right)\end{array}$} & 1 & 1,25 & 1,5 & 1,75 & 1,88 \\
\cline { 2 - 6 } & Tarifa Ponta/ Tarifa Regular \\
\hline 0,5 & Inviável & Inviável & Inviável & Inviável & Inviável \\
\hline 1 & Inviável & Inviável & Inviável & Inviável & Inviável \\
\hline 2 & Inviável & Inviável & Inviável & Inviável & Inviável \\
\hline 4 & $58 \%$ & $60 \%$ & $61 \%$ & $62 \%$ & $63 \%$ \\
\hline 8 & $301 \%$ & $307 \%$ & $314 \%$ & $321 \%$ & $324 \%$ \\
\hline
\end{tabular}

\section{Solar Absorção}

\begin{tabular}{|c|c|c|c|c|c|}
\hline \multicolumn{7}{|c|}{ Absorção Solar - Tarifa Básica R\$ 0,30 - Payback + Depreciação } \\
\hline \multirow{2}{*}{$\begin{array}{c}\text { Carga } \\
\left(\mathrm{kW} / \mathrm{m}^{2}\right)\end{array}$} & 1 & 1,25 & 1,5 & 1,75 & 1,88 \\
\cline { 2 - 6 } & \multicolumn{5}{|c|}{ Tarifa Ponta/ Tarifa Regular } \\
\hline 0,5 & 60,42676605 & 48,93720415 & 41,11885396 & 35,45453435 & 33,0846017 \\
\hline 1 & 28,57054375 & 23,82439273 & 20,43047366 & 17,88294703 & 16,79402111 \\
\hline 2 & 0 & 0 & 848,9370395 & 155,2518876 & 108,9560751 \\
\hline 4 & 31,95595746 & 22,43843631 & 17,28916262 & 14,06212311 & 12,8180246 \\
\hline 8 & 74,01501078 & 37,39717882 & 25,01926666 & 18,79755458 & 16,6451391 \\
\hline
\end{tabular}

\begin{tabular}{|c|c|c|c|c|c|}
\hline \multicolumn{5}{|c|}{ Absorção Solar - Tarifa Básica R\$ 0,30 - TIR } \\
\hline \multirow{2}{*}{$\begin{array}{c}\text { Carga } \\
\left(\mathrm{kW} / \mathrm{m}^{2}\right)\end{array}$} & 1 & 1,25 & 1,5 & 1,75 & 1,88 \\
\cline { 2 - 6 } & $\mathrm{PB}>10$ & $\mathrm{~PB}>10$ & $\mathrm{~PB}>10$ & $\mathrm{~PB}>10$ & $\mathrm{~PB}>10$ \\
\hline 0,5 & $\mathrm{~PB}>10$ & $\mathrm{~PB}>10$ & $\mathrm{~PB}>10$ & $\mathrm{~PB}>10$ & $\mathrm{~PB}>10$ \\
\hline 1 & Inviável & Inviável & $\mathrm{PB}>10$ & $\mathrm{~PB}>10$ & $\mathrm{~PB}>10$ \\
\hline 2 & $\mathrm{~PB}>10$ & $\mathrm{~PB}>10$ & $\mathrm{~PB}>10$ & $\mathrm{~PB}>10$ & $\mathrm{~PB}>10$ \\
\hline 4 & $\mathrm{~PB}>10$ & $\mathrm{~PB}>10$ & $\mathrm{~PB}>10$ & $\mathrm{~PB}>10$ & $\mathrm{~PB}>10$ \\
\hline 8 & & & & & \\
\hline
\end{tabular}




\begin{tabular}{|c|c|c|c|c|c|}
\hline \multicolumn{6}{|c|}{ Absorção Solar - Tarifa Básica R\$ 0,60 - Payback + Depreciação } \\
\hline \multirow{2}{*}{$\begin{array}{c}\text { Carga } \\
\left(\mathrm{kW} / \mathrm{m}^{2}\right)\end{array}$} & 1 & 1,25 & 1,5 & 1,75 & 1,88 \\
\hline 0,5 & 12,29927742 & 11,22632116 & 10,32554782 & 9,558589323 & 9,20312389 \\
\hline 1 & 8,459532518 & 7,566857976 & 6,844596221 & 6,248201159 & 5,977369367 \\
\hline 2 & 33,88595255 & 24,97679816 & 19,77708803 & 16,36930062 & 15,02320451 \\
\hline 4 & 9,025774753 & 7,28117637 & 6,101762401 & 5,251171187 & 4,896249541 \\
\hline 8 & 13,29270735 & 9,834036493 & 7,803594879 & 6,46811736 & 5,939551775 \\
\hline
\end{tabular}

\begin{tabular}{|c|c|c|c|c|c|}
\hline \multicolumn{6}{|c|}{ Absorção Solar - Tarifa Básica R\$ 0,60 - TIR } \\
\hline \multirow{2}{*}{$\begin{array}{c}\text { Carga } \\
\left(\mathrm{kW} / \mathrm{m}^{2}\right)\end{array}$} & 1 & 1,25 & 1,5 & 1,75 & 1,88 \\
\hline & Tarifa Ponta/ Tarifa Regular \\
\hline 0,5 & $\mathrm{~PB}>10$ & $\mathrm{~PB}>10$ & $\mathrm{~PB}>10$ & $1 \%$ & $2 \%$ \\
\hline 1 & $3 \%$ & $5 \%$ & $8 \%$ & $10 \%$ & $11 \%$ \\
\hline 2 & $\mathrm{~PB}>10$ & $\mathrm{~PB}>10$ & $\mathrm{~PB}>10$ & $\mathrm{~PB}>10$ & $\mathrm{~PB}>10$ \\
\hline 4 & $2 \%$ & $6 \%$ & $10 \%$ & $14 \%$ & $16 \%$ \\
\hline 8 & $2 \%$ & $7 \%$ & $12 \%$ & $16 \%$ & $18 \%$ \\
\hline
\end{tabular}

\begin{tabular}{|c|c|c|c|c|c|}
\hline \multicolumn{6}{|c|}{ Absorção Solar - Tarifa Básica R\$ 1,10 - Payback + Depreciação } \\
\hline \multirow{2}{*}{$\begin{array}{c}\text { Carga } \\
\left(\mathrm{kW} / \mathrm{m}^{2}\right)\end{array}$} & 1 & 1,25 & 1,5 & 1,75 & 1,88 \\
\hline 0,5 & 5,284481926 & 4,914493946 & 4,592924689 & 4,310853346 & 4,177444784 \\
\hline 1 & 3,892699987 & 60,39492562 & 3,246497482 & 2,997684186 & 2,882795899 \\
\hline 2 & 10,60714109 & 8,804792025 & 7,525987782 & 6,571540098 & 6,164980981 \\
\hline 4 & 4,110235666 & 3,425081251 & 2,935713442 & 2,568703006 & 2,41190915 \\
\hline 8 & 5,615034447 & 4,41305471 & 3,634942446 & 3,090095149 & 2,866657471 \\
\hline
\end{tabular}

\begin{tabular}{|c|c|c|c|c|c|}
\hline \multirow{6}{*}{$\begin{array}{c}\text { Carga } \\
\left(\mathrm{kW} / \mathrm{m}^{2}\right)\end{array}$} & \multicolumn{6}{|c|}{ Absorção Solar - Tarifa Básica R\$ 1,10 - TIR } \\
\cline { 2 - 6 } & 1 & 1,25 & 1,5 & 1,75 & 1,88 \\
\hline 0,5 & $14 \%$ & $16 \%$ & $17 \%$ & $19 \%$ & $20 \%$ \\
\hline 1 & $22 \%$ & $\mathrm{~PB}>10$ & $28 \%$ & $31 \%$ & $33 \%$ \\
\hline 2 & $\mathrm{~PB}>10$ & $2 \%$ & $6 \%$ & $8 \%$ & $10 \%$ \\
\hline 4 & $21 \%$ & $26 \%$ & $32 \%$ & $37 \%$ & $40 \%$ \\
\hline 8 & $20 \%$ & $27 \%$ & $34 \%$ & $41 \%$ & $44 \%$ \\
\hline
\end{tabular}




\section{Solar Absorção + RNI}

\begin{tabular}{|c|c|c|c|c|c|}
\hline \multicolumn{6}{|c|}{ Absorção Solar + RD - Tarifa Básica R\$ 0,30 - Payback + Depreciação } \\
\hline \multirow{2}{*}{$\begin{array}{c}\text { Carga } \\
\left(\mathrm{kW} / \mathrm{m}^{2}\right)\end{array}$} & 1 & 1,25 & 1,5 & 1,75 & 1,88 \\
\cline { 2 - 6 } & 0 & 0 & 0 & 0 & 0 \\
\hline 0,5 & 0 & 0 & 0 & 0 & 0 \\
\hline 1 & 0 & 0 & 0 & 0 & 0 \\
\hline 2 & 0 & 0 & 1072,845548 & 149,4964111 & 103,2761696 \\
\hline 4 & 0 & 0 & 371,9193025 & 102,6388444 & 74,56534766 \\
\hline 8 & &
\end{tabular}

\begin{tabular}{|c|c|c|c|c|c|}
\hline \multicolumn{7}{|c|}{ Absorção Solar + RD - Tarifa Básica R\$ 0,30 - TIR } \\
\hline \multirow{2}{*}{$\begin{array}{c}\text { Carga } \\
\left(\mathrm{kW} / \mathrm{m}^{2}\right)\end{array}$} & 1 & 1,25 & 1,5 & 1,75 & 1,88 \\
\cline { 2 - 6 } & 1 & Tarifa Ponta/ Tarifa Regular & Inviável \\
\hline 0,5 & Inviável & Inviável & Inviável & Inviável & Inviável \\
\hline 1 & Inviável & Inviável & Inviável & Inviável & Inviável \\
\hline 2 & Inviável & Inviável & Inviável & Inviável & PB $>10$ \\
\hline 4 & Inviável & Inviável & PB $>10$ & PB $>10$ & PB $>10$ \\
\hline 8 & Inviável & Inviável & PB $>10$ & PB $>10$ & \\
\hline
\end{tabular}

\begin{tabular}{|c|c|c|c|c|c|}
\hline \multicolumn{6}{|c|}{ Absorção Solar + RD - Tarifa Básica R\$ 0,60 - Payback + Depreciação } \\
\hline \multirow{2}{*}{$\begin{array}{c}\text { Carga } \\
\left(\mathrm{kW} / \mathrm{m}^{2}\right)\end{array}$} & 1 & 1,25 & 1,5 & 1,75 & 1,88 \\
\hline & 0 & 0 & 0 & 0 & 0 \\
\hline 0,5 & 0 & 0 & 0 & 0 & 0 \\
\hline 1 & 0 & 0 & 0 & 0 & 0 \\
\hline 2 & 46,97849348 & 30,48744943 & 22,56601356 & 17,91200634 & 16,17709933 \\
\hline 4 & 50,99137625 & 29,65647538 & 20,90836905 & 16,1456916 & 14,43577664 \\
\hline 8 & & & & & \\
\hline
\end{tabular}

\begin{tabular}{|c|c|c|c|c|c|}
\hline \multicolumn{6}{|c|}{ Absorção Solar + RD - Tarifa Básica R\$ 0,60 - TIR } \\
\hline \multirow{2}{*}{$\begin{array}{c}\text { Carga } \\
\left(\mathrm{kW} / \mathrm{m}^{2}\right)\end{array}$} & \multicolumn{5}{|c|}{ Tarifa Ponta/ Tarifa Regular } \\
\cline { 2 - 6 } & 1 & 1,25 & 1,5 & 1,75 & 1,88 \\
\hline 0,5 & Inviável & Inviável & Inviável & Inviável & Inviável \\
\hline 1 & Inviável & Inviável & Inviável & Inviável & Inviável \\
\hline 2 & Inviável & Inviável & Inviável & Inviável & Inviável \\
\hline 4 & $\mathrm{~PB}>10$ & $\mathrm{~PB}>10$ & $\mathrm{~PB}>10$ & $\mathrm{~PB}>10$ & $\mathrm{~PB}>10$ \\
\hline 8 & $\mathrm{~PB}>10$ & $\mathrm{~PB}>10$ & $1 \%$ & $4 \%$ & $6 \%$ \\
\hline
\end{tabular}




\begin{tabular}{|c|c|c|c|c|c|}
\hline \multicolumn{6}{|c|}{ Absorção Solar + RD - Tarifa Básica R\$ 1,10 - Payback + Depreciação } \\
\hline \multirow{2}{*}{$\begin{array}{c}\text { Carga } \\
\left(\mathrm{kW} / \mathrm{m}^{2}\right)\end{array}$} & 1 & 1,25 & 1,5 & 1,75 & 1,88 \\
\hline 0,5 & 0 & 0 & 0 & 0 & 0 \\
\hline 1 & 0 & 0 & 880,4805491 & 386,5026541 & 299,211634 \\
\hline 2 & 0 & 0 & 0 & 0 & 0 \\
\hline 4 & 13,4408351 & 10,47019291 & 8,574982855 & 7,260719683 & 6,724763326 \\
\hline 8 & 14,01954687 & 10,28868201 & 8,126158535 & 6,714808554 & 6,158603397 \\
\hline
\end{tabular}

\begin{tabular}{|c|c|c|c|c|c|}
\hline \multicolumn{7}{|c|}{ Absorção Solar + RD - Tarifa Básica R\$ 1,10 - TIR } \\
\hline \multirow{2}{*}{$\begin{array}{c}\text { Carga } \\
\left(\mathrm{kW} / \mathrm{m}^{2}\right)\end{array}$} & 1 & 1,25 & 1,5 & 1,75 & 1,88 \\
\cline { 2 - 6 } & 1 & Tarifa Ponta/ Tarifa Regular \\
\hline 0,5 & Inviável & Inviável & Inviável & Inviável & Inviável \\
\hline 1 & Inviável & Inviável & PB>10 & PB>10 & PB>10 \\
\hline 2 & Inviável & Inviável & Inviável & Inviável & Inviável \\
\hline 4 & PB>10 & PB $>10$ & $3 \%$ & $6 \%$ & $8 \%$ \\
\hline 8 & $8 \%$ & $13 \%$ & $18 \%$ & $23 \%$ & $25 \%$ \\
\hline
\end{tabular}

Absorção + RI

\begin{tabular}{|c|c|c|c|c|c|}
\hline \multicolumn{6}{|c|}{ Absorção Solar + RI - Tarifa Básica R\$ 0,30 - Payback + Depreciação } \\
\hline \multirow{2}{*}{$\begin{array}{c}\text { Carga } \\
\left(\mathrm{kW} / \mathrm{m}^{2}\right)\end{array}$} & 1 & 1,25 & 1,5 & 1,75 & 1,88 \\
\hline & \multicolumn{5}{|c|}{ Tarifa Ponta/ Tarifa Regular } \\
\hline 0,5 & 14,48032808 & 13,69514855 & 12,99074025 & 12,35524949 & 12,04875625 \\
\hline 1 & 7,374752549 & 6,987685399 & 6,63922285 & 6,323863818 & 6,171431422 \\
\hline 2 & 7,504618586 & 7,146119698 & 6,820310504 & 6,522914758 & 6,378291444 \\
\hline 4 & 1,964672558 & 1,889067888 & 1,819066442 & 1,754067579 & 1,722070418 \\
\hline 8 & 1,561964634 & 1,501748782 & 1,446003394 & 1,394248451 & 1,368773265 \\
\hline
\end{tabular}

\begin{tabular}{|c|c|c|c|c|c|}
\hline \multicolumn{6}{|c|}{ Absorção Solar + RI - Tarifa Básica R\$ 0,30 - TIR } \\
\hline \multirow{2}{*}{$\begin{array}{c}\text { Carga } \\
\left(\mathrm{kW} / \mathrm{m}^{2}\right)\end{array}$} & \multicolumn{5}{|c|}{ Tarifa Ponta/ Tarifa Regular } \\
\cline { 2 - 6 } & 1 & 1,25 & 1,5 & 1,75 & 1,88 \\
\hline 0,5 & $0 \%$ & $0 \%$ & $0 \%$ & $0 \%$ & $0 \%$ \\
\hline 1 & $6 \%$ & $7 \%$ & $8 \%$ & $9 \%$ & $10 \%$ \\
\hline 2 & $6 \%$ & $7 \%$ & $8 \%$ & $9 \%$ & $9 \%$ \\
\hline 4 & $50 \%$ & $52 \%$ & $54 \%$ & $56 \%$ & $57 \%$ \\
\hline 8 & $64 \%$ & $66 \%$ & $69 \%$ & $71 \%$ & $73 \%$ \\
\hline
\end{tabular}




\begin{tabular}{|c|c|c|c|c|c|}
\hline \multicolumn{6}{|c|}{ Absorção Solar + RI - Tarifa Básica R\$ 0,60 - Payback + Depreciação } \\
\hline \multirow{2}{*}{$\begin{array}{c}\text { Carga } \\
\left(\mathrm{kW} / \mathrm{m}^{2}\right)\end{array}$} & 1 & 1,25 & 1,5 & 1,75 & 1,88 \\
\hline 0,5 & 5,394764645 & 5,173744775 & 4,970122218 & 4,781920645 & 4,689579882 \\
\hline 1 & 3,143368226 & 3,001629708 & 2,87212203 & 2,753327544 & 2,695356261 \\
\hline 2 & 3,20277251 & 3,071261596 & 2,950124796 & 2,838181163 & 2,783262925 \\
\hline 4 & 0,940107386 & 0,905427934 & 0,873216025 & 0,843217348 & 0,828418311 \\
\hline 8 & 0,754383997 & 0,726255019 & 0,700148345 & 0,675853454 & 0,663874627 \\
\hline
\end{tabular}

\begin{tabular}{|c|c|c|c|c|c|}
\hline \multicolumn{7}{|c|}{ Absorção Solar + RI - Tarifa Básica R\$ 0,60 - TIR } \\
\hline \multirow{2}{*}{$\begin{array}{c}\text { Carga } \\
\left(\mathrm{kW} / \mathrm{m}^{2}\right)\end{array}$} & 1 & 1,25 & 1,5 & 1,75 & 1,88 \\
\hline & $13 \%$ & $14 \%$ & $15 \%$ & $16 \%$ & $17 \%$ \\
\hline 0,5 & $29 \%$ & $31 \%$ & $33 \%$ & $34 \%$ & $35 \%$ \\
\hline 1 & $29 \%$ & $30 \%$ & $32 \%$ & $33 \%$ & $34 \%$ \\
\hline 2 & $106 \%$ & $110 \%$ & $114 \%$ & $119 \%$ & $121 \%$ \\
\hline 4 & $133 \%$ & $138 \%$ & $143 \%$ & $148 \%$ & $151 \%$ \\
\hline 8 & &
\end{tabular}

\begin{tabular}{|c|c|c|c|c|c|}
\hline \multicolumn{7}{|c|}{ Absorção Solar + RI - Tarifa Básica R\$ 1,10 - Payback + Depreciação } \\
\hline \multirow{2}{*}{$\begin{array}{c}\text { Carga } \\
\left(\mathrm{kW} / \mathrm{m}^{2}\right)\end{array}$} & 1 & 1,25 & 1,5 & 1,75 & 1,88 \\
\hline & 2,5 Tarifa Ponta/ Tarifa Regular \\
\hline 0,5 & 2,637077154 & 2,53984168 & 2,44952183 & 2,365405153 & 2,323907553 \\
\hline 1 & 1,606811314 & 3,959297166 & 1,476162356 & 1,418493871 & 1,390251502 \\
\hline 2 & 1,637930565 & 1,574710275 & 1,516188928 & 1,461861411 & 1,435121585 \\
\hline 4 & 0,502957996 & 0,484747184 & 0,467809025 & 0,452014616 & 0,444215739 \\
\hline 8 & 0,405209261 & 0,390321955 & 0,376489796 & 0,363604448 & 0,357246538 \\
\hline
\end{tabular}

\begin{tabular}{|c|c|c|c|c|c|}
\hline \multirow{5}{*}{$\begin{array}{c}\text { Carga } \\
\left(\mathrm{kW} / \mathrm{m}^{2}\right)\end{array}$} & \multicolumn{5}{|c|}{ Absorção Solar + RI - Tarifa Básica R\$ 1,10 - TIR } \\
\cline { 2 - 6 } & 1 & 1,25 & 1,5 & 1,75 & 1,88 \\
\hline 0,5 & $36 \%$ & $38 \%$ & $39 \%$ & $41 \%$ & $42 \%$ \\
\hline 1 & $62 \%$ & $22 \%$ & $67 \%$ & $70 \%$ & $72 \%$ \\
\hline 2 & $61 \%$ & $63 \%$ & $66 \%$ & $68 \%$ & $69 \%$ \\
\hline 4 & $199 \%$ & $206 \%$ & $214 \%$ & $221 \%$ & $225 \%$ \\
\hline 8 & $247 \%$ & $256 \%$ & $266 \%$ & $275 \%$ & $280 \%$ \\
\hline
\end{tabular}


Absorção Solar + RID

\begin{tabular}{|c|c|c|c|c|c|}
\hline \multicolumn{6}{|c|}{ Absorção Solar + RDI - Tarifa Básica R\$ 0,30 - Payback + Depreciação } \\
\hline \multirow{2}{*}{$\begin{array}{c}\text { Carga } \\
\left(\mathrm{kW} / \mathrm{m}^{2}\right)\end{array}$} & 1 & 1,25 & 1,5 & 1,75 & 1,88 \\
\hline 0,5 & 0 & 0 & 0 & 0 & 0 \\
\hline 1 & 0 & 0 & 0 & 0 & 0 \\
\hline 2 & 0 & 0 & 0 & 0 & 0 \\
\hline 4 & 7,756366459 & 7,333210373 & 6,953837057 & 6,611785634 & 6,446885802 \\
\hline 8 & 3,802421678 & 3,600912016 & 3,419685491 & 3,255826417 & 3,176674686 \\
\hline
\end{tabular}

\begin{tabular}{|c|c|c|c|c|c|}
\hline \multicolumn{6}{|c|}{ Absorção Solar + RDI - Tarifa Básica R\$ 0,30 - TIR } \\
\hline \multirow{2}{*}{$\begin{array}{c}\text { Carga } \\
\left(\mathrm{kW} / \mathrm{m}^{2}\right)\end{array}$} & 1 & 1,25 & 1,5 & 1,75 & 1,88 \\
\cline { 2 - 6 } & Tarifa Ponta/ Tarifa Regular \\
\hline 0,5 & Inviável & Inviável & Inviável & Inviável & Inviável \\
\hline 1 & Inviável & Inviável & Inviável & Inviável & Inviável \\
\hline 2 & Inviável & Inviável & Inviável & Inviável & Inviável \\
\hline 4 & $5 \%$ & $6 \%$ & $7 \%$ & $8 \%$ & $9 \%$ \\
\hline 8 & $23 \%$ & $25 \%$ & $26 \%$ & $28 \%$ & $29 \%$ \\
\hline
\end{tabular}

\begin{tabular}{|c|c|c|c|c|c|}
\hline \multicolumn{6}{|c|}{ Absorção Solar + RDI - Tarifa Básica R\$ 0,60 - Payback + Depreciação } \\
\hline \multirow{2}{*}{$\begin{array}{c}\text { Carga } \\
\left(\mathrm{kW} / \mathrm{m}^{2}\right)\end{array}$} & 1 & 1,25 & 1,5 & 1,75 & 1,88 \\
\hline 0,5 & 0 & 0 & 0 & 0 & 0 \\
\hline 1 & 0 & 0 & 0 & 0 & 0 \\
\hline 2 & 0 & 0 & 0 & 0 & 0 \\
\hline 4 & 3,313595407 & 3,1578999411 & 3,016179133 & 2,886632322 & 2,823569782 \\
\hline 8 & 1,756173721 & 1,669856073 & 1,591626101 & 1,52039799 & 1,485821543 \\
\hline
\end{tabular}

\begin{tabular}{|c|c|c|c|c|c|}
\hline \multicolumn{5}{|c|}{ Absorção Solar + RDI - Tarifa Básica R\$ 0,60 - TIR } \\
\hline \multirow{2}{*}{$\begin{array}{c}\text { Carga } \\
\left(\mathrm{kW} / \mathrm{m}^{2}\right)\end{array}$} & 1 & 1,25 & 1,5 & 1,75 & 1,88 \\
\cline { 2 - 6 } & Tarifa Ponta/ Tarifa Regular \\
\hline 0,5 & Inviável & Inviável & Inviável & Inviável & Inviável \\
\hline 1 & Inviável & Inviável & Inviável & Inviável & Inviável \\
\hline 2 & Inviável & Inviável & Inviável & Inviável & Inviável \\
\hline 4 & $28 \%$ & $29 \%$ & $31 \%$ & $33 \%$ & $33 \%$ \\
\hline 8 & $56 \%$ & $59 \%$ & $62 \%$ & $65 \%$ & $67 \%$ \\
\hline
\end{tabular}




\begin{tabular}{|c|c|c|c|c|c|}
\hline \multicolumn{6}{|c|}{ Absorção Solar + RDI - Tarifa Básica R\$ 1,10 - Payback + Depreciação } \\
\hline \multirow{2}{*}{$\begin{array}{c}\text { Carga } \\
\left(\mathrm{kW} / \mathrm{m}^{2}\right)\end{array}$} & 1 & 1,25 & 1,5 & 1,75 & 1,88 \\
\hline 0,5 & 0 & 0 & 0 & 0 & 0 \\
\hline 1 & 0 & 0 & 0 & 0 & 0 \\
\hline 2 & 0 & 0 & 0 & 0 & 0 \\
\hline 4 & 1,695236852 & 1,620308257 & 1,551722905 & 1,488708005 & 1,457921071 \\
\hline 8 & 0,925809766 & 0,881757772 & 0,84170754 & 0,805137471 & 0,787349138 \\
\hline
\end{tabular}

\begin{tabular}{|c|c|c|c|c|c|}
\hline \multicolumn{6}{|c|}{ Absorção Solar + RDI - Tarifa Básica R\$ 1,10 - TIR } \\
\hline \multirow{2}{*}{$\begin{array}{c}\text { Carga } \\
\left(\mathrm{kW} / \mathrm{m}^{2}\right)\end{array}$} & 1 & 1,25 & 1,5 & 1,75 & 1,88 \\
\hline & 1 & Tarifa Ponta/ Tarifa Regular \\
\hline 0,5 & Inviável & Inviável & Inviável & Inviável & Inviável \\
\hline 1 & Inviável & Inviável & Inviável & Inviável & Inviável \\
\hline 2 & Inviável & Inviável & Inviável & Inviável & Inviável \\
\hline 4 & $58 \%$ & $61 \%$ & $64 \%$ & $67 \%$ & $68 \%$ \\
\hline 8 & $108 \%$ & $113 \%$ & $119 \%$ & $124 \%$ & $127 \%$ \\
\hline
\end{tabular}

PV

\begin{tabular}{|c|c|c|c|c|c|}
\hline \multicolumn{6}{|c|}{ PV - Tarifa Básica R\$ 0,30 - Payback + Depreciação } \\
\hline \multirow{2}{*}{$\begin{array}{c}\text { Carga } \\
\left(\mathrm{kW} / \mathrm{m}^{2}\right)\end{array}$} & 1 & 1,25 & 1,5 & 1,75 & 1,88 \\
\hline & 0 & 0 & 0 & 0 & 0 \\
\hline 0,5 & 0 & 0 & 0 & 0 & 737,9860831 \\
\hline 1 & 0 & 0 & 0 & 0 & 0 \\
\hline 2 & 0 & 0 & 0 & 133,1888443 & 77,27705942 \\
\hline 4 & 0 & 0 & 0 & 102,9675841 & 64,41115562 \\
\hline 8 & 0 & \multicolumn{5}{c}{} \\
\hline
\end{tabular}

\begin{tabular}{|c|c|c|c|c|c|}
\hline \multicolumn{5}{|c|}{ PV - Tarifa Básica R\$ 0,30 - TIR } \\
\hline $\begin{array}{c}\text { Carga } \\
\left(\mathrm{kW} / \mathrm{m}^{2}\right)\end{array}$ & 1 & 1,25 & 1,5 & 1,75 & 1,88 \\
\cline { 2 - 6 } & Inviável & Inviável & Inviável & Inviável & Inviável \\
\hline 0,5 & Inviável & Inviável & Inviável & Inviável & PB>10 \\
\hline 1 & Inviável & Inviável & Inviável & Inviável & Inviável \\
\hline 2 & Inviável & Inviável & Inviável & PB $>10$ & PB $>10$ \\
\hline 4 & Inviável & Inviável & Inviável & PB $>10$ & PB $>10$ \\
\hline 8
\end{tabular}




\begin{tabular}{|c|c|c|c|c|c|}
\hline \multicolumn{7}{|c|}{ PV - Tarifa Básica R\$ 0,60 - Payback + Depreciação } \\
\hline \multirow{2}{*}{$\begin{array}{c}\text { Carga } \\
\left(\mathrm{kW} / \mathrm{m}^{2}\right)\end{array}$} & 1 & 1,25 & 1,5 & 1,75 & 1,88 \\
\hline 0,5 & 46,29237145 & 32,77015058 & 25,36183771 & 20,68549092 & 18,8756848 \\
\hline 1 & 46,29663395 & 27,84668326 & 19,91159393 & 15,49593017 & 13,89374523 \\
\hline 2 & 46,28852462 & 28,5962567 & 20,68868609 & 16,20703969 & 14,56624028 \\
\hline 4 & 46,29527998 & 23,5327384 & 15,77597857 & 11,86506648 & 10,51020118 \\
\hline 8 & 46,2751235 & 22,74310507 & 15,07639429 & 11,27543886 & 9,968571363 \\
\hline
\end{tabular}

\begin{tabular}{|c|c|c|c|c|c|}
\hline \multicolumn{5}{|c|}{ PV - Tarifa Básica R\$ 0,60 - TIR } \\
\hline \multirow{2}{*}{$\begin{array}{c}\text { Carga } \\
\left(\mathrm{kW} / \mathrm{m}^{2}\right)\end{array}$} & 1 & 1,25 & 1,5 & 1,75 & 1,88 \\
\hline & Tarifa Ponta/ Tarifa Regular \\
\hline 0,5 & $\mathrm{~PB}>10$ & $\mathrm{~PB}>10$ & $\mathrm{~PB}>10$ & $\mathrm{~PB}>10$ & $\mathrm{~PB}>10$ \\
\hline 1 & $\mathrm{~PB}>10$ & $\mathrm{~PB}>10$ & $\mathrm{~PB}>10$ & $\mathrm{~PB}>10$ & $\mathrm{~PB}>10$ \\
\hline 2 & $\mathrm{~PB}>10$ & $\mathrm{~PB}>10$ & $\mathrm{~PB}>10$ & $\mathrm{~PB}>10$ & $\mathrm{~PB}>10$ \\
\hline 4 & $\mathrm{~PB}>10$ & $\mathrm{~PB}>10$ & $\mathrm{~PB}>10$ & $\mathrm{~PB}>10$ & $\mathrm{~PB}>10$ \\
\hline 8 & $\mathrm{~PB}>10$ & $\mathrm{~PB}>10$ & $\mathrm{~PB}>10$ & $\mathrm{~PB}>10$ & $0 \%$ \\
\hline
\end{tabular}

\begin{tabular}{|c|c|c|c|c|c|}
\hline \multicolumn{7}{|c|}{ PV - Tarifa Básica R\$ 1,10 - Payback + Depreciação } \\
\hline \multirow{2}{*}{$\begin{array}{c}\text { Carga } \\
\left(\mathrm{kW} / \mathrm{m}^{2}\right)\end{array}$} & 1 & 1,25 & 1,5 & 1,75 & 1,88 \\
\cline { 2 - 6 } & 10,27495926 & 8,797717095 & 7,691851209 & 6,832954397 & 6,457973031 \\
\hline 0,5 & 10,27534423 & 154,8252149 & 6,675821905 & 5,680809059 & 5,272190242 \\
\hline 1 & 10,2746118 & 8,208052146 & 6,833593534 & 5,853423335 & 5,447144158 \\
\hline 2 & 10,27522195 & 7,373202214 & 5,749404241 & 4,71173938 & 4,307479342 \\
\hline 4 & 10,27340108 & 7,229030231 & 5,576512901 & 4,538936493 & 4,138525195 \\
\hline 8 & \multicolumn{5}{cc}{} \\
\hline
\end{tabular}

\begin{tabular}{|c|c|c|c|c|c|}
\hline \multicolumn{6}{|c|}{ PV - Tarifa Básica R\$ 1,10 - TIR } \\
\hline \multirow{2}{*}{$\begin{array}{c}\text { Carga } \\
\left(\mathrm{kW} / \mathrm{m}^{2}\right)\end{array}$} & \multicolumn{5}{|c|}{ Tarifa Ponta/ Tarifa Regular } \\
\hline & 1 & 1,25 & 1,5 & 1,75 & 1,88 \\
\hline 0,5 & $P B>10$ & $2 \%$ & $5 \%$ & $8 \%$ & $9 \%$ \\
\hline 1 & $P B>10$ & $P B>10$ & $8 \%$ & $12 \%$ & $14 \%$ \\
\hline 2 & $\mathrm{~PB}>10$ & $4 \%$ & $8 \%$ & $11 \%$ & $13 \%$ \\
\hline 4 & $\mathrm{~PB}>10$ & $6 \%$ & $12 \%$ & $17 \%$ & $19 \%$ \\
\hline 8 & $\mathrm{~PB}>10$ & $6 \%$ & $12 \%$ & $17 \%$ & $20 \%$ \\
\hline
\end{tabular}


$P V+R D$

\begin{tabular}{|c|c|c|c|c|c|}
\hline \multicolumn{5}{|c|}{ PV + RD - Tarifa Básica R\$ 0,30 - Payback + Depreciação } \\
\hline \multirow{2}{*}{ Carga (kW/m $\left.{ }^{2}\right)$} & \multicolumn{5}{c|}{ Tarifa Ponta/ Tarifa Regular } \\
\cline { 2 - 6 } & 1 & 1,25 & 1,5 & 1,75 & 1,88 \\
\hline 0,5 & 0 & 0 & 0 & 0 & 0 \\
\hline 1 & 0 & 0 & 0 & 0 & 0 \\
\hline 2 & 0 & 0 & 0 & 0 & 0 \\
\hline 4 & 0 & 0 & 0 & 0 & 0 \\
\hline 8 & 0 & 0 & 0 & 0 & 0 \\
\hline
\end{tabular}

\begin{tabular}{|}
\hline \multicolumn{5}{|c|}{ PV + RD - Tarifa Básica R\$ 0,30 - TIR } \\
\hline \multirow{2}{*}{ Carga (kW/m²) } & \multicolumn{5}{|c|}{ Tarifa Ponta/ Tarifa Regular } \\
\cline { 2 - 6 } & 1 & 1,25 & 1,5 & 1,75 & 1,88 \\
\hline \multirow{2}{*}{0,5} & Inviável & Inviável & Inviável & Inviável & Inviável \\
\cline { 2 - 6 } & Inviável & Inviável & Inviável & Inviável & Inviável \\
\hline 1 & Inviável & Inviável & Inviável & Inviável & Inviável \\
\hline 2 & Inviável & Inviável & Inviável & Inviável & Inviável \\
\hline 4 & Inviável & Inviável & Inviável & Inviável & Inviável \\
\hline 8
\end{tabular}

\begin{tabular}{|c|c|c|c|c|c|}
\hline \multicolumn{7}{|c|}{ PV + RD - Tarifa Básica R\$ 0,60 - Payback + Depreciação } \\
\hline \multirow{2}{*}{ Carga $\left(\mathrm{kW} / \mathrm{m}^{2}\right)$} & 1,25 & 1,5 & 1,75 & 1,88 \\
\cline { 2 - 6 } & 1 & 0 & 0 & 0 & 0 \\
\hline 0,5 & 0 & 0 & 0 & 0 & 0 \\
\hline 1 & 0 & 0 & 0 & 0 & 0 \\
\hline 2 & 0 & 303,7701363 & 60,19586142 & 33,40804191 & 27,13000403 \\
\hline 4 & 0 & 1481,476241 & 73,45661773 & 37,66201408 & 30,04811373 \\
\hline 8 & 0 &
\end{tabular}

\begin{tabular}{|c|c|c|c|c|c|}
\hline \multicolumn{7}{|c|}{ PV + RD - Tarifa Básica R\$ 0,60 - TIR } \\
\hline \multirow{2}{*}{$\begin{array}{c}\text { Carga } \\
\left(\mathrm{kW} / \mathrm{m}^{2}\right)\end{array}$} & 1 & & & & \\
\hline 0,5 & Inviável & Inviável & Inviável & Inviável & Inviável \\
\hline 1 & Inviável & Inviável & Inviável & Inviável & Inviável \\
\hline 2 & Inviável & Inviável & Inviável & Inviável & Inviável \\
\hline 4 & Inviável & PB $>10$ & PB $>10$ & PB $>10$ & PB $>10$ \\
\hline
\end{tabular}




\begin{tabular}{|l|l|l|l|l|l|}
\hline 8 & Inviável & $\mathrm{PB}>10$ & $\mathrm{~PB}>10$ & $\mathrm{~PB}>10$ & $\mathrm{~PB}>10$ \\
\hline
\end{tabular}

\begin{tabular}{|c|c|c|c|c|c|}
\hline \multicolumn{7}{|c|}{ PV + RD - Tarifa Básica R\$ 1,10 - Payback + Depreciação } \\
\cline { 2 - 6 } Carga $\left(\mathrm{kW} / \mathrm{m}^{2}\right)$ & 1 & 1,25 & 1,5 & 1,75 & 1,88 \\
\cline { 2 - 6 } & 0 & 0 & 0 & 0 & 0 \\
\hline 0,5 & 0 & 0 & 85,13319111 & 40,53747008 & 31,8592106 \\
\hline 1 & 0 & 0 & 0 & 321,1619214 & 123,4287021 \\
\hline 2 & 28,59066571 & 16,83577614 & 11,93058428 & 9,238808787 & 8,268705472 \\
\hline 4 & 32,3844445 & 18,31516585 & 12,76811484 & 9,800017418 & 8,743145365 \\
\hline 8
\end{tabular}

\begin{tabular}{|c|c|c|c|c|c|}
\hline \multicolumn{5}{|c|}{$\mathrm{PV}+\mathrm{RD}$ - Tarifa Básica R\$ 1,10 - TIR } \\
\hline \multirow{2}{*}{ Carga $\left(\mathrm{kW} / \mathrm{m}^{2}\right)$} & 1 & 1,25 & 1,5 & 1,75 & 1,88 \\
\cline { 2 - 6 } & Inviável & Inviável & Inviável & Inviável & Inviável \\
\hline 0,5 & Inviável & Inviável & $\mathrm{PB}>10$ & $\mathrm{~PB}>10$ & $\mathrm{~PB}>10$ \\
\hline 1 & Inviável & Inviável & Inviável & $\mathrm{PB}>10$ & $\mathrm{~PB}>10$ \\
\hline 2 & $\mathrm{~PB}>10$ & $\mathrm{~PB}>10$ & $\mathrm{~PB}>10$ & $1 \%$ & $4 \%$ \\
\hline 4 & $\mathrm{~PB}>10$ & $\mathrm{~PB}>10$ & $3 \%$ & $7 \%$ & $9 \%$ \\
\hline 8 & \multicolumn{7}{|c}{} \\
\hline
\end{tabular}

$P V+R I$

\begin{tabular}{|c|c|c|c|c|c|}
\hline \multicolumn{7}{|c|}{ PV + RI - Tarifa Básica R\$ 0,30 - Payback + Depreciação } \\
\hline \multirow{2}{*}{$\begin{array}{c}\text { Carga } \\
\left(\mathrm{kW} / \mathrm{m}^{2}\right)\end{array}$} & 1 & 1,25 & 1,5 & 1,75 & 1,88 \\
\hline & 1 & \multicolumn{5}{|c|}{ Tarifa Ponta/ Tarifa Regular } \\
\hline 0,5 & 64,12112589 & 49,82602444 & 40,74285251 & 34,46073772 & 31,90281846 \\
\hline 1 & 11,95998072 & 10,85367185 & 9,93470298 & 9,159202987 & 8,801923688 \\
\hline 2 & 15,51331154 & 13,89205106 & 12,5775955 & 11,49038391 & 10,9961196 \\
\hline 4 & 2,020019498 & 1,92781043 & 1,843652113 & 1,766534284 & 1,728928369 \\
\hline 8 & 1,465971893 & 1,392302342 & 1,325682748 & 1,265147332 & 1,235803113 \\
\hline
\end{tabular}

\begin{tabular}{|c|c|c|c|c|c|}
\hline \multicolumn{5}{|c|}{ PV + RI - Tarifa Básica R\$ 0,30 - TIR } \\
\hline \multirow{2}{*}{$\begin{array}{c}\text { Carga } \\
\left(\mathrm{kW} / \mathrm{m}^{2}\right)\end{array}$} & 1 & 1,25 & 1,5 & 1,75 & 1,88 \\
\hline 0,5 & $\mathrm{~PB}>10$ & $\mathrm{~PB}>10$ & $\mathrm{~PB}>10$ & $\mathrm{~PB}>10$ & $\mathrm{~PB}>10$ \\
\hline 1 & $\mathrm{~PB}>10$ & $\mathrm{~PB}>10$ & $0 \%$ & $2 \%$ & $2 \%$ \\
\hline 2 & $\mathrm{~PB}>10$ & $\mathrm{~PB}>10$ & $\mathrm{~PB}>10$ & $\mathrm{~PB}>10$ & $\mathrm{~PB}>10$ \\
\hline 4 & $49 \%$ & $51 \%$ & $53 \%$ & $56 \%$ & $57 \%$ \\
\hline 8 & $68 \%$ & $71 \%$ & $75 \%$ & $79 \%$ & $81 \%$ \\
\hline
\end{tabular}




\begin{tabular}{|c|c|c|c|c|c|}
\hline \multicolumn{7}{|c|}{ PV + RI - Tarifa Básica R\$ 0,60 - Payback + Depreciação } \\
\hline \multirow{5}{*}{$\begin{array}{c}\text { Carga } \\
\left(\mathrm{kW} / \mathrm{m}^{2}\right)\end{array}$} & 1 & 1,25 & 1,5 & 1,75 & 1,88 \\
\hline 0,5 & 10,11172982 & 9,27267496 & 8,56219775 & 7,952846488 & 7,669037171 \\
\hline 1 & 4,26578 & 3,976636415 & 3,724202123 & 3,501903564 & 3,396480444 \\
\hline 2 & 5,149990259 & 4,779639328 & 4,458980909 & 4,17864242 & 4,046356211 \\
\hline 4 & 0,947559195 & 0,906864976 & 0,869522163 & 0,835133119 & 0,818304149 \\
\hline 8 & 0,699983558 & 0,666314872 & 0,635736425 & 0,607841435 & 0,594281895 \\
\hline
\end{tabular}

\begin{tabular}{|c|c|c|c|c|c|}
\hline \multicolumn{7}{|c|}{ PV + RI - Tarifa Básica R\$ 0,60 - TIR } \\
\hline \multirow{2}{*}{$\begin{array}{c}\text { Carga } \\
\left(\mathrm{kW} / \mathrm{m}^{2}\right)\end{array}$} & 1 & 1,25 & 1,5 & 1,75 & 1,88 \\
\hline & $\mathrm{PB}>10$ & $1 \%$ & $3 \%$ & $4 \%$ & $5 \%$ \\
\hline 0,5 & $19 \%$ & $22 \%$ & $24 \%$ & $26 \%$ & $27 \%$ \\
\hline 1 & $14 \%$ & $16 \%$ & $18 \%$ & $20 \%$ & $21 \%$ \\
\hline 2 & $105 \%$ & $110 \%$ & $115 \%$ & $120 \%$ & $122 \%$ \\
\hline 4 & $143 \%$ & $150 \%$ & $157 \%$ & $165 \%$ & $168 \%$ \\
\hline 8 & & & & & \\
\hline
\end{tabular}

\begin{tabular}{|c|c|c|c|c|c|}
\hline \multicolumn{7}{|c|}{ PV + RI - Tarifa Básica R\$ 1,10 - Payback + Depreciação } \\
\hline \multirow{2}{*}{$\begin{array}{c}\text { Carga } \\
\left(\mathrm{kW} / \mathrm{m}^{2}\right)\end{array}$} & \multicolumn{5}{|c|}{ Tarifa Ponta/ Tarifa Regular } \\
\cline { 2 - 6 } & 1 & 1,25 & 1,5 & 1,75 & 1,88 \\
\hline 0,5 & 4,206494227 & 3,934938163 & 3,696317278 & 3,484982423 & 3,384362922 \\
\hline 1 & 2,058560763 & 6,625280473 & 1,823902447 & 1,725553291 & 1,678489068 \\
\hline 2 & 2,436850742 & 2,283368452 & 2,148074414 & 2,027916408 & 1,970596634 \\
\hline 4 & 0,502721342 & 0,481696813 & 0,462360243 & 0,444516201 & 0,435770908 \\
\hline 8 & 0,374151925 & 0,356499392 & 0,340437509 & 0,325760548 & 0,31861769 \\
\hline
\end{tabular}

\begin{tabular}{|c|c|c|c|c|c|}
\hline \multicolumn{5}{|c|}{ PV + RI - Tarifa Básica R\$ 1,10 - TIR } \\
\hline \multirow{2}{*}{$\begin{array}{c}\text { Carga } \\
\left(\mathrm{kW} / \mathrm{m}^{2}\right)\end{array}$} & 1 & 1,25 & 1,5 & 1,75 & 1,88 \\
\hline 0,5 & $20 \%$ & $22 \%$ & $24 \%$ & $26 \%$ & $27 \%$ \\
\hline 1 & $48 \%$ & $8 \%$ & $54 \%$ & $57 \%$ & $59 \%$ \\
\hline 2 & $40 \%$ & $43 \%$ & $45 \%$ & $48 \%$ & $50 \%$ \\
\hline 4 & $199 \%$ & $208 \%$ & $216 \%$ & $225 \%$ & $229 \%$ \\
\hline 8 & $267 \%$ & $281 \%$ & $294 \%$ & $307 \%$ & $314 \%$ \\
\hline
\end{tabular}


$P V+R N D I$

\begin{tabular}{|c|c|c|c|c|c|}
\hline \multirow{6}{*}{$\begin{array}{c}\text { Carga } \\
\left(\mathrm{kW} / \mathrm{m}^{2}\right)\end{array}$} & \multicolumn{6}{|c|}{ Tarifa Ponta/ Tarifa Regular } \\
\cline { 2 - 6 } & 1 & 1,25 & 1,5 & 1,75 & 1,88 \\
\hline 0,5 & 0 & 0 & 0 & 0 & 0 \\
\hline 1 & 0 & 0 & 0 & 0 & 0 \\
\hline 2 & 0 & 0 & 0 & 0 & 0 \\
\hline 4 & 0 & 0 & 0 & 0 & 0 \\
\hline 8 & 0 & 0 & 0 & 0 & 1723,000075 \\
\hline
\end{tabular}

\begin{tabular}{|c|c|c|c|c|c|}
\hline \multicolumn{7}{|c|}{ PV + RI - Tarifa Básica R\$ 0,30 - TIR } \\
\hline \multirow{2}{*}{$\begin{array}{c}\text { Carga } \\
\left(\mathrm{kW} / \mathrm{m}^{2}\right)\end{array}$} & 1 & 1,25 & 1,5 & 1,75 & 1,88 \\
\cline { 2 - 6 } & Inviável & Inviável & Inviável & Inviável & Inviável \\
\hline 0,5 & Inviável & Inviável & Inviável & Inviável & Inviável \\
\hline 1 & Inviável & Inviável & Inviável & Inviável & Inviável \\
\hline 2 & Inviável & Inviável & Inviável & Inviável & Inviável \\
\hline 4 & Inviável & Inviável & Inviável & Inviável & PB>10 \\
\hline 8 &
\end{tabular}

\begin{tabular}{|c|c|c|c|c|c|}
\hline \multicolumn{7}{|c|}{ PV + RI - Tarifa Básica R\$ 0,60 - Payback + Depreciação } \\
\hline \multirow{2}{*}{$\begin{array}{c}\text { Carga } \\
\left(\mathrm{kW} / \mathrm{m}^{2}\right)\end{array}$} & \multicolumn{5}{|c|}{ Tarifa Ponta/ Tarifa Regular } \\
\cline { 2 - 6 } & 1 & 1,25 & 1,5 & 1,75 & 1,88 \\
\hline 0,5 & 0 & 0 & 0 & 0 & 0 \\
\hline 1 & 0 & 0 & 0 & 0 & 0 \\
\hline 2 & 0 & 0 & 0 & 0 & 0 \\
\hline 4 & 0 & 118,8821619 & 44,93763678 & 27,70510396 & 23,09898523 \\
\hline 8 & 224,7439588 & 48,61245217 & 27,2537381 & 18,93452848 & 16,34075806 \\
\hline
\end{tabular}

\begin{tabular}{|c|c|c|c|c|c|}
\hline \multicolumn{5}{|c|}{ PV + RI - Tarifa Básica R\$ 0,60 - TIR } \\
\hline \multirow{2}{*}{$\begin{array}{c}\text { Carga } \\
\left(\mathrm{kW} / \mathrm{m}^{2}\right)\end{array}$} & 1 & 1,25 & 1,5 & 1,75 & 1,88 \\
\cline { 2 - 6 } & Tarifa Ponta/ Tarifa Regular \\
\hline 0,5 & Inviável & Inviável & Inviável & Inviável & Inviável \\
\hline 1 & Inviável & Inviável & Inviável & Inviável & Inviável \\
\hline 2 & Inviável & Inviável & Inviável & Inviável & Inviável \\
\hline 4 & Inviável & $\mathrm{PB}>10$ & $\mathrm{~PB}>10$ & $\mathrm{~PB}>10$ & $\mathrm{~PB}>10$ \\
\hline 8 & $\mathrm{~PB}>10$ & $\mathrm{~PB}>10$ & $\mathrm{~PB}>10$ & $\mathrm{~PB}>10$ & $\mathrm{~PB}>10$ \\
\hline
\end{tabular}




\begin{tabular}{|c|c|c|c|c|c|}
\hline \multicolumn{7}{|c|}{ PV + RI - Tarifa Básica R\$ 1,10 - Payback + Depreciação } \\
\hline \multirow{2}{*}{$\begin{array}{c}\text { Carga } \\
\left(\mathrm{kW} / \mathrm{m}^{2}\right)\end{array}$} & 1 & 1,25 & 1,5 & 1,75 & 1,88 \\
\hline 0,5 & 0 & 0 & 0 & 0 & 0 \\
\hline 1 & 0 & 0 & 162,3758187 & 55,99922796 & 41,76972639 \\
\hline 2 & 0 & 0 & 0 & 2358,837931 & 201,1407842 \\
\hline 4 & 24,56506173 & 15,13224015 & 10,93375167 & 8,559023261 & 7,690461891 \\
\hline 8 & 17,1858654 & 11,39689895 & 8,525223275 & 6,809447388 & 6,164322908 \\
\hline
\end{tabular}

\begin{tabular}{|c|c|c|c|c|c|}
\hline \multicolumn{5}{|c|}{$\mathrm{PV}+\mathrm{RI}-$ Tarifa Básica R\$ 1,10 - TIR } \\
\hline \multirow{2}{*}{$\begin{array}{c}\text { Carga } \\
\left(\mathrm{kW} / \mathrm{m}^{2}\right)\end{array}$} & 1 & 1,25 & 1,5 & 1,75 & 1,88 \\
\hline & \multicolumn{5}{|c|}{ Tarifa Ponta/ Tarifa Regular } \\
\hline 0,5 & Inviável & Inviável & Inviável & Inviável & Inviável \\
\hline 1 & Inviável & Inviável & $\mathrm{PB}>10$ & $\mathrm{~PB}>10$ & $\mathrm{~PB}>10$ \\
\hline 2 & Inviável & Inviável & Inviável & $\mathrm{PB}>10$ & $\mathrm{~PB}>10$ \\
\hline 4 & $\mathrm{~PB}>10$ & $\mathrm{~PB}>10$ & $\mathrm{~PB}>10$ & $3 \%$ & $5 \%$ \\
\hline 8 & $\mathrm{~PB}>10$ & $\mathrm{~PB}>10$ & $3 \%$ & $8 \%$ & $10 \%$ \\
\hline
\end{tabular}

